\title{
Disappearing Architecture
}

by

Vera Guo

A thesis

presented to the University of Waterloo in fulfilment of the

thesis requirement for the degree of

Master of Architecture

Waterloo, Ontario, Canada, 2010

(C) Vera Guo 2010 



\section{Author's Declaration}

I hereby declare that I am the sole author of this thesis. This is a true copy of the thesis, including any required final revision, as accepted by my examiners.

I understand that my thesis my be made electronically available to the public. 



\section{ABSTRACT}

Media facades dominate the skylines of many of our cities. A quick stroll through today's urban areas involves a one-sided conversation directed at pedestrians. Advertisements aggressively compete for attention, creating a visually chaotic battlefield of logos, brand names, and flashing lights. Structures themselves recede into the background behind this visual confusion, withdrawing completely under giant billboards that are plastered with images and LED lights. In the visual order, architecture comes second, if at all, behind graphics and media messages. Building facades are now covered with flat images and advertisements which use savvy marketing schemes. The vast and overtly stimulating messages, however, have gradually desensitized viewers as they become increasingly accustomed to this visual noise. More explicit images, brighter lights, and larger movements are now required to make an impact. As media facades are such a large part of the competitive communications industry, these facades have come to influence architectural practices which are in danger of succumbing to the demands of the ad industry. It is thus important to create a balance between media and architecture, which is mutually beneficial to both. Architecture can be preserved while advertisements can also flourish.

This thesis examines the use of digital media to enhance the public's connection to the built form within public spaces. Chapter one explores the various spaces in which people gather and their relationships to the city. Specifically, this chapter looks at the progress and decline of public realms in North America. Case studies of Times Square in New York City, Shinjuku Station in Tokyo, and the Las Vegas Strip in Nevada illustrate how each city negotiates media saturation. Chapter two presents eight design principles for the successful integration of digital media in public spaces. These principles were established through the use of historical references, case studies, and precedents showcasing each principle's potential. Chapter three looks at Galt City Centre in Cambridge, Ontario where the principles outlined in chapter two are demonstrated through a video application that was part of a public Christmas event in Cambridge. The project in Galt addresses the existing features of the city which engage its public spaces, encouraging a symbiotic relationship between the architecture and video facade.

The integration of digital media and architecture can be enriched in the choice of strategic locations highlighting local character. Installations can be cultural, create local identity, become reactive for community engagement, and encourage the public to inhabit the city by transforming existing spaces into communal areas. Installations connect with users in their use of the characters inherent to outdoor spaces; texture, sounds, emotions, and the experiences of different seasons and times of day. With a more responsive approach to content design and implementation, the outcomes of the use of digital media on facades can be positive. 



\section{Acknowledgements}

I would like to express my gratitude to my thesis supervisor, Jeff Lederer and committee members, Terri Myer Boake and Vincent Hui for their guidance, encouragement and expertise throughout my thesis. I would also like to express my appreciation to Gerry Remers, my external reader for his valuable time and involvement.

I am sincerely grateful to all those who have offered me their time throughout my journey. Without their constant support this would not be possible. Thank you especially to my loving family, great friends, Bei, 39 Water family and extended family, I would not have survived without your patience and generosity. 

to my parents 



\section{TABLE OF CONTENTS}

\begin{tabular}{|c|c|}
\hline & Author's Declaration \\
\hline & Abstract \\
\hline & Acknowledgments \\
\hline & Dedication \\
\hline & Table of Contents \\
\hline & List of Illustrations \\
\hline chapter 1.0 & List of Tables \\
\hline 1.1 & Introduction \\
\hline 1.2 & Public Space and Our City Experience \\
\hline & The historical progress of public realms: Its \\
\hline 1.3 & decline in North America \\
\hline & ‘Brandscapes’ \\
\hline & Times Square, New York City \\
\hline & Shinjuku, Tokyo \\
\hline 1.4 & Las Vegas Strip, Nevada \\
\hline chapter $\mathbf{2 . 0}$ & Field of Vision \\
\hline 2.1 & Case studies \\
\hline 2.2 & Las Vegas, Nevada \\
\hline 2.3 & Times Square, New York \\
\hline
\end{tabular}

2.4 Shinjuku, Tokyo

2.5 Eight Design Principles 103

$\begin{array}{lll}\text { chapter 3.0 Case Studies Synopsis } & 127\end{array}$

3.1 Galt City Centre, Cambridge, Ontario 139

3.2 The Application 145

3.3 Video Concept 151

chapter 4.0 Building from Unsilent Night 161

Conclusion 179

Bibliography 184

Appendix 192

11 
fig.1.0.1 typical North American strip

MerchantBrooklyn, NY "Pass Up Fast Food on Road Trips" Planet Green. http: / / planetgreen.discovery.com/travel-outdoors/avoidfast-food.html (accessed March 18, 2010).

fig.1.0.2 the Sistine Chapel ceiling

Tisch School of the Arts | NYU. http://itp.nyu.edu/isco/1/1.html (accessed March 23, 2010).

fig.1.1.1 MMORPG

MMO Hut. http://mmohut.com/editorials/the-best-free-mmorps (accessed March 18, 2010).

fig. 1.1.2 Hong Kong billboard advertising

"MediaValue." Design by Janssen4All. http://www. mediavalue.nl/ site $/$ index.php?option=com_content\&task=view\&id=25\&ltemid=37 (accessed August 5, 2009).

fig.1.2.1 the agora

"Greek Glossary." Greece. http://www.toursingreece.gr/GreekGlossary.htm (accessed February 27, 2010).

fig.1.2.2 Basilica di Santa Maria del Fiore

"Duomo de la Cattedrale di S. Maria del Fiore." Flickr. http:// www. flickr.com/photos/gbatistini/2827538804/ (accessed February 18, 2010).

fig.1.2.3 Trevi Fountain in Rome. Palio race in Siena's Piazza del

Campo. Chicago's Grant Park. (from left to right)

"Rome Fontana di Trevi." Flickr. http: / / www.flickr.com/ photos/22499269@N07/2970703421/ (accessed March 18, 2010).; “PALIO DI SIENA.” Flickr. http: / / www.flickr.com/ photos/paoloci/3687031663/ (accessed March 18, 2010).;

“Obama’s Grant Park Rally.” CNN Political. http://political- 
ticker.blogs.cnn.com/2008/11/04/barack-obamas-grant-parkrally/?fbid=d8xWWOgVzSS (accessed March 18, 2010).

fig.1.2.4 typical North American suburburban community "Money Saving Gas Tips."The Daily Green. http://www.thedailygreen.com/environmental-news/latest/save-moneygas-47050902 (accessed January 18, 2010).

fig.1.2.5 large unused backyards in the suburban

"Environmental Geography." Bridgewater. http://webhost.bridgew.edu/jhayesboh/ (accessed March 18, 2010).

fig.1.2.6 Granville Island Vancouver B.C.

"Dinner at Granville Island." Flickr - Photo Sharing. http://www. flickr.com/photos/gord99/842944450/ (accessed April 18, 2010). "Granville Island Public Market." Flickr - Photo Sharing. http:// www.flickr.com/photos/andreamccorkle/2381440397/ (accessed March 18, 2010).

fig.1.2.7 Paley Park in New York City

"Paley Park." Flickr - Photo Sharing. http://www.flickr.com/photos/b2tse/3001180031/ (accessed March 18, 2010).

fig.1.2.8 Central Park in New York City

Flickr - Photo Sharing. http://www. flickr.com/photos/myrstudio/385235523/ (accessed March 18, 2010).

fig.1.2.9 Rockefeller Center in New York City "Ice Skaters at Rockefeller Center." Flickr - Photo Sharing. http:// www.flickr.com/photos/denial_land/3207060566/ (accessed March 18, 2010).

fig.1.2.10 Lincoln Road pedestrian mall in Miami, Florida

"Lincoln Rd. in Miami Beach." Flickr - Photo Sharing. http: / /www. flickr.com/photos/digitalkunde/2853287045/ (accessed August 28, 2009).

fig.1.2.11 section through Lincoln Road graphic by author

fig.1.2.12 section through Ocean Drive graphic by author

fig.1.2.13 advertising on the Ritz-Carlton hotel in Hong Kong "Djimon Hounsou is 27 Stories Tall." Poshbot. http://www.poshbot.com/fashion-news/djimon-hounsou-is-27-stories- (accessed August 20, 2009).

fig.1.2.14 Boston City Hall Government Centre Plaza Flickr - Photo Sharing. http: / /www. flickr.com/photos/ sjb5/2824424274/ (accessed February 18, 2010).

fig.1.2.15 edge condition along the plaza

"Boston City Hall Plaza." Flickr - Photo Sharing. http://www. flickr. com/photos/photopia/2993540941/ (accessed February 18, 2010).

fig.1.2.16 Piazza del Campo in Siena

"Piazza del Campo." Flickr - Photo Sharing. http://www. flickr. com/photos/13945579@N03/3855589077/ (accessed February 18, 2010).

fig.1.2.17 Cloud Gate and Crown Fountain

"Millennium Park Crown Fountain." Flickr - Photo Sharing. http:// www.flickr.com/photos/26428082@N03/2708416820/ (accessed January 18, 2010).

fig.1.2.18 Jay Pritzker Pavilion in Millennium Park

"Jay Pritzker Pavilion." Flickr - Photo Sharing. http:/ / www. flickr. com/photos/wallyg/170845648/ (accessed January 18, 2010).

fig.1.2.19 advertising in Wanchai, Hong Kong.

"Raquel Zimmerman for H\&M" nitro:licious. http://www. nitrolicious.com/blog/2008/03/08/raquel-zimmerman-for-hm-springsummer-08/ (accessed January 18, 2010).

fig.1.2.20 Toronto Life Square

photograph courtesy of Terri Meyer Boake 
fig.1.2.21 Toronto Life Square

"Toronto Life Square." Flickr. http:/ / www. flickr.com/photos/

mikeinto/2308776056/ (accessed May 11, 2010).

fig.1.2.22 Vancouver 2010 Olympics opening ceremony "2010 Vancouver Winter Olympics Opening Ceremony." Flickr.

http: / / www.flickr.com/photos/43110135@N02/4388982641/ (accessed May 11, 2010).

fig.1.3.1

graphic by author, [source: Flickr. http://www.flickr.com]

fig.1.3.2

graphic by author, [source: Flickr. http://www.flickr.com]

fig.1.3.3

graphic by author, [source: Flickr. http://www. flickr.com]

fig.1.3.4

graphic by author, [source: Flickr. http://www.flickr.com]

fig.1.3.5

graphic by author, [source: Flickr. http://www.flickr.com]

fig.1.3.6

graphic by author, [source: Flickr. http://www.flickr.com]

fig.1.3.7

graphic by author, [source: Flickr. http://www.flickr.com]

fig.1.3.8

graphic by author, [source: Flickr. http://www.flickr.com]

fig.1.3.9

graphic by author, [source: Flickr. http://www.flickr.com]

fig.1.3.10

graphic by author, [source: Flickr. http://www.flickr.com]

fig.1.3.11 graphic by author, [source: Flickr. http://www.flickr.com] fig.1.3.12 section of Times Square graphic by author

fig.1.3.13 section Times Square

graphic by author

fig.1.3.14

graphic by author [source: Flickr. http://www.flickr.com]

fig.1.3.15

graphic by author [source: Flickr. http://www.flickr.com]

fig.1.3.16

graphic by author [source: Flickr. http://www.flickr.com]

fig.1.3.17

graphic by author [source: Flickr. http://www.flickr.com]

fig.1.3.18

graphic by author [source: Flickr. http://www. flickr.com]

fig.1.3.19

graphic by author [source: Flickr. http://www.flickr.com]

fig.1.3.20

graphic by author [source: Flickr. http://www.flickr.com]

fig.1.3.21

graphic by author [source: Flickr. http://www.flickr.com]

fig.1.3.22

graphic by author [source: Flickr. http://www.flickr.com]

fig.1.3.23

graphic by author [source: Flickr. http://www.flickr.com]

fig.1.3.24

graphic by author [source: Flickr. http://www.flickr.com] 
fig.1.3.25 section through Shinjuku Dori Avenue graphic by author

fig.1.3.26

graphic by author [source: Flickr. http://www.flickr.com]

fig.1.3.27

graphic by author [source: Flickr. http://www.flickr.com]

fig.1.3.28

graphic by author [source: Flickr. http://www.flickr.com]

fig.1.3.29

graphic by author [source: Flickr. http://www.flickr.com]

fig.1.3.30 section through Las Vegas Boulevard South

graphic by author

fig.1.4.1 Water Street South facing north

graphic by author

fig.1.4.2 Map showing distances from subject

graphic by author [source: Google Maps. http://maps.google.

$\mathrm{com} /]$

fig.1.4.3 Water Street South facing north

graphic by author

fig.1.4.4 Yonge Street facing north

graphic by author

fig.1.4.5 map showing distances from subject

graphic by author [source: Google Maps. http://maps.google. $\mathrm{com} /]$

fig.1.4.6 Yonge Street facing north graphic by author

fig.2.1.1 the 'Welcome to Fabulous Las Vegas' sign

Wikivisual. http://en.wikivisual.com/index.php/Las_Vegas_Mono- rail (accessed March 18, 2010).

fig.2.1.2 Viva Las Vegas by Theo Deutinger

"Viva Las Vegas." TD. http://td-architects.eu/oldsite/projectslasvegas.htm (accessed February 18, 2010).

fig.2.1.3 Hermitage Guggenheim, Las Vegas, Nevada, 2001 oma.nl. http://www.oma.nl/ (accessed March 18, 2010).

fig.2.1.4 Fremont Street in 1986

image by Larry D. Moore (๑ 1986)

fig.2.1.5 from "Learning from Las Vegas" by Robert Venturi 81 Intercontinental Curatorial Project. http://www.curatorialproject. com/interviews/venturiandscottbrown.html (accessed March 18, 2010).

fig.2.1.6 pedestrian bridge

Flickr - Photo Sharing. http://www. flickr.com/photos/something forkate/3915098096/ (accessed March 11, 2010).

fig.2.1.7 Fremont Street Experience

photograph courtesy of Terri Meyer Boake

fig.2.2.1 Times Square

Flickr - Photo Sharing. http: / /www.flickr.com/photos/ jarabadan/1808076962/ (accessed March 18, 2010).

fig.2.2.2 map showing Times Square Alliance district boundary 88 graphic by author [source: http://www.timessquarenyc.org/]

fig.2.2.3 Disney Theatre in Times Square 1998

“Times Square, NYC 1998." Flickr - Photo Sharing. http://www.

flickr.com/photos/canadagood/3055382200/ (accessed March 18, 2010).

fig.2.2.5 the Hershey Store in Times Square

Flickr - Photo Sharing. http://www. flickr.com/photos/myflickrdiet/2469431825/ (accessed March 18, 2010). 
fig.2.2.6 solar and wind powered billboard in Times Square "Eco Gadgets." Solar Feeds News Network. http: / / www.solarfeeds.com/ecofriend/4849-eco-gadgets-3-million-solar-andwind-powered-billboard-for-times-square (accessed February 18, 2010).

fig.2.2.7 map showing the sections on Broadway graphic by author [source: Flickr. http://www.flickr.com]

fig.2.3.1 Outside Shinjuku station, south west exit "Outside Shinjuku station." Flickr - Photo Sharing. http://www. flickr.com/photos/tristanf/3543565799/ (accessed March 18, 2010).

fig.2.3.2 map of Shinjuku area highlighting Shinjuku Station "Map Tokyo Japan." Weather Tokyo Japan.com. http://www. weather-in-japan.com/map-tokyo-japan-9,JAXX0085,2.html (accessed April 21, 2010)

fig.2.3.3 Shinjuku Station south exit

"Shinjuku Station." Flickr - Photo Sharing. http://www.flickr.com/ photos/skolem/3454611881/ (accessed March 18, 2010).

fig.2.3.4 street musicians at the south exit of Shinjuku station 99 "MINXZONE." Flickr - Photo Sharing. http://www.flickr.com/photos/acafe/1771560170/ (accessed March 18, 2010).;

fig.2.3.5 hokousha tengoku

"Tokyo." SkyscraperCity. http: / / www.skyscrapercity.com/printthread.php?t=2008\&pp=25\&page $=60$ (accessed March 18, 2010).

fig.2.3.6 busy streets of Shinjuku

"Shinjuku." Flickr - Photo Sharing. http://www.flickr.com/photos/28064283@N00/163937198/ (accessed February 18, 2010).

fig.2.3.7 Shinjuku's active street life and array of neon signs 101 "Evening in Shinjuku." Flickr - Photo Sharing. http: / /www. flickr. com/photos/ericflexyourhead/2359010431/ (accessed February
18, 2010).

fig.2.4.1 G.R.L in Rome

104

“Enzimi 2007." Digicult. http://www.digicult.it/Agency/sections/ curating/grlEnzimi.asp (accessed January 18, 2010).

fig.2.4.2 'L.A.S.E.R TAG' on G.R.L.'s Rotterdam tour

"L.A.S.E.R. Tag." Hacked Gadgets. http://hackedgadgets.

com/2007/02/25/graffiti-research-labs-laser-tag/ (accessed January 18,2010$)$.

fig.2.4.3 Spots Installation in Potsdamer Platz 105

"SPOTS - realities:united." Interactive architecture. http://www. interactivearchitecture.org/spots-realitiesunited.html (accessed August 6, 2009).

fig.2.4.4 shimmering animation sequences

Manchester Urban Screens. http: / /www. manchesterurbanscreens. org.uk/index.php?page=USMSpeakers (accessed Jan 26, 2010).;

fig.2.4.5 GreenPix - Zero Energy Media Wall

"China's Next Great Wall." Inhabitat. http://www.inhabitat. com/2008/09/04/beijing-zero-energy-media-wall-video/ (accessed August 23, 2009).

fig.2.4.6 Habitat Hotel concept by James Clar \& Associates "Habitat Hotel-MoMA." Enric Ruiz Geli. http:/ /www.ruiz-geli. com/04_html/04_forest.html (accessed April 26, 2010).

\section{fig.2.4.7 close-up of the individual nodes}

"Habitat Hotel-MoMA." Enric Ruiz Geli. http://www.ruiz-geli. com/04_html/04_forest.html (accessed April 26, 2010).

fig.2.4.8 the Astrovision screen above the stage 108 "Project: AT\&T Global Olympic Village." Entertainment Design Corporation. http://www.entdesign.com/credits/att-olympic.html (accessed August 23, 2009).

fig.2.4.9 the Sony Center in Potsdamer Platz 
"Sony Center, Berlin." Garden Landscape Guide. http://www. gardenvisit.com/garden/sony_center_am_potsdamer_platz-sony_ platz (accessed July 21, 2009).

fig.2.4.10 T-Mobile Bonn Headquarters by ag4 mediatecture 109 "T-MOBILE headquarters" NAIT5. http:/ / nait5.wordpress. com/2008/06/03/t-mobile-headquarters/ (accessed February 18, 2010).

\section{fig.2.4.11 Chanel Ginza Façade}

"Chanel Headquarters." MediaRuimte. http://www. mediaruimte. be/digital_territories/projects/programmed/Chanel-Headquar-

ters_Peter-Marino-Architects.html?KeepThis=true\&TB_iframe=true \&height $=600 \&$ width $=800$ (accessed January 18, 2010).

fig.2.4.12 Adobe's CS3 Launch at Union Square 111 “TSFIM » Adobe CS3 Reactive Mural." TSFIM COVER. http:/ /www. thestudioforinteractivemedia.com/work/adobe-reactive-mural (accessed August 18, 2009).

fig.2.4.13 Body Movies by Rafael Lozano-Hemmer

"Disco: Body Movies." Flickr - Photo Sharing. http://www. flickr. com/photos/87313211@N00/70233138/ (accessed July 18, 2009).

fig.2.4.14 Touch by LAb[au] on the Dexia Tower in Brussels 113 "Touch - LAb[au]." laboratory for Architecture and Urbanism. http://lab-au.com/projects/touch/?lang=nl\#/projects/touch/ (accessed February 18, 2010).

fig.2.4.15 Twists and turns on the Uniqa Tower, Vienna

114

"twists and turns" Holger Mader | Alexander Stublic | Heike Wiermann. http://webblick.de/twists_and_turns/twists_and_turns_indexEN.html (accessed March 18, 2010).

fig.2.4.16 555KUBIK facade video projection

"555 KUBIK Facade Projection" today and tomorrow. http://www. todayandtomorrow.net/2009/07/23/555-kubik-facade-projection/ (accessed March 18, 2010). fig.2.4.17 Stereoscope, Toronto during Nuit Blanche 116 "stereoscope at city hall." [daily dose of imagery]. http://wvs. topleftpixel.com/08/10/03/ (accessed January 18, 2010).

fig.2.4.18 the projections transformed the grain silos

"CBC News - Projecting the past." CBC.ca. http://www.cbc.ca/ arts/artdesign/story/2008/08/21/f-lepage-image-mill.html (accessed April 27, 2010).

\section{fig.2.4.19 The Image Mill by Robert Lepage}

"Quebec 400th Image Mill." Flickr. http://www.flickr.com/photos/43572660@N02/4069614422/ (accessed April 27, 2010).

fig.2.4.20 Rock Formations by Jennifer Steinkamp

"denver." Jennifer Steinkamp Artist Web Site. http://jsteinkamp. com/html/body_denver.htm (accessed May 4, 2010).

fig.2.4.21 Swell by Jennifer Steinkamp

"Steinkamp_art." Jennifer Steinkamp Artist Web Site. http:// jsteinkamp.com/html/art_documentation.htm (accessed May 4, 2010).

fig.2.4.22 Loop by Jennifer Steinkamp

"Steinkamp_Loop." Jennifer Steinkamp Artist Web Site. http:// jsteinkamp.com/html/corcoran.htm (accessed May 4, 2010).

fig.2.5.1

rendering by author

fig.2.5.2

rendering by author

fig.2.5.3

"Times Square, 42nd Street" Flickr. http://www.flickr.com/photos/oquendo/157468855/ (accessed January 26, 2010).

fig.2.5.4

"Times Square 42nd Street Station" Flickr. http: / / www. flickr.com/ photos/chrisbrennan/483823208/ (accessed January 26, 2010). 
fig.2.5.5

rendering by author

\section{fig.2.5.6}

"Times Square, street view" Flickr. http: / /www. flickr.com/photos/worldtourtm/1994651154/ (accessed January 26, 2010).

fig.2.5.7

"Times Square Street Scene" Flickr. http:/ / www.flickr.com/photos/terriaw/4144725845/ (accessed January 26, 2010).

fig.2.5.8

rendering by author

fig.2.5.9

rendering by author

fig.2.5.10

"at Shinjuku Station" Flickr. http://www.flickr.com/photos/naoyafujii/2688623796/ (accessed January 26, 2010).

fig.2.5.11

rendering by author

fig.2.5.12

rendering by author

fig.2.5.13

"Las Vegas Strip." Flickr. http://www. flickr.com/photos/robertalonso/2604248498/ (accessed January 26, 2010).

fig.3.0.1 Main Street Galt

"Downtown Galt." Flickr - Photo Sharing. http:/ / www. flickr.com/ photos/carmichaels/2617554296/in/set-72157605857104787/ (accessed February 18, 2010).

fig.3.0.2 Galt City Centre boundary

graphic by author, [source: http://www.cambridge.ca]

fig.3.0.3 many choose to shop along Hespeler Road
“Hespeler Road.” Flickr - Photo Sharing. http://www. flickr.com/ photos/carolem250/1083702223/ (accessed March 9, 2010).

fig.3.0.5 map of bicycle and pedestrian paths graphic by author, [source: http://maps.google.com/]

fig.3.0.4 the historical facade of Main Street tos/creativetrade-offs/3784664520/ (accessed March 10, 2010).

fig.3.0.6 the Grand River

"Stillness" Flickr - Photo Sharing. http://www. flickr.com/photos/10668686@N06/3981723577/ (accessed March 18, 2010).

fig.3.1.1 map highlighting many of Galt's features graphic by author, [source: http://maps.google.com/]

\section{fig.3.1.2 Tiger Lofts}

146

Lancer Developments . http: / /www.lancerdevelopments.com/projDisp. php?gp=11\&proj=22\&pg=4 (accessed March 18, 2010).

fig.3.1.3 Mill Race Park

"Mill Race" Welcome to Flickr - Photo Sharing. http: / /www.flickr. com/photos/dj_moss/176578621/ (accessed March 18, 2010).

fig.3.1.4 Unsilent Night route and potential attractions graphic by author, [source: http://maps.google.com/]

fig.3.1.5 old postcard showing the corner of Main Street "Galt, Ontario." ePodunk Canada. http://ca.epodunk.com/profiles/ontario/galt/2004015.html (accessed February 18, 2010).

fig.3.1.6 corner of Main Street in 1984

"Main Street Heritage Conservation District Plan" http://www. cambridge.ca/planning_services/policy_planning/main_street_ heritage_conservation_district_plan (accessed February 18, 2010).

fig.3.2.1 renderings of the potential storyboard sketches 150 graphic by author 
fig.3.2.2 storyboard sketches

graphic by author

fig.3.2.4 concept sketches

graphic by author

fig.3.2.3 filming Darcy infront of the 'green' screen

graphic by author

fig.3.2.5 rendering of view from the Mellville Cafe patio

graphic by author

fig.3.2.6 variation of diagrams

graphic by author

fig.3.2.7 view from Mellville Cafe patio

graphic by author

fig.3.2.8 dimesions of the facade

graphic by author

fig.3.2.9 two stacked Christie Roadster HD18K

graphic by author

fig.3.2.10 video still from the Cambirdge Times

"Cambridgetimes.ca | Cambridge online newspaper" http://

www.cambridgetimes.ca (accessed February 18, 2010).

fig.3.2.11 participants follow the route

photograph courtesy of Bob McNair

fig.3.2.12 view from Mellville patio photograph courtesy of Bob McNair

fig.3.2.13 looking from Main Street Bridge

photograph courtesy of Bob McNair

fig.3.2.14 tracing the outlines of the church steeple photograph courtesy of Bob McNair

fig.3.2.15 one object transforms into the next photograph courtesy of Bob McNair

fig.3.2.16 Darcy and his red umbrella

fig. 3.3.1

graphic by author

fig. 3.3.2

graphic by author

fig. 3.3.3

graphic by author

fig. 3.3.4

fig.3.3.5

graphic by author

fig.3.3.6

graphic by author

fig.3.3.7

fig. 3.3.8

fig.3.3.9

graphic by author

fig.3.3.10

172

graphic by author

fig.3.3.11 
fig.3.3.13

graphic by author

fig.4.0.1

photograph courtesy of Bob McNair

fig.4.0.2

photograph courtesy of Bob McNair

fig.4.0.3

photograph courtesy of Bob McNair 


\section{LIST OF TABLES}

table 2.5.1 Eight Design Principles

Appendix

table Digital Media Outlets 

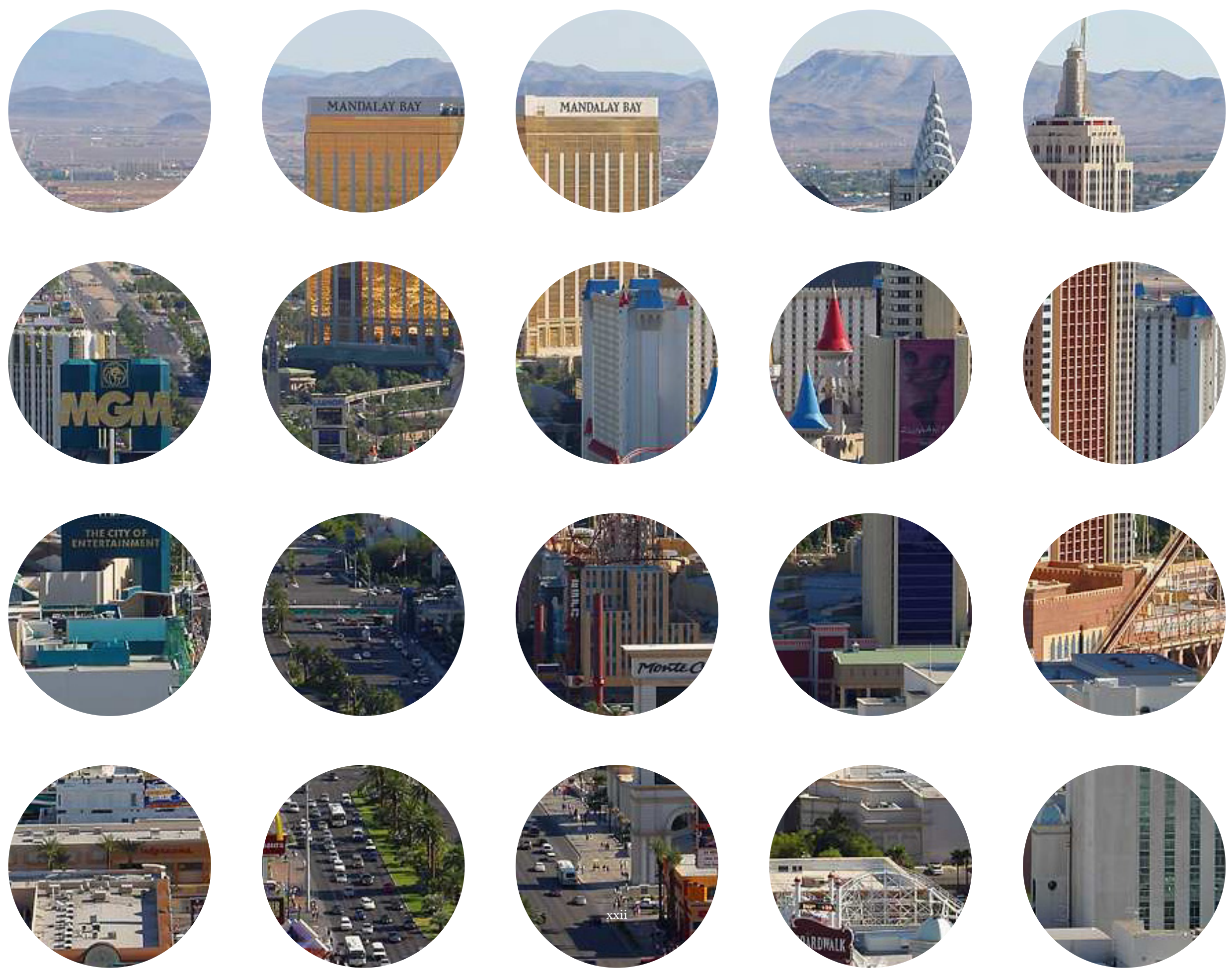

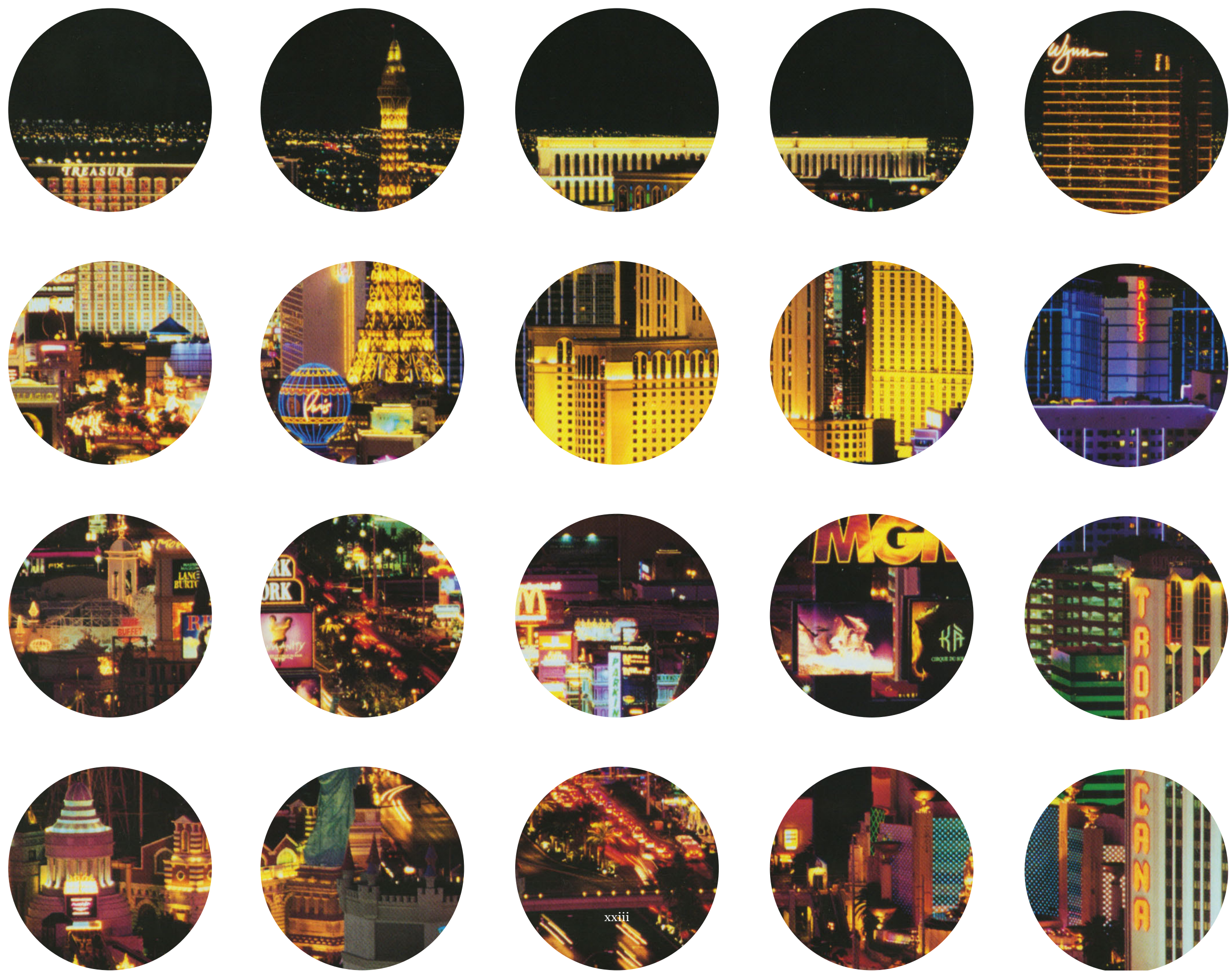




\subsection{INTRODUCTION}

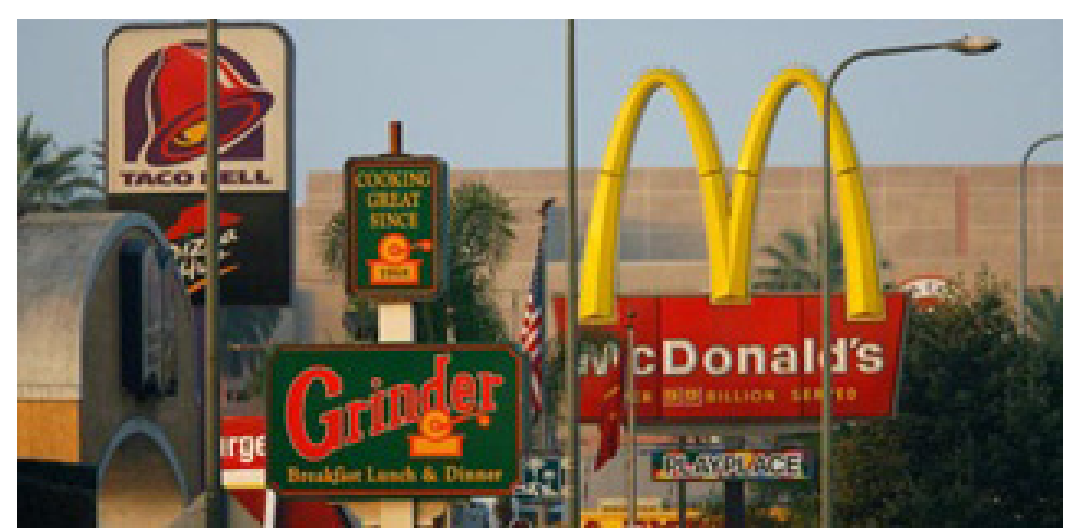

fig.1.0.1 a typical North American strip featuring commonly seen logos
Technology has changed how we use the city, and is changing at a unprecedented pace. As new developments are made in the digital realm we are slowly losing the connections we had to the physical city. In its place a virtual domain is growing, parallel to the streets and metropolitans that we live in. The accessibility of communication technology is rendering physical location insignificant, transforming our urban fabric and social networks. Products and services are mass produced in retail shops and online stores. As goods and services are becoming commodified their acquisition is a secondary goal. Tangible objects are now tools to obtain a desired lifestyle as consumers shift into an experience economy.

Since the 1960s, with the advent of shopping malls and suburban sprawl, we have begun to distance ourselves not only from our natural environment but also from our built environment. As suburban developments emerged, an equal number of 'power malls' filled the void of public space. Our city centres, divided up between the suburbs, suddenly lost their relevance to society. Individuals now go about their daily lives in malls and parking lots, disengaged from the markers of identity that city centres once held. Every mall has the same stores and restaurants. Globalization has created places that are unmemorable, almost indistinguishable, from one another. People 
no longer feel a connection towards unmemorable 'non-places' as each place produces the same experiences. Furthermore our public spaces, once our places to congregate and connect back to nature, are now filled with advertisements. These advertisements, which sell us lifestyles and experiences, all react to society's need for consumption, creating visual clutter. Such resulting from the competition for attention, has prompted many new uses of the traditional billboard. Everywhere there are now megascreens running commercials, LED lights scaling storefronts, and jumbotrons showing real-time footage. These strategies to sell to people are at the expense of architecture. Swaths of brand names and digital screens occupy facades of brick, stone, and glass. Buildings themselves have quietly bowed down to commercialism and have passively taken second place. Instead of architectural facades being engulfed by global corporations we need to find possibilities in which both architecture and digital communication can exist symbiotically.

An exemplary of communication and architecture, Michelangelo's ceiling in the Sistine chapel creates an aesthetically pleasing fusion. The chapel is an example of the harmonious combination of a structural vault veiling with a story in a work of art. When a message needed to be communicated, it was able to reach the masses through architecture. For the public the art conveyed that message while simultaneously elevating the built form.

Michelangelo's pure concept is what we must keep in mind in our efforts to refocus design in conjunction with public connectivity and

\footnotetext{
Augé, Marc. 1995. Non-places: Introduction to Anthropology of Supermodernity. London New York: Verso.
}

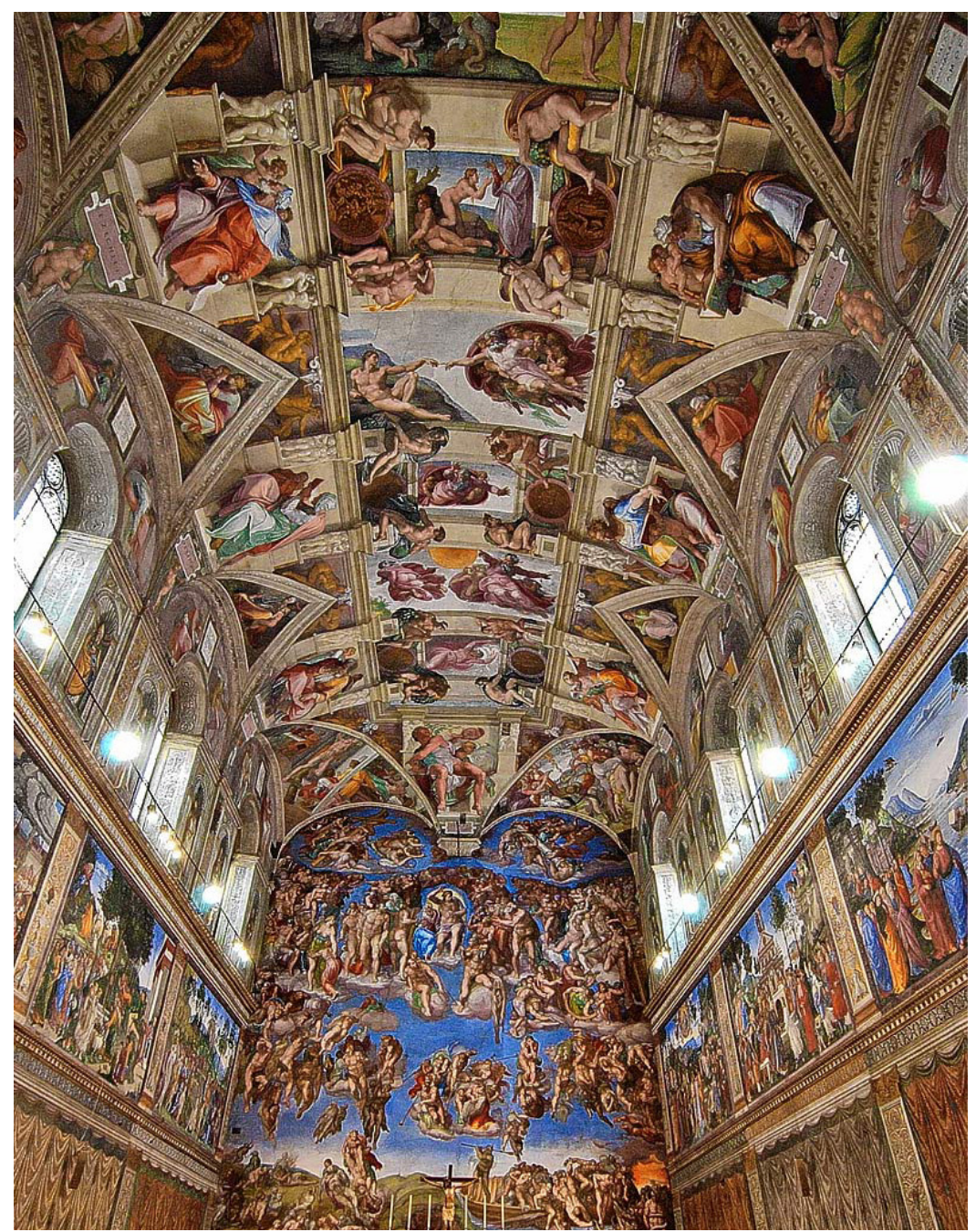

fig.1.0.2 the Sistine Chapel ceiling, painted by Michelangelo between $1508-1512$ 
awareness to architecture. We must first approach the larger context of cityscapes and public spaces with communication media. The commercial and media sector continue to expand; instead of letting it engulf architectural facades, a clear understanding of the benefits of digital media could help in the future of many urban areas to combine harmoniously architecture and new media. Digital media can be used as a representational form of art in architecture, but these applications can affect architecture both positively and negatively. As such, it is important that designers are aware of the implications of digital media to ensure the success of their designs. This thesis will investigate the role of architecture in the visual and physical setting of public space enhanced by digital media. Furthermore it will explore the use of digital media as a tool to improve public space, while engaging with the facades of buildings and structural surfaces. Three case studies, demonstrate the successful integration of digital media and public space providing key design principles. These principles have been applied to a project located along the Grand River in Cambridge for the event 'Unsilent Night'. The aim of the event was to capture the attention of participants and passersby, creating a lasting emotional connection to the Grand River.
Jane Jacobs has suggested that:

To approach a city, or even a city neighborhood, as if it were a larger architectural problem, capable of being given order by converting it into a disciplined work of art, is to make the mistake of attempting to substitute art for life. ${ }^{2}$

This thesis does not argue for the ways in which to make urban areas more aesthetically pleasing, rather it argues for how people can reconnect with the architecture of public spaces. Thus, I argue that by understanding the nature of digital media and its effects, architects can once again take a prominent role in the design of the urban fabric. 



\subsection{PUBLIC SPACE AND OUR CITY EXPERIENCE}

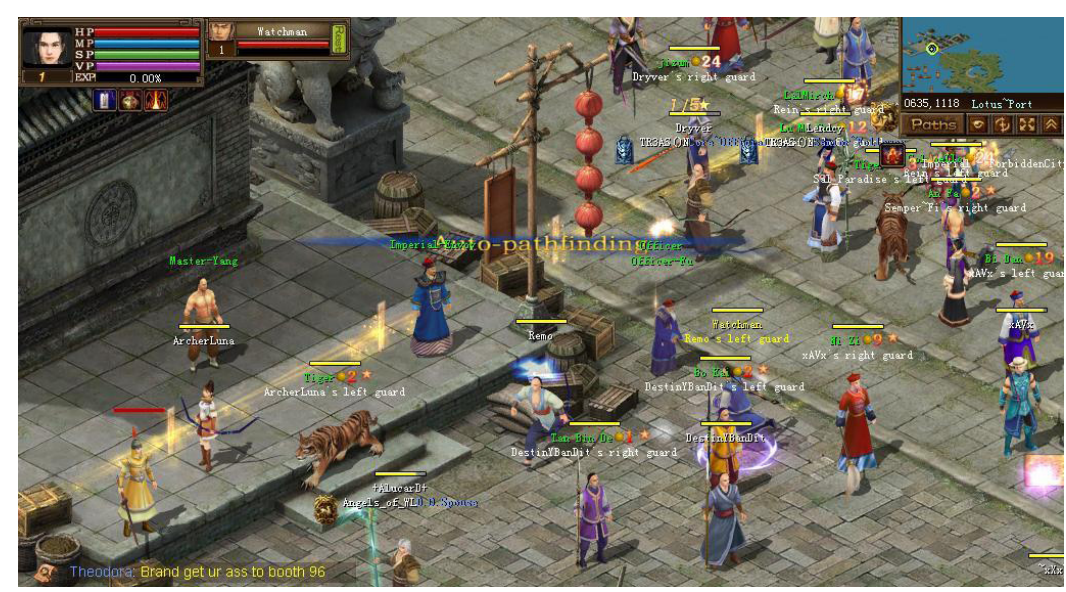

fig.1.1.1 MMORPG: 'Massively multiplayer online role-playing game'. Players around the world interact with one another within a virtual game world.
Public spaces have served historically as a platform for the people of a city to share information. The presence of people within public spaces encourages social interaction. Today public spaces come in varying forms. They are the traditional areas that are bound by formal design, places like parks and squares. They are the informal undesigned spaces that are created by events and programs. They are the privatized areas of consumption like shopping malls, commercial strips and plazas. Most recently, they are also the digital communities accessed through communication technologies and online networks.

The web has created new dimensions of public space, virtual areas populated by real users from all across the world using the space just like one would in an actual public space for a plethora of activities. As a result, new activities that encourage public interaction, such as collective participation and unpredictable collaboration, are ever more valuable within the physical world. Collective participation and unpredictable collaboration can be encourage through experimental installations and interactive interfaces.

Designers should take advantage of communication platforms and digitization both to showcase the qualities of physical space over virtual space, and to render such physical spaces public through digital communication such as mobile media devices and interfaces. Thus, users shape the spaces that they are enjoying; their presence 
as a collective whole is both a part of the public atmosphere and effectively creates public space. Space becomes animated and engages with the people creating its own dimension through activity.

The appeal of virtual spaces is that they allow people to manipulate digital environments to their own specifications, qualities which public spaces lacks. However, in a public space it is the pedestrian and the activities which take place in that area which shape the public realm. The activities could be small scale informal events, unanticipated street musicians, performers, or the distribution of pamphlets. These events concentrate in areas of high traffic, revealing locations of density and successful pedestrian usage.

As the commercial sector continues to enclose common areas in cities, the issue of public spaces and their relevance to architecture becomes a challenge. As entertainment and commerce are becoming more of a necessity in the production of public spaces it is important to take into consideration the effects of commercialization on architecture. Contemporary social and political systems tend to encourage privatization within cities. ${ }^{1}$ As many urban spaces today are quickly becoming privatized, especially in the downtown areas where space is of higher value, the presence of commercial screens has altered the dynamics of the public street and thus the experience of the city. The act of de-privatization makes it possible to counter these effects, re-inscribing these spaces and surfaces with design that prioritizes the need to reconnect architecture with public spaces. A public space must provide a shared sense of meaning for the community, fulfilling

1 Klingmann, Anna. Brandscapes: Architecture in the Experience Economy. London: The Mit Press, 2007. 81

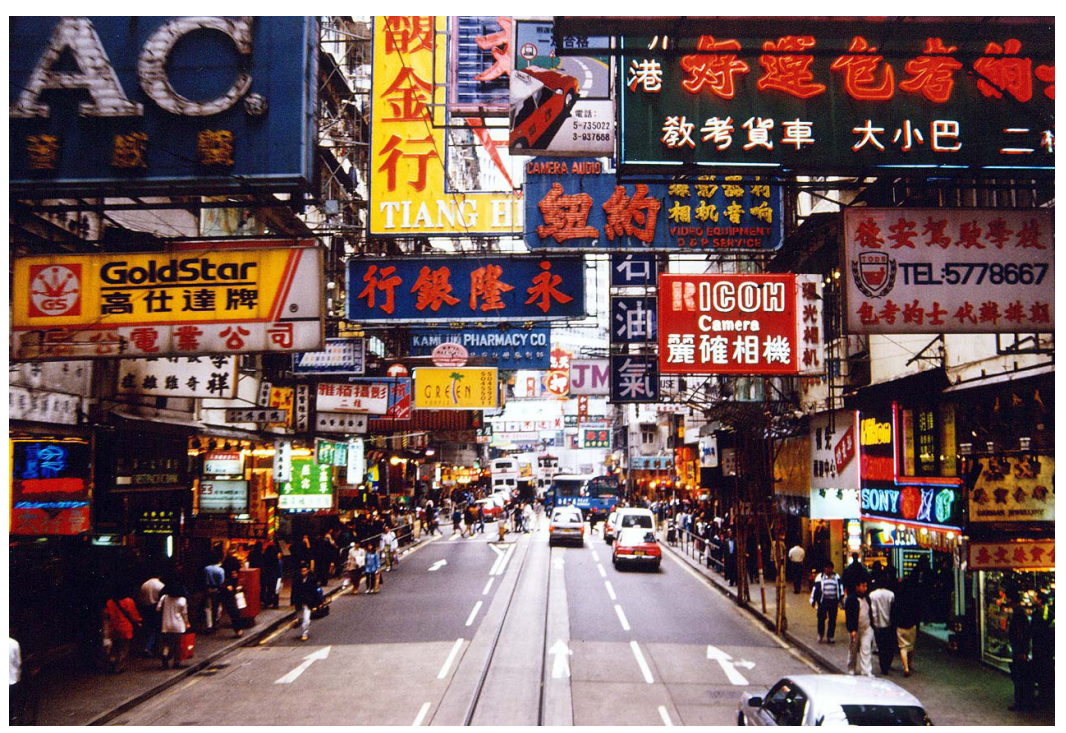

fig. 1.1.2 in Hong Kong billboards and advertisements obstruct physical space 
the needs of many different groups of people and not just one private interest group. Space should be inviting to everyone and encourage its use, allowing participation in activities that take place in it, and developing a sense of responsibility for its care. Public spaces should enable a variety of uses, including self discovery, which makes public space more meaningful:

The challenge to the creative use of media technologies is fostering the diversity of public actors and terrains to develop strategies of articulating the new public domains that connect physical urban spaces and the potential public sphere of the electronic networks. This public sphere will only come into being if there are complex forms of interaction, of participation and learning, that use the technical possibilities of the new networks and that allow for new creative forms of becoming visible, becoming present, becoming active, in short, of becoming public. ${ }^{2}$

Thus I argue for a new model, evolved from our current perception of public spaces, which takes care to use the communicative ability of media culture, our advancing technology, and the traditional enjoyment of space.

2 McQuire, Scott. Media city : Media, Architecture and Urban space. Los Angeles, Calif. ; London: SAGE Publications, 2008.150 

1.2 THE HISTORICAL PROGRESS OF

\section{PUBLIC REALMS: ITS DECLINE IN NORTH AMERICA}

Public space is where members of the public have the opportunity to exercise their right to freedom of expression. In ancient Greece, these places were called agoras. Citizens gathered there to hear the monarch speak, or else men would assemble for military duty there. This same space would be used by merchants and consumers as a place to buy and sell goods. It was a versatile space suitable for both political and commercial functions. These public spaces became the life of the city, constantly being used from dawn till dusk. Entertainers, vendors, and citizens alike would spend most of the day in the agora, buying, selling, debating and socializing. ${ }^{1}$

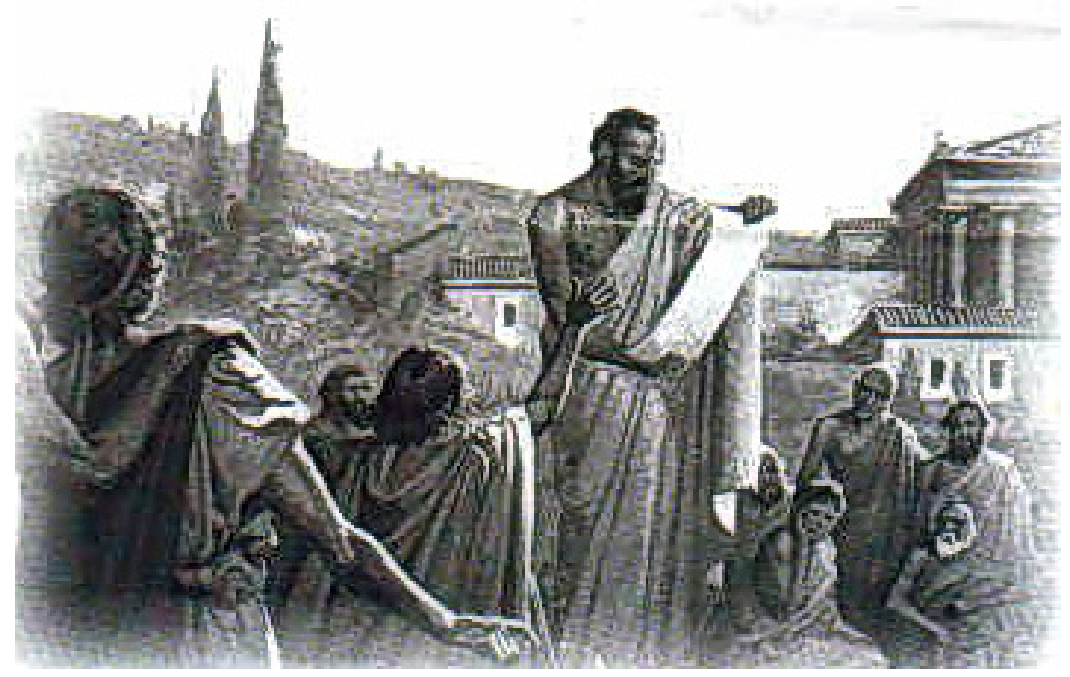

fig.1.2.1 assembly of citizens in the agora
Places of worship such as cathedrals were the anchors of many public squares, which became a platform for the monuments of world leaders, rulers and deities. These spaces were used for military processions and parades, providing a great opportunity to harness the energy of the public. Power resonated within these public spaces when political hearings and revolutions took place for many generations. Religious congregations were 'the civic institutions' of the time. Similarly, in Europe the churches were the symbolic centres of the city for religious, political and educational functions essential to the public realm. The Duomo, for example, at Basilica di Santa Maria del Fiore in Florence is visible from every angle of the city,

1 Carr, Stephen, Mark Francis, Leanne G. Rivlin, and Andrew M. Stone. Public Space
(Environment and Behavior). New York: Cambridge University Press, 1993. 52 
visually symbolic of civic life in Florence.

Public spaces and monuments also evoke a city's past, forming collective memories for current visitors and locals. These monuments and spaces are like a historical inheritance, which create a symbolic attachment between a city and its visitors. The Trevi Fountain in Rome, into which many people throw coins for luck and love, evokes feelings of passion for many people. Similarly, the Palio race in Sienna's Piazza del Campo, or Barack Obama's presidential acceptance speech on the lawn in Chicago's Grant Park connect those particular places with the energies of the historical events which took place there.

\section{Public life and privatized space}

Many of the ideals discussed above have been lost over time due to changes in society. One such change is the shift in attitudes towards private space. The dynamics and lifestyles of the modern family have altered the balance between the public and private realms. By the seventeenth century the workplace and the home start to separate. Domestic privacy became a standard for the working class, a liberty once reserved only for the upper class. ${ }^{2}$ The emergence of an intimacyseeking society evolved even more rapidly with the development of the private automobile. The industrial era marked cities with tower blocks and vast arterial roads for automobiles as devised in Le Corbusier's 'Radiant City', he saw the plan of the city through the eyes of the automobile: "Our fast car takes the special elevated motor

2 Slessor, Catherine. "Public Engagement - evolution of public space $\mid$ Architectural Review, The" Find Articles at BNET. http://findarticles.com/p/articles/mi_m3575/is_1250_209/ ai_74929075/?tag=content;coll (accessed February 13, 2010).

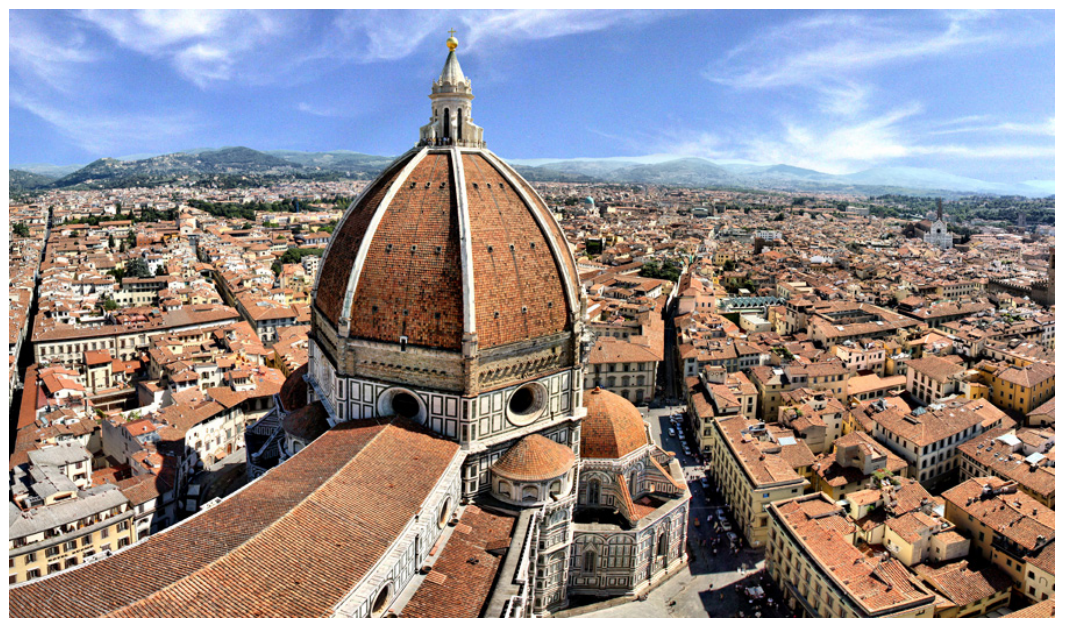

fig.1.2.2 Basilica di Santa Maria del Fiore captures the skyline in Florence
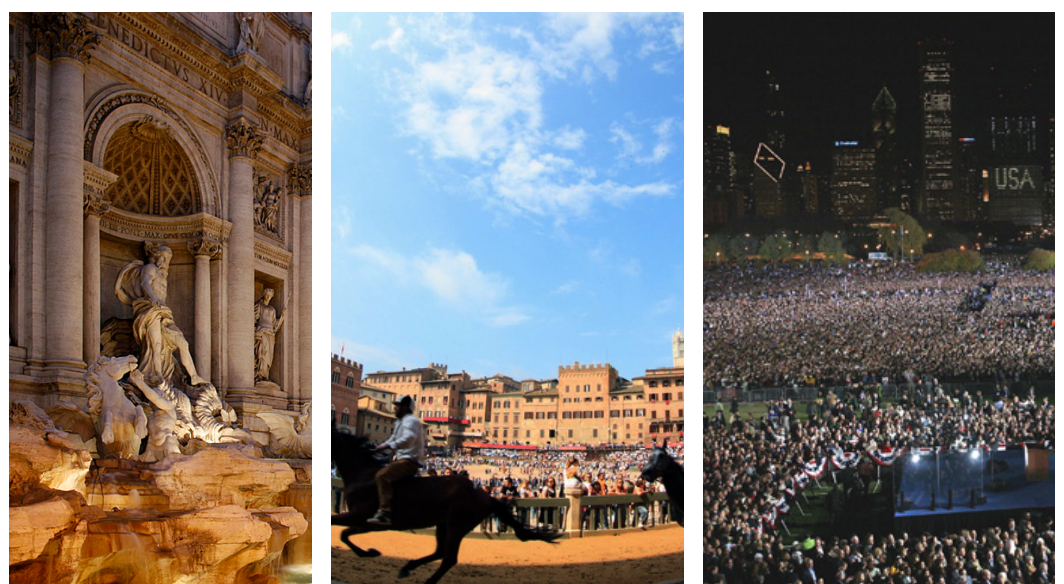

fig.1.2.3 Trevi Fountain in Rome. Palio race in Siena's Piazza del Campo. Chicago's Grant Park. (from left to right) 


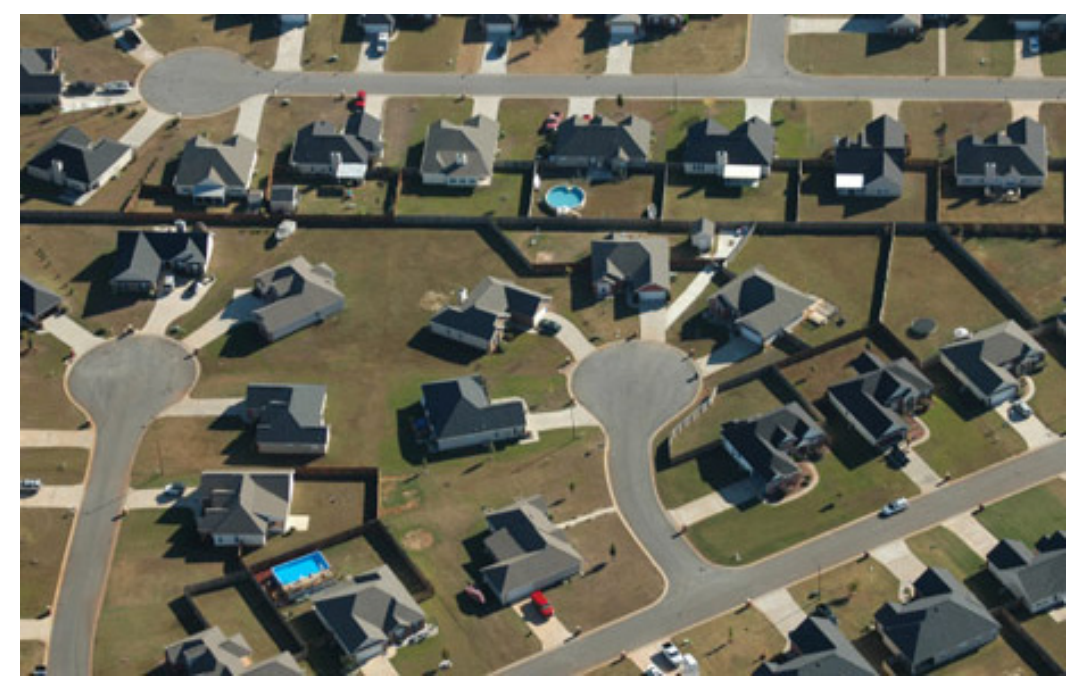

fig.1.2.4 aerial view of a typical North American suburburban community

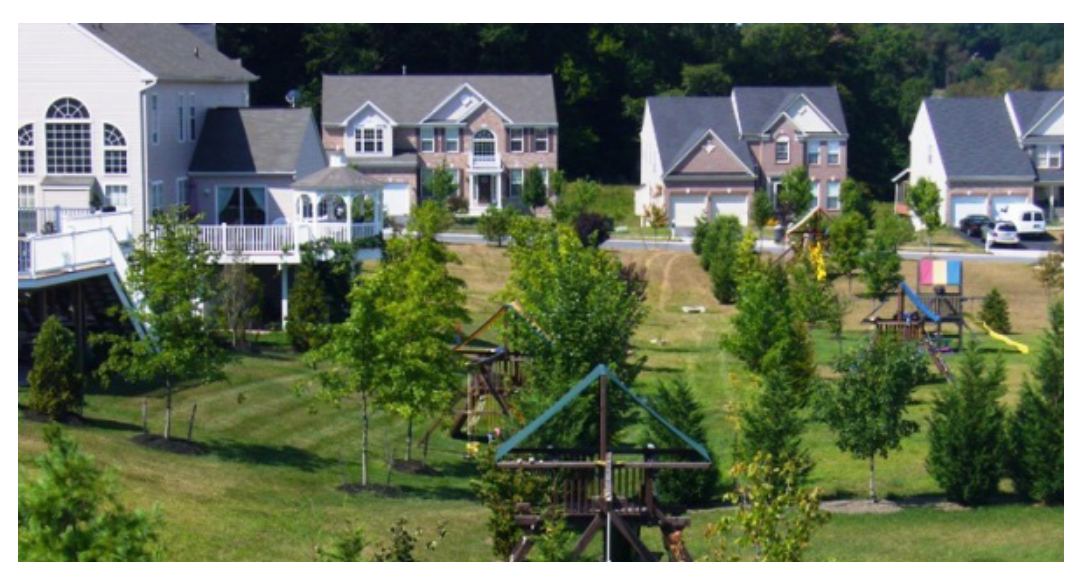

fig.1.2.5 large (unused) backyards in suburban areas reduce the use of public parks and therefore social interaction track between the majestic skyscrapers". ${ }^{3}$ This city model which Le Corbusier described as a 'park' influenced many planners in North America to design projects that embodied his ideals.

As automobiles became the standard, vehicle-owners needed amenities such as parking lots rather than shared spaces. The unfavourable environmental condition of the industrial city also prompted many individuals to seek more livable areas. Suburban developments promoted an ideal lifestyle that promised dreams of health, ownership, and prosperity which captured the attention of many people. Parks and public squares became redundant in suburban development because people could now participate in recreational activities in their own backyards. The neglect of public life continued to manifest as a result of suburban sprawl; the community spirit once predominantly held in the public realm was lost.

Centralized suburban planning during the modernist period (1940s-1960s) created large privatized indoor spaces as an alternative to the public realm. Traditional outdoor places for social interaction were increasingly lost to shopping malls and convention centres. ${ }^{4}$ These private realms were not only controlled but limited to a certain type of user - the consumer - who went to these places primarily to purchase goods. Exteriors of such consumer spaces did not need to be attractive. Subsequently, public realms were shielded from the exterior elements with massive blank facades. Such development led to a new phenomenon, that of consumer boredom or disinterest.

3 Jacobs, Jane. The Death and Life of Great American Cities. 21
4 Carr et al. Public Space (Environment and Behavior). 19 
Despite the initial consumerist lure of "iconic designer buildings' after one visit, people fail to be excited to use the same space once again. Thus, the human connection is compromised and the venue is no longer profitable, both in capital and social experiences.

The issue of public space and its relevance to architecture seems to become more imperative as capital continues to enclose more of what were once thought of as common areas. As entertainment and commerce are becoming more of a necessity in the production of public spaces, it is important to include and design them into the equation. After the industrial revolution foray, there were many opportunities to turn old factory areas and warehouses into effective public spaces with the help of the private sector. The right balance of awareness for the public realm and funding from corporations can be a positive outcome for many industrial riverfronts, docksides, and former factory buildings. For example, Granville Island in Vancouver B.C. was redeveloped from an industrial manufacturing area into a public market place full of numerous, lively attractions. This development owes much of its popularity to the flexibility of the complex and to its range of uses, which appeal to many interests. ${ }^{5}$

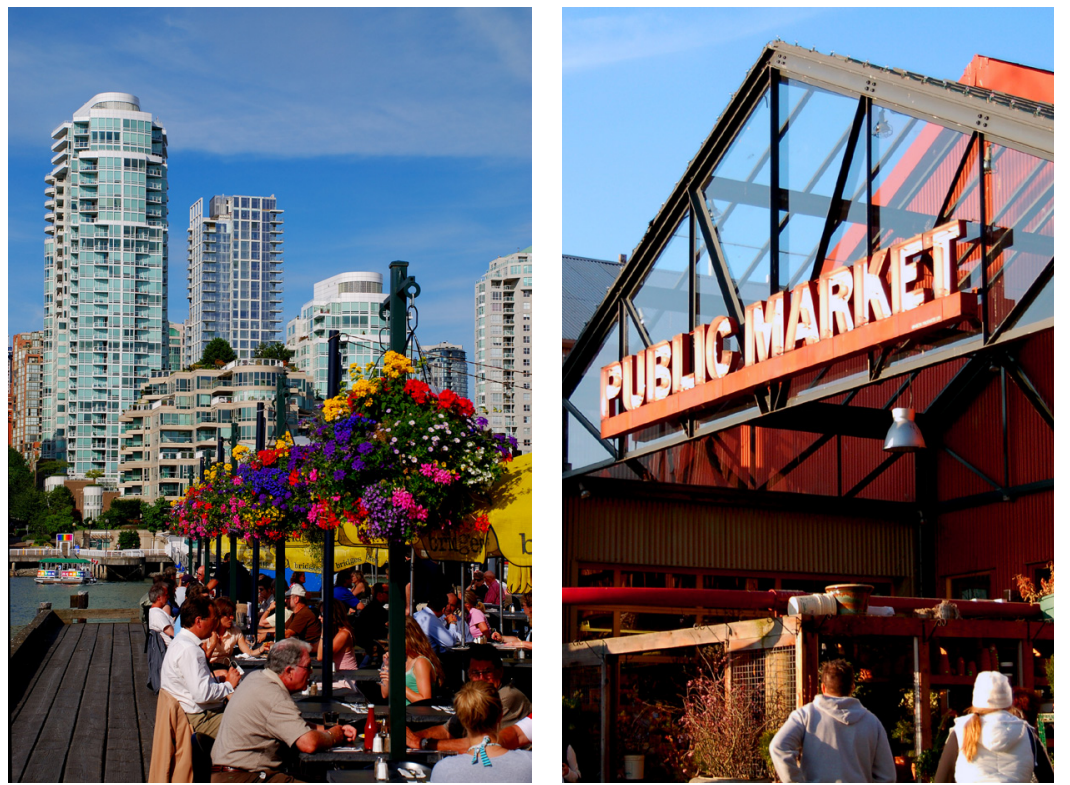

fig.1.2.6 Granville Island Vancouver B.C.
5 "Granville Island" Placemaking for Communities | Project for Public Spaces (PPS) . http:// www.pps.org/info/newsletter/november2004/november2004_granville (accessed February 20, 2010) 


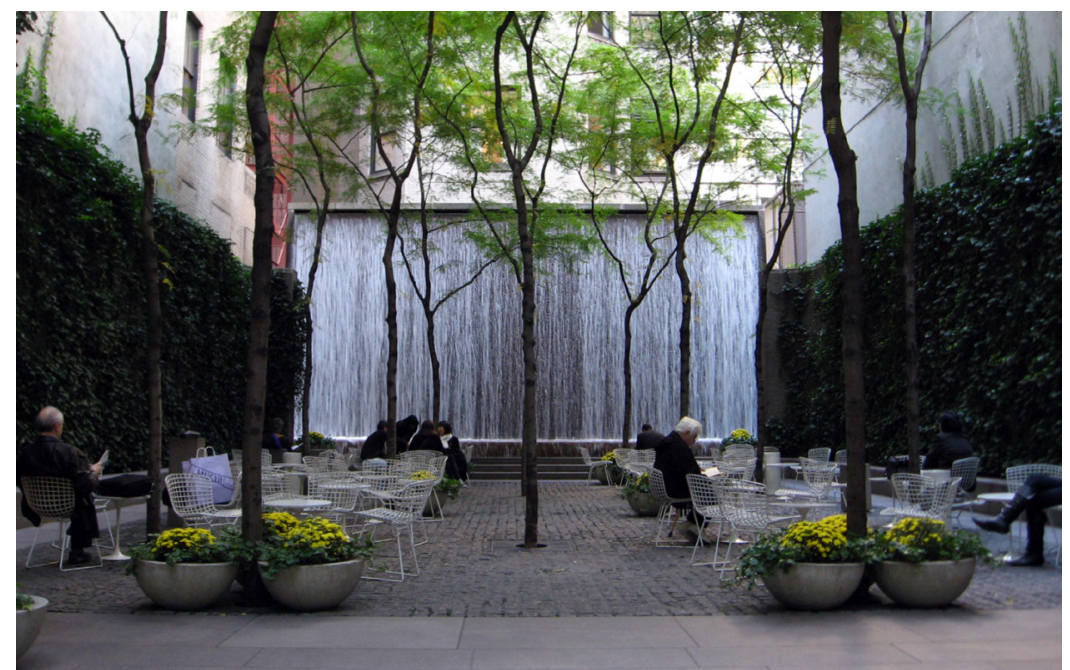

fig.1.2.7 Paley Park in New York City

\section{The many forms of public space}

It is almost impossible to design and designate a public space suited for everybody. Different spaces appeal to different social groups. Our diverse society deserves to choose from an abundant variety of public realms. Spaces that provide greater choice have a better chance of enticing people to leave their private realms for the public one. The expanding range of public spaces that are available and constantly being transformed speaks to the current demand for more public space: "Since the late 1950s, America has witnessed the emergence of new public space forms-the downtown pedestrian mall, the corporate plaza, the festival marketplace, the adventure playground, the town trail, and the vest-pocket park-as well as the revival of older forms, such as the farmers' market, the community garden, and the waterfront esplanade." ${ }^{6}$ The three major forms of public space in North America which continue to expand and evolve are the park, the square, and the street.

\section{Parks}

Parks are designed and designated open areas that are located in the centre of cities. Parks are usually publicly developed and managed. They are used and shared by local residents and/or tourists in more intimate settings (e.g. Paley Park in New York City), and in larger projects (e.g. Central Park in New York City). Parks are an important amenity in the city system, creating breathing room from the dense structures and tight alleyways of many downtowns. After industrialization altered the nature-oriented lifestyles of farming societies, the public longed to be part of the countryside once again.

6 Carr et al. Public Space (Environment and Behavior). 19 
By the nineteenth century, people had come to value the benefits of exposure to fresh air and nature, to escape the negative effects of industrialization. The 'Garden City' movement, initiated by Ebenezer Howard's in 1898, recognized the need for nature. In Howard's book 'Garden Cities of Tomorrow' he envisioned a utopian life which opposed the habits of city life which he believed caused the ills of society. His ideal city included reserving space for public parks and private lawns in efforts to combine the benefits of both country and city. ${ }^{7}$ The response to these demands started a widespread injection of parks into the cities. Facets of "country living" - meadows, lakes, openness, and sunshine - helped to remind people of what was lacking in the urban areas, and helped inspire new strategies and solutions for parks. The urban park would have all the amenities to allow the public to escape the city, place to exercise, contemplate nature, and breath in fresh air to restore the body from the stresses of city life. As homes in the city became smaller because of high land values residents increasingly spent more time in public spaces to improve their quality of life.

The benefits of parks are most apparent when looking at the quality of a city - the most successful cities are those with an abundance of parks. The benefits of providing access to parks range from open air recreation to healthier and greener cities. Parks cater to sports and concerts geared towards larger groups and also provide sheltered areas to enjoy a quiet picnic or book. Some parks include programming such as children's playgrounds, sports facilities and even playful fountains.

7 Howard, Ebenezer. Garden Cities of To-morrow. Albany New York: Bibliolife, 2009.

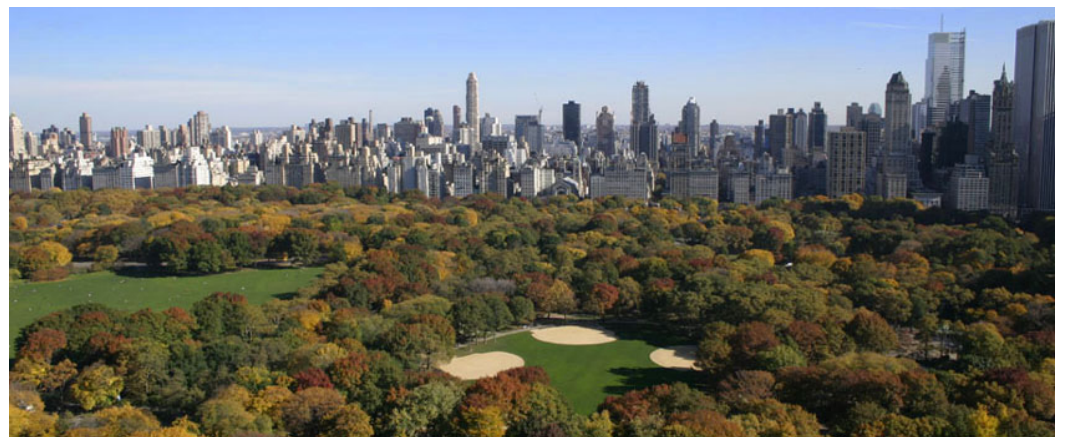

fig.1.2.8 Central Park in New York City 


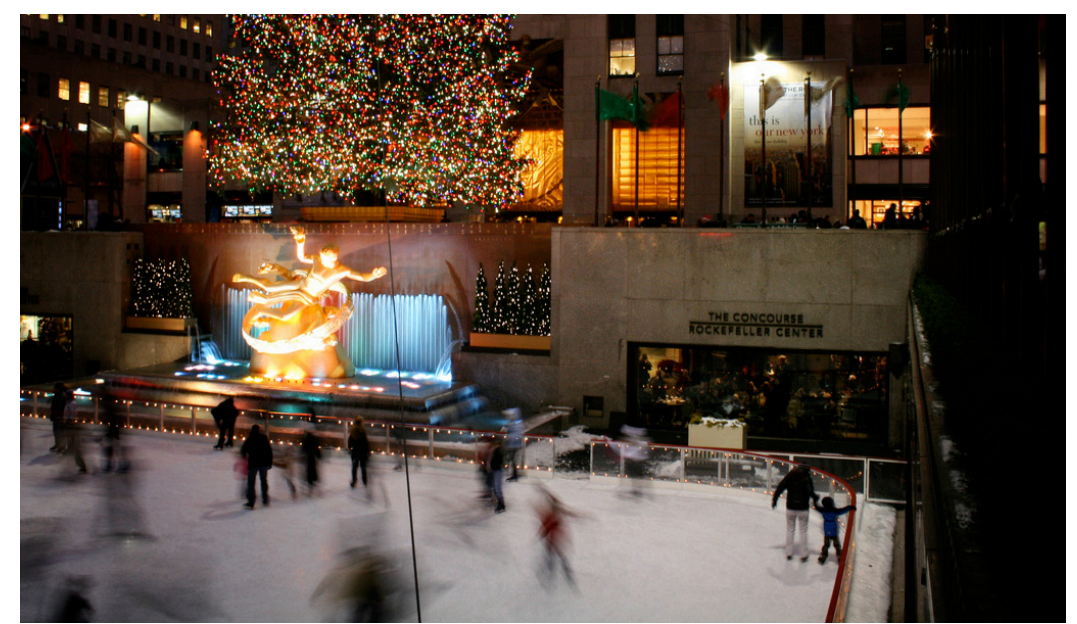

fig.1.2.9 lower plaza of Rockefeller Center in New York City. The square features a skating rink, sculptures and fountains all surrounded by commercial buildings

\section{Squares/plazas}

The square or plaza are typically planned places which are designed and formed by the surrounding of government official buildings. These places are part of a city centre and are often surrounded by corporate commercial buildings. In the past they were formed as a meeting place of streets where the buildings made way for a space, commonly outside a religious structure or government building, creating a central public gathering place when exiting or entering the building. The medieval European city usually contained piazzas adjacent to its town halls. By the mid-fifteenth century these piazzas gradually changed their character from market stalls to places expressing civic dignity. ${ }^{8}$ The public squares by the Renaissance were formally designed, taking symmetrical forms, such as St. Peter's Square in Rome. These central spaces for public assembly represented civic and religious pride for the city. ${ }^{9}$

The square as a momentous place within the city continued in North America where many cities were established around a main plaza. In 1682 the Boston Commons served as a communal space for churches and civic buildings, and was also used variously for cattle grazing and militia drills. With its rich history Boston Commons is symbolic of its community. Squares have become places where civic life has a voice. Rallies and political events happen in major squares because they evoke a sense of belonging and because such locations are connected to the past. ${ }^{10}$

\footnotetext{
8 Carr, et all. Public Space (Environment and Behavior). 54

9 ibid. 56

10 ibid. 47
} 


\section{Streets}

In North America, the largest public realm is right on the streets. The culture of the North American society is visible on the sidewalks. The constant traffic of various users enables different social interactions. Pedestrian sidewalks are the paths to destinations, whether leisurely or hurriedly. There is much interaction between the city and the individual. Streets have the ability to convey the distinct character of a particular district in the public realm - microcosms within the city - while squares/plazas uphold the image of the larger city. Small residential streets are a great place for neighborly interactions and are quiet and personal in character. The typical main street has a high level of activity with its wide sidewalks and busy traffic. The sidewalk can be the platform for both commercial and public contact. Although many streets cater to vehicular traffic, many urban areas are now transforming streets into pedestrian streets by closing off popular roads to traffic with bollards. This conversion helps to accommodate high pedestrian traffic in popular locations, providing a safe and more leisurely experience. One of the most popular roads adapted for pedestrians is Lincoln Road in Miami. This popular destination once a road for automobile traffic - has been redesigned to become a successful pedestrian mall. Comprised mostly of retail shops, it is a place where local residents walk their dogs and/or take a stroll with their families. In the evenings, many of the restaurants and bars include musical entertainment providing a place full of activity day and night.

AS host to both vehicles and people, the street is a hybrid of public space allowing multi-functional pedestrian activity. A successful street will attract pedestrians who choose to be there sometimes

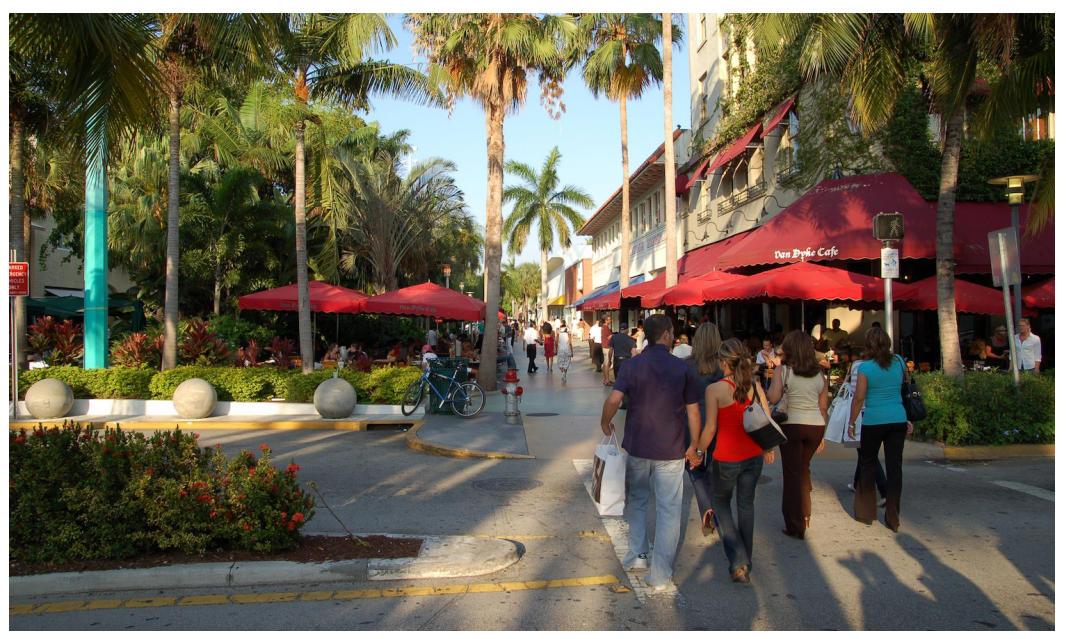

fig.1.2.10 Lincoln Road pedestrian mall in Miami, Florida a thriving shopping and dining area

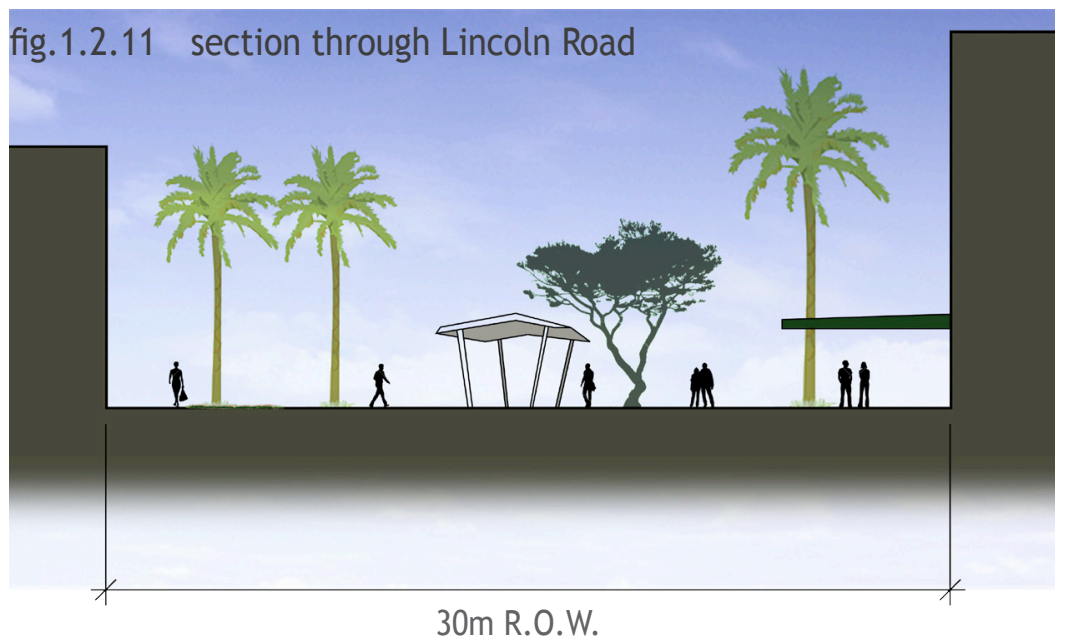



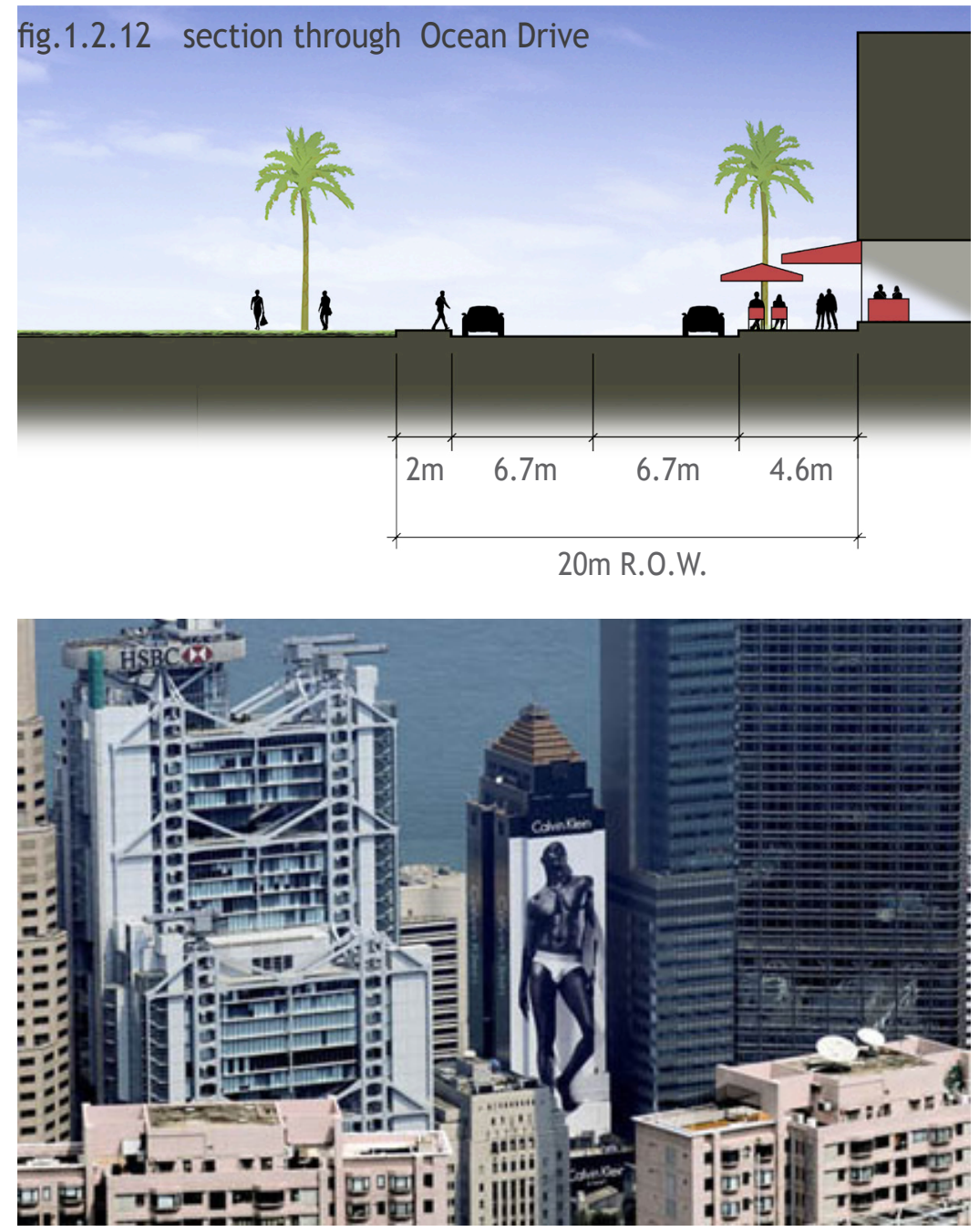

fig.1.2.13 27-story tall Calvin Klein advertisement on the RitzCarlton hotel in Hong Kong without any particular purpose (i.e. shopping, dining, resting) ${ }^{11}$. Another example of a successful street is Miami's, Ocean Drive. Lined with bustling restaurants, it is also filled with rollerbladers along the streets, people out walking their dogs, and pedestrians enjoying the view. The quality of the public realm can be attributed to the ability of the storefronts to define space, which they designate as patio areas of restaurants.

Many successful streets also have trees planted at spatial intervals to denote the pedestrian realm. Street trees protect pedestrians from vehicular traffic, filter the sunlight on scorching hot summer days, and soften the edges of the buildings to create a natural vaulted ceiling on smaller roads. These busy intersections provide the perfect opportunity to encounter the eyes of consumers. ${ }^{12}$

Marketing and advertising firms have taken notice and capitalized on the opportunity to integrate the private and public realms. ${ }^{13}$ However, the addition of multimedia can either provide an additional interface for the public realm, or take away from its spirit with overwhelming private advertising. For example, many advertising campaigns in Hong Kong have taken advertising to the extreme with unnecessarily large billboards. Billboards now cover the full facade of a 27-storey building, which are thus marketed not only to pedestrians and vehicular traffic but also to passersby in flight. The overwhelming impact of such large scale ads can cause a negative effect on street life with its out of scale presence as it takes a prominent role in the identity of the street.

11 Whyte, William H. City: Rediscovering the Center New York: Doubleday, 1988.79

12 Halprin, Lawrence. Cities. Revised ed. London: The Mit Press, 1972. 163

13 Klingmann, Anna. Brandscapes: Architecture in the Experience Economy. London: The Mit Press, 2007. 81 


\section{In need of improvement | Boston City Hall Government Centre Plaza}

Civic institutions have an inherent ability to attract civilians because of the services they offer. Yet so many of them are inadvertently designed to appear barren and uninviting to the public. In North America, many civic centres are deigned to make a statement in the city, rather than remain functional for the public. ${ }^{14}$ Boston City Hall Plaza is one example of a collection of government buildings that were considered a modern architectural masterpiece. However, the public never took pride in its modernity or embraced it as a usable public space. Boston City Hall towers over the plaza with 45,000 $\mathrm{m}^{2}$ of concrete in front of its doors at grade. The civic institutions surrounding the concrete and brick plaza all face away from the plaza creating a shapeless and "buffer-less" edge surrounding the plaza. City Hall effectively becomes a wall. The plaza in Boston does not provide any navigational markers like those found in the Piazza del Campo in Sienna with its gentle slope towards the city hall and many narrow streets spilling onto the space. William Whyte argues for a key point in planning, which is that people gather where there are places provided for seating, creating crowds and drawing additional passersby ${ }^{15}$ In contrast, the grade change in Boston Plaza works against the natural paths of pedestrians. With too many wide streets for access (and even five subway stops), there is no natural connections to the successful festival marketplace Faneuil Hall and Quincy Market. There is no purposeful gesture that encourages

14 Carr, et al. Public Space (Environment and Behavior). 87

15 Whyte, William H. City: Rediscovering the Center. 110

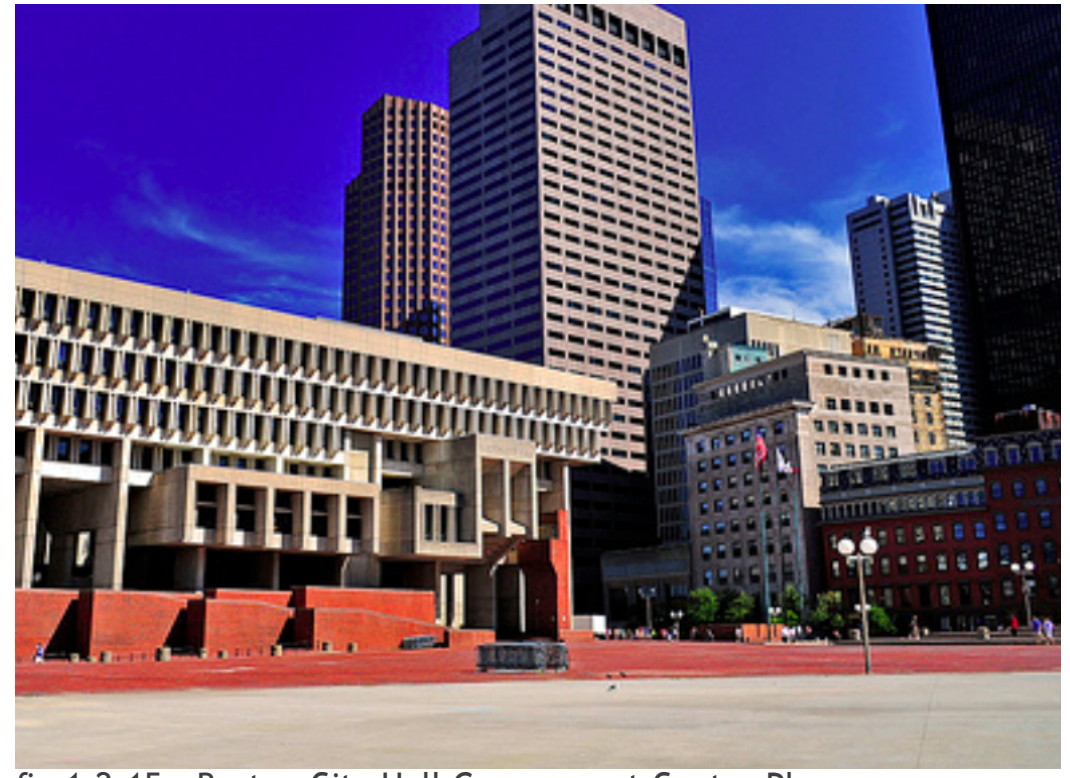

fig.1.2.15 Boston City Hall Government Centre Plaza

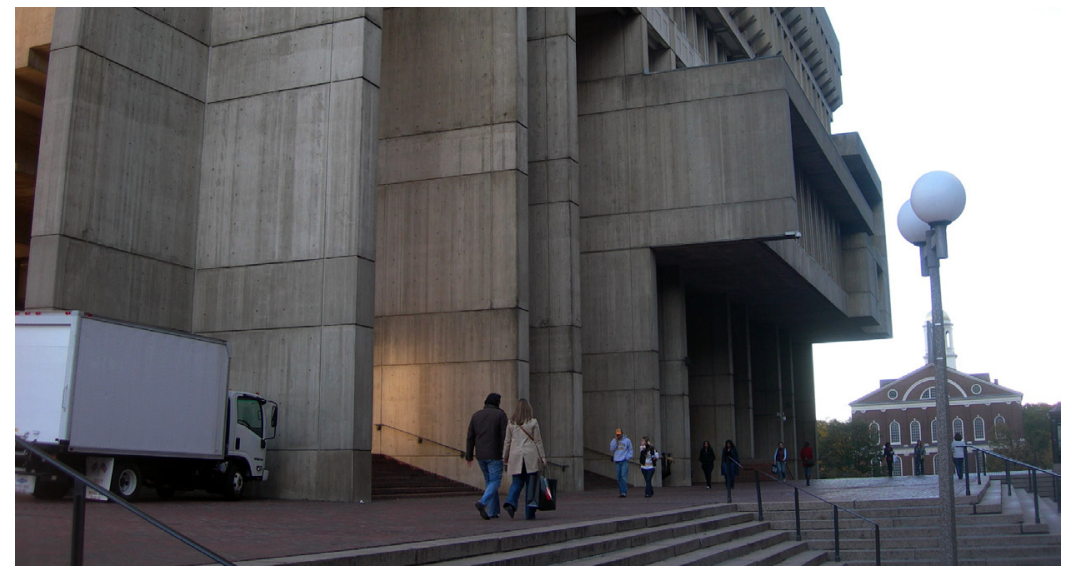

fig.1.2.16 unfriendly edge condition along the plaza 


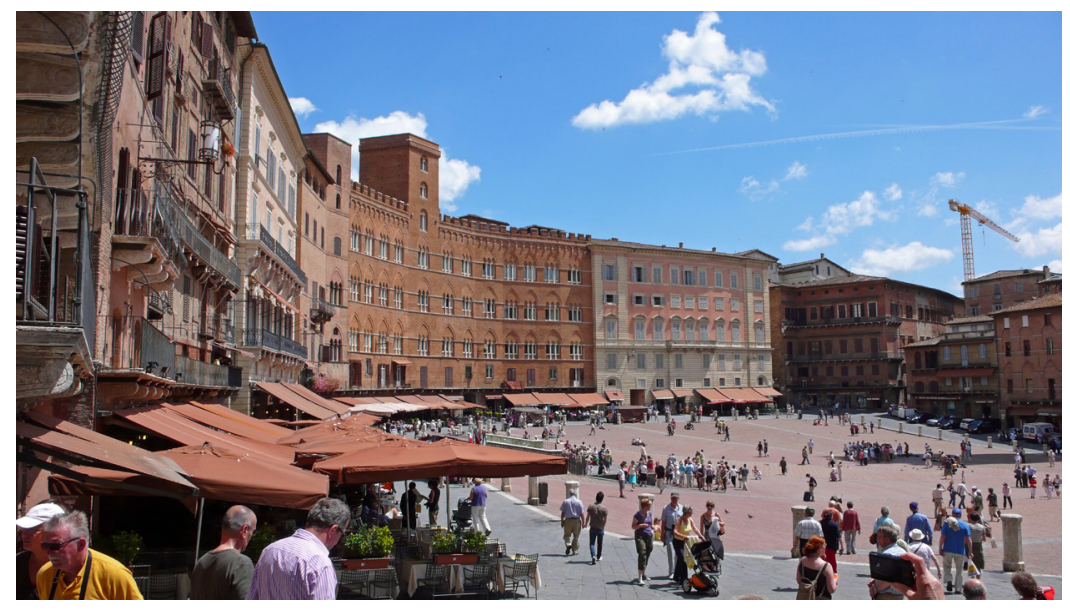

fig.1.2.17 The Piazza del Campo in Siena gently slopes towards the Torre del Mangia, the focal point of the piazza
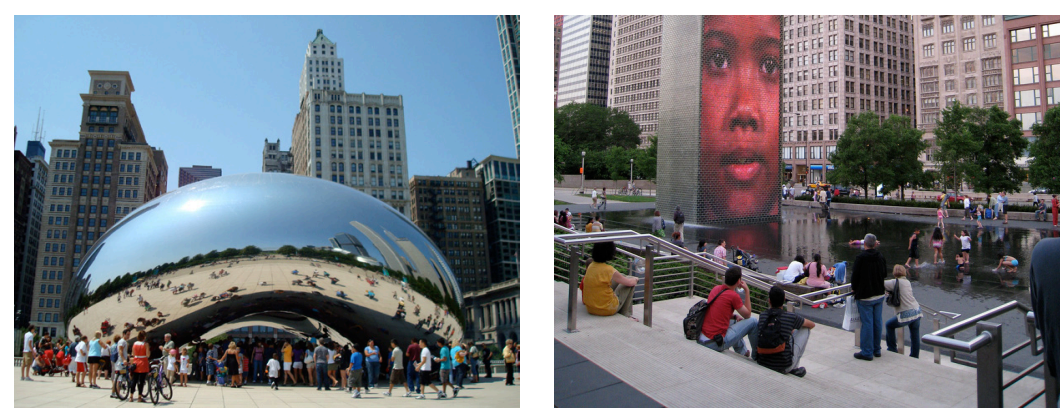

fig.1.2.18 Cloud Gate and Crown Fountain: public sculpture and video and fountain sculpture featured in Chicago's Millennium Park people to use the space. The place simply does not read as a space for people. ${ }^{16}$ The emptiness of the plaza leaves it with no protection from the natural elements, such as the summer sun, cold winter winds, and the dust in the spring and fall. The plaza does not provide any benches, trees, or vendor spaces, limiting options to the passersby. Without any available seating the area remains barren even during lunch hours.

\section{Thriving Public Space| Chicago's Millennium Park}

In Fred Kent's article 'The Power of Ten: Why Great Places are more than the sum of their parts" he notes that "it's not enough to have a single use dominate a particular place -- you need a diverse array of activities for people." ${ }^{17}$ Millennium Park in Chicago is an example of what makes a public space popular. The park offers free access to art pieces, gardens and a music pavilion. The project is a successful combination of public art and corporate sponsorship..$^{18}$ It is popular with tourists but also offers relaxing places for locals to gather. The public art pieces are all functional and promote interaction with its visitors. Children are allowed to play in the water fountain sculptures on hot summer days. People are drawn to the novelty of the Cloud Gate, which reflects its viewers and the beautiful Chicago skyline.

16 Whyte, William H. City: Rediscovering the Center. 89

17 Kent, Fred. "Project for Public Spaces (PPS) - Placemaking for Communities - The Power of Ten." Placemaking for Communities | Project for Public Spaces (PPS). http://www.pps.org/ info/newsletter/november2004/november2004 ten (accessed March 13, 2010).

18 Gilfoyle, Timothy J. Millennium Park: Creating a Chicago Landmark (Historical Studies of Urban America). Chicago: University Of Chicago Press, 2006. 341 
The sheer volume of art pieces situated in Millennium Park are what makes the overall impact so powerful. Without a singular dominant theme, contributing artists were allowed the freedom to create their own interpretations of the park's characteristics. ${ }^{19}$ The distinct expressions of artists generates dynamic dialogues between the installations, where the transition between each piece is flawlessly executed. Grade changes between each art piece create vistas which help visitors navigate, allowing for a seamless stroll from one art piece to the next. The main centerpiece of the park is the Pritzker Pavilion, by Frank Gehry. It is both a stunning architectural piece and a successful urban project. The trellis that holds the sound system also defines the seating area over the lawn. Even without a concert, people choose to sit leisurely on the grass facing the stage. In the summer the skating arena becomes an outdoor patio for the year round café and coffee shop.

Each attraction is designed with a consideration of scale in relation to the city, while some of the world's tallest skyscrapers and Lake Michigan frame the site. The Crown Fountain and Cloud gate, located in the spacious open plaza are of a scale which invites viewers near and far, both pedestrian and vehicular. ${ }^{20}$ Thorough consideration was paid in the details of the attractions as well as practical amenities. The park offers a bicycle station and numerous bicycle racks dispersed throughout the site that are integrated into the design of the fences. The connection of bicycle amenities to the rest of the city encourages the park to be used as a hub for multimodal transit and solidifies Chicago as one of North America's leading bicycle friendly cities. ${ }^{21}$

19 ibid. 342

20 Gilfoyle, Timothy J. Millennium Park: Creating a Chicago Landmark. 344

21 ibid. 324

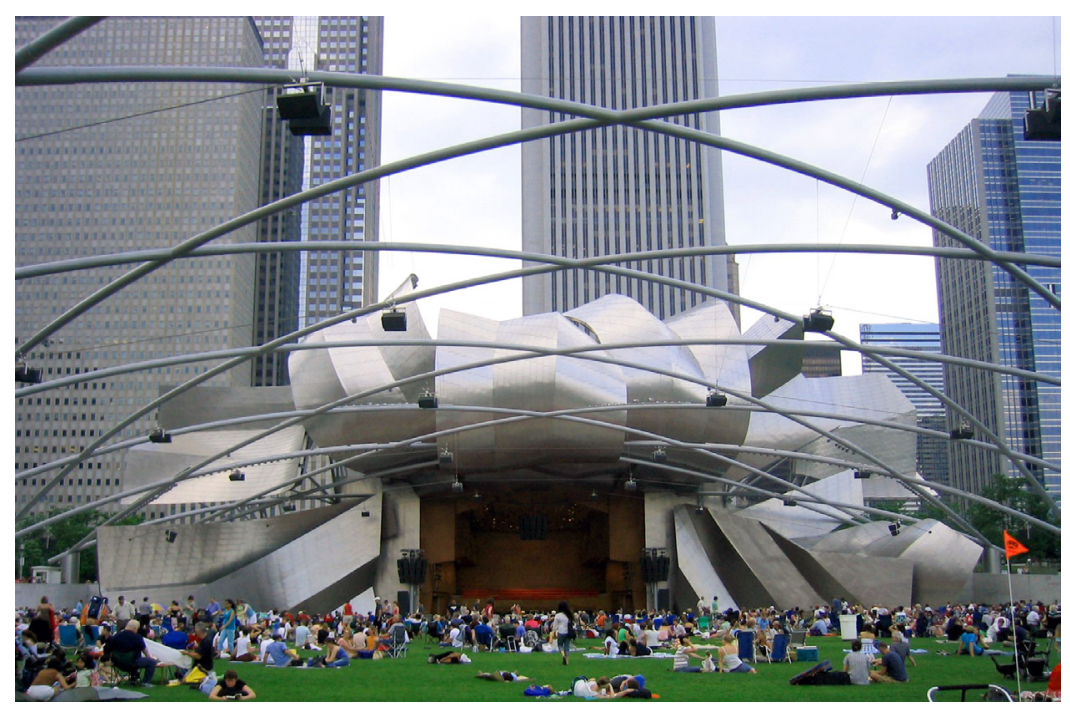

fig.1.2.19 Jay Pritzker Pavilion in Millennium Park, Chicago designed by Frank Gehry 


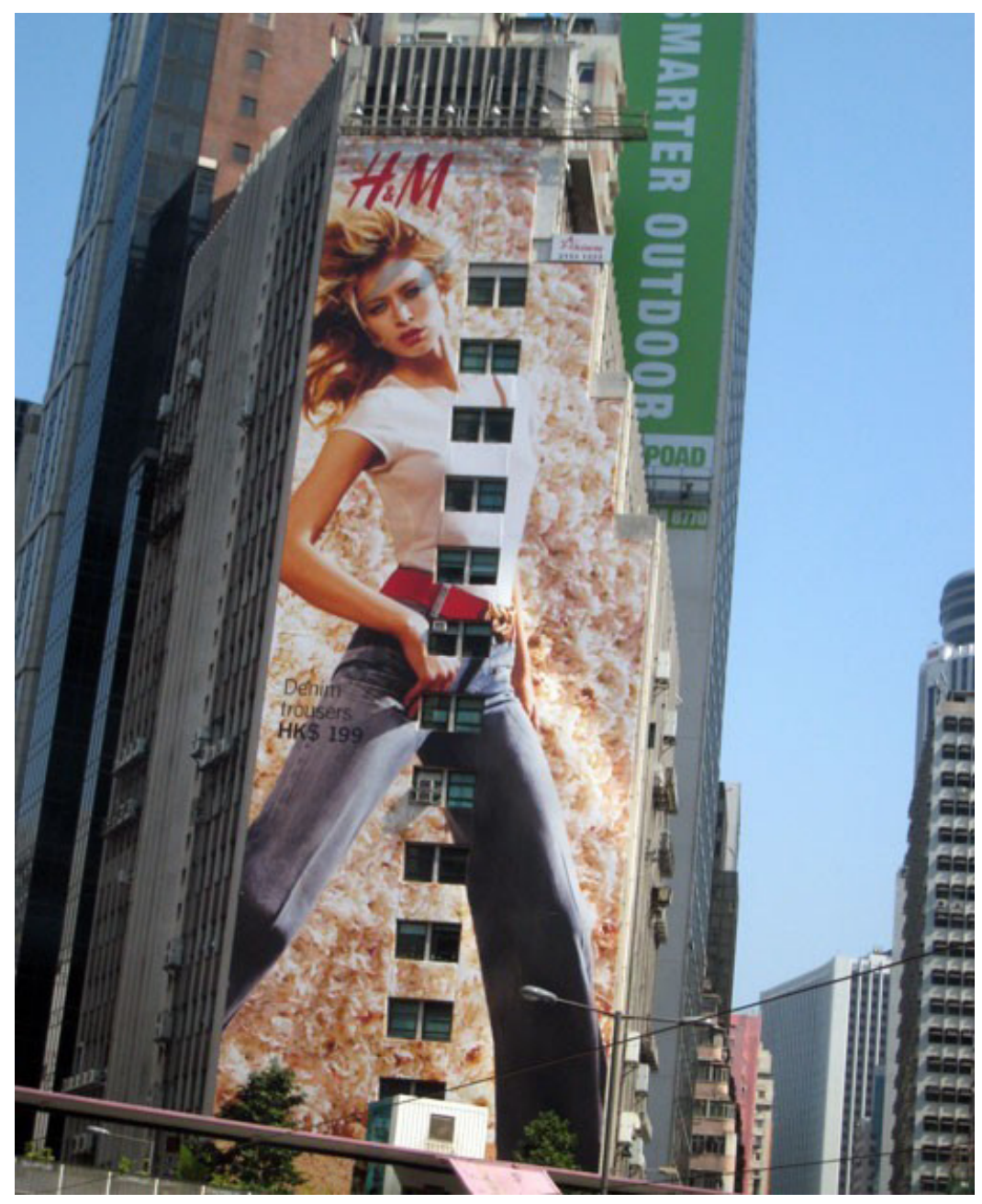

fig.1.2.20 advertising in Wanchai, Hong Kong.

\section{Digital landscapes | the potential of multimedia}

The building being co-opted as a billboard prevails in our landscapes despite numerous experimental facades being produced in architecture. We are seeing more and more facades which interact with the environment, weather conditions, and nearby pedestrian traffic, both built and theoretical. The skin of a building is an expressive element in architecture and possesses the ability to define public space:

\begin{abstract}
Large public screens and mobile media devices mean that media consumption is increasingly occurring in public space. What impact will the electronic screen have on the street, the self-proclaimed birthplace of modernism? How will pervasive media alter the dynamics of public space? New forms of public interaction clearly have the potential to transform existing configurations of power defining the uses and ambiance of public space. ${ }^{22}$
\end{abstract}

The combination of public space and digitized building facade is a new development that ought to be explored further by architects and urban designers. The effects of a building as a billboard are seen on the Toronto Life Square with approximately 20,00o square feet of

22 McQuire, Scott. Media city: Media, architecture and urban space. 131 
signage applied on the 10 storey structure. ${ }^{23}$ For many structures which have billboards applied to their facades, the process required to adhere advertising to their exteriors is not as efficient as those used to construct the Toronto Life Square. The effects of such applications are irreversible. Yet concepts exist that make it possible to advertise with cleanliness and impermanence, such as those afforded by digital projections. Furthermore, public interest must be privileged over private ones, as privatized messages are cluttering our streets: ${ }^{24}$

If urban space has historically been defined by the relation between static structures and mobile subjects, this dichotomy is fast giving way to hybrid spatiality characterized by dynamic flows which not only dissolve the fixity of traditional modes of spatial enclosure, but problematize the unified presence of the subject traversing their contours. ${ }^{25}$

Like any successful design, public space needs to be constructed and designed thoughtfully. So that the visual landscape of our city reflects the interests of its people. We cannot take a passive stance by allowing haphazard individual decisions on branding and commercialism to take over. Architects must actively participate in developing positive public space and take a stand against brands defining the experience of the city:

The challenge to the creative use of media technologies

23 "Toronto Life Square." PCL http://www.pcl.com/projects/Active/0900342/index.aspx (accessed May 11, 2010)

24 Lynch, Kevin. The Image of the City. London: The Mit Press, 1960. 116

25 McQuire, Scott. Media city: Media, architecture and urban space. 131

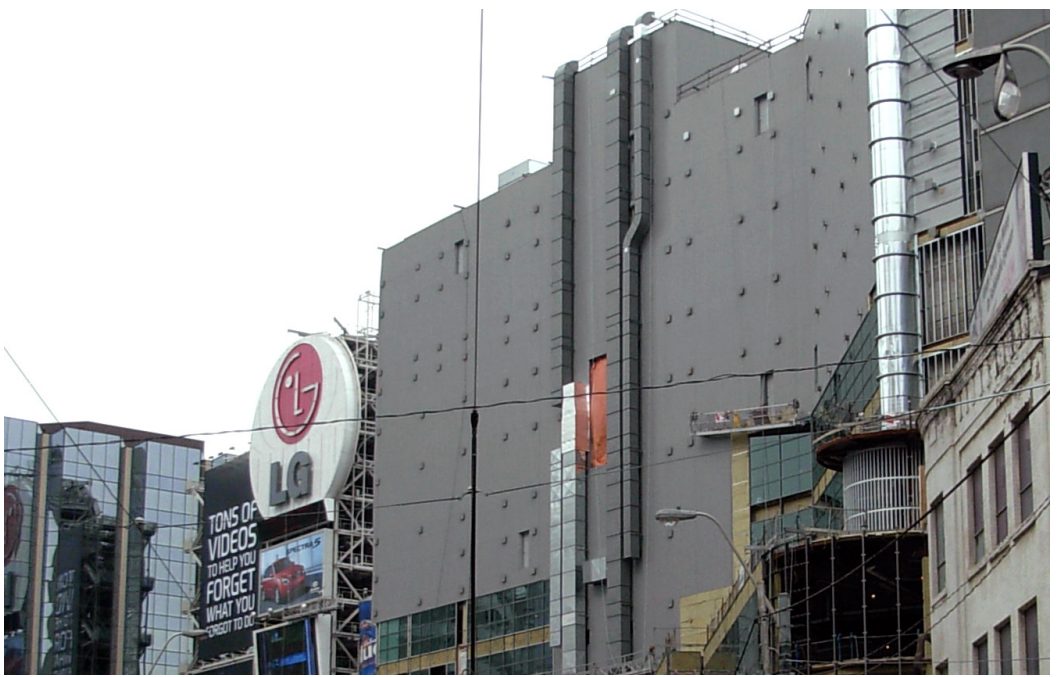

fig.1.2.21 Toronto Life Square before the installation of billboards

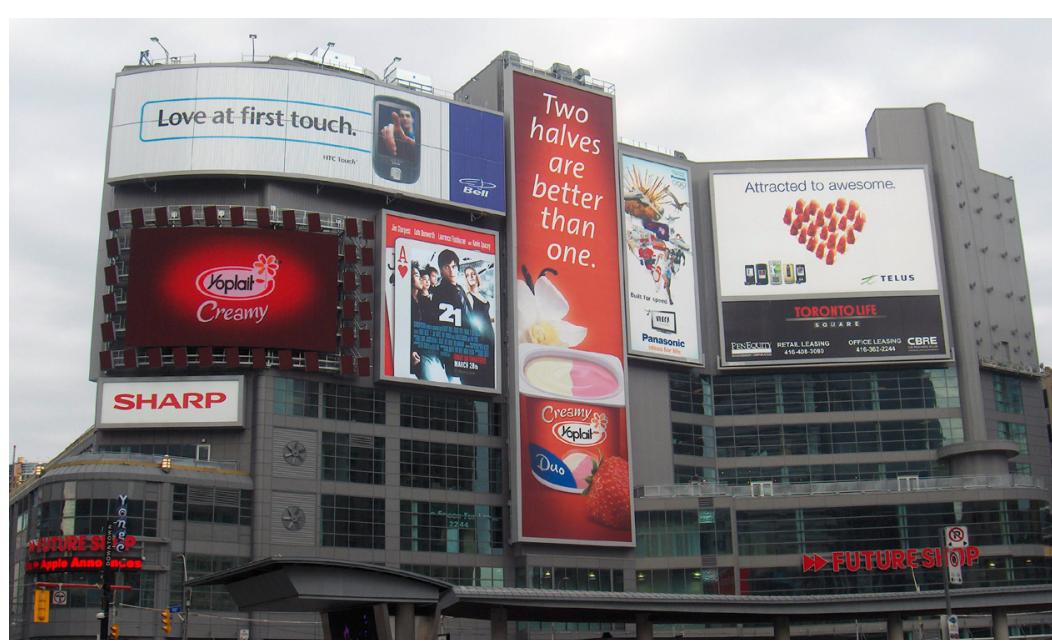

fig.1.2.22 Toronto Life Square 


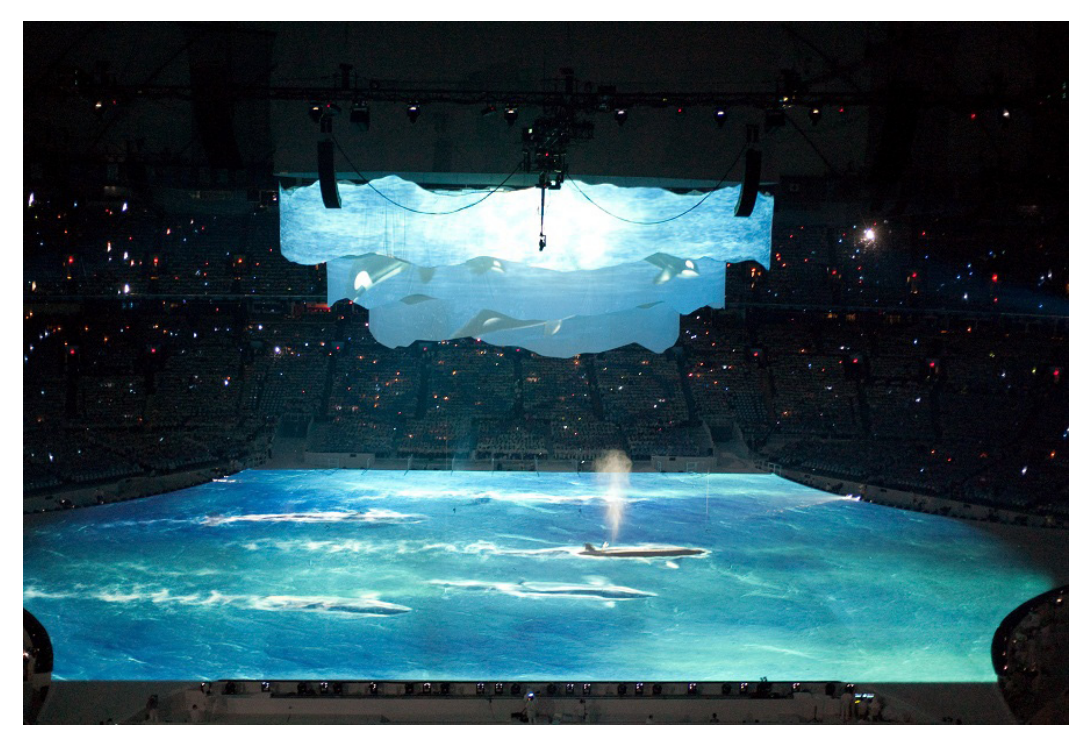

fig.1.2.23 projections together with sound and water-sprays brought the whales to life on the floor of the stadium at the Vancouver 2010 Olympics opening ceremony is fostering the diversity of public actors and terrains and to develop strategies of articulating the new public domains that connect physical urban spaces and the potential public sphere of the electronic networks. This public sphere will only come into being if there are complex forms of interaction, of participation and learning, that use the technical possibilities of the new networks and that allow for new creative forms of becoming visible, becoming present, becoming active, in short, of becoming public. ${ }^{26}$

The world watched as the Winter Olympics in 2010 transformed the inside of Vancouver's BC Place with video projections celebrating Canada's heritage, natural beauty, and individualism. ${ }^{27}$ The performance used all the surfaces within the stadium with projections of wildlife: salmon spawned, swimming up the four poles that were central to the stage, and seasons were cast upon the floor as well as the audience. The installation captured viewers through dynamic visuals, sound, and movement. This form of media is frequently employed at high profile events, while the media used to smaller degrees is seen in much of our entertainment and day to day lives. However, we must seek to apply these technologies more broadly. In this modern context, novel forms of public communication must be explored for applications on a broader urban scale. New media can be used in combination with experimental interfaces. The public

26 McQuire, Scott. Media city: Media, architecture and urban space. 150

27 Solomon, Linda. "What We Saw at the Opening Ceremonies of the Vancouver 2010 Olympic Games." The Vancouver Observer, February 13, 2010. http://www.vancouverobserver.com/ blogs/overheardolympics/2010/02/13/what-we-saw-opening-ceremonies-vancouver-2010olympic-games (accessed May 10, 2010). 
realm can benefit greatly from new applications that involve public interaction. By using the foundations of a successful public space and new media, many spaces in need of improvement could transform and, in so doing, attract more user traffic.

\section{Design and implementation of public spaces with digital media}

Public spaces are a reflection of our culture and community, acting as a mirror to society's values and beliefs. By definition, people must actively choose to use a space in order to make it a successful public space. Designers and architects need to incorporate the understanding that "ultimately, people make places and imbue them with meaning and value". ${ }^{28}$ In order to create spaces that will be used regularly, we must first understand how people use places and what activities are attractive to them. The configuration and feeling that a space exudes has the power to influence residents in becoming more active and involved with their respective neighbourhoods and communities. A space should be inviting to neighbours so that they can interact and play in the company of one another. The character of a public space influences the extent to which citizens come out and enjoy that space, or else stay home. Well-defined public spaces are meaningful to the neighborhood and the energy of the spaces draws people to them regularly, even without an obvious incentive. Space needs to be versatile, providing many different kinds of uses and options to various users. It is not enough to just provide an empty space off a street between buildings. Public space must offer something that

28 Carmona, Matthew, Tim Heath, Taner Oc, and Steven Tiesdell. Public Places - Urban Spaces. London: Architectural Press, 2003. makes people want to engage with it. It needs to create a destination by offering room to socialize, eat, read, play sports, and even view free public art. The space needs to be easily accessible and well linked to other public elements within the city, and must not be simply a space to pass through.

Successful characteristics of public space can be broken down into simple elements of openness, safety, and comfort. Yet these spaces are harder to come by as populations grow and land values rise. These simple passive elements can also be assisted by the onset of new technology to keep in pace with the digital social networks and the visually dominating advertising sector. Many cities are letting the commercial sector define their streets and skylines with the use of new media. However, new media can also be designated for expressing ideas and inspiration among the community. ${ }^{29}$ The use of digital media in spaces can bring art and communication to people. Artistic projections can encourage interaction and social discourse. They can help turn unfriendly streets, plazas and neglected civic squares into vibrant entertaining spaces, connecting the public realms within the city through new media.
29 Klingmann, Anna. Brandscapes: Architecture in the Experience Economy. London: The Mit Press, 2007. 272 
If you build buildings with lights outside, you can make them indefinite, and then when you're through with using them you shut the lights off and they disappear.

- Andy Warhol $1975^{1}$ 



\section{3 'BRANDSCAPES'}

The following exercise seeks to amplify the phenomenon that is happening within urban city centres. The more that iconic corporate symbols are being placed at major intersections the more the public is relating certain popular destinations with its corresponding corporate advertisement. Advertisements are a quickly recognizable marker for tourists and locals, becoming iconic markers of identification. Tourism has brought about a competition among advertisers to connect themselves with particular tourist locations. Moreover, cities themselves compete to distinguish themselves through memorable buildings or advertisements. Many will still associate only the Toshiba jumbotron, the Coca-Cola sign, and NASDAQ market site with Times Square, despite its mass array of advertisements. Another example of this is Shinjuku, the busiest station in the world, for which the famous electric sign at the entrance of Kabukicho has become synonymous. Well known for its extravagance and excess, Las Vegas is now recognizable not for its own monuments, but for its appropriation of other cities' iconic monuments, replicating them and their advertisements along its main strip.

To what extent are these iconic places still recognizable without the advertising of these universal brands? The following images were altered using Adobe Photoshop as a means by which to identify the magnitude of media influences on our memories of many urban city centres. Ordinarily identifiable, these locations without their signs and symbols, are hardly recognizable. In the next example, these same areas, have their building facades removed, with only the media remaining. By contrast, the locations are still identifiable by virtue of their advertisements. Thus we can understand the magnitude of media and its power to shape urban identity. 

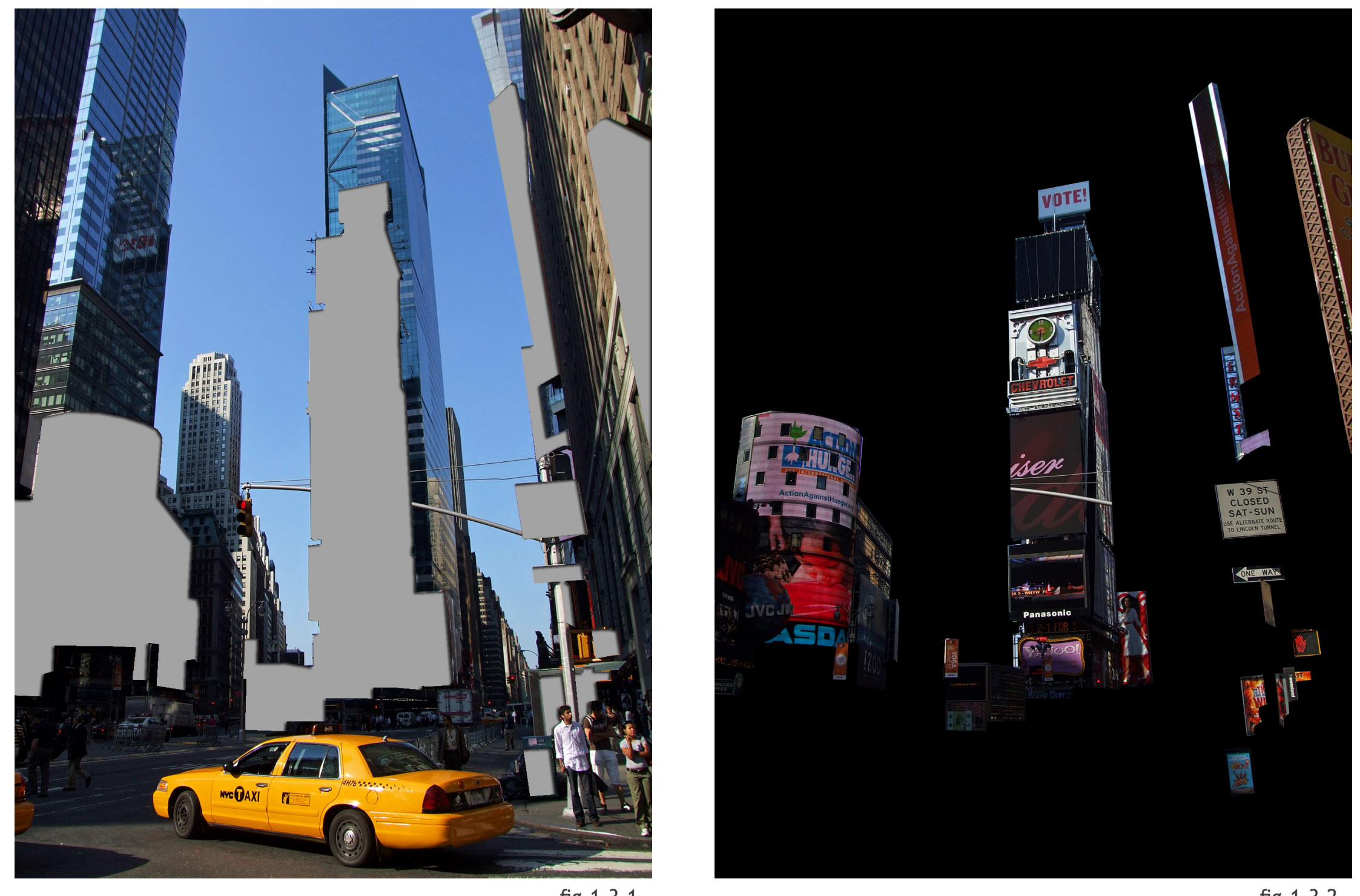

fig.1.3.1

fig.1.3.2 


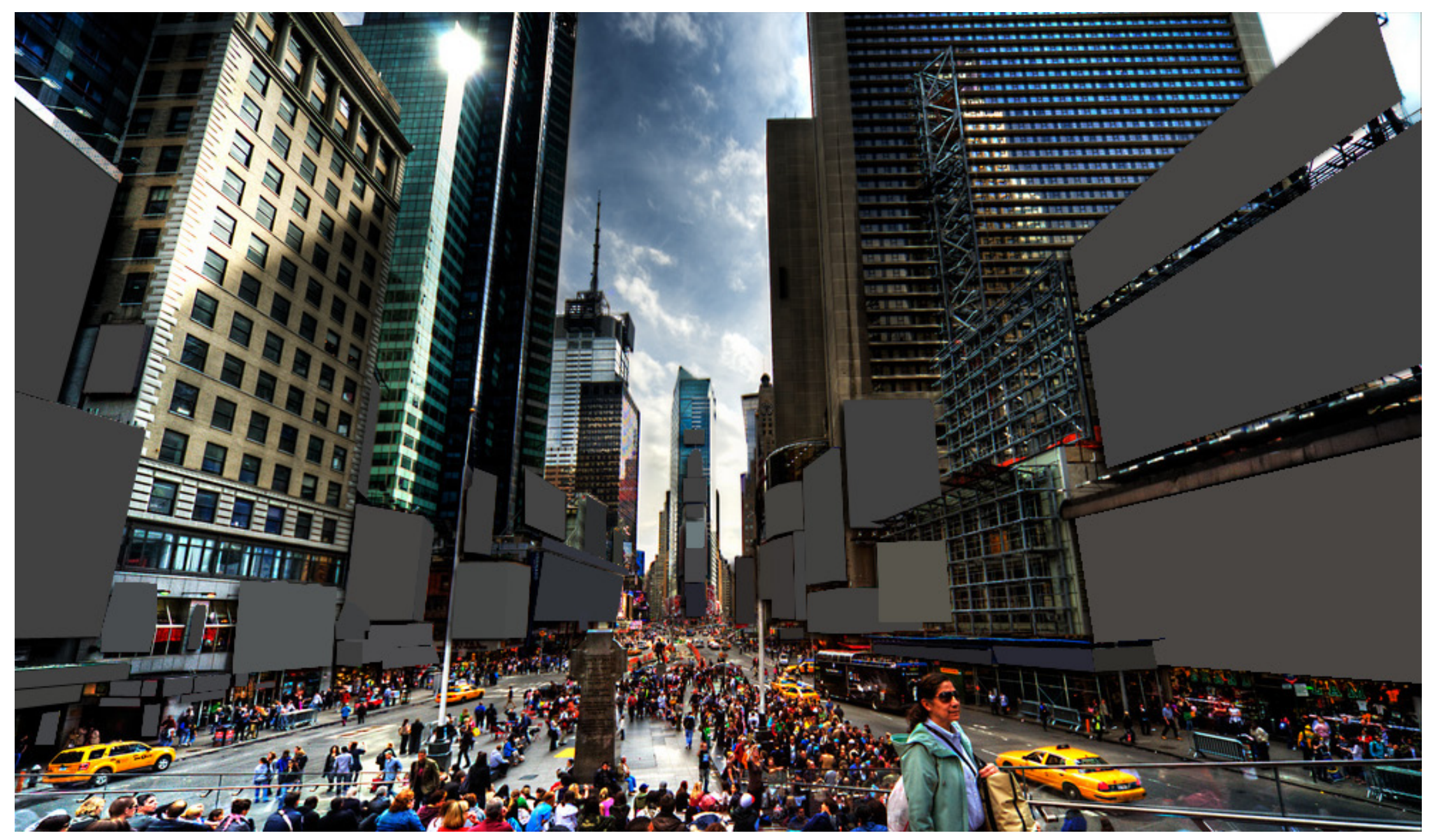

fig.1.3.3 


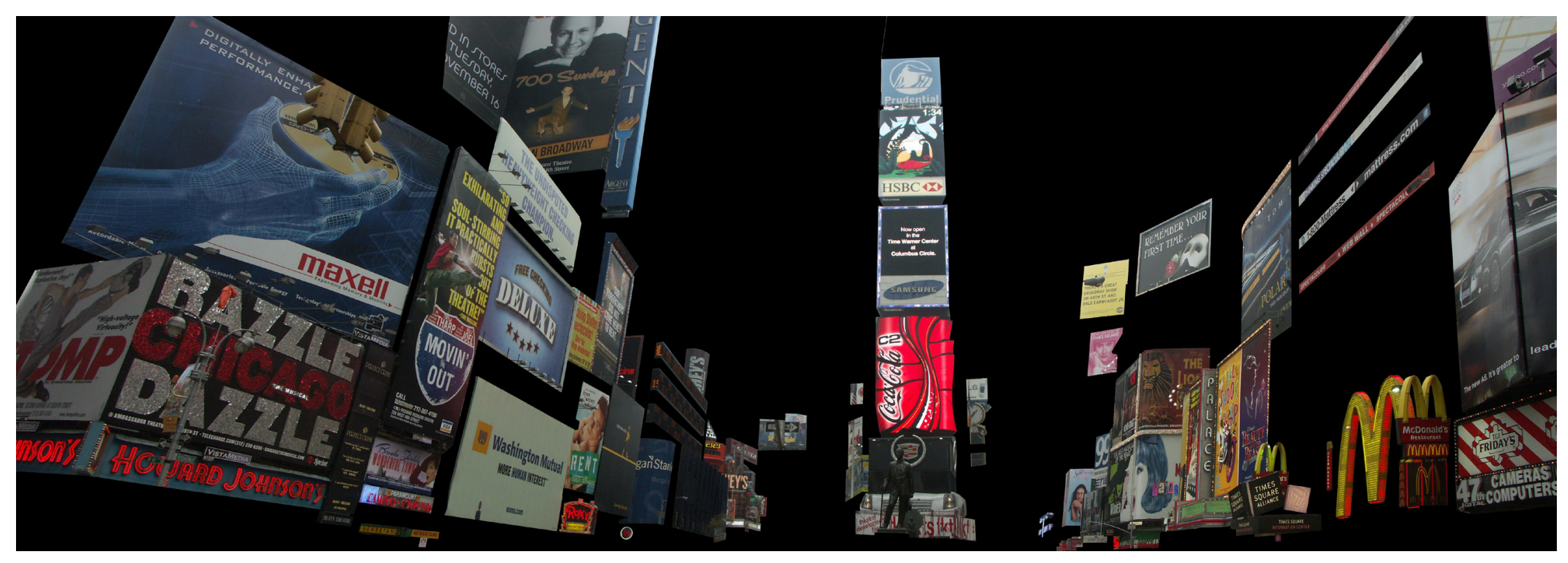

fig.1.3.4 


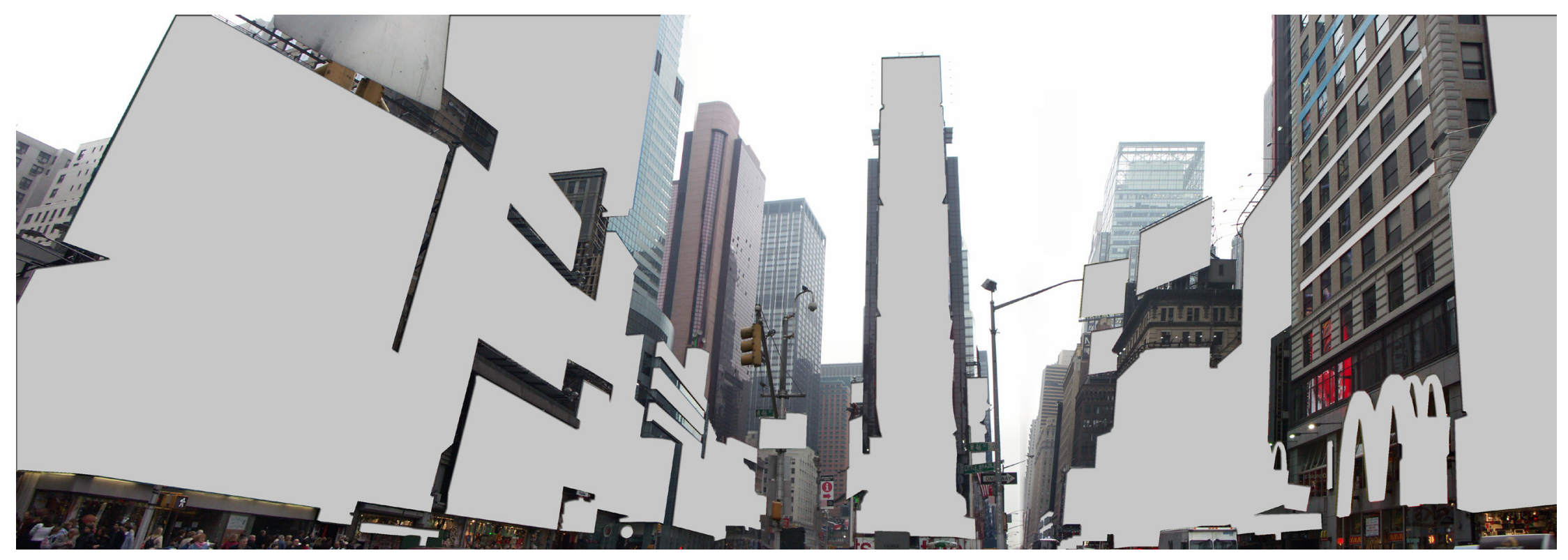

fig. 1.3.5 


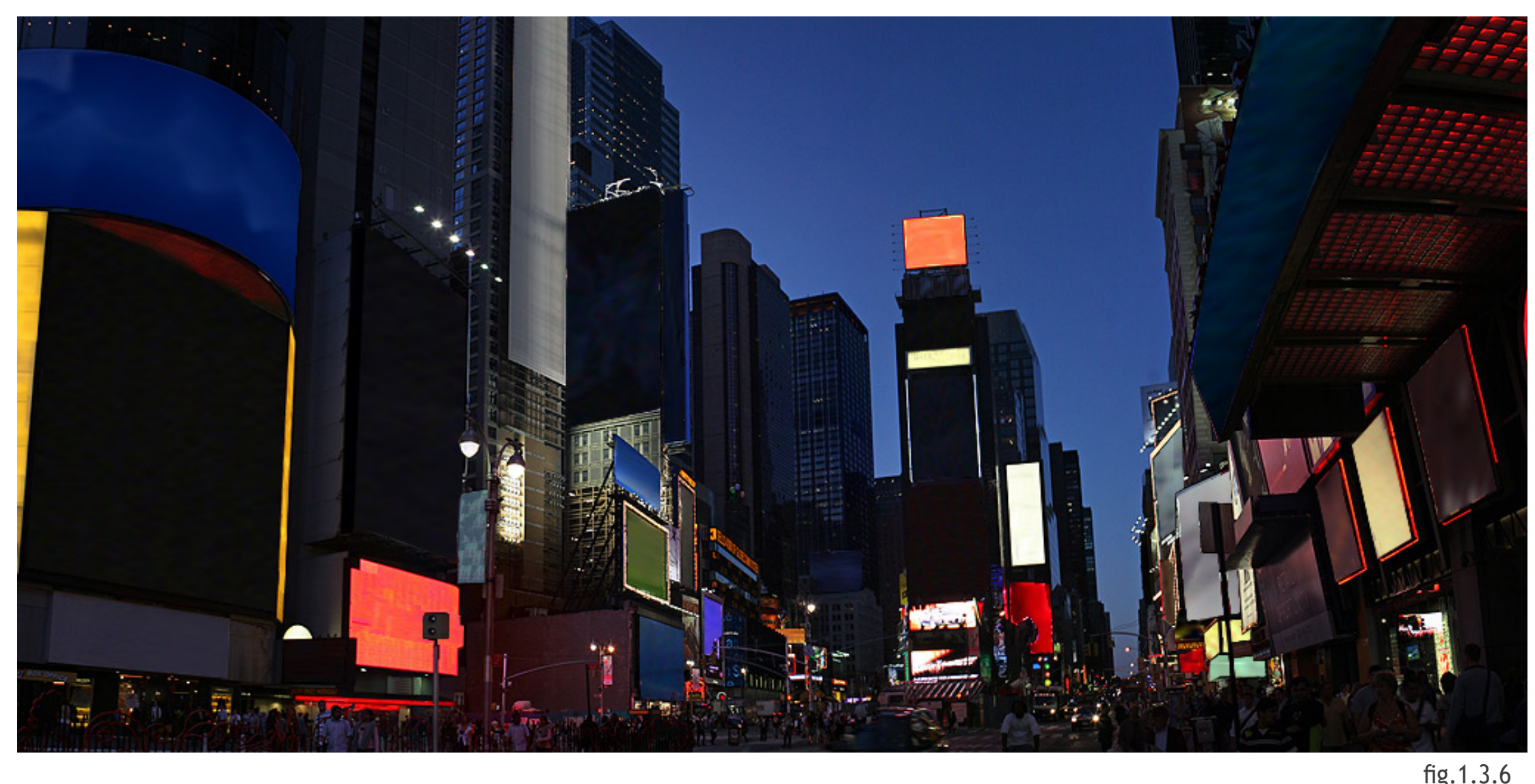




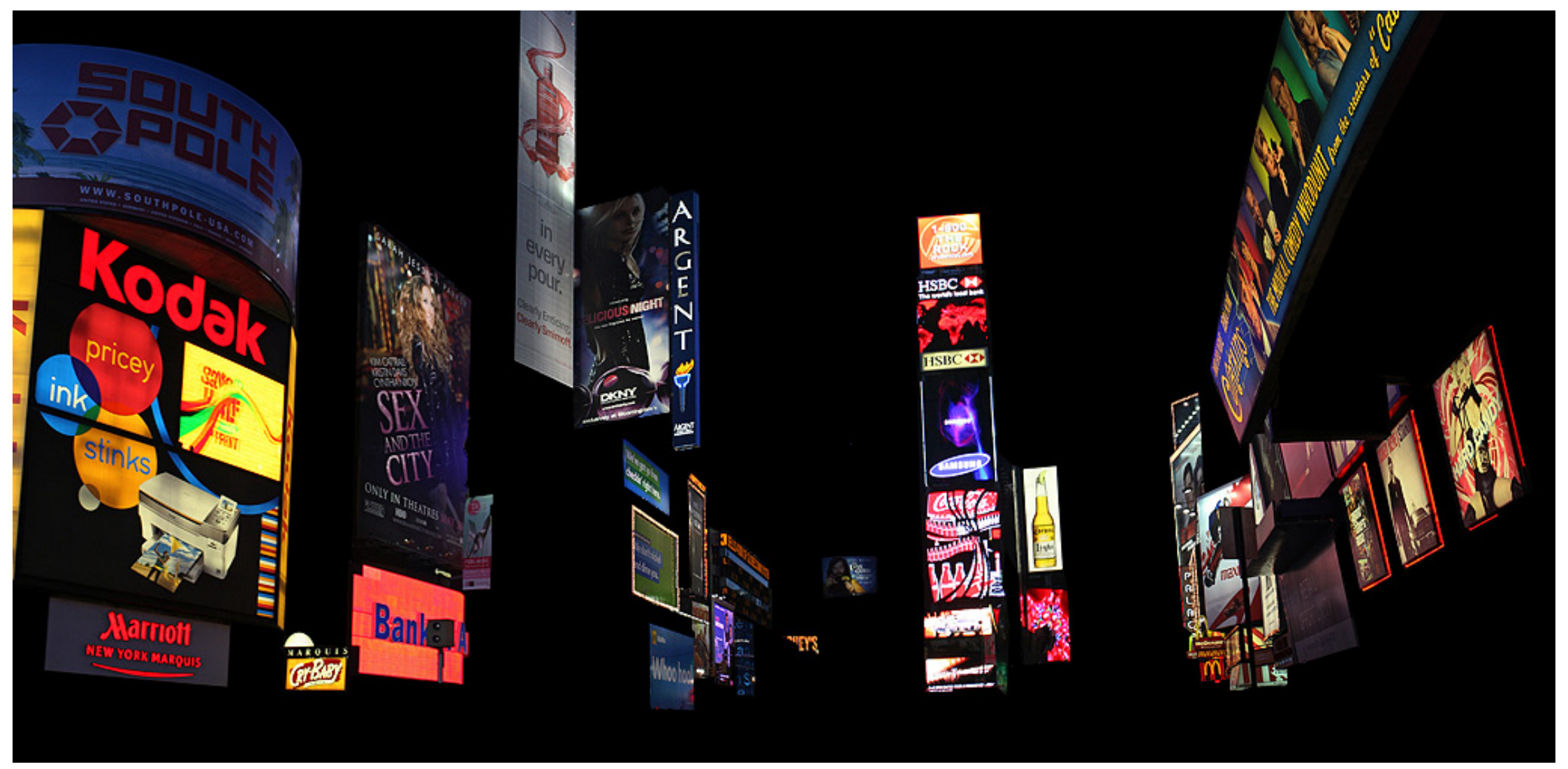

fig.1.3.7 

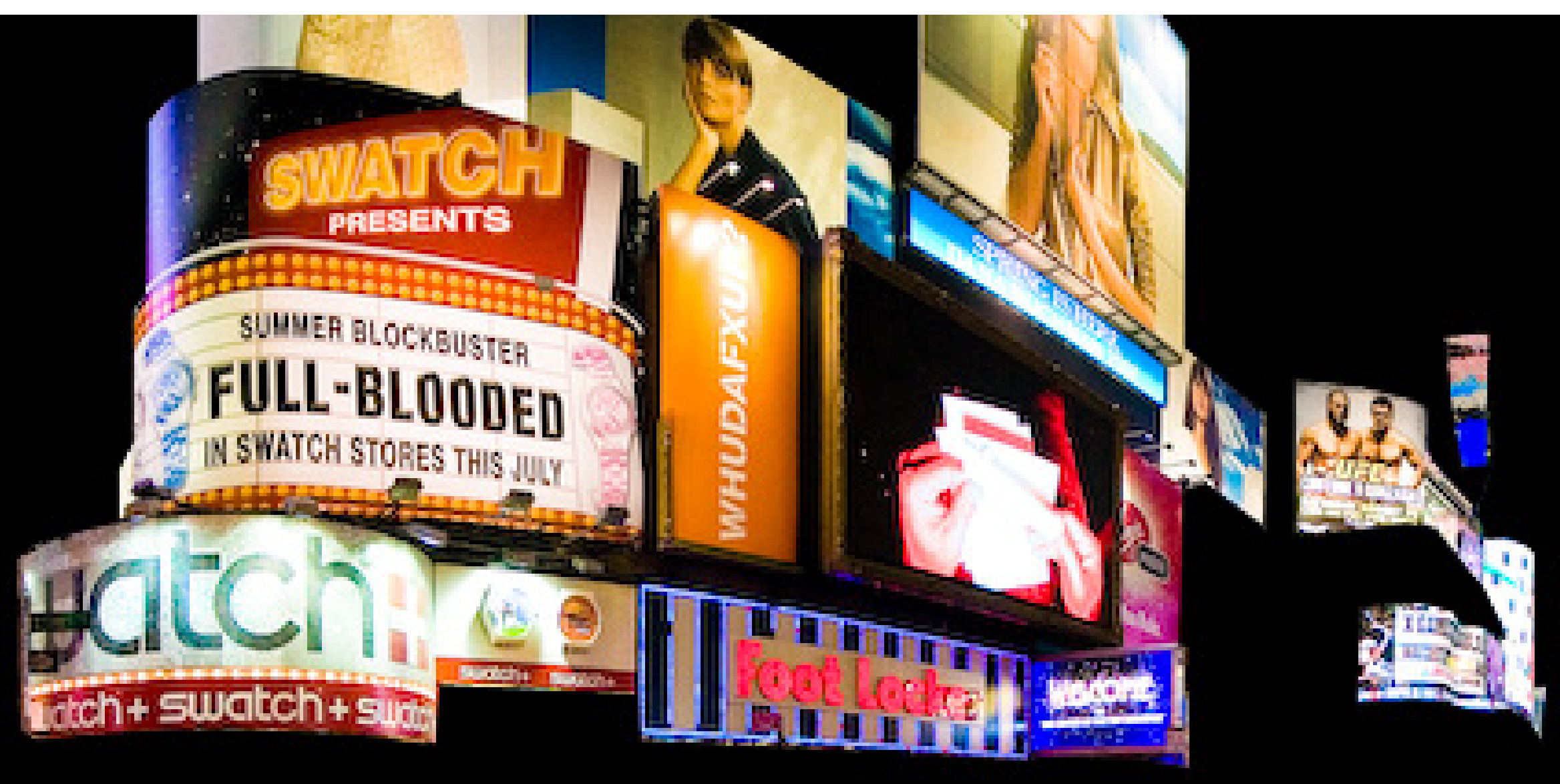

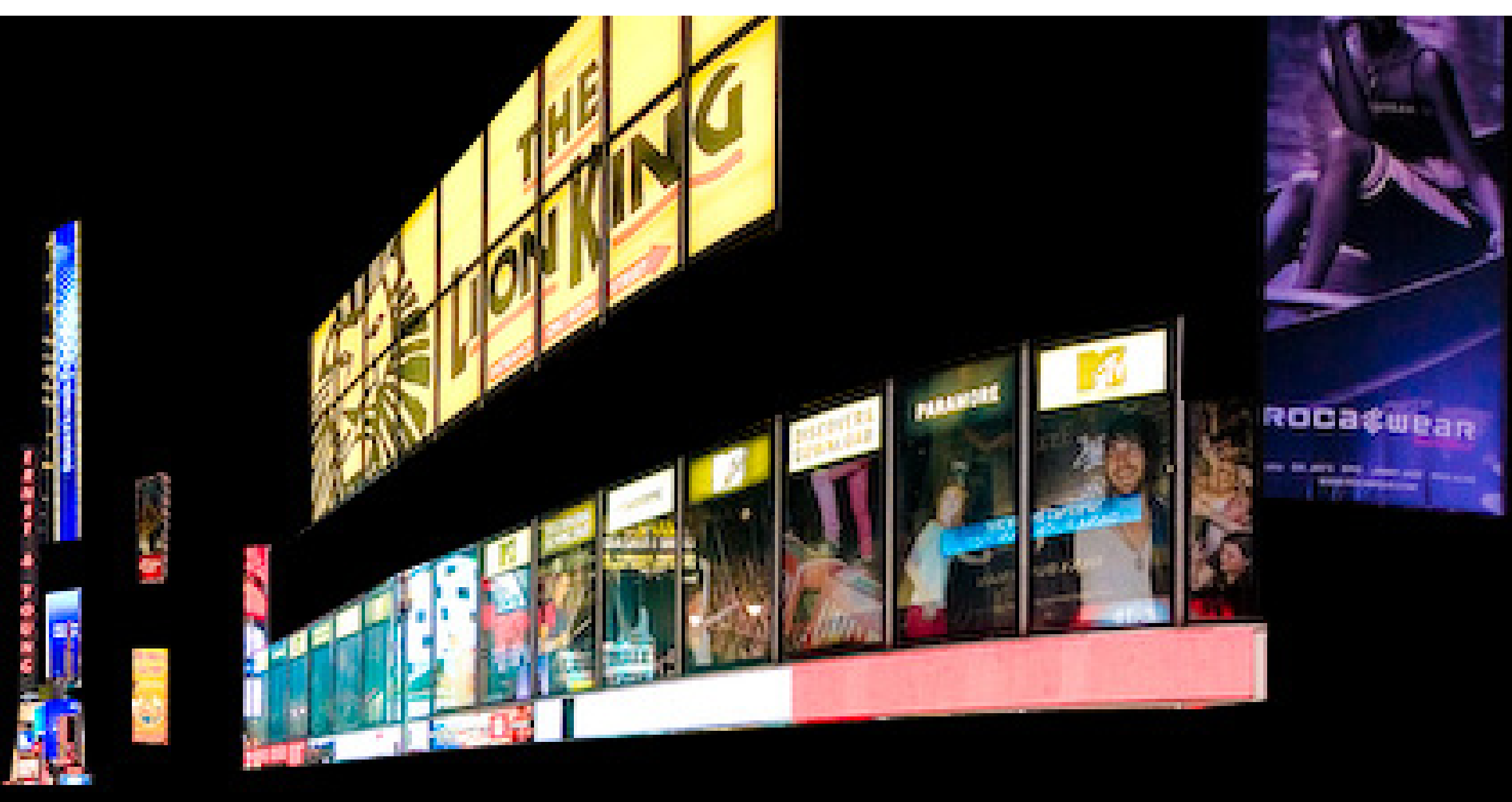

reverturs hents 

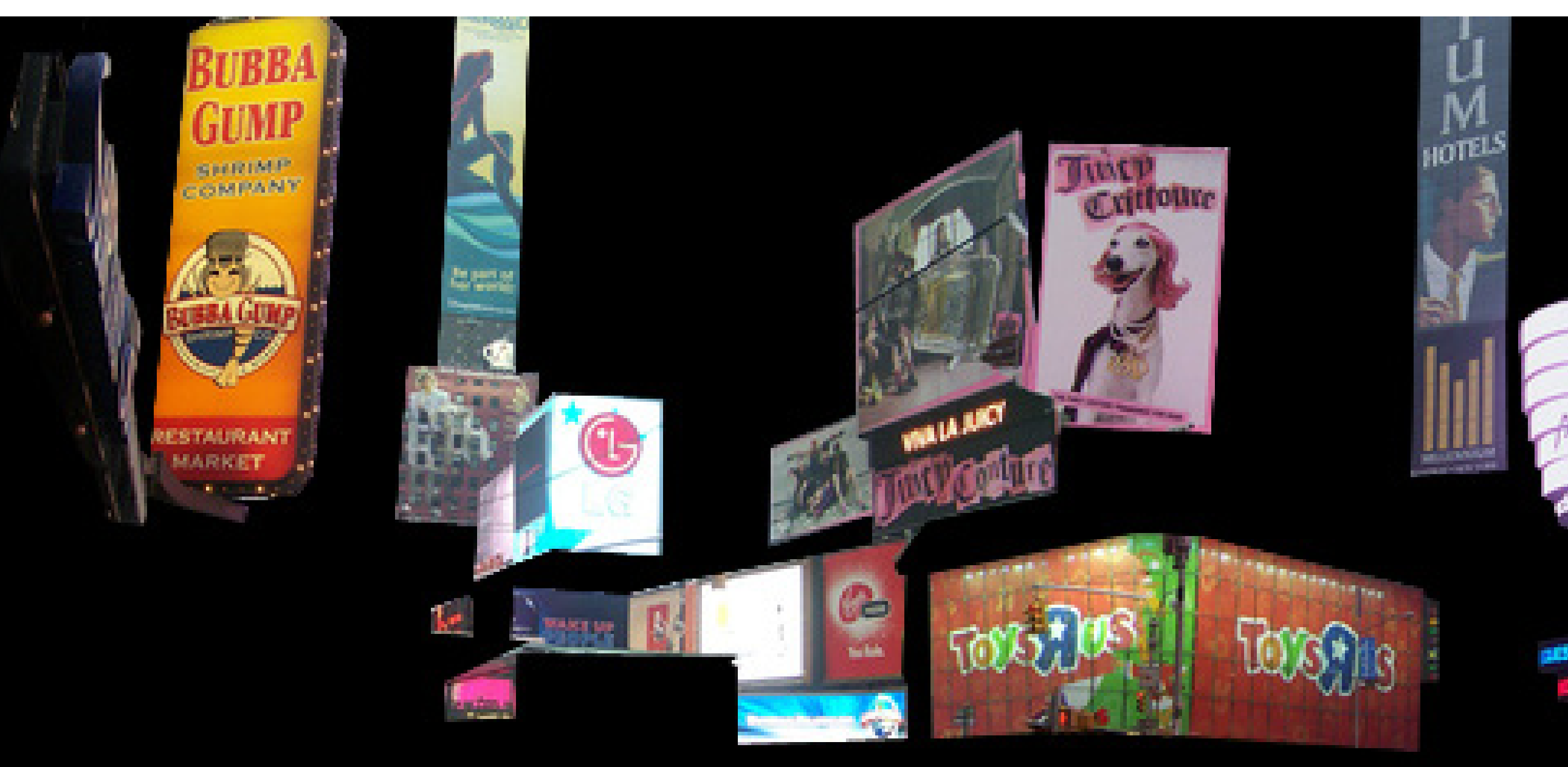


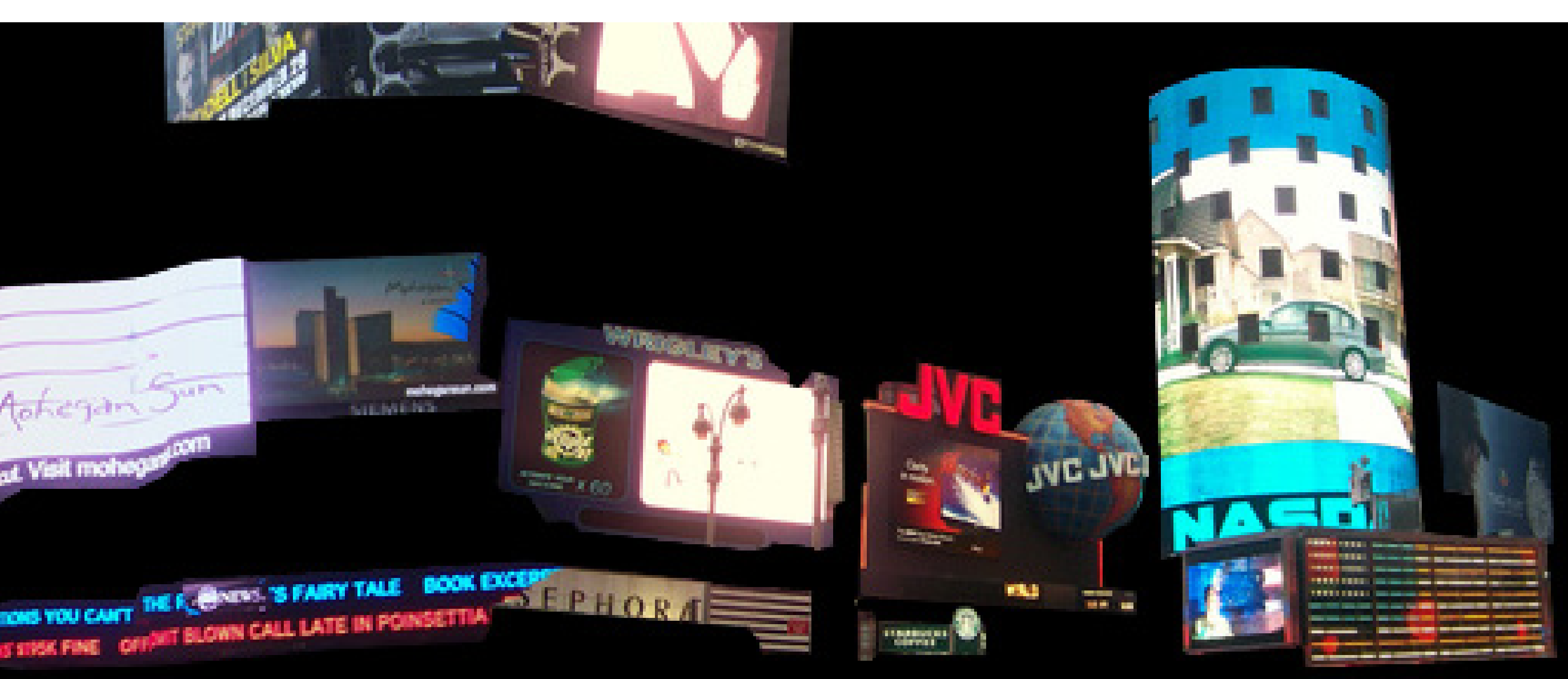




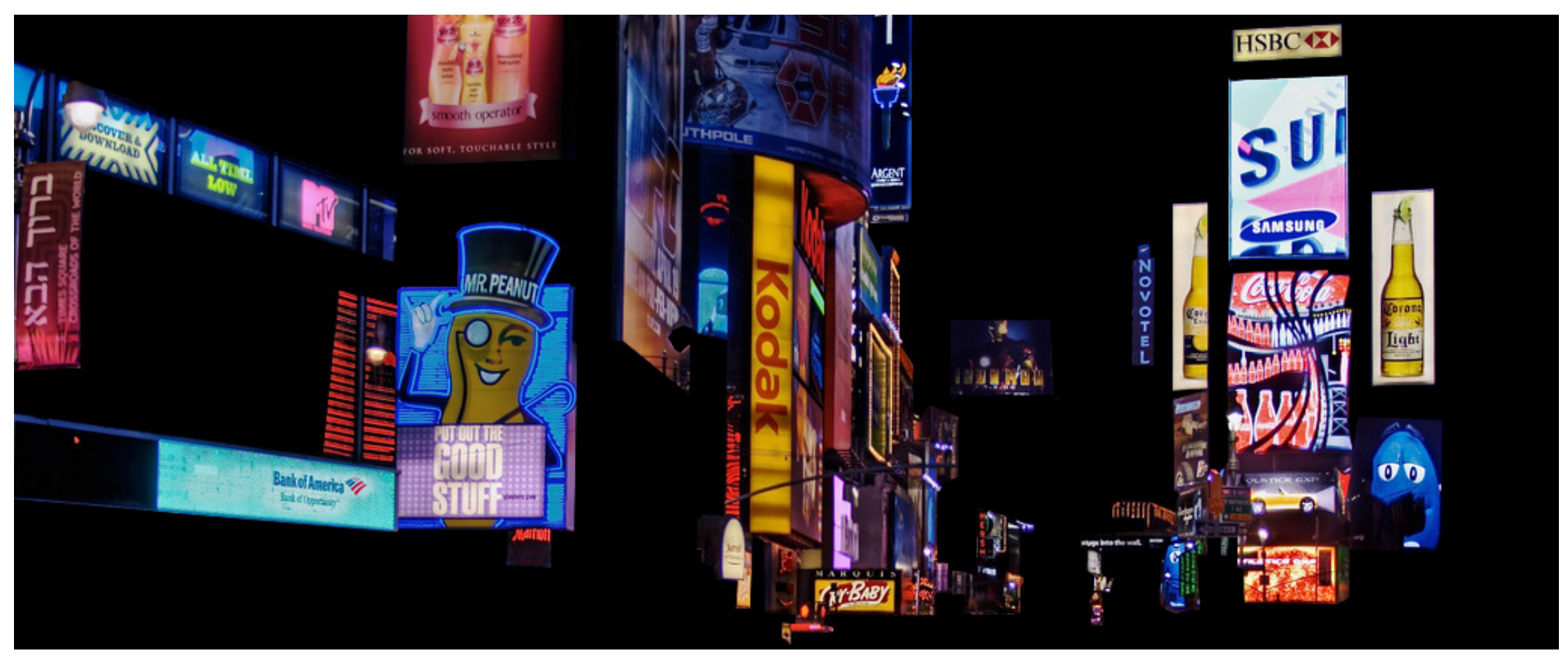

fig.1.3.10 


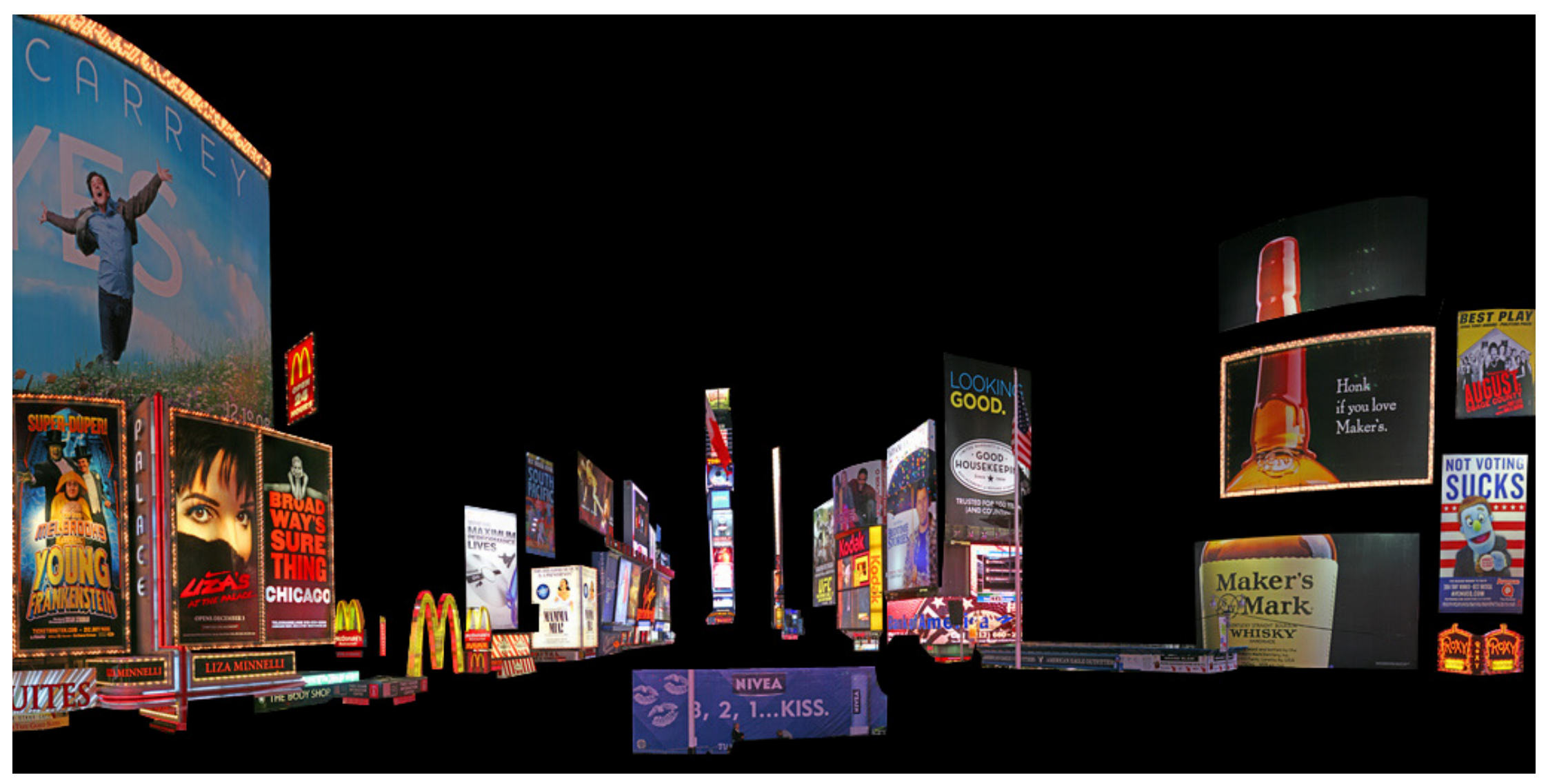

fig.1.3.11 
fig.1.3.12 visual representation of Times Square before the pedestrian friendly boulevards. Narrow sidewalks meant that visitors never felt the overall scale of the space. Since people do not generally notice signage directly above them.

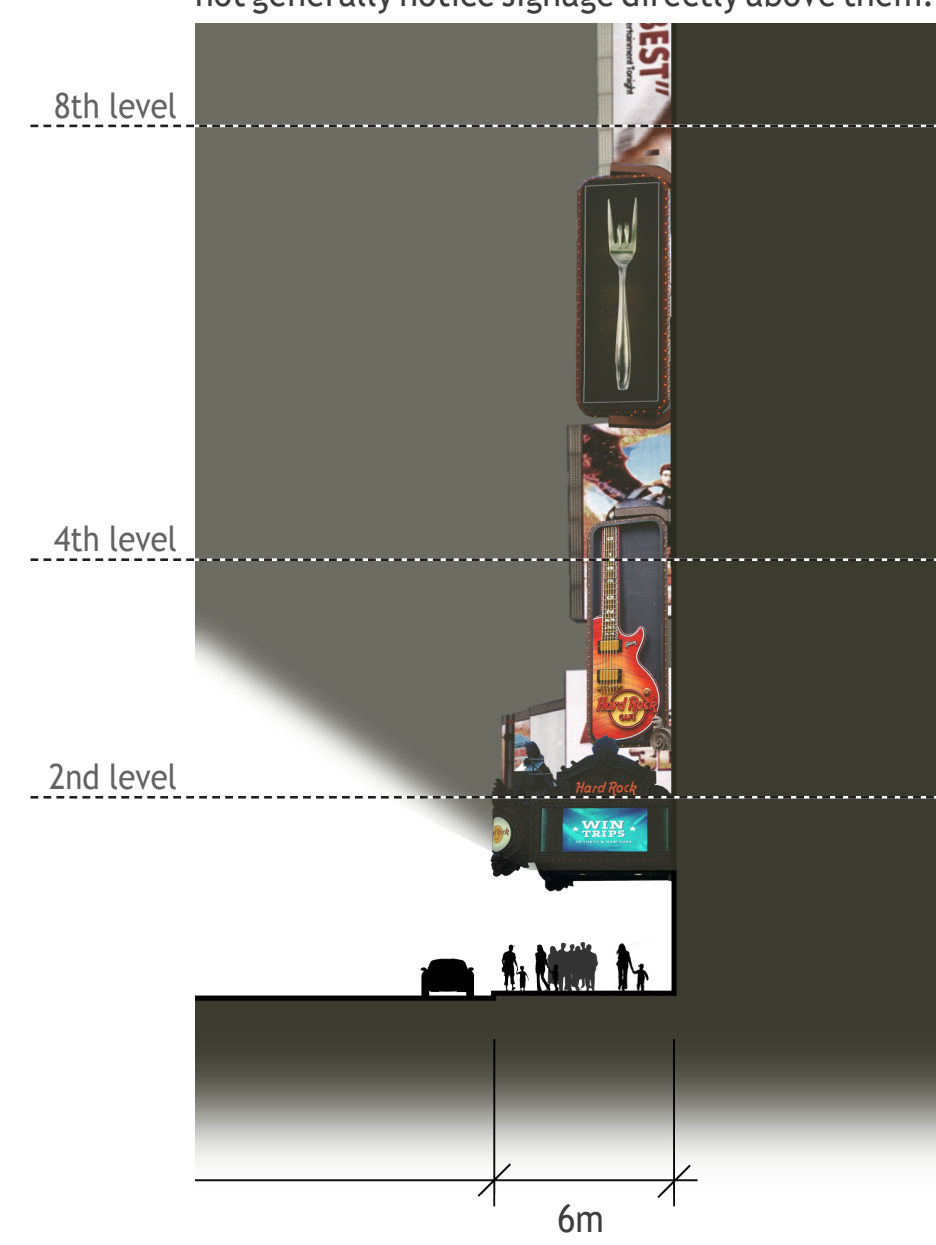

fig.1.3.13 visual representation of Times Square after the pedestrian friendly boulevards. Standing in the middle of Broadway, visitors can get a feel for the vastness of the place with its towering billboards and digital screens pressing in on all sides.

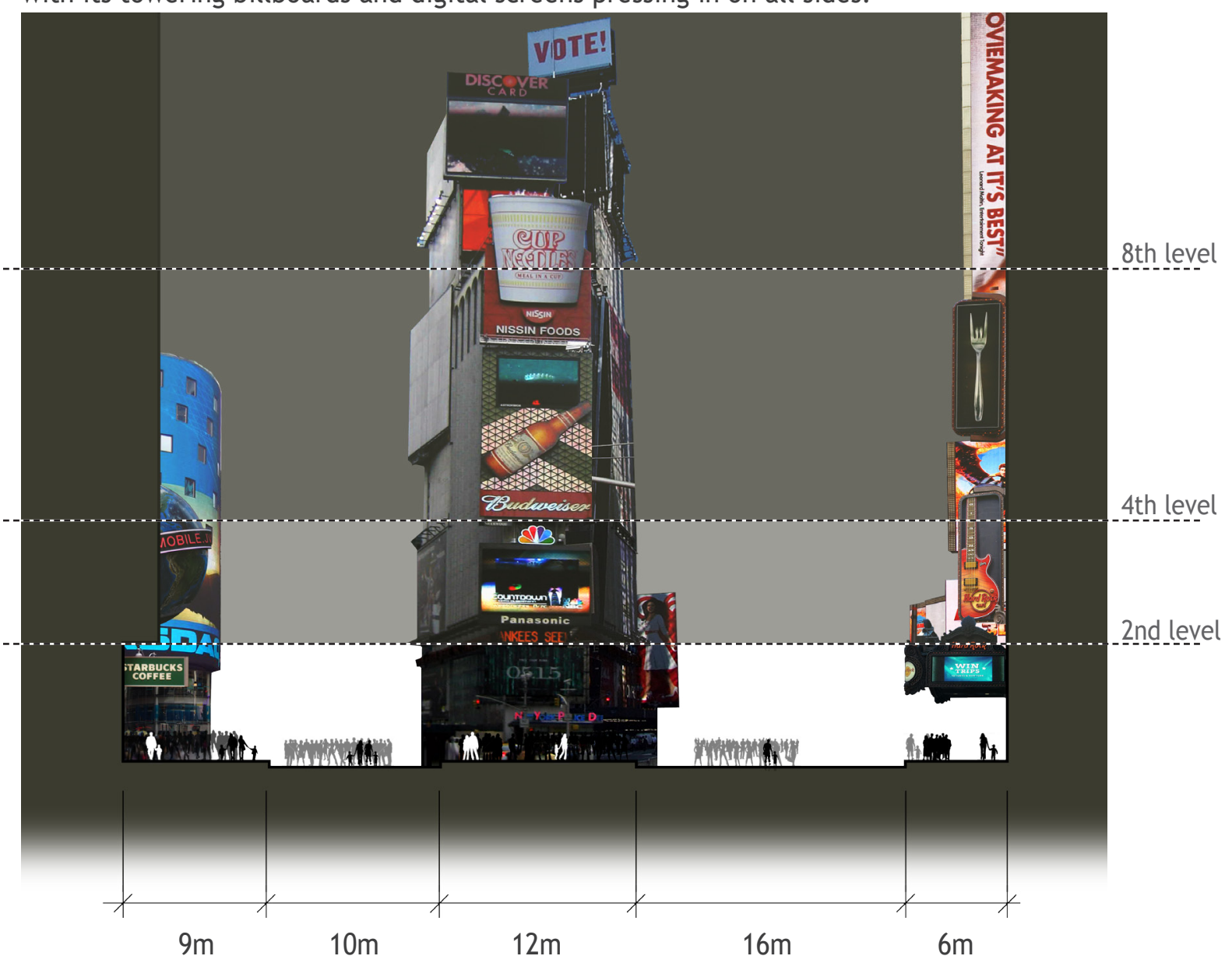




\section{TIMES SQUARE, NEW YORK CITY}

\section{Media Buildings}

In the preceding images of Times Square the advertisements were mostly giant billboards, arranged orthogonally. Once in a while a sign takes the shape of a McDonald's arch or a company's mascot, but in most cases advertisements for movies or theatre productions dominate. Occasional advertising comes in the form of a product feature movement relating to the product, such as for example, the ;Nissan Cup Noodles' with their billowing steam. Yet, the competition between the various brands provide a field for innovative advertising. In some cases the advertisement is not related to the company, on whose building it is posted, like the Times building. There are billboards advertising everything from electronics to soft drinks and television series. One Times Square houses no companies within its building except for that of the retail space at grade; advertising is the sole purpose of that building. In face, the revenue made from companies renting advertising space surpasses the amount generated from renting units within the building.

The architectural styles of the buildings in Times Square tower over the advertisements but paradoxically are not visible at the pedestrian level. Thus people are unaware of the unique architectural distinctions that are present among the buildings themselves. The scaffolding and lighting for the advertisements are not often hidden and sit atop other advertisements or architectural structures. Large billboards take up most, if not all, of the facades at retail level. Advertisements are concentrated enough so that reflections of the neon signs are kept away from the glazed office towers above. This consistent brightness and location of advertising reflects the zoning code put forth by the city. ${ }^{1}$ 


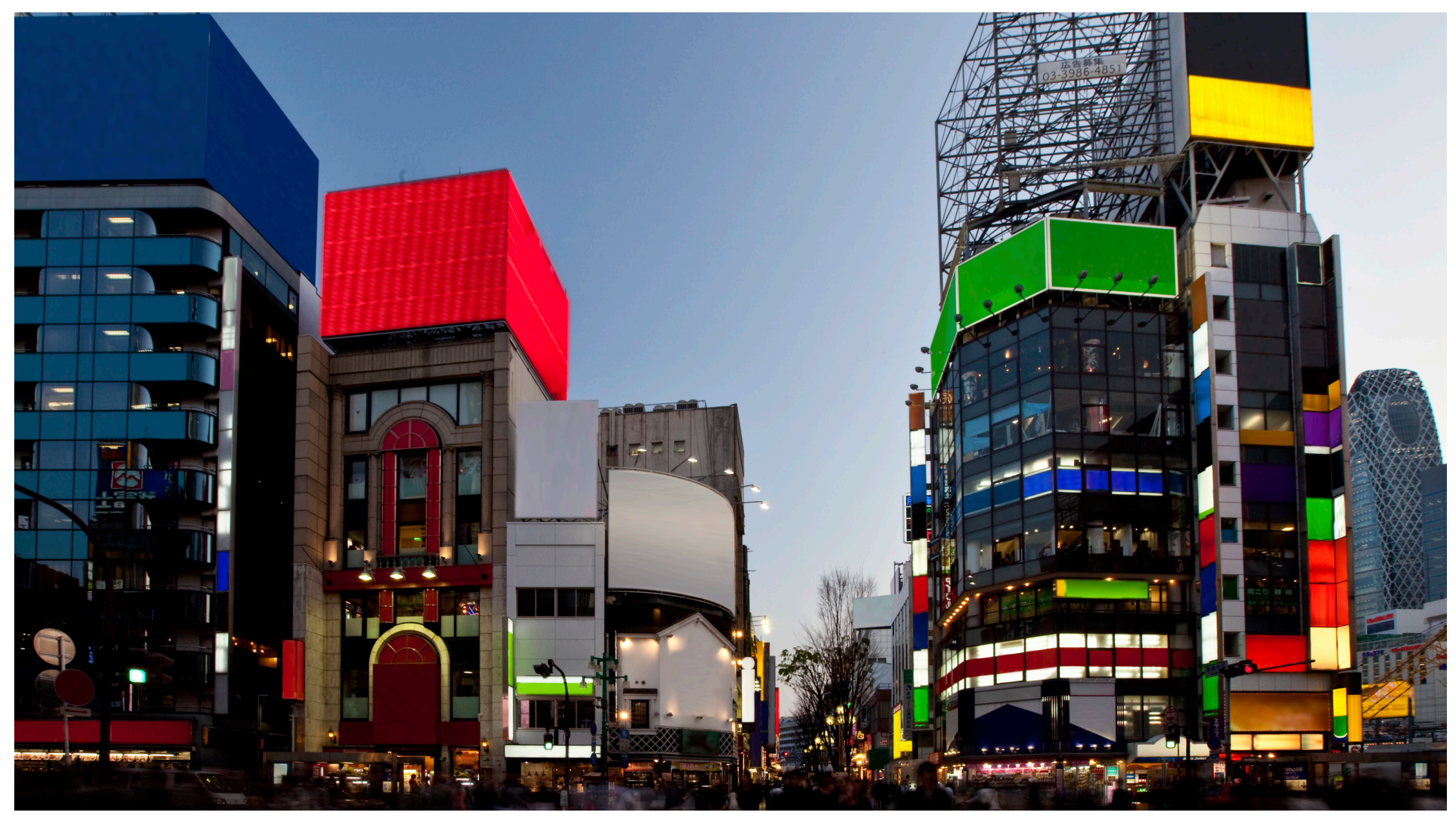

fig.1.3.14 


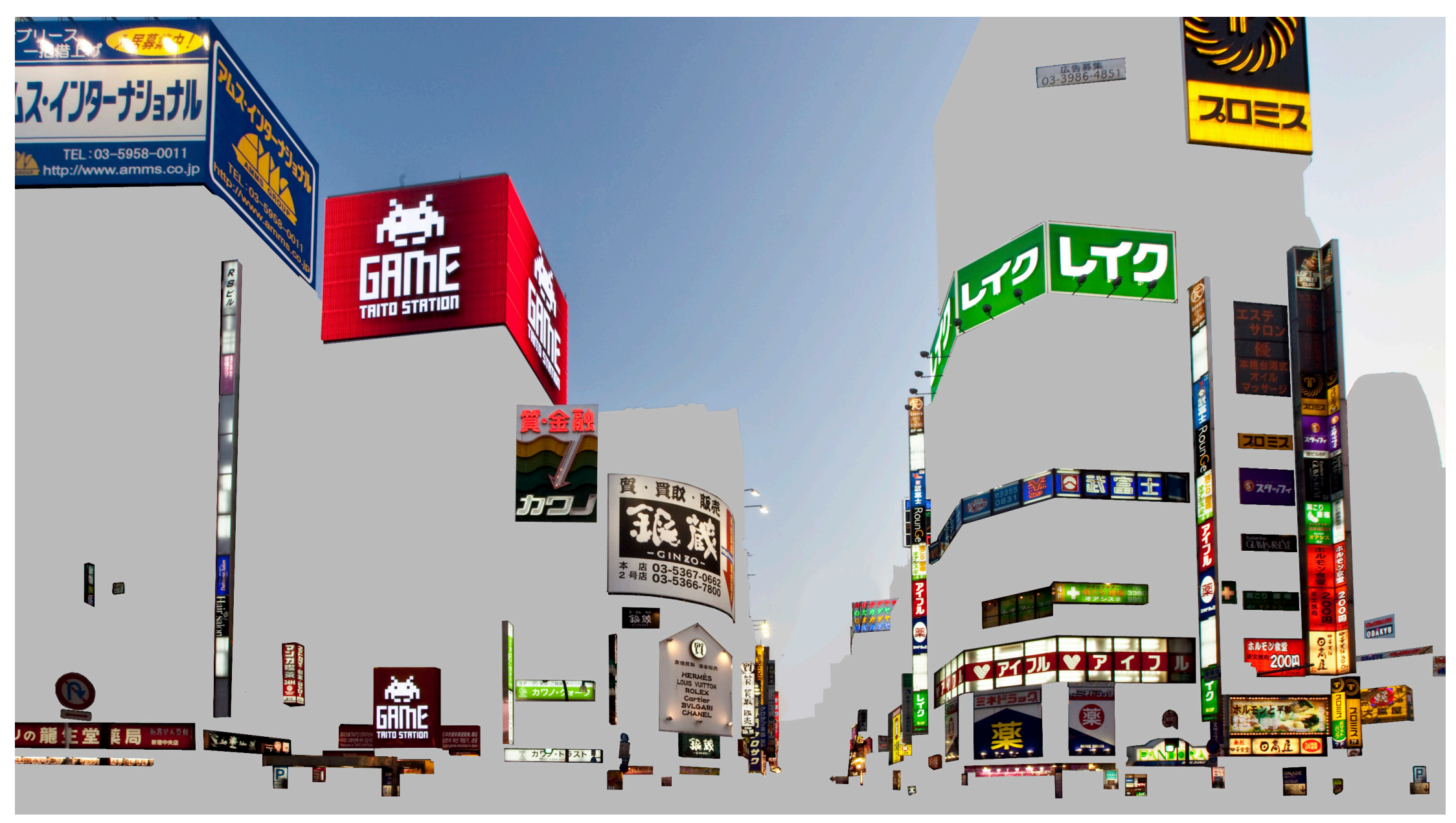

fig.1.3.15 


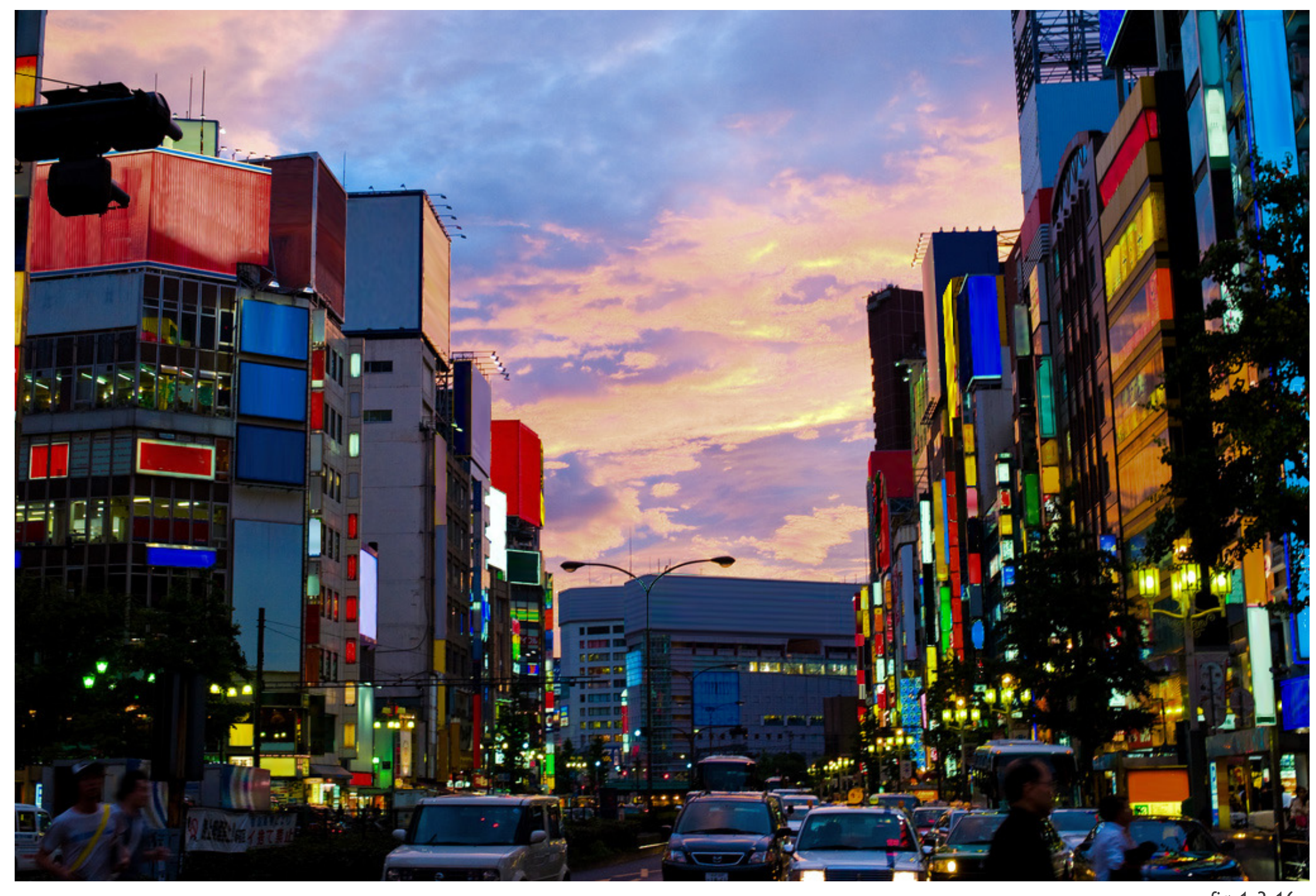

fig.1.3.16 


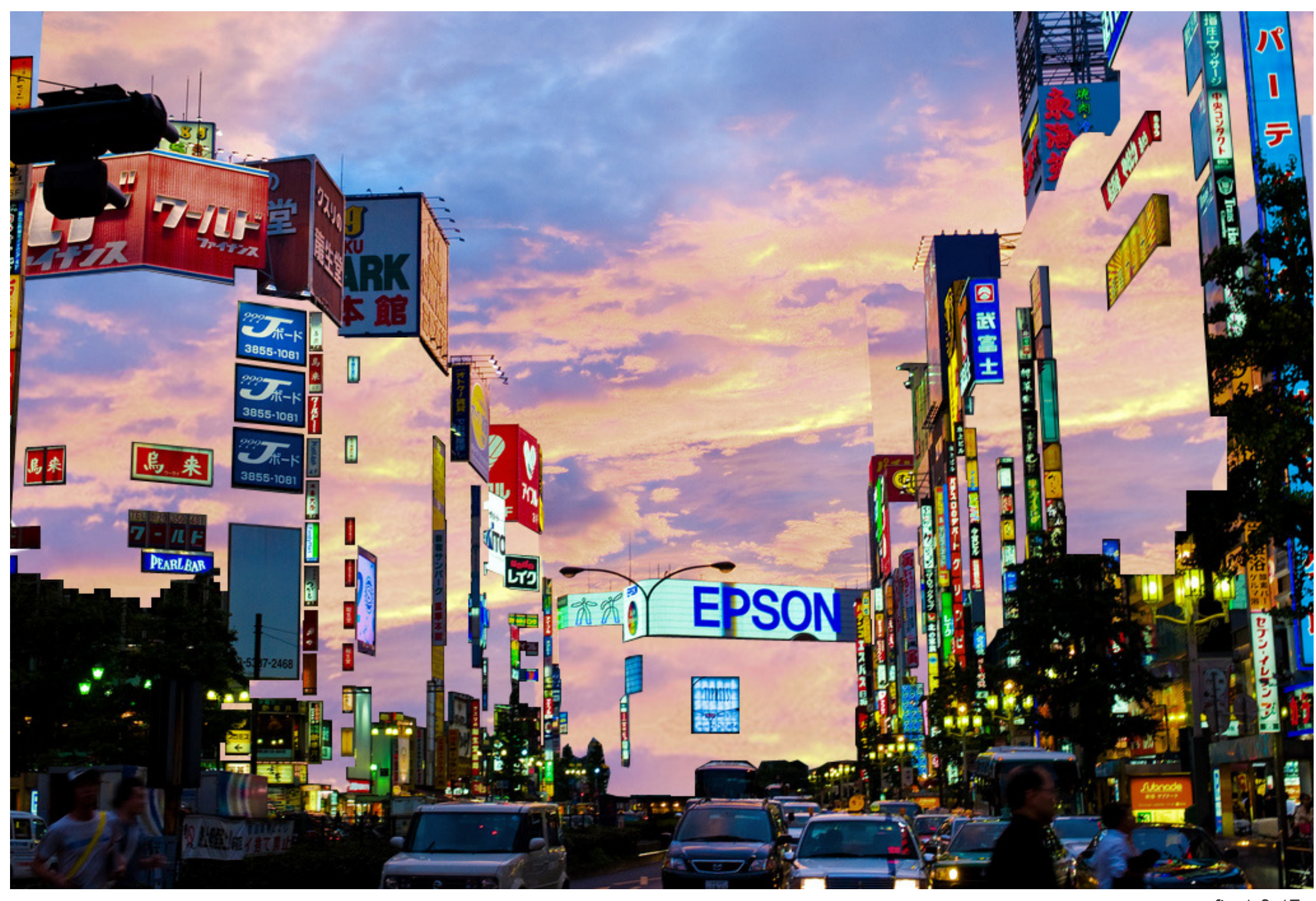

fig.1.3.17 


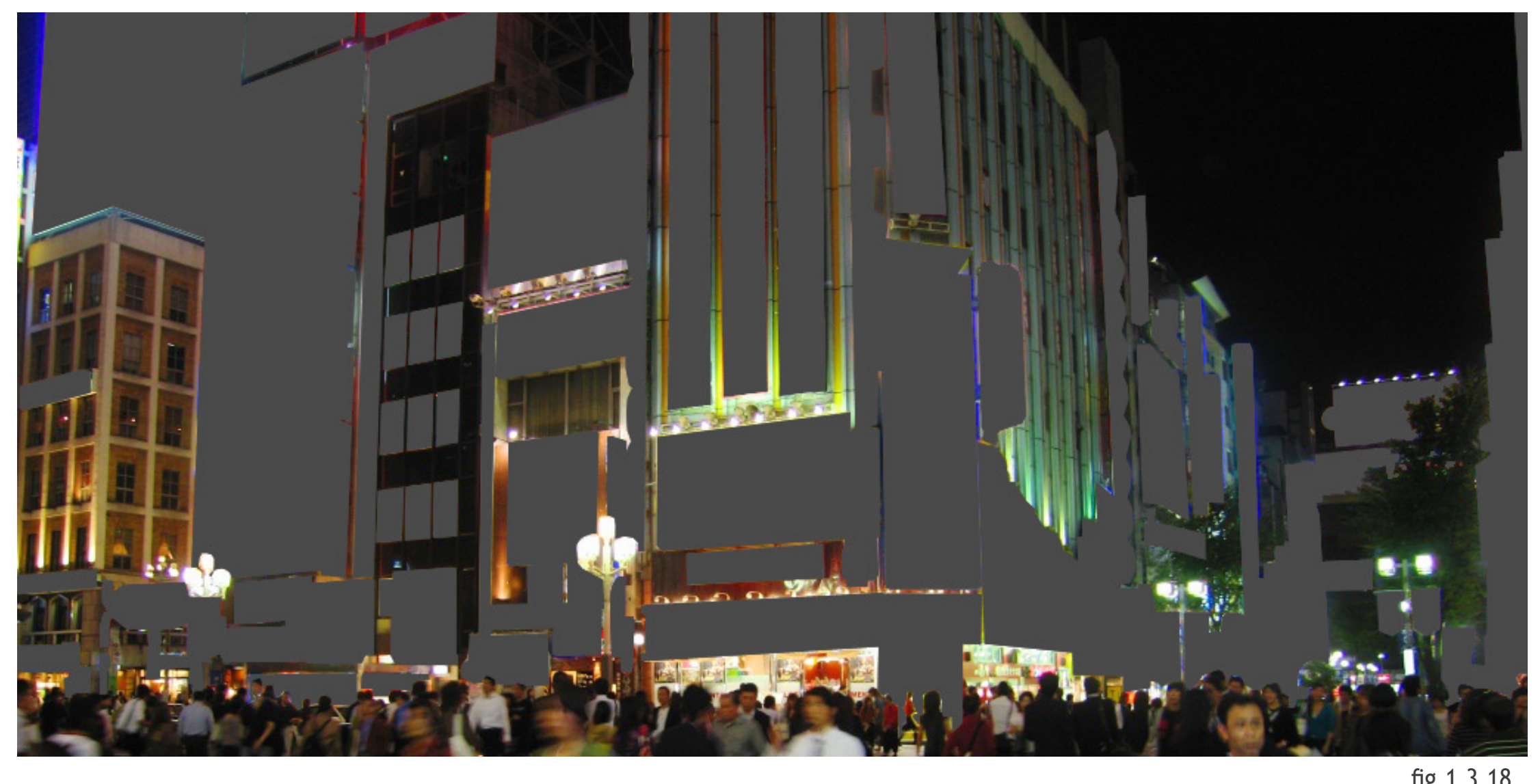

fig.1.3.18 


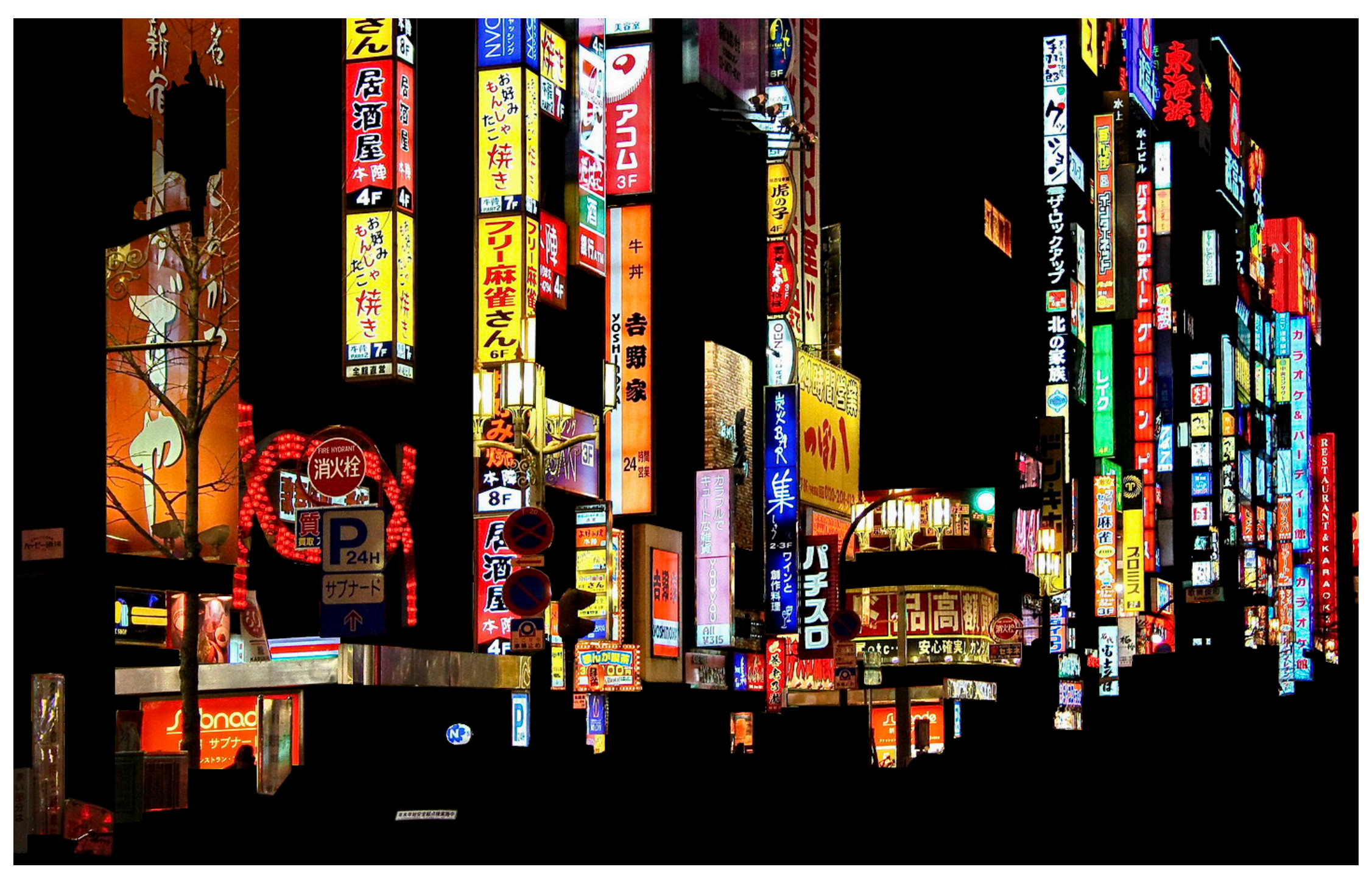




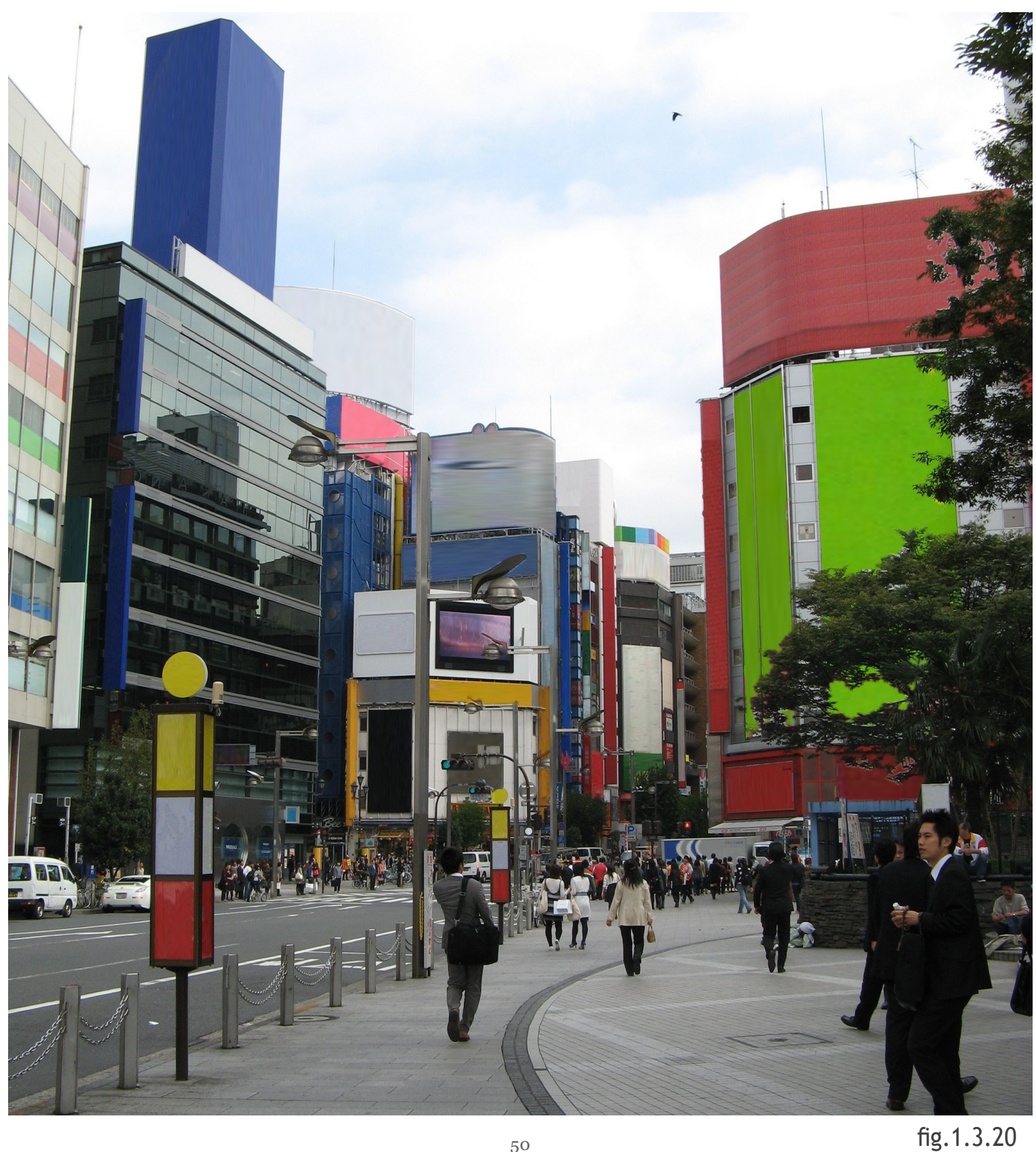




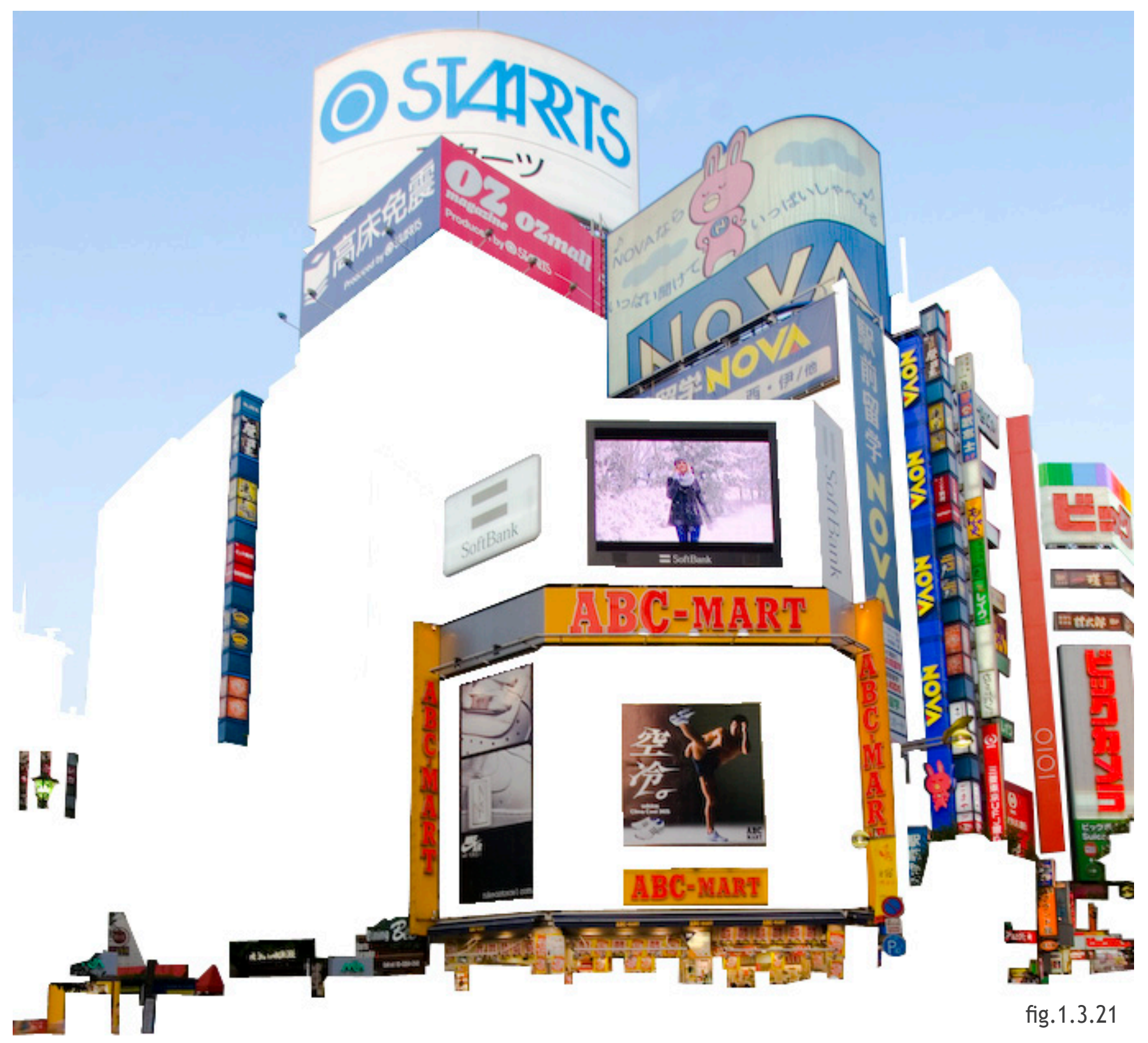




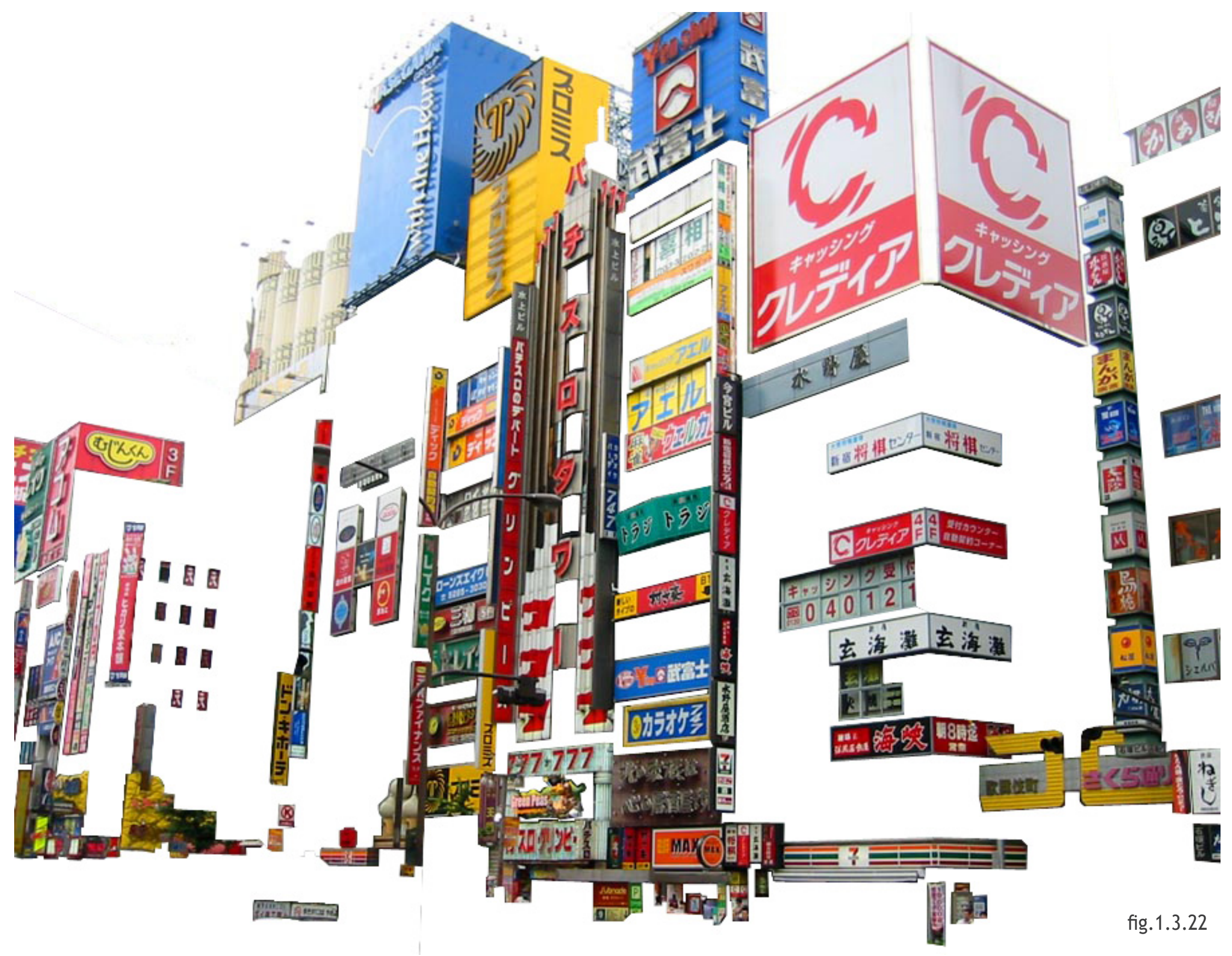




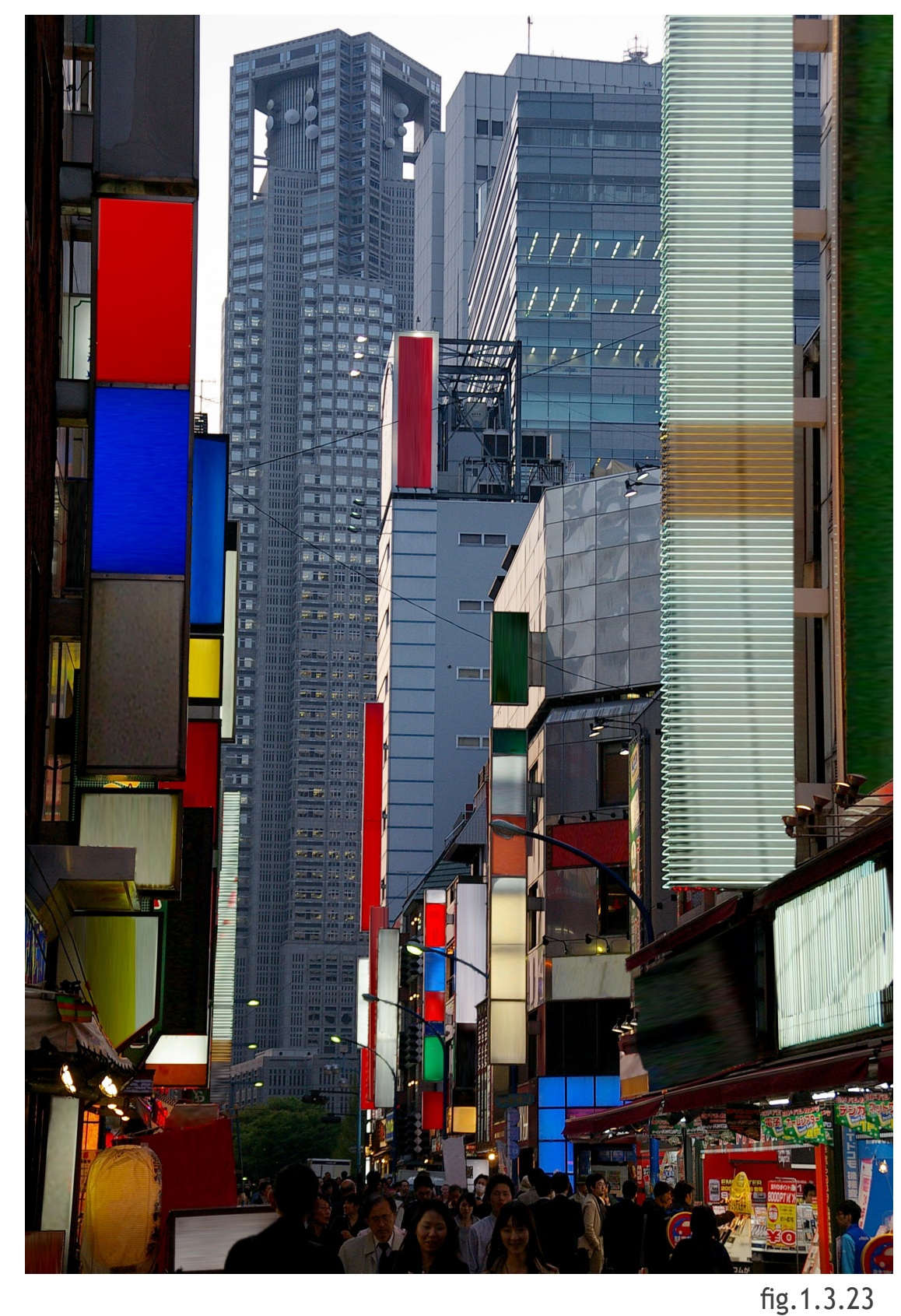




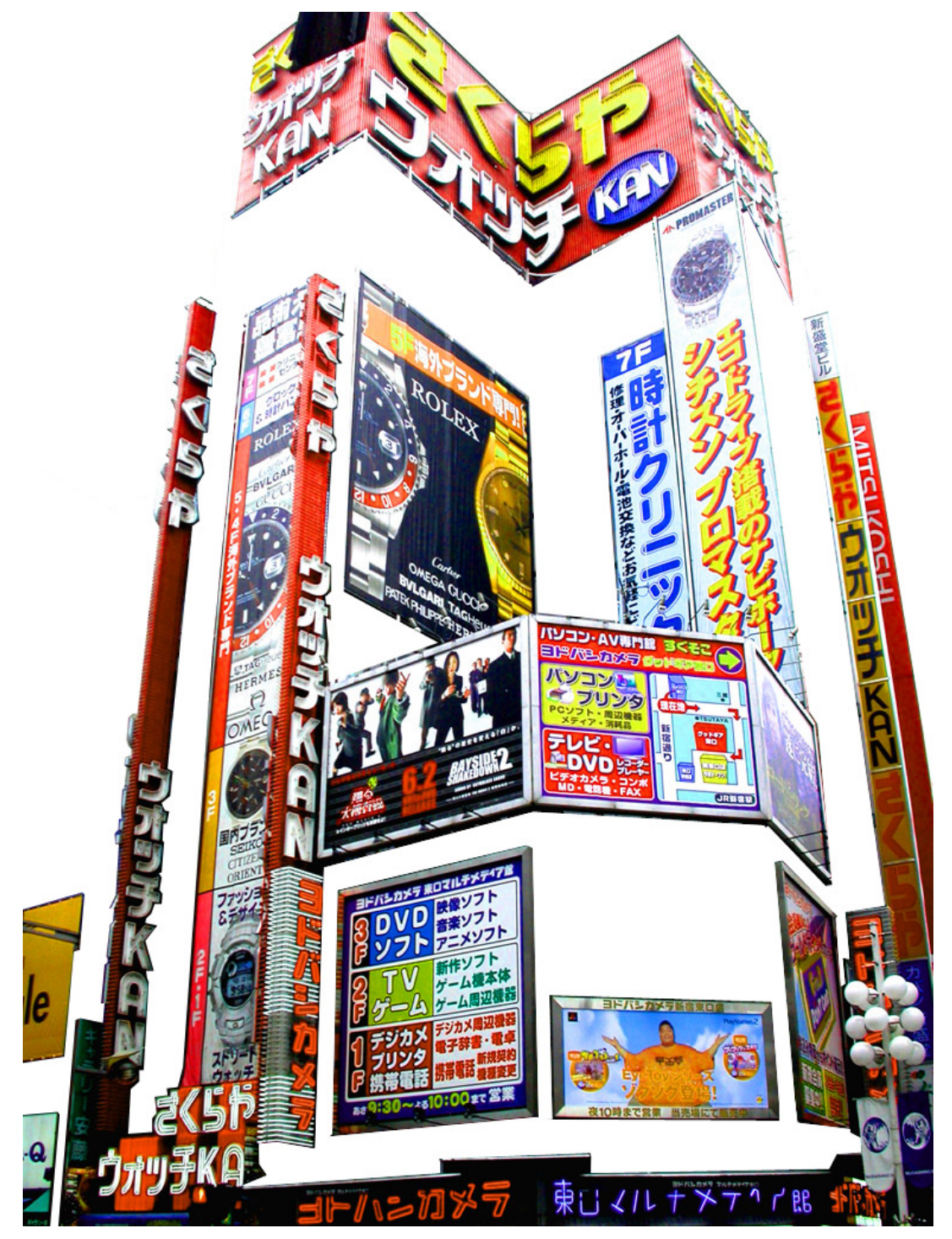

fig.1.3.24

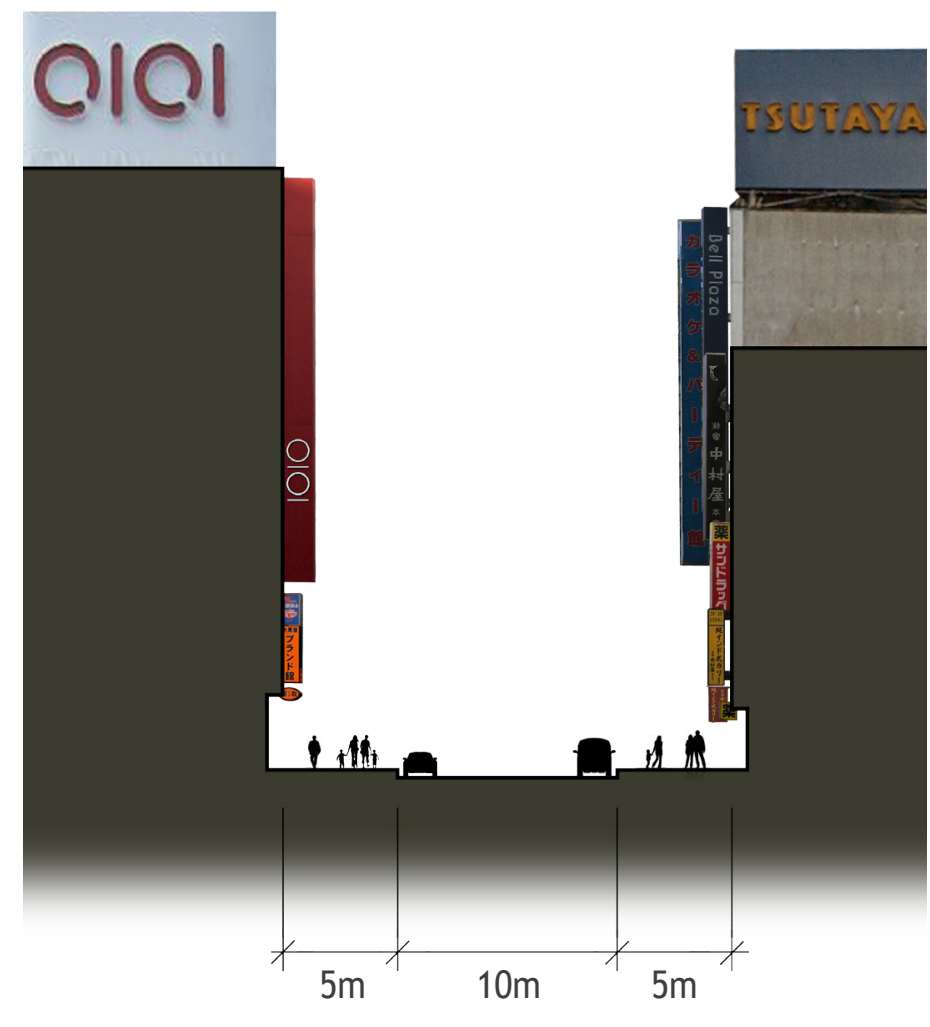

fig.1.3.25 section through Shinjuku Dori Avenue outside of Shinjuku Station 


\section{SHINJUKU, TOKYO}

\section{Media Buildings}

In contrast to North American main streets, advertisements in Tokyo stretch vertically above pedestrian eye level. Some advertisements make use of the many office windows, plastering advertisements and phone numbers from the interior. The window advertisements are easily visible during the day and compete with the neon signage. Signage is set up so that the various stores in the building have advertisements presented in a row, uniformly sized and shaped.

The narrowness of the street demands that both parallel and perpendicular signs (relative to the pedestrian) serve as a directory of stores located within each building. At pedestrian level, different advertisements are hung randomly at the storefront. Except for the few anchoring jumbotrons featuring a rotating array of product commercials, the signage in Shinjuku mostly corresponds with its housing store, advertising its name at the pedestrian level in neon lights, as well as giant logos for vehicular and aerial traffic.

In contrast to the large sweeping billboards in Times square, in Shinjuku, strips of advertising leave bare small areas of building facades. Although it appears chaotic at first glance, with massive amounts of advertising seen in the streets of Shinjuku, there are three discernible categories of ads: small pedestrian eye level ads, slim store directory signage fastened to the tops of buildings, and finally buildings capped with large cube like company logos. The ones in the preceding images orderly and neat because varying depths and hierarchies appear. 


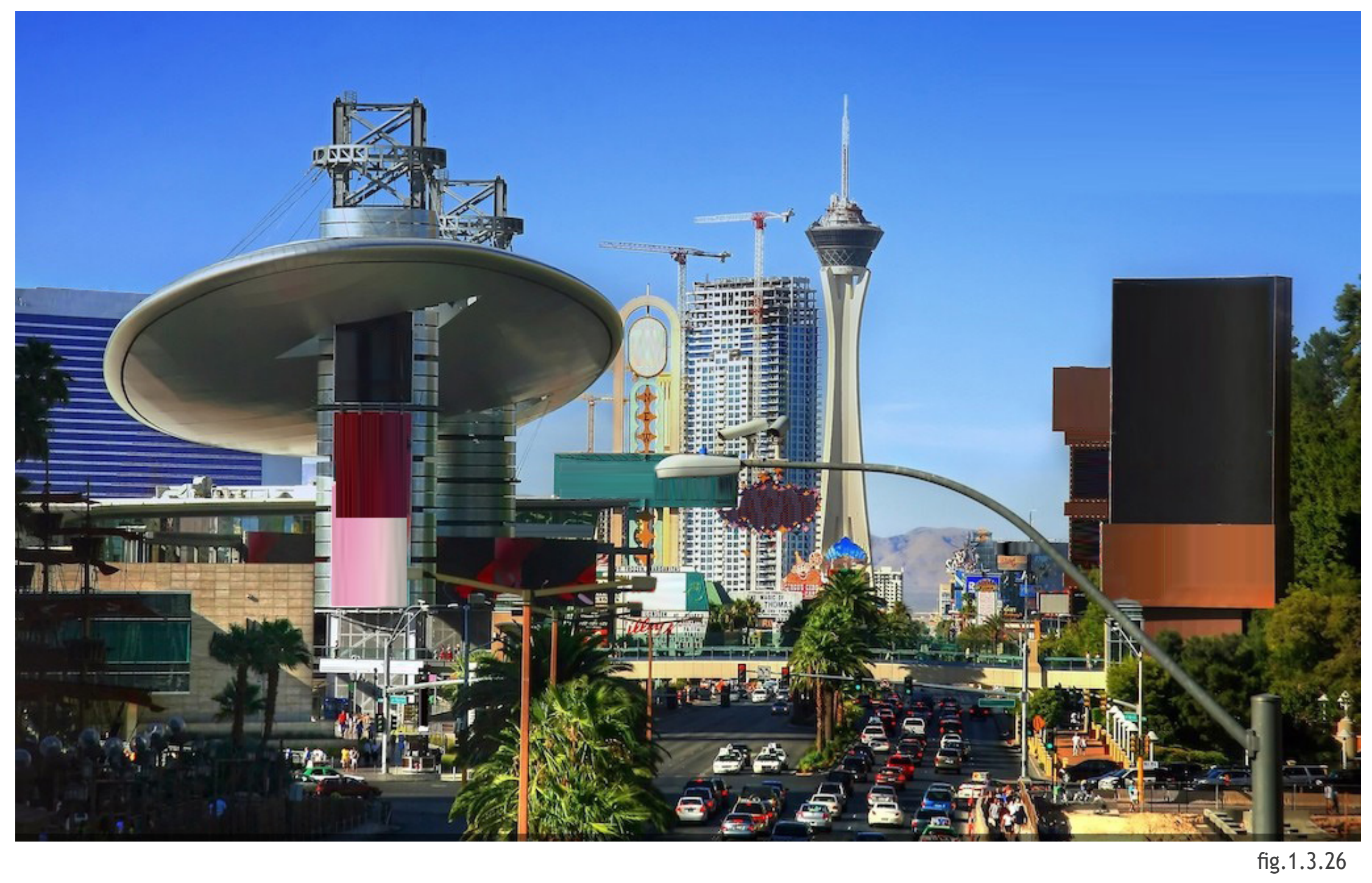




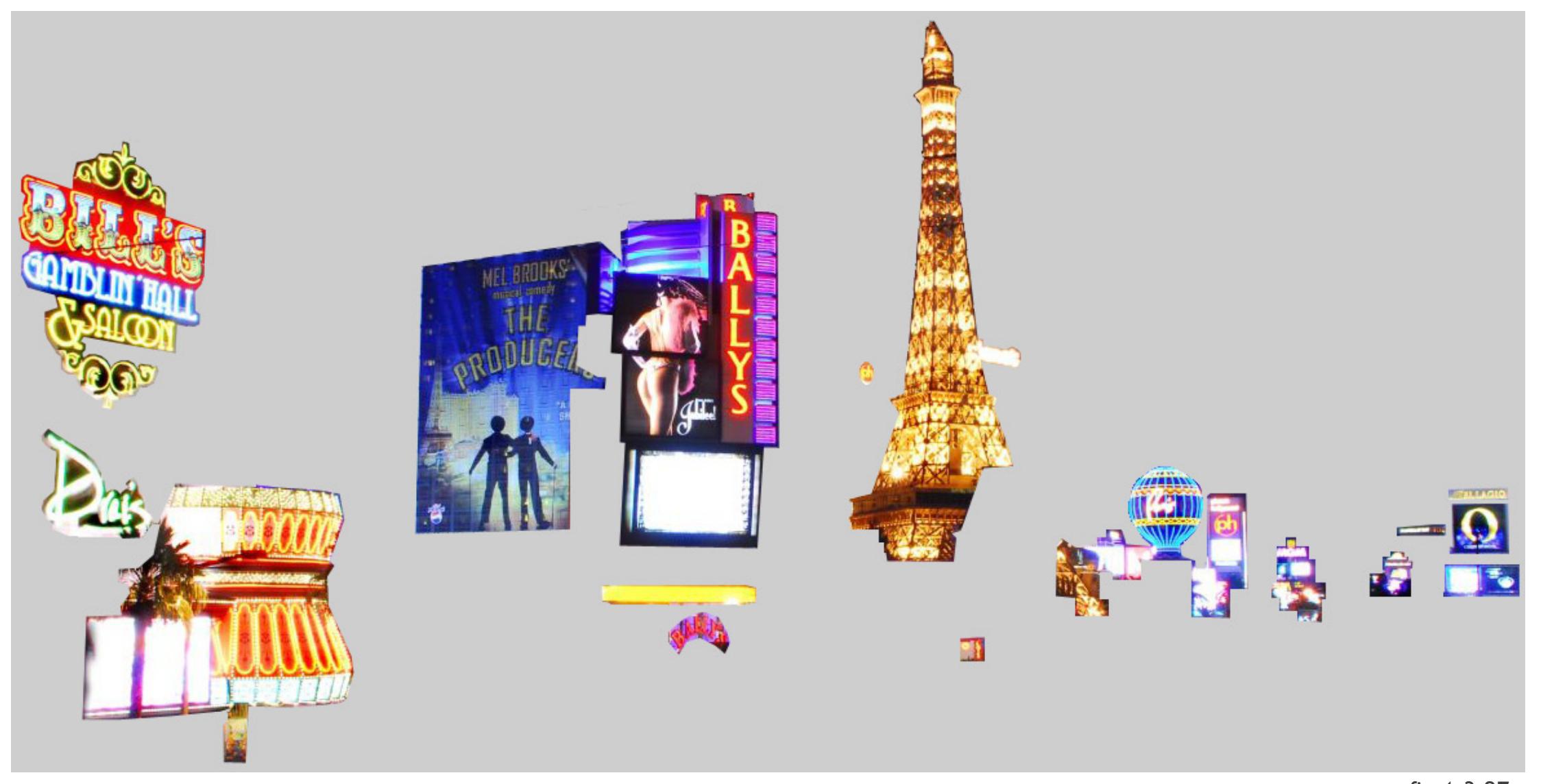

fig.1.3.27 


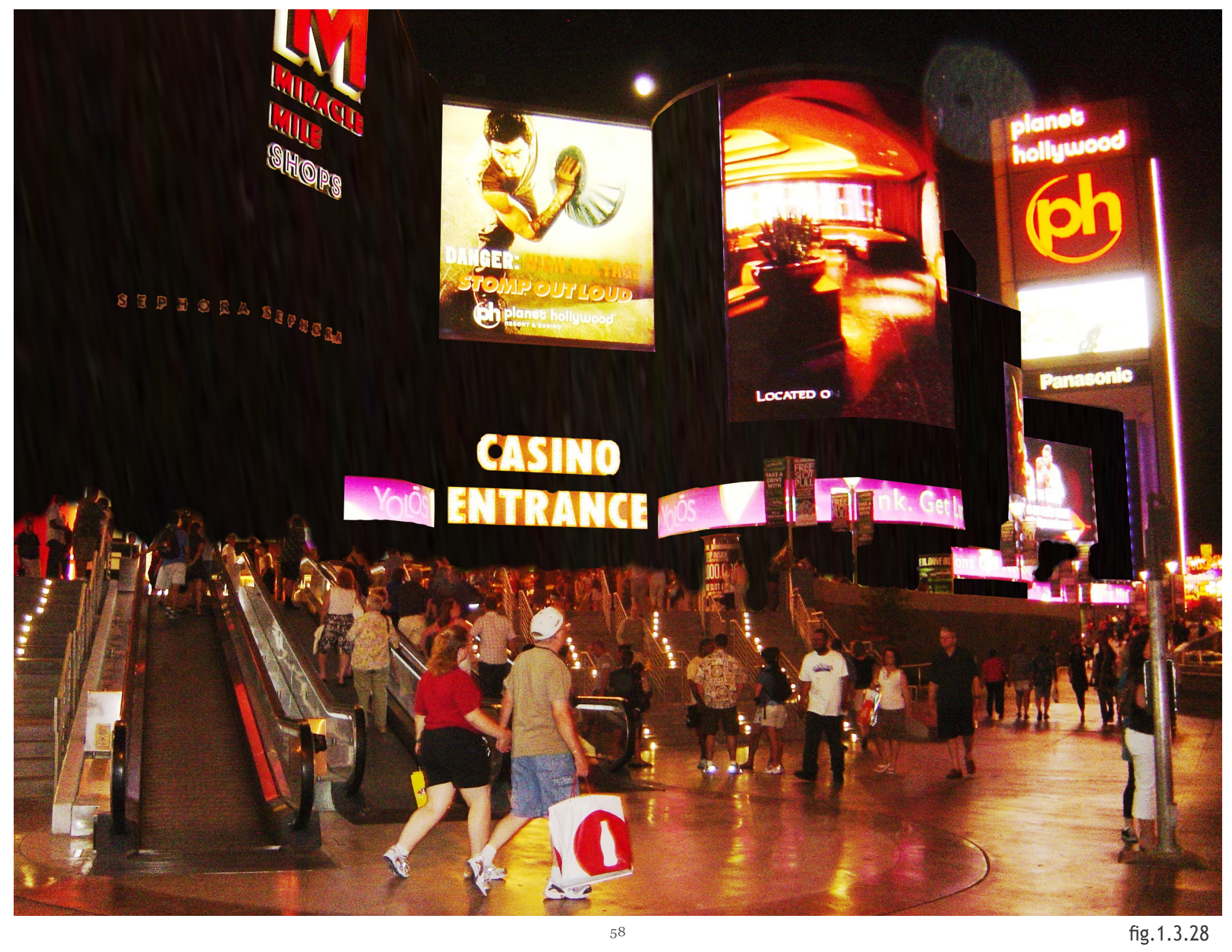




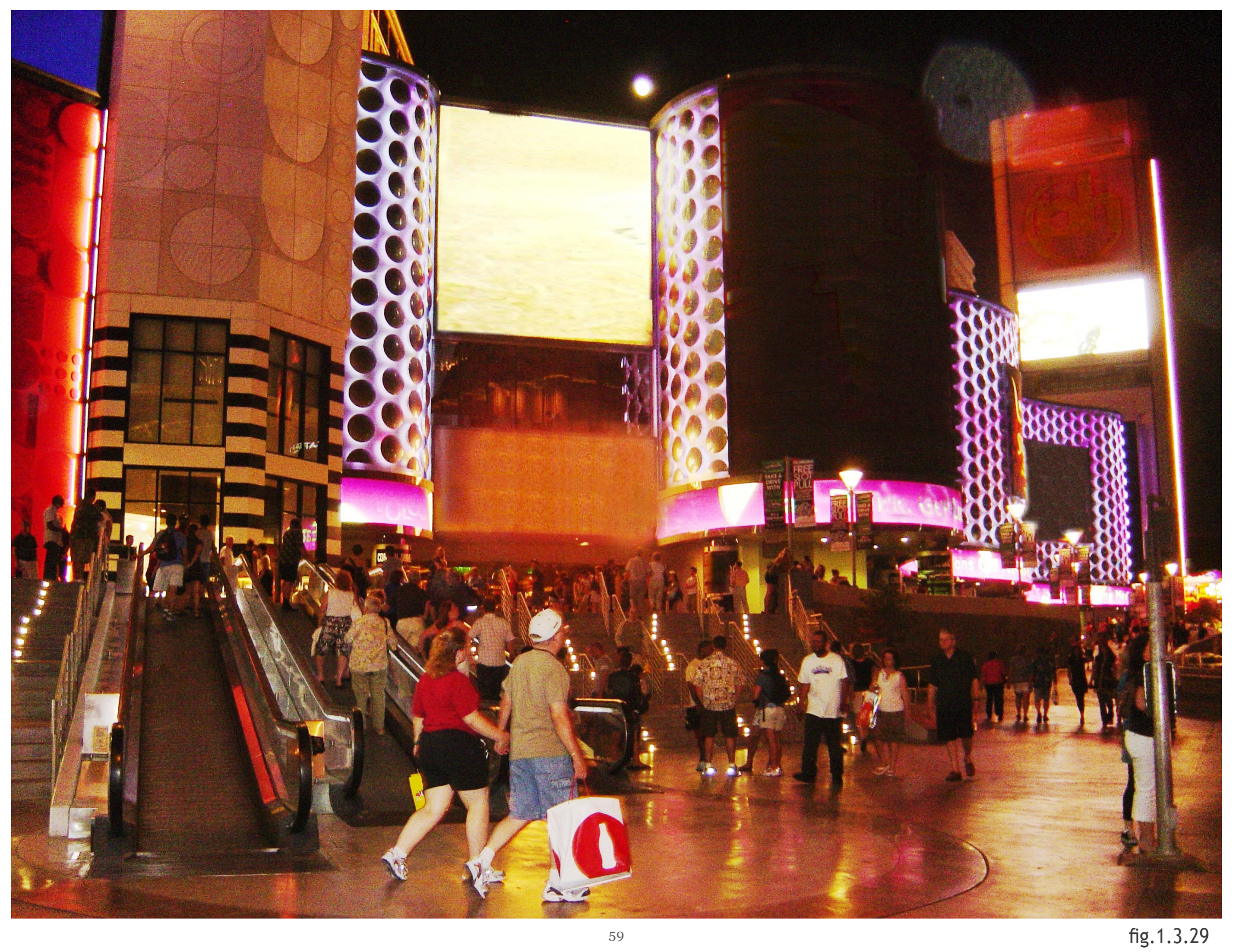




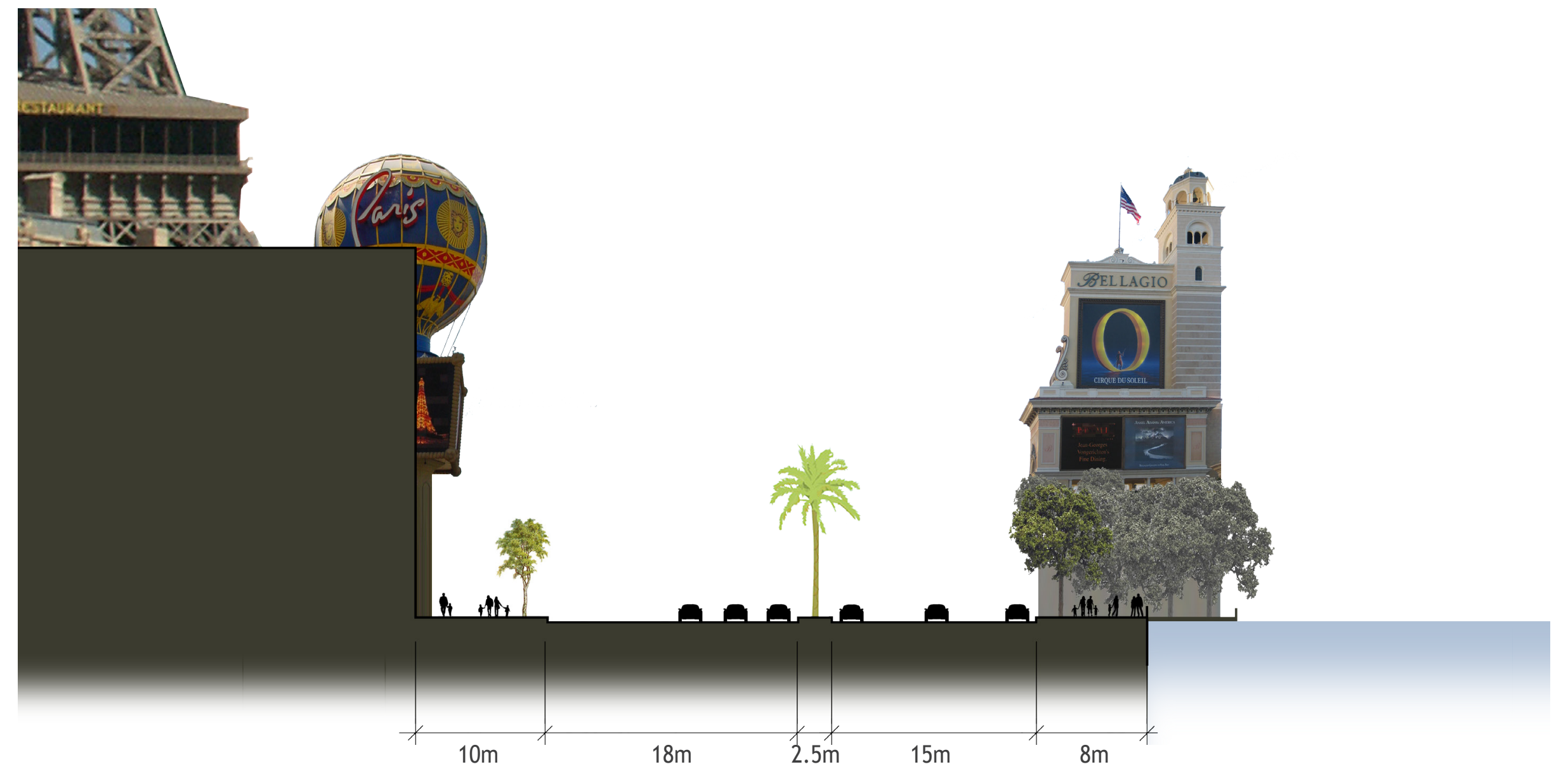

fig.1.3.30 section through Las Vegas Boulevard South, between the Paris replica Eiffel Tower and the Fountains of Bellagio illustrating the roadside signs and attractions. 


\section{LAS VEGAS STRIP, NEVADA}

\section{Media Buildings}

Las Vegas' landscape is visibly dominated by large land parcels with hotel towers located at the far edge of the streets. The front lots establish brands with statement signs, usually adopting the structure which corresponds to that resort's theme. Buildings take on forms and details consistent with the theme of the casino resort as well. This contrasts with the orthogonal billboards featured in Times Square, and the hierarchal advertisements in Shinjuku. In Las Vegas, the building itself does the advertising.

Las Vegas is still identifiable without its buildings, but when media is removed it becomes difficult to guess it's identity: it could be any major city centre or suburb in North America.

The task of finding images for the Las Vegas strip was a challenge. The urban sprawl of the Las Vegas strip meant that images could only capture one or two hotels or casinos per frame. The buildings are spread out horizontally, making it difficult to get one image which encompasses enough of the signature landmarks, only aerial shots capture the entire view. The massive lots and recessed hotel towers create a streetscape shot that includes both sides of the road to be a tunnel of identifying signage without any hotel buildings present. 
fig.1.4.1 Water Street South facing north. $7 \mathrm{~m}$ from subject

fig.1.4.2 Map showing distances from subject. Galt, Cambridge 


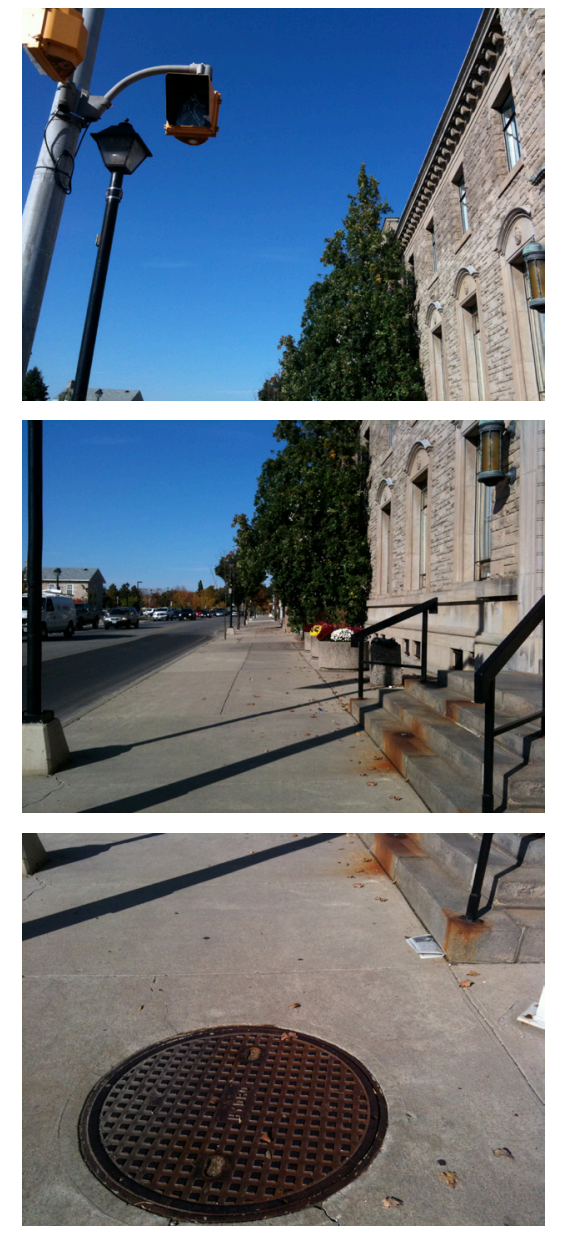

$100 \mathrm{~m}$
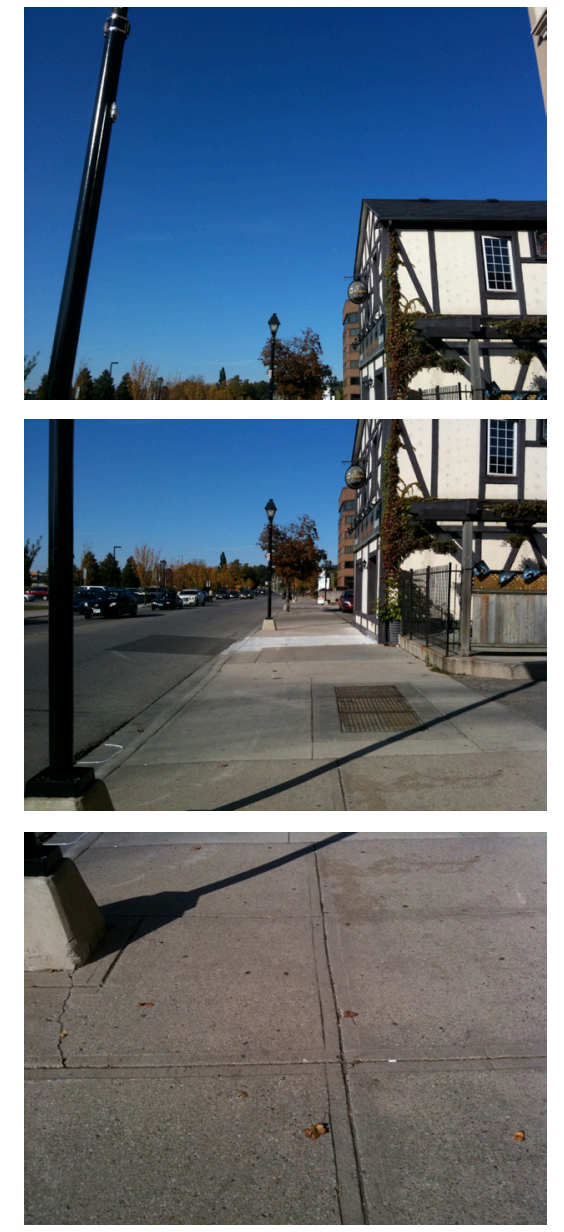

$70 \mathrm{~m}$
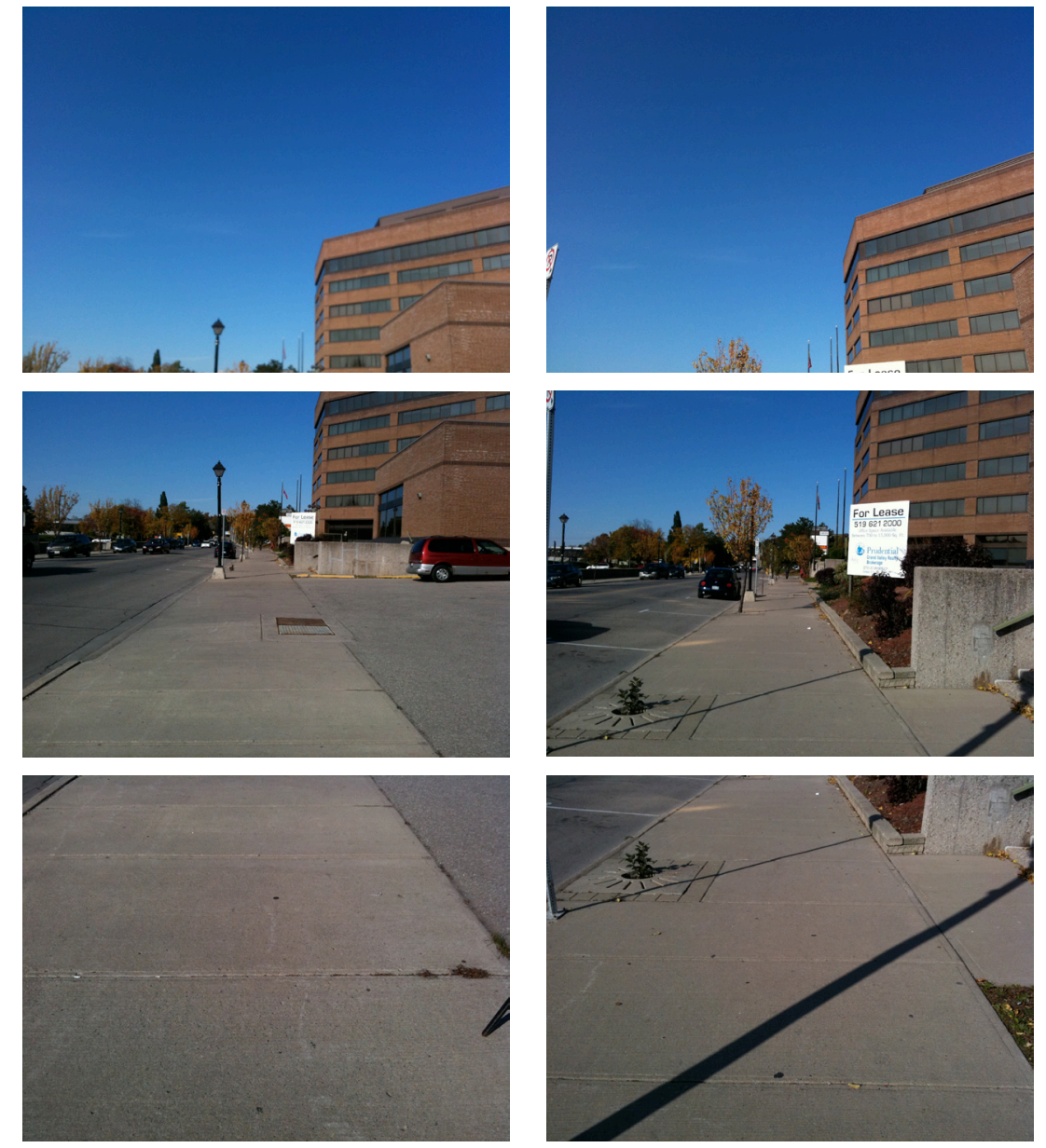

$40 \mathrm{~m}$

$30 \mathrm{~m}$ 

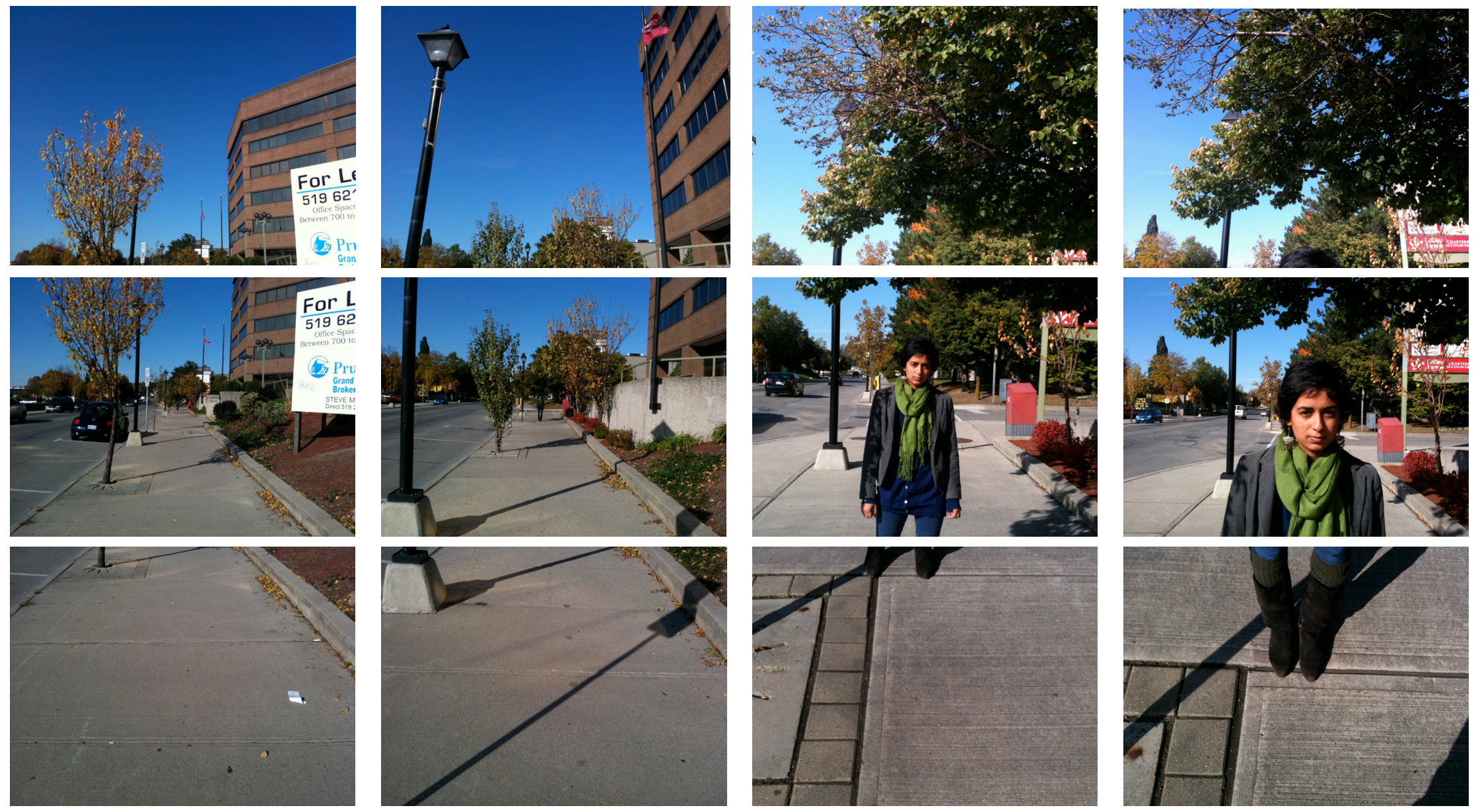

fig.1.4.3 Water Street South facing north at varying distances from the 
fig.1.4.4 Yonge Street facing north. $7 \mathrm{~m}$ from subject

fig.1.4.5 map showing distances from subject. Dundas Square, Toronto 

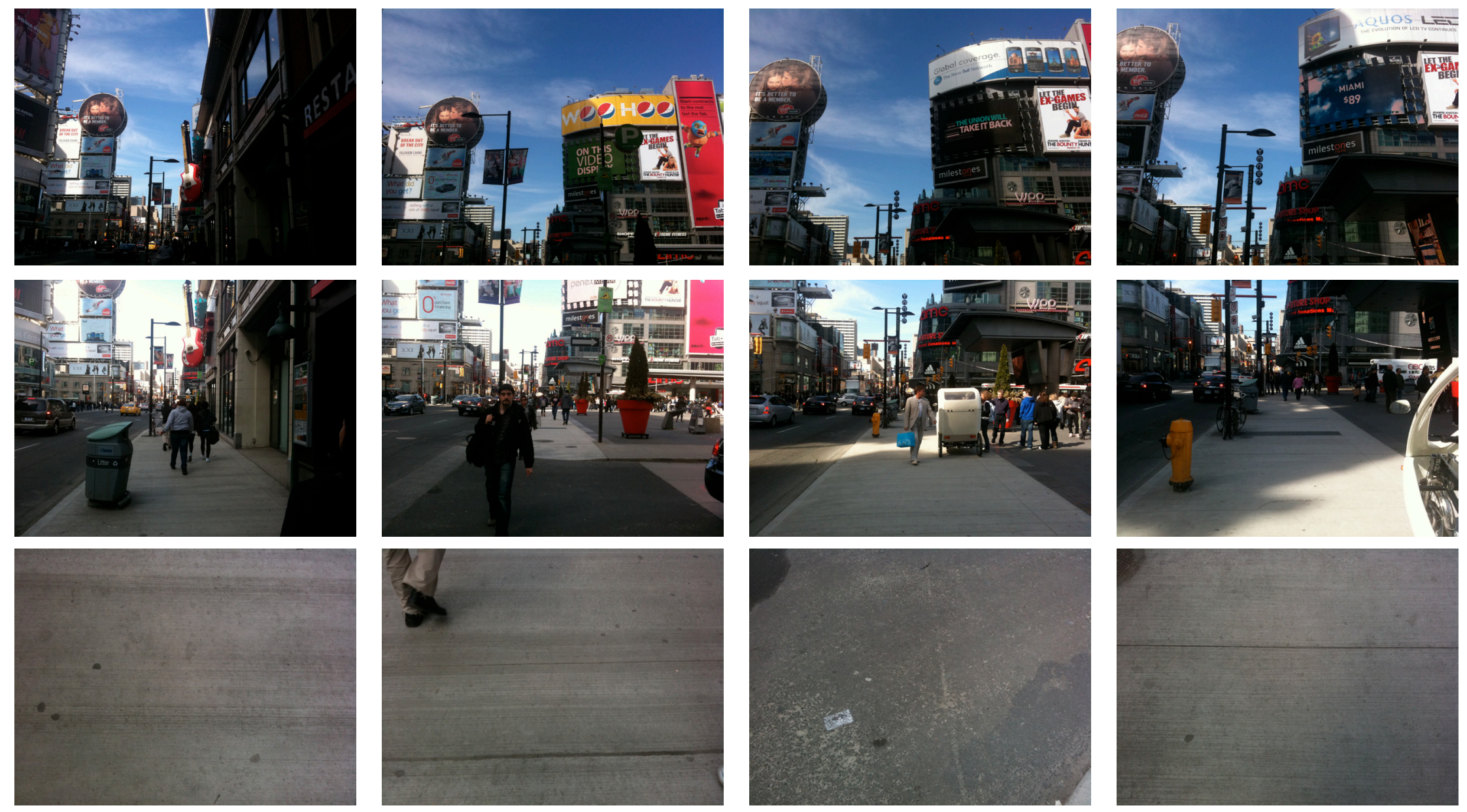

$70 \mathrm{~m}$

$40 \mathrm{~m}$

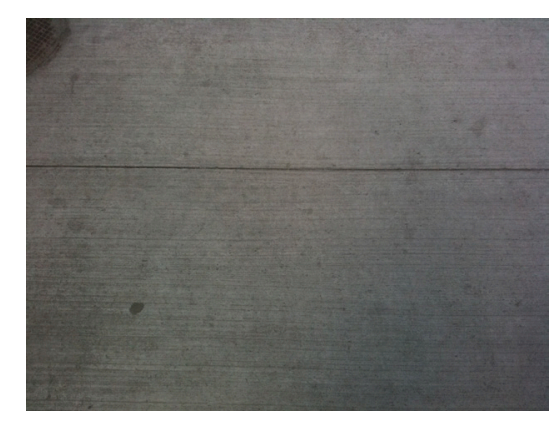

$30 \mathrm{~m}$ 

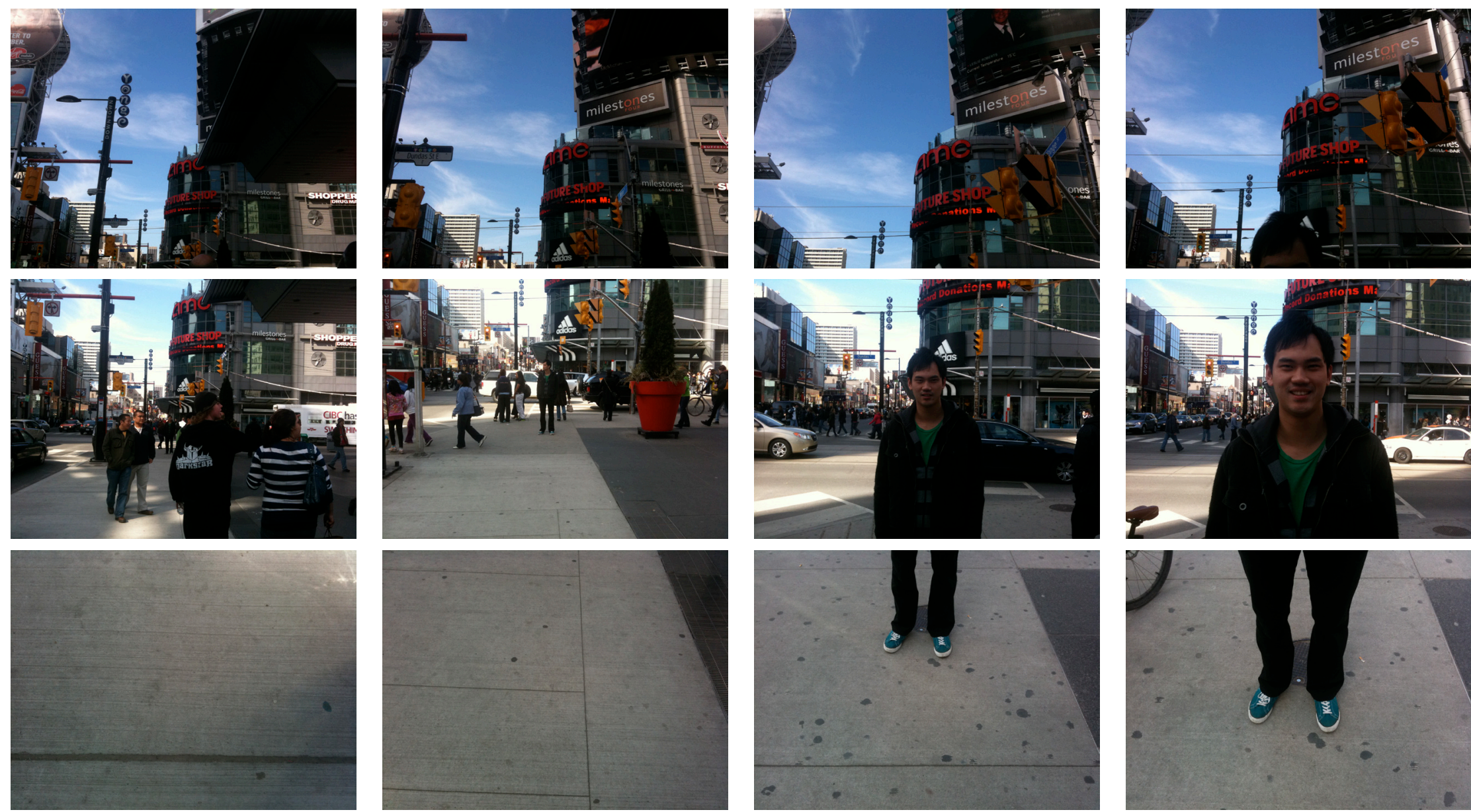

$20 \mathrm{~m}$

$10 \mathrm{~m}$

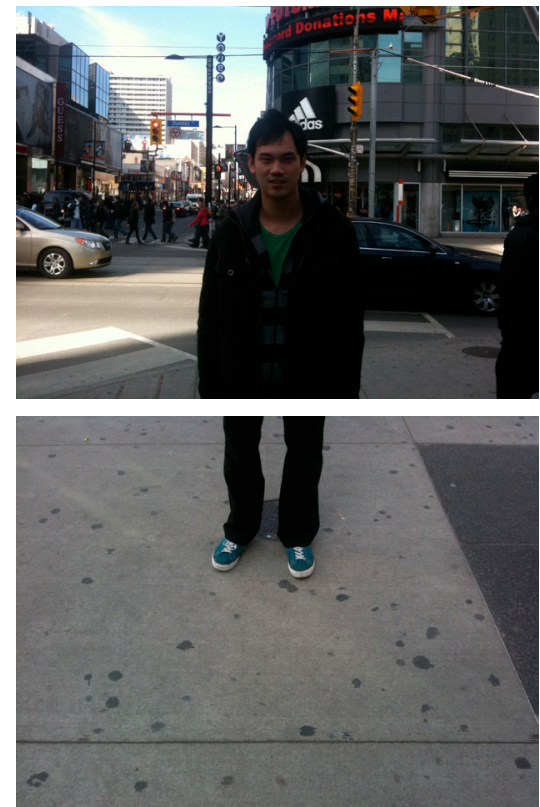

$3 \mathrm{~m}$

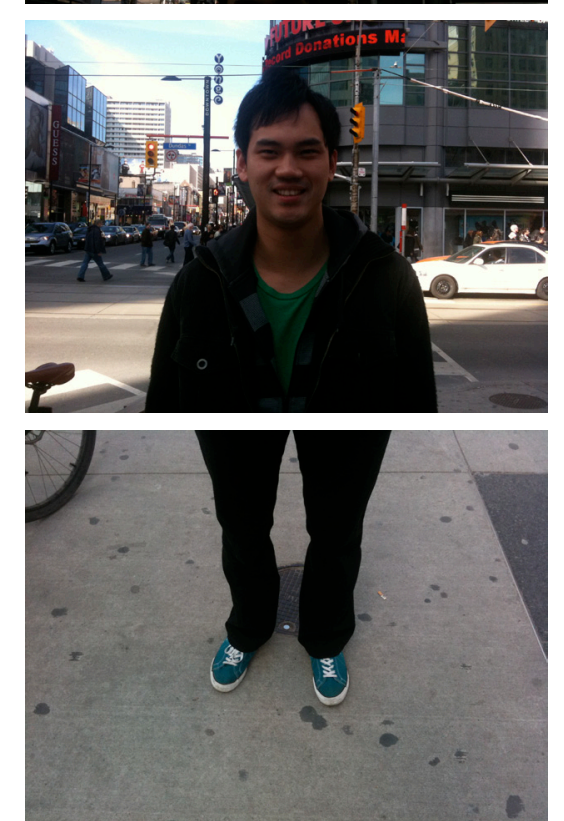

$1 \mathrm{~m}$

fig.1.4.6 Yonge Street facing

north at varying distances from the subject 

2.0 Case Studies 



\subsection{CASE STUDIES: LAS VEGAS STRIP, SHINJUKU STATION, + TIMES SQUARE}

The following cities have been chosen for their emblematic uses of digital media. Their identities and attractions as destinations rely heavily on corporate branding; due to heavy corporate control over design of the spaces many elements of comfort have been overlooked infavour of the commercial interests of specific groups, such as tourists. Yet each city's situations are unique: Las Vegas with land usage in the desert has a suburban layout; Times Square with its dense vertical use of space is an entertainment district on the island of Manhattan; and, Shinjuku Station with its multiple layers of advertising, commuter traffic, and intricate webs of transit connected to a bustling city.

I have examined each area in terms of how commercial media is an integral part of each city's history. Certain public areas have evolved successfully while others need improvement to create a more viable and lasting public space. I have also evaluated the success of each area's attempts to connect with the rest of their host cities. I assess each area through an examination of written information and personal experience. Finally, I apply creative design principles to each area, illustrated through vignettes, to establish how the addition of urban design and multimedia could enhance each city's urban realm, to create vibrant public networks that bring new interactive experiences to the public. 


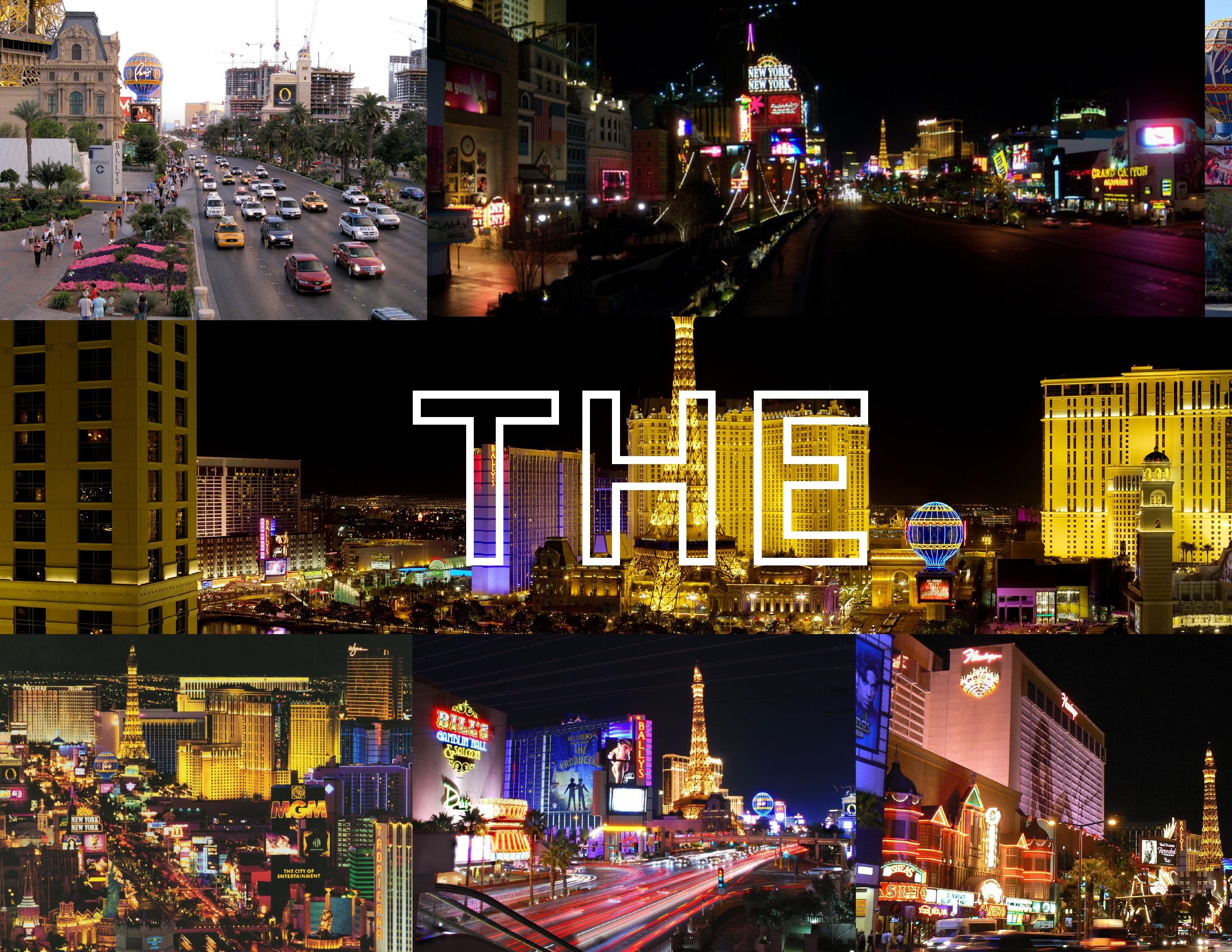




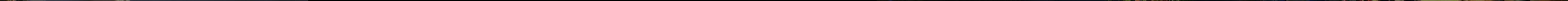




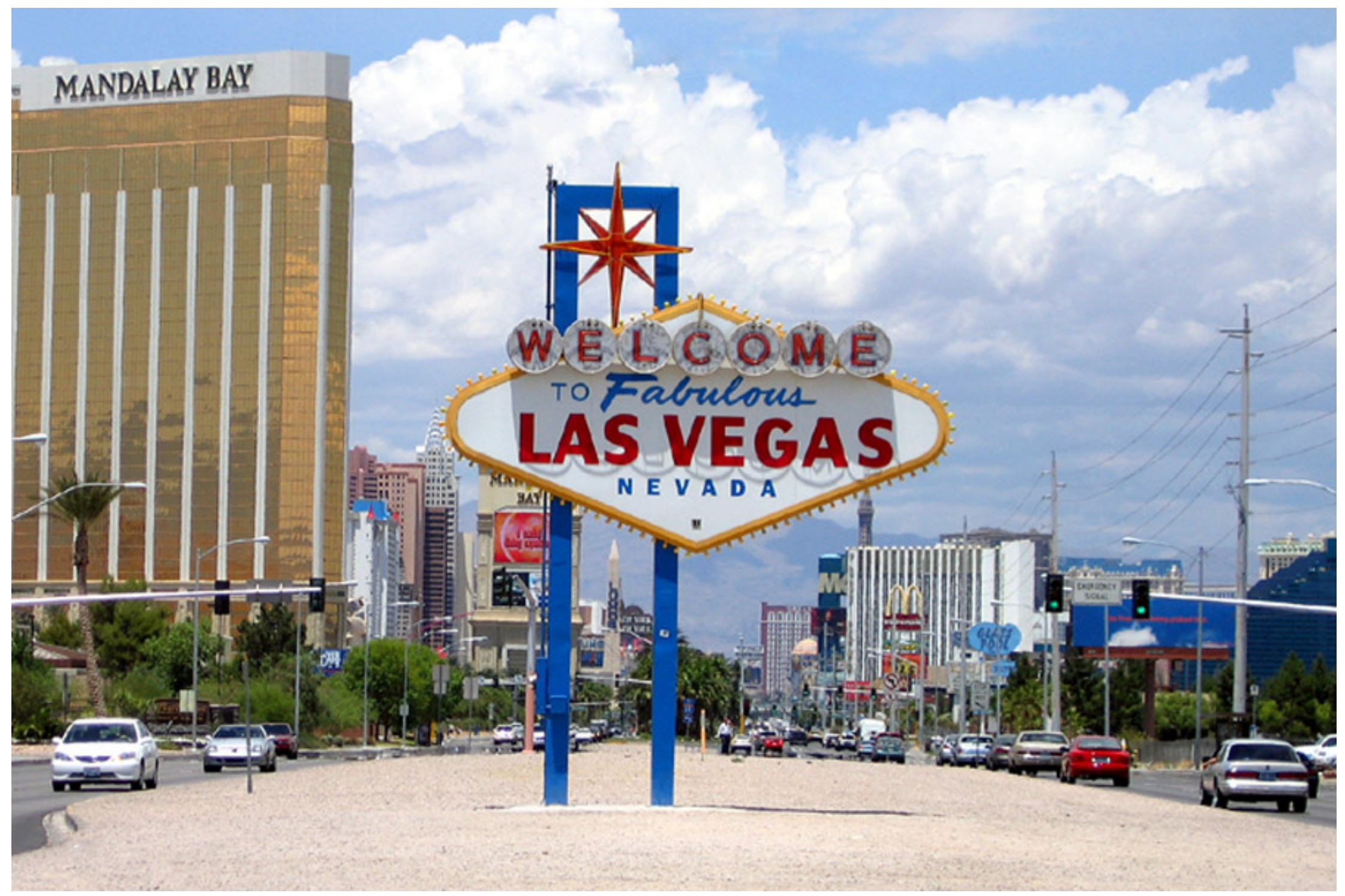

fig.2.1.1 the 'Welcome to Fabulous Las Vegas' sign has been a Las Vegas Strip 


\subsection{LAS VEGAS, NEVADA}

\section{AKA "The Entertainment Capital of the World"}

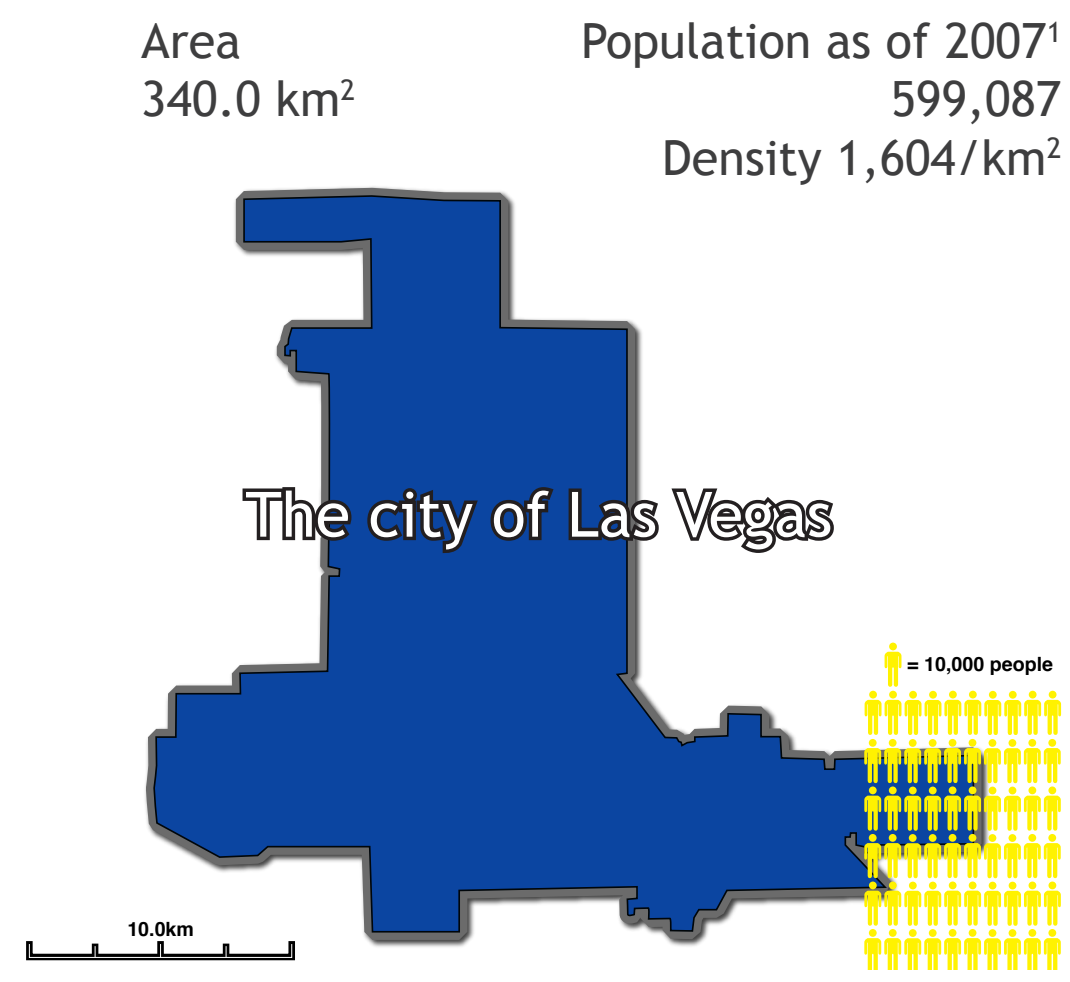

1 "Demographics." Official City of Las Vegas Web Site. http://www.lasvegasnevada.gov/ FactsStatistics/demographics.htm (accessed February 11, 2010).

\section{Historical Development}

In 1890, railroad developers concluded that Las Vegas Valley was a profitable location for a railway stop facility and town. The city, situated in the arid desert climate of the Mojave Desert in Clark County, was founded in 1905 when 110 acres of desert land was auctioned off in a single day. ${ }^{1}$ By 1931, the State of Nevada legalized gambling, which protected the city from the economic depression of the 1930s. At the same time, the Hoover Dam began construction, further solidifying additional growth by attracting tourists and encouraging business ventures. Fremont Street was at the forefront of the gambling success, named after John C. Fremont, who led an expedition through Las Vegas Springs in $1844 .{ }^{2}$ Fremont Street was the first paved street in Las Vegas, created in 1925, and lined with casinos and competing neon lights. Casino designs evolved to compete with the thriving resort trade set in motion by the tourist attraction to the Hoover Dam, becuase of which developers looked to investments south of downtown Fremont Street. The first successful casino-hotel, called the 'El Rancho Vegas', opened in 1941 and led to the construction of many additional hotel-casinos of the same style facing the two-

\footnotetext{
1 Paher, Stanley W. Las Vegas, As It Began, As It Grew. Salt Lake City, UT: Nevada Publications, 1971. 80 2 ibid. 15
} 


\section{Viva Las Vegas}

\section{*

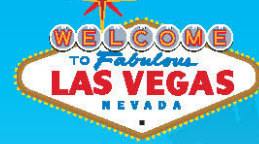

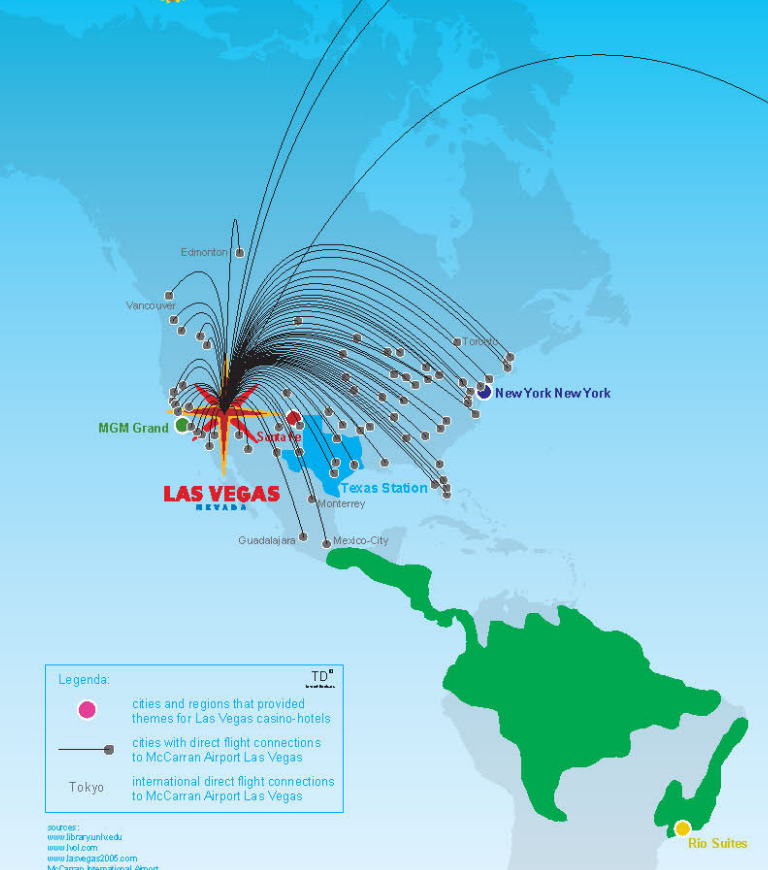

Tropicana

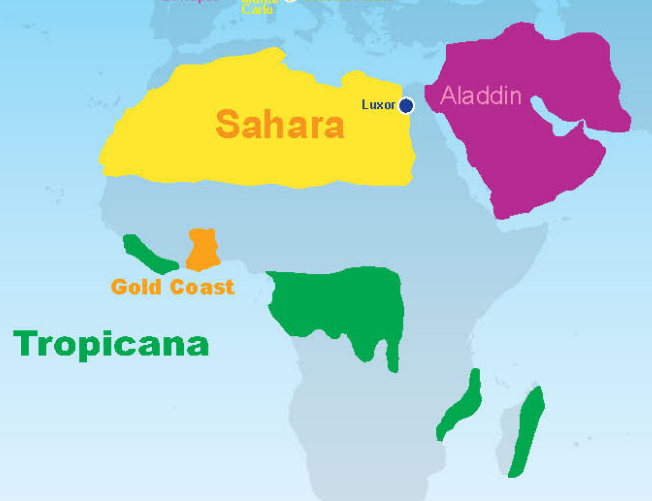

fig.2.1.2 Viva Las Vegas by Theo Deutinger. A Snapshot of Globalization. Viva Las Vegas illustrates the city's evolution from signs, to symbols, to sameness over the course of the last century

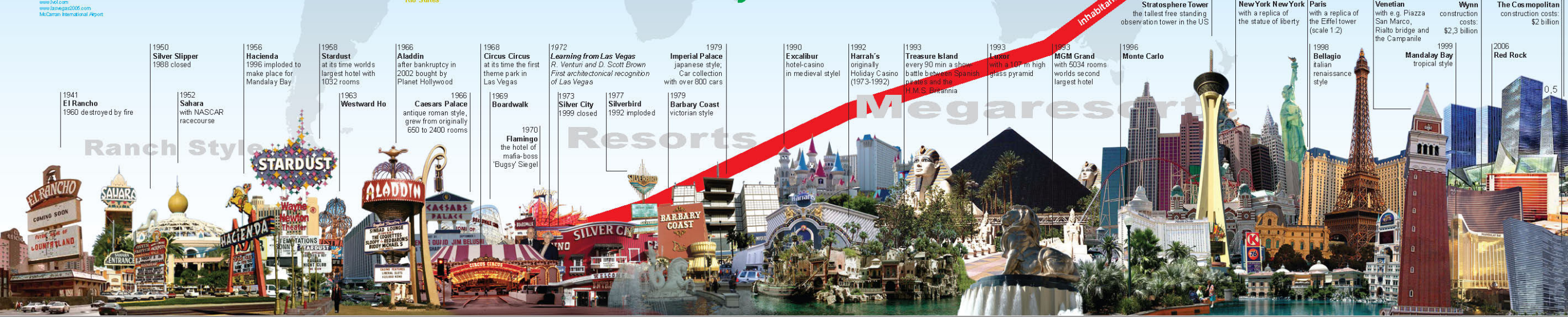


lane highway leading into Las Vegas from Los Angeles. ${ }^{3}$ Fremont Street could not sustain the loss of frequenters from the train station as people came by McCarran International Airport or by car along the Interstate Highway instead. As hotel construction persisted along the strip, the downtown began to decline. This prompted the establishment of the lucrative area that is the now the famous Las Vegas Strip. The western ranch-styled El Rancho governed the style of the first casino-hotels up until The Flamingo in 1946, which started the luxury casino trend. Thus began the trend of opulence and neon, attributed to the infamous mobster, Benjamin Siegel, who had access to finances for the Flamingo after World War II. ${ }^{4}$ The advent of convention centers hedged the economic/tourist decline during the off-season in Las Vegas. However, city officials soon realized that they could not remain the sole gaming capital for long, since Atlantic City in New Jersey legalized casino gaming in 1976. It was clear that Las Vegas needed to offer other attractions to stay ahead of the game, needing to appeal to a larger demographic in order to compete as a vacation spot. Mega resorts emerged that offered a family friendly destination and appealed to travelers of all ages.

Each hotel-casino was based on themes that affected their design at every level, from the shape of the building to the entertainment that it offered. The Mirage set the standard for megaresorts in 1989 when it opened with attractions other than a casino, such as a white tiger

3 ibid. 168

4 "American Experience | Las Vegas: An Unconventional History | People \& Events | PBS." PBS. http://www.pbs.org/wgbh/amex/lasvegas/peopleevents/p_siegel.html (accessed February $18,2010)$. habitat, a dolphin pool, and a replica volcano. ${ }^{5}$ This trend was quickly emulated by the Excalibur in 1990, which devoted entire floors to non-gambling entertainment for families and children. The Excalibur had court jesters perform in public areas and a showroom featuring jousting on horseback by the 'knights of King Arthur's court'. Luxor, built in 1991, featured an attraction level containing a replica of the tomb of Pharaoh Tutankhamun. In 2007, one of the pyramid's massive black facades was covered with a 15-story advertisement for Absolut Vodka, but was taken down a year later due to negative reaction from the public. Now the world's most powerful beam of light shines from the top of the Luxor pyramid, and is visible from airplanes all the way to Los Angeles. ${ }^{6}$

The latest economic recession as well as the rise of Macau as a leading gambling city has forced Las Vegas to rethink their tourist-attracting strategies. The Nevada town plans to improve its casinos and invest more non-gaming venues, expanding their appeal to a more diverse market with new extravagant structures totalling over 74,00o hotel rooms and 20 of the 26 worlds largest hotels. ${ }^{7}$

\section{Authenticity}

The energy of Las Vegas draw people there. People flock to Vegas to have fun, escape, and have a chance at winning the jackpot. What works in Las Vegas happens to be counter-intuitive to the

\footnotetext{
5 "Las Vegas History| Downtown \& Las Vegas Strip." Las Vegas Journey. http://www. vegasjourney.com/las_vegas_history.htm (accessed May 8, 2010).

6 "History of Las Vegas." Complete information about Las Vegas. http://www.lvol.com lvoleg/hist/lvhist.html (accessed February 11, 2010).

7 "The 24 Largest Hotels in the World." The Future of Las Vegas. http://www.
} vegastodayandtomorrow.com/largesthotels.htm (accessed February 11, 2010). 
rest of the creative world. Perfect replicas of historical monuments from around the world have become great tourist attractions in Vegas, while places that celebrate authenticity seem unappealing. The Guggenheim museum opened in Las Vegas in 2001. Designed by a celebrity architecture firm, OMA, the museum facade was comprised of harsh, red Cor-Ten steel, contrasted against the light decorative courtyard entrance of the Venetian. After 15 months, the Guggenheim decided to conclude their residency. With all the sights of the hotels that remained conveniently accessible, visitors were unwilling to pay to see art within the museum walls, distracted by the pull of the extraordinary strip. The lineup of historical replicas provided a unique experience that people choose to visit instead.

\section{Image}

Las Vegas maintains its success because it reinvents itself according to the demands of the public. Owners have changed and premises have been demolished and rebuilt to remain consistent with the strip's culture of change. Vegas has evolved from 'homegrown' ranch styles to Miami style resorts in the 1950 os to the themed mega resorts of the 1990s. The latest iteration has changed Las Vegas from a "city of signs' to a 'city of symbols'. ${ }^{8}$ The city of signs evolved out of necessity, as Robert Venturi reminds us in his seminal work 'Learning from Las Vegas': "[Vegas] is an architecture of communication over space; communication dominates space as an element in the architecture and in the landscape. But it is for a new scale of landscape... of big

8 Deutinger, Theo, and Andreas Kofler. "Viva Las Vegas." TD Architects. http://td-architects. $\mathrm{eu} / \mathrm{id}=45$ (accessed February 11, 2010).

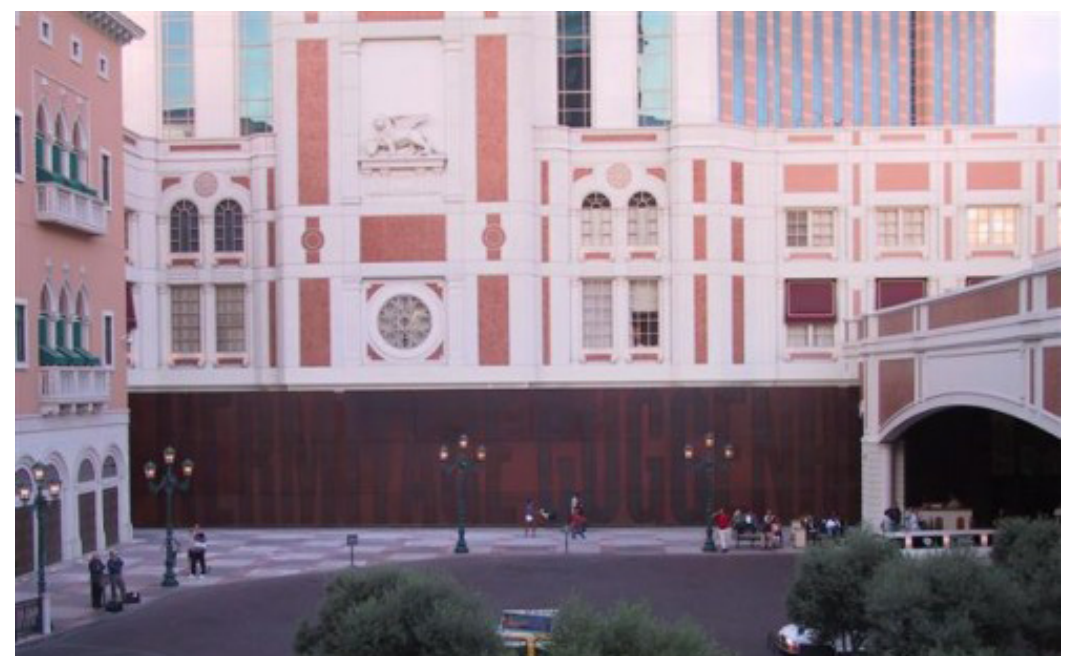

fig.2.1.3 Hermitage Guggenheim, Las Vegas, Nevada, 2001

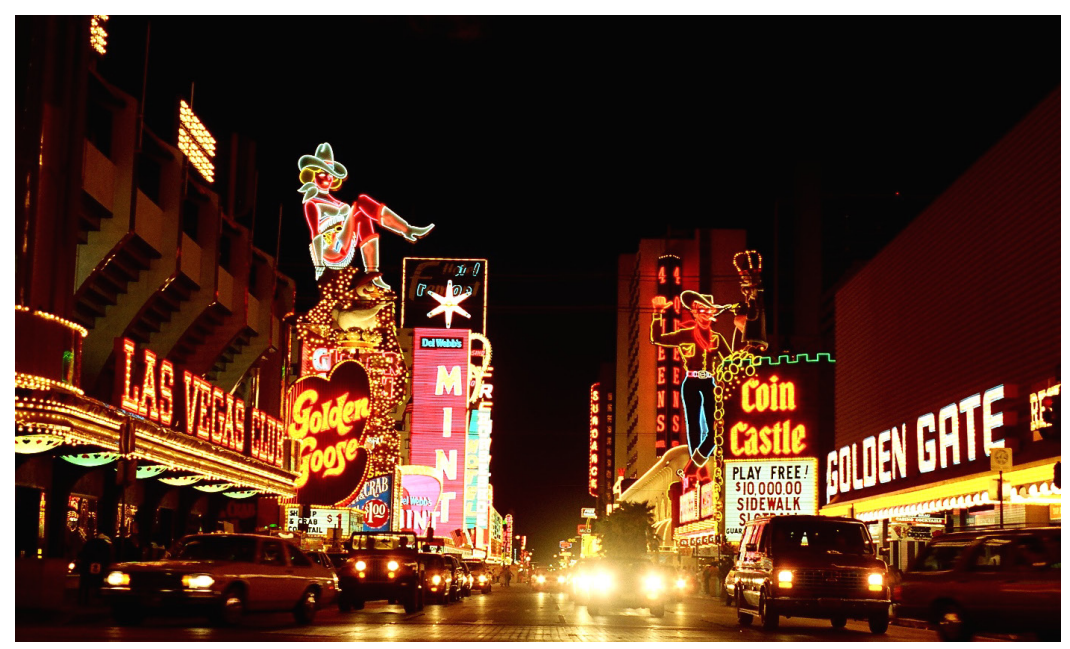

fig.2.1.4 Fremont Street in 1986 

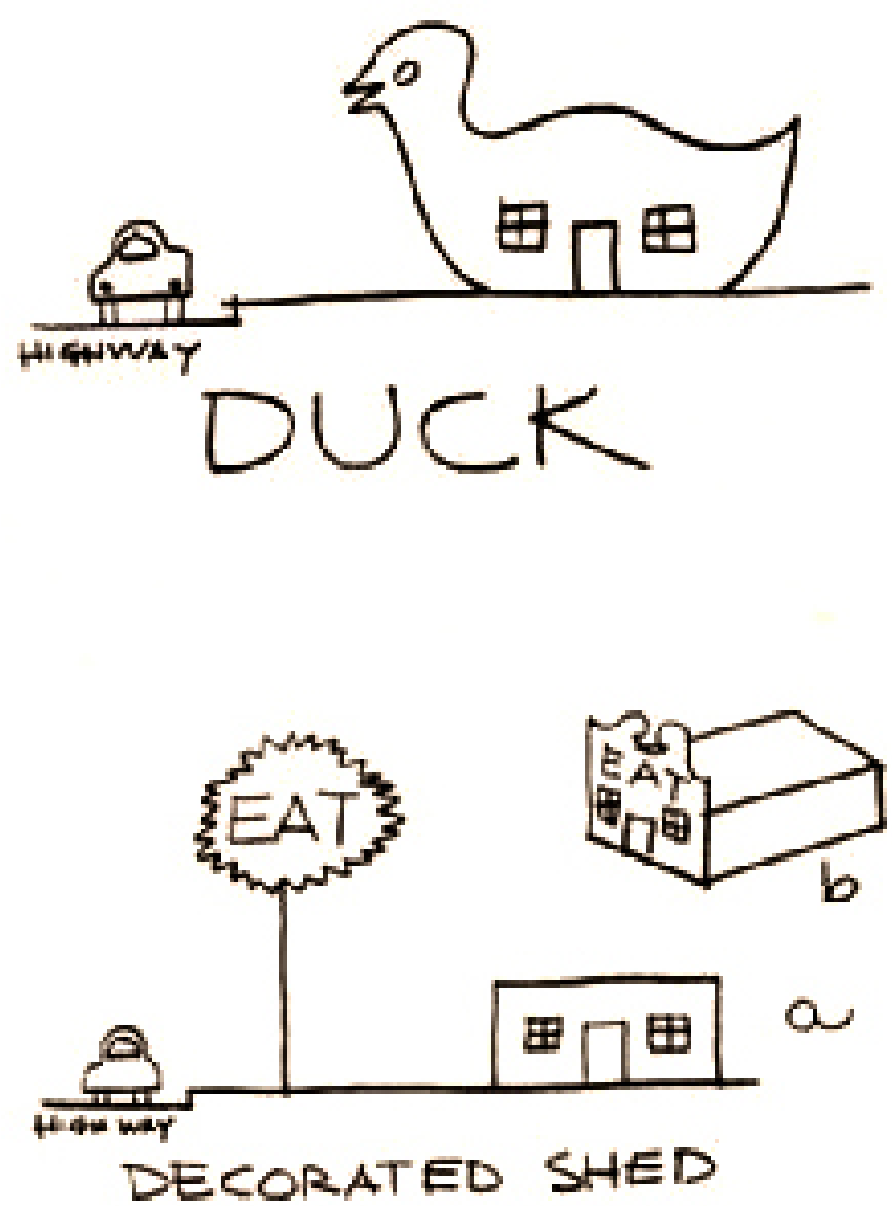

fig.2.1.5 from "Learning from Las Vegas" by Robert Venturi. The sign at the street is important as the building becomes a modest necessity. Sometimes the building itself becomes a sign, like the duck store in the shape of a duck. spaces, high speed, and complex programs." 9 This 'architecture of communication' is apparent in the 'American Main Street', where large signs engage drivers at high speeds on the roadsides of long directional spaces..$^{10}$ The signs on the strip pulsate with lights and with excitement: electric neon is the life of Las Vegas. Even the historical reproductions are integral to the image of the city itself, becoming a 'city of symbols', which is what it is famous for today.

\section{Pedestrian Friendly}

The combination of attractions in Las Vegas encourages people to stroll along the strip for visual stimulation. However, the atmosphere is not always pedestrian friendly and many efforts have been made to make the strip more conducive to pedestrian traffic. The scorching heat combined with the large frontages leading up to the resorts made for lengthy strolls in order to enjoy the sights of the strip. The wide laneways made it overwhelming for pedestrians to see attractions on both sides of the strip. Thus strategies were put in place to reduce strain on the tourists. CityCentre, which completed construction in 2009 has fashioned their exterior design to facilitate pedestrian use. ${ }^{11}$ Footbridges, placed at many of the intersections, helped connect resorts and allowed traffic to run smoothly. Outdoor escalators also helped connect both sides of the strip. In addition to outdoor connections, there other newly formed means of transportation between the large-scale resorts. Linking the resorts from the MGM

9 Robert Venturi and Denise Scott Brown: Learning from Las Vegas 2007 ed. Samantha Hardingham. Abingdon England; New York: Routledge. 4

10 ibid. 69

11 Schumacher, Geoff. "The last megaresort?" Las Vegas News. December 4, 2009. http:// www.lvrj.com/opinion/the-last-megaresort-i-dont-think-so-78503102.html (accessed May 8, 2010). 
Grand northwards to the Sahara Casino resort, the monorail provides pedestrians access from above grade..$^{12}$ Each resort also offers free trams from retail attractions to casino live shows, thereby resolving many of the past isolation issues stemming from large properties. With several options connecting the urban fabric of the strip, the themed resorts designed their facades in order to entice passersby to approach their entrances. In addition to the roadside mega signs, resorts have sidewalk entertainment to announce their presence on the strip. The entrances offer an array of free visual shows from the dancing water fountain at Bellagio Resort, to the volcano eruption in front of the Mirage, to the pirate show at Treasure Island. Pedestrians gather along the sidewalks around each public spectacle that now forms the public realm.

In contrast to the expansive lots of the Strip, Fremont Street has retained its vintage neon signs and pedestrain scale. Patrons of Fremont Street and the city of Las Vegas launched 'The Fremont Street Experience' in 1994 and Fremont Street was officially closed to vehicular traffic to initiate a revival of the historic Las Vegas downtown. ${ }^{13}$ To compete with the draw of the Strip, The Jerde Partnership designed a space frame sheltering Fremont Street with light and sound creating a pedestrian mall filled with a multi- sensory show. The vaulted ceiling is animated daily while surrounding casinos and stores turn off their neon signs.

12 "Las Vegas Strip." Las Vegas, Nevada, United States. http://www.vegasnvus.com/Las Vegas_Strip.html (accessed May 8, 2010).

13 "Jerde : Fremont Street Experience.” The Jerde Partnership. http://www.jerde.com/projects project.php?id=58 (accessed June 28, 2010)

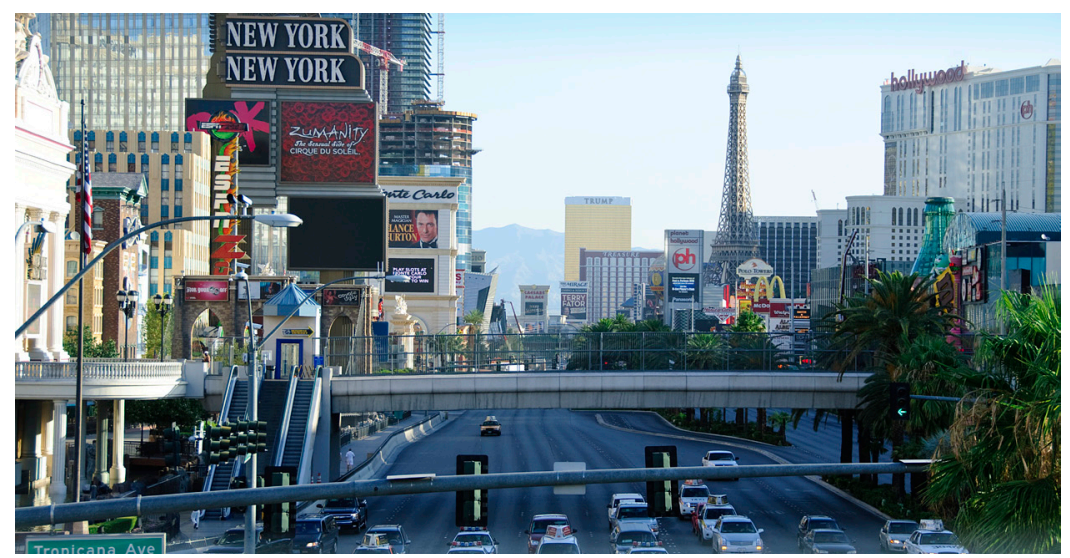

fig.2.1.6 one of the many pedestrian bridges and outdoor escalators along the strip to assist pedestrian crossing

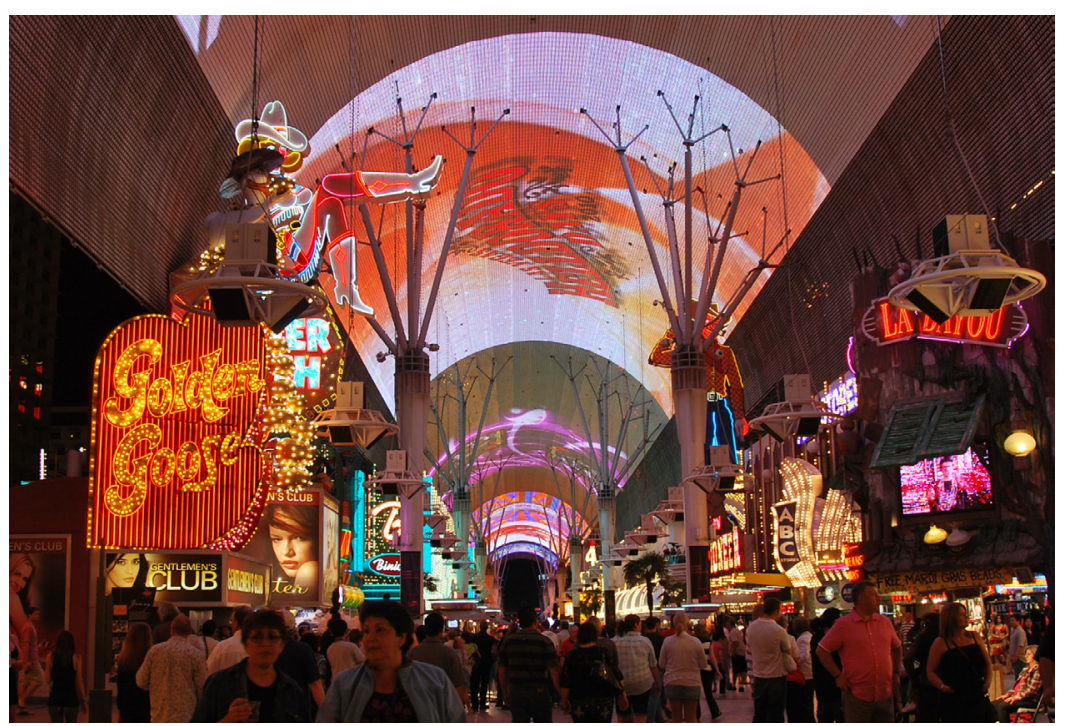

fig.2.1.7 Fremont Street Experience 


\section{Visual Assessment}

Since the relationship between drivers and roadside has changed in Las Vegas and large signs are no longer the main selling feature, signage has become more sophisticated by integrating with architecture. It has evolved from signs and building to buildings as signs. Through this architecture, spectators immediately know what to expect from each resort. The Strip has evolved from the two-dimensional highway sign with neon lights, to a competition of spectacle and light advertising the whole resort. The building tower, no longer the backdrop for the sign, has become the display at the entrance.

\section{Public Spaces}

Critics have argued that in Las Vegas "public space becomes private space, and private space pretends to be public space", ${ }^{14}$ all of which is privately owned and managed. However, from the perspective of the pedestrian, everything is a seamless flow of public space from the lobbies to casino floors, retail spaces to sidewalk, and ceremonial displays at the entrance. The connection from one free attraction to the next is rarely disrupted. Visitors have the freedom to experience everything that is visible to them. Each resort creates a distinct monument on its property, making it easy for visitors to locate themselves. Navigation and bearing are crucial elements of public space. Visual markers are key factors in creating pedestrian friendly environments where visitors know where they are, and have visual markers to guide them. ${ }^{15}$

14 Venturi et al. Learning from Las Vegas. 117

15 Lynch, Kevin. The Image of the City. London: The Mit Press, 1960. 83

\section{Strategies}

The Las Vegas strip has successfully managed its tourist traffic adapting to new consumer demands. As the public continually demands new forms of public interaction involving new technology.

\section{Design}

Many have described the architecture in Las Vegas strip as "kitsch" or "Disney-fied", but it remains as one of the most iconic sites. More and more the style and structures of buildings show sophistication, with increasing numbers of streamlined resorts and fewer themed hotels. The most recent Wynn hotels did not have themes but rather exuded luxury as its style. Resorts are also now looking at sustainable design in the context of today's eco-friendly consumer. Setting a new model for development on the strip, CityCentre's towers are LEED gold certified. ${ }^{16}$ The complex takes a slight departure from the themed mega resorts as it does not resemble a particular city but symbolizes an entire urban area. The high-density masterplan includes residential condos as well as amenities for daily living, such as a grocery store, the first on the strip. Structures are built right up to Las Vegas Boulevard, with the entire development becoming sidewalk entertainment.
16 Basulto, David. "City Center Las Vegas." ArchDaily, February 5, 2010. http://www. archdaily.com/50724/city-center-las-vegas-6-leed-gold-certifications/ (accessed May 9, 2010). 


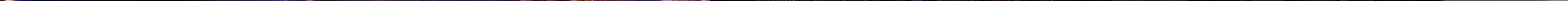




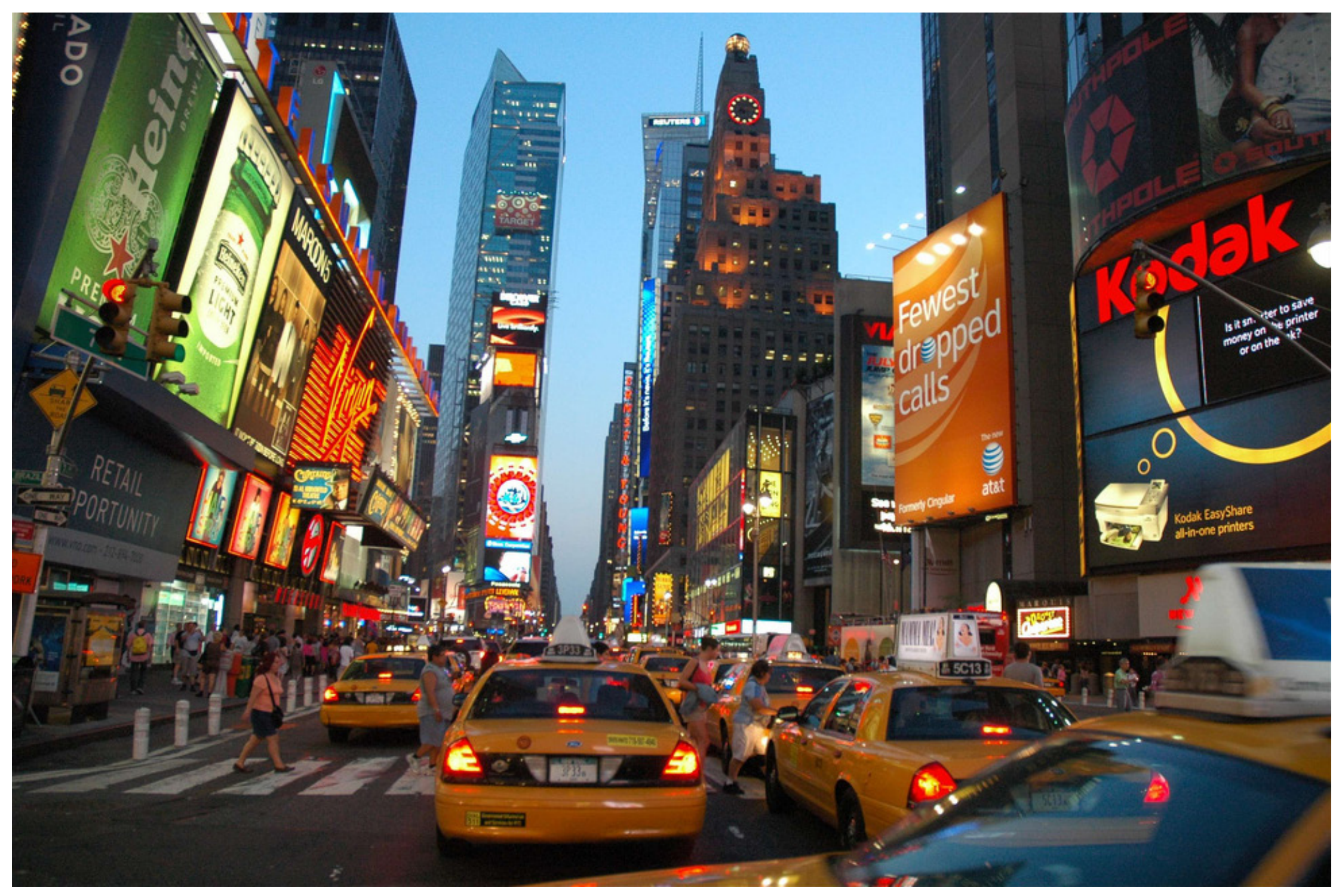

fig.2.2.1 Times Square 


\subsection{TIMES SQUARE, NEW YORK}

\section{AKA "The Crossroads of the World"}

Manhattan Area

$59.5 \mathrm{~km}^{2}$

Population as of $2008^{1}$

$1,634,795$

Density $27,490.9 / \mathrm{km}^{2}$

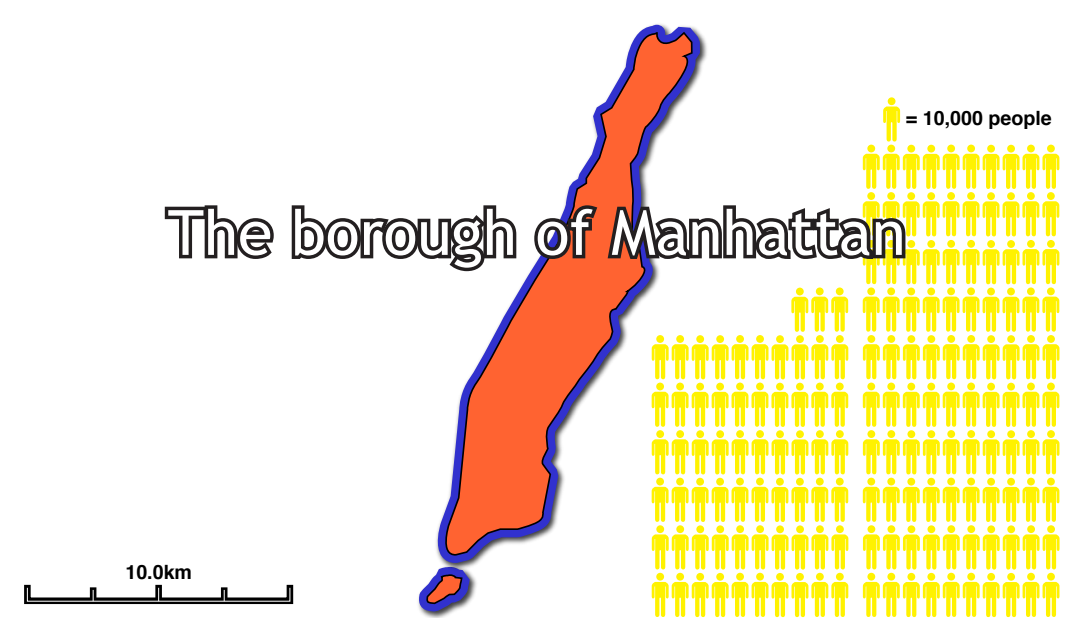

1 "Population." New York City Department of City Planning. www.nyc.gov/html/dcp/html/ census/popcur.shtml (accessed February 19, 2010).

\section{Historical Development}

In 1904, the New York Times moved to Longacre Square, renaming the location One Times Square (a.k.a. Times Square). ${ }^{1}$ Times Square grew to become one of the most sought after locations in Manhattan until the 1920s. At that time, prosperity brought about crime and corruption from gambling and prostitution. These lewd activities continued into the Great Depression. Since fewer people attended the theatre during the depression, business declined and the atmosphere of the area changed. The subsequent decades saw Times Square as a place tourists avoided because of its reputation as a dangerous neighborhood. ${ }^{2}$ Throughout the 1980 , redevelopment proposals were submitted with little response. By the 1990s, Times Square became notorious for drug trafficking and adult businesses which contributed to its decline. To mitigate this problem, a collaborative effort between the government and local businesses resulted in the formation of the "Times Square Alliance" in 1992. This team was committed to reviving the area. One successful effort, led by Mayor Rudolph Giuliani, occurred in the mid 1990s, which helped return Times Square to the thriving theatre district it once was. Various strategies included replacing many of the adult establishments

1 Sagalyn, Synne B. Time Square Roulette: Remaking the city icon. London: The MIT Press, 2001.39

2 Taylor, William R. Inventing Times Square: Commerce and Culture at the Crossroads of the World. New York: Russell Sage Foundation Publications, 1991. 181 
with tourist friendly attractions, reconstructing a safer and cleaner neighborhood, and providing more police presence. When the Walt Disney Company took ownership of the theatres in Times Square, it became clear that Times Square had cleaned up its reputation allowing for a family-friendly experience. Critics like Frank Rich, a columnist for the NY Times, argued that the shift took away any character that Times Square possessed, changing it from a historical theatre and red-light district to a New York themed-park controlled by large corporations ${ }^{3}$. Today Times Square occupies the blocks between Sixth and Eighth Avenues from east to west, and West 4oth and West 53rd Streets from south to north, making up the western part of the commercial area of Midtown Manhattan. The area splits into three properties owned by Disney, Warner Brothers, and Ford. It is now a thriving retail-based district teeming with shoppers and visitors day and night. ${ }^{4}$

\section{Authenticity and Traditions New Year's Eve}

The Times Square ball drop happens every New Year's Eve and has been a world famous televised event for many years. The tradition of celebrating New Year's Eve in Times Square started in 1904 when a fireworks display was held to celebrate both the new headquarters of the New York Times and the name change of the Square to One Times Square. ${ }^{5}$

3 Sagalyn, Synne B. Time Square Roulette: Remaking the city icon. London: The MIT Press, 2001. 464

4 Eliot, Marc. Down 42nd Street: Sex, Money, Culture, and Politics at the Crossroads of the World. New York: Warner Books, 2001. http://www.newyorkhistory.info/42nd-Street/ timessquare.html (accessed February 19, 2010).

5 Taylor, William R. Inventing Times Square: Commerce and Culture at the Crossroads of the World. New York: Russell Sage Foundation Publications, 1991. 42

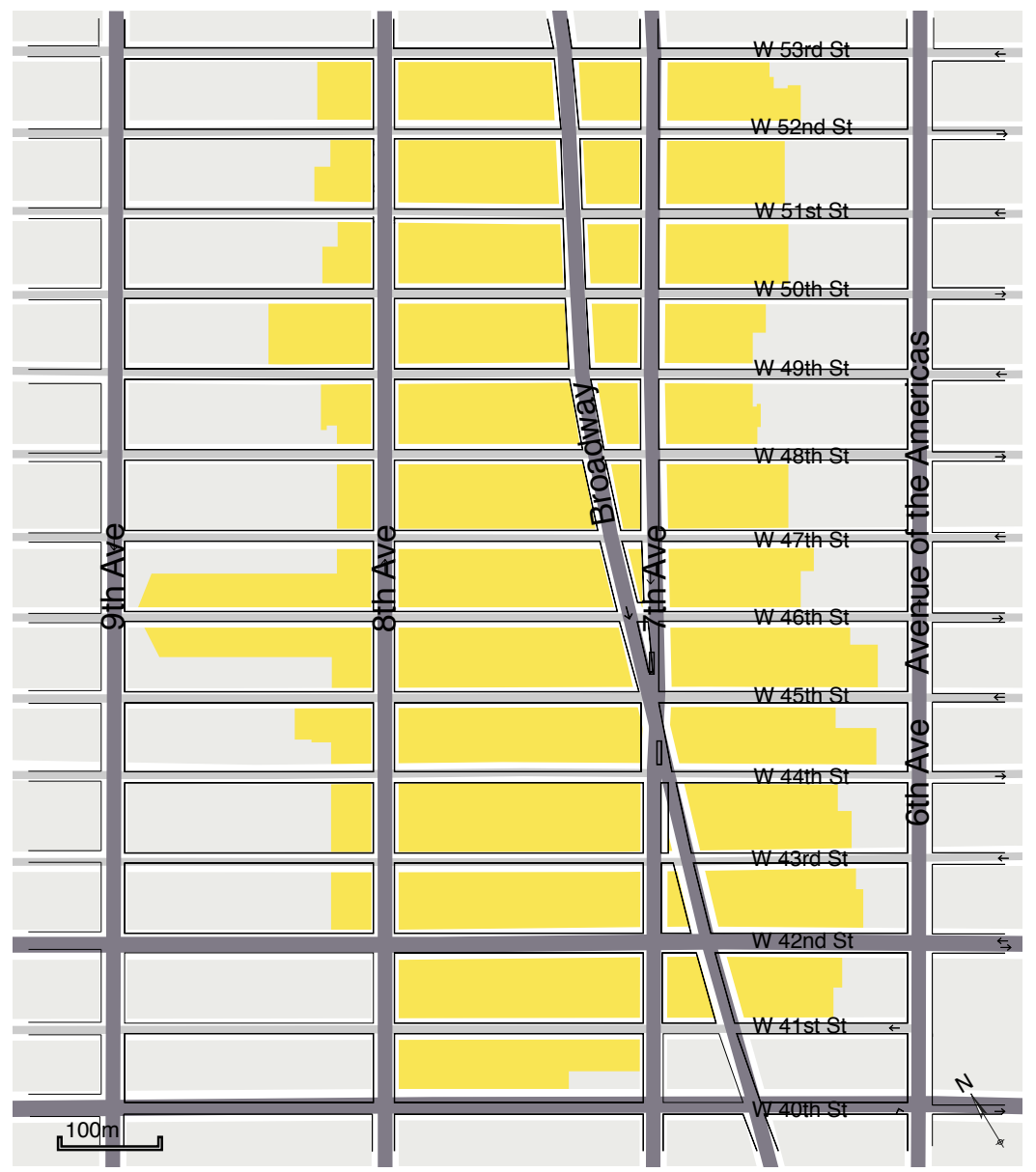

fig.2.2.2 map showing Times Square Alliance district boundary 


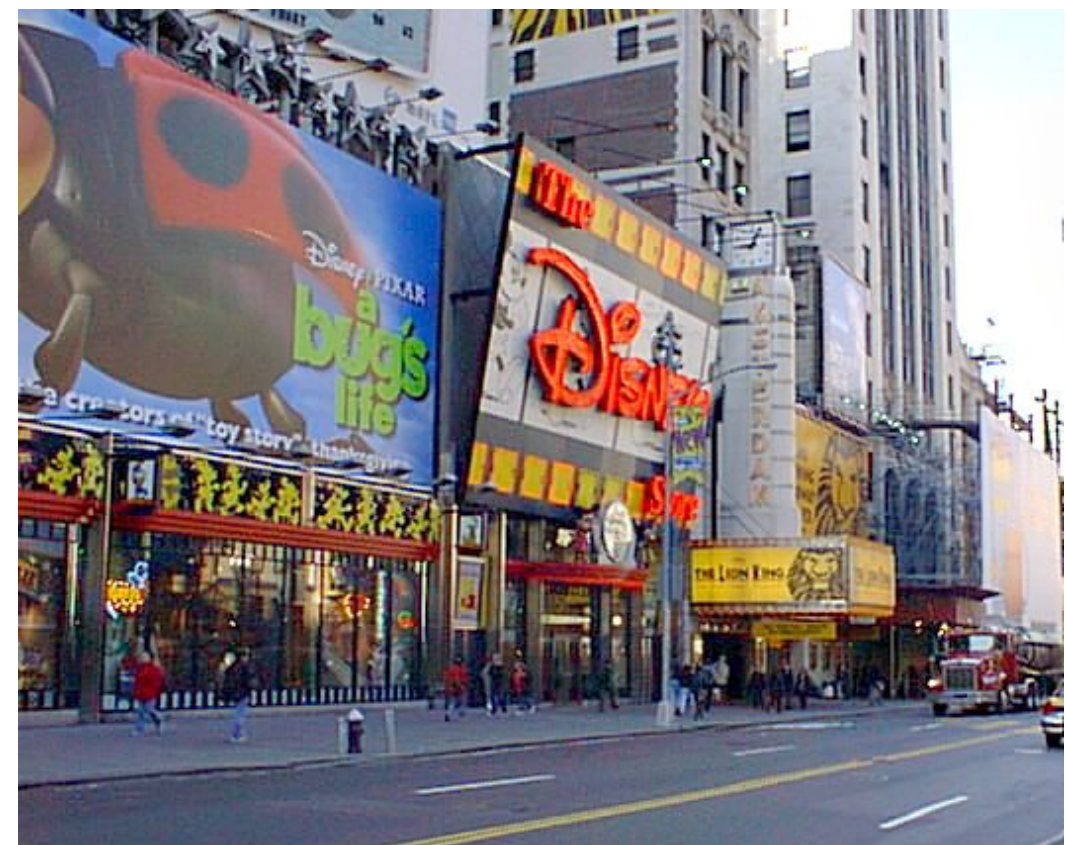

fig.2.2.3 Disney Theatre in Times Square 1998

\section{An Entertainment District}

Times Square's reputation as an entertainment district can be traced back to 1895 when businessman and theatre organizer Oscar Hammerstein created The Olympia, an entertainment complex on $42^{\text {nd }}$ Street. ${ }^{6}$ The success of this entertainment palace inspired subsequent theatres to locate there, and by World War I Times Square became the first theatre district in the nation. During the Great Depression theatergoers dwindled and many businesses were replaced with adult entertainment. Times Square became a "redlight" district. However after the "Disneyfication" of Times Square the place returned to its former self as a theatre district, featuring famed Broadway productions as well as many live audience shows. ${ }^{7}$ Times Square is also known as an area for 'people watching', as visitors from all over the world gather. As a public realm Times Square also features the interaction of actors, well known for their daily performances, with people on the street. Many will recall the 'naked cowboy' standing in the middle of Times Square, wearing underwear, cowboy boots and a hat, playing a guitar painted with the American flag. Another infamous character of Times Square is Reverend Billy, preaching to the crowd with a megaphone while wearing a white suit black shirt and clerical collar. He gathers protestors against the rampant consumerism evident in today's society and together they go around to different stores and touch cash registers as if to exorcise them from corporate evils. ${ }^{8}$

6 Taylor, William R. Inventing Times Square: Commerce and Culture at the Crossroads of the World. New York: Russell Sage Foundation Publications, 1991. 135

7 Sagalyn, Synne B. Time Square Roulette: Remaking the city icon. London: The MIT Press, 2001.7

8 "Sin, Salvation and Shopping in Times Square" Times Square. http://www.timessquare. com/New_York_City/Times_Square_NYC/Sin,_Salvation_and_Shopping_in_Times_Square/ (accessed February 21, 2010) 


\section{Thriving commercial district}

The commercial culture of Times Square can be attributed to its role as a tourist attraction. Sales often consist of impulse purchases of souvenirs. Visitors go there more for sightseeing than shopping, making it a great place to establish a brand culture by placing the flagship stores there for tourists. The commercial competition among retail stores in Times Square is as fierce as competition for billboards soaring above. The same stores can be found in most suburban malls, but in Times Square, they are especially decorated and ornamented to keep up with competition.

\section{Image}

The image of Times Square is strongly linked to the corporate billboards that occupy it. In the redevelopment of Times Square, international brands fused together to create a themed brand experience for the consumer. The district benefited from the 'clean' images of these corporations who used the historical roots of the legendary entertainment district to their advantage.

Times Square first became famous as a theatre district around the 1910s. The large crowds that it drew made it a prime location for advertising. Billboards were placed around the theatres and by 1917 the first electric billboard was used. Now, Times Square is so widely known for its spectacular display of lights that the zoning codes for the area require advertisements to be illuminated. ${ }^{9}$ The density of illuminated signs has made the area iconic. With all the signs

9 Sagalyn, Synne B. Time Square Roulette: Remaking the city icon. London: The MIT Press, 2001. 255

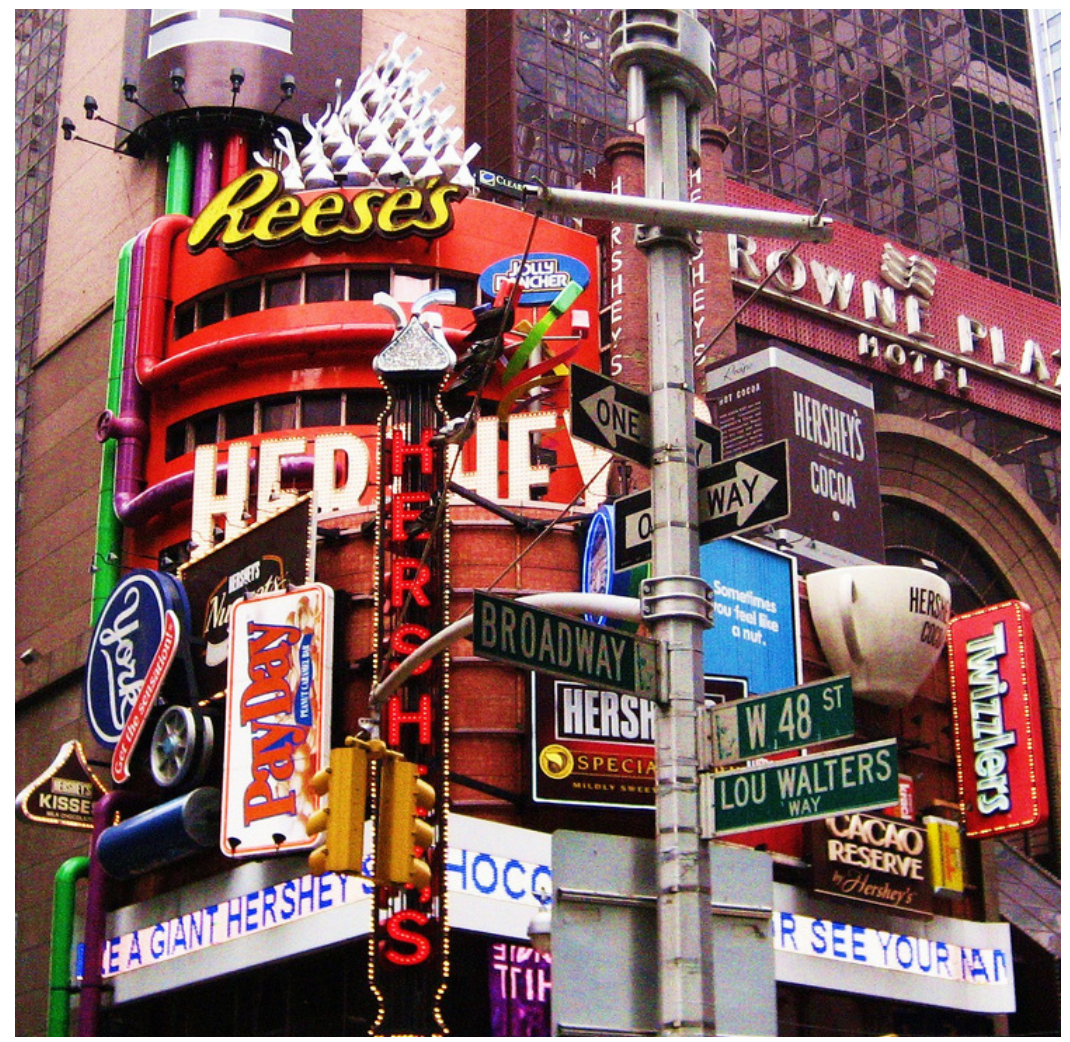

fig.2.2.5 the Hershey Store in Times Square is as much an attraction as a retail store 


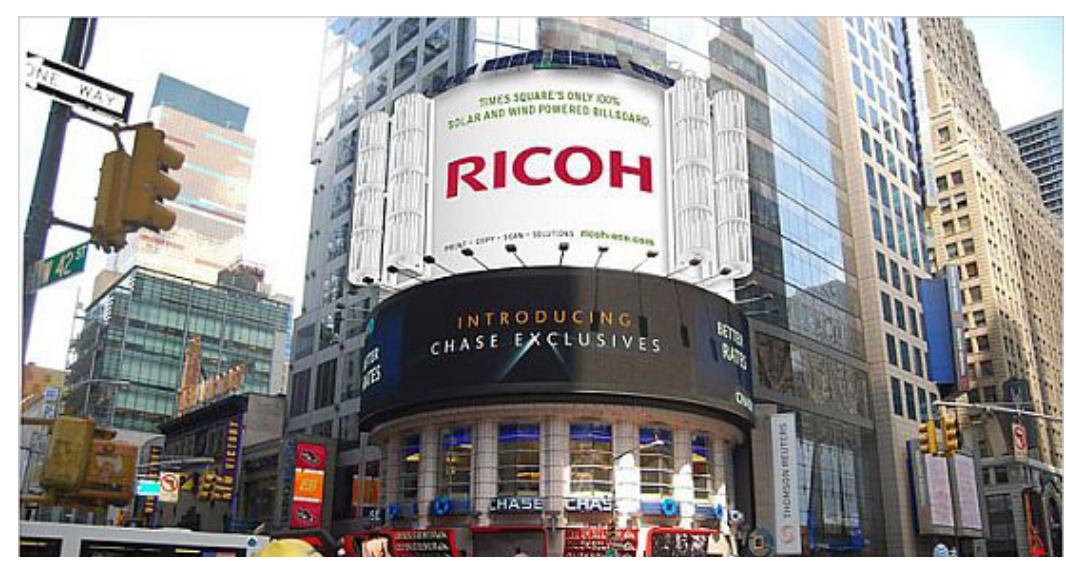

fig.2.2.6 The first solar and wind powered billboard in Times Square along the streets of Times Square, it is hard to single out particular examples but a few stand out. The Toshiba billboard that displays in high definition, directly under the New Year's Eve ball drop, is the most energy efficient sign in Times Square. Another example is the uniquely curved seven-storey NASDAQ sign erected in 2000 that stands at $36.6 \mathrm{~m} .^{10}$

\section{Digital Media}

The visual intensity and the dynamic contrasting colours of Times Square were created due to the fierce competition for space and attention. Graphics are designed for quick impact and short attention spans. The flickering lights moving in meaningless patterns catch the attentions of passerby. Advertisements that are not striving for attention fall into the background and just become "visual white noise". The popularity of Times Square continues to rise because of its ability to keep up with technological advancements. The amount of capital gained from commercial displays means the different mediums of communication must stay innovative and competitive. New York has a high concentration of media companies and many of them are located in and around Times Square. ${ }^{11}$ Times Square is a kind of laboratory for integrating the latest means of communication and testing their impact on the eyes of a populace. It is the city's headquarters for new media, with each firm showcasing its creativity and keeping pace with the global communications industry. Many of the billboards have turned from glowing static images to full-blown LED video screens. The area is even more exciting then ever. In 2008,

10 Sagalyn, Synne B. Time Square Roulette: Remaking the city icon. London: The MIT Press,
2001. 479 11 ibid. 450 
Times Square was fitted with the world's third environmentally friendly billboard. The Ricoh billboard is powered solely by wind and solar energy. The lighting works with 45 solar panels and 4 giant wind turbines but without any source for back up. The company does not seem to mind that it will be without advertisement during dark rainy days. ${ }^{12}$

\section{Pedestrian Friendly}

The public realm in Times Square has transformed from the hostile environment of the 1920 s into a friendly vibrant streetscape. It has increased its diversity of uses, from media headquarters broadcasting live television shows to themed restaurants and theatres. The number of visitors it attracts is overwhelming, to the point where it has actually become a liability to the city. Overcrowding has become a public safety hazard: as too many people crowd the sidewalks, many have began to walk on the roads. These rises in popularity pose new challenges for the public realm. Public officials now need a response to maintain pedestrian safety while continuing to support a commercially successful space.

On Memorial Day 2009, Mayor Michael Bloomberg closed off sections of Times Square to traffic, echoing pedestrian friendly strategies implemented in many high traffic areas around the world, such as Tokyo and Miami. The areas on Broadway from 42nd Street to 47th Street were transformed into pedestrian plazas for a trial period of a year. The success of it was clear and the next day the streets were filled

12 Collins, Glenn. "An Eco-Friendly Billboard for Times Square" The New York Times, November 14, 2008. http://www.nytimes.com/2008/11/15/nyregion/15billboard.html (accessed May 10, 2010).

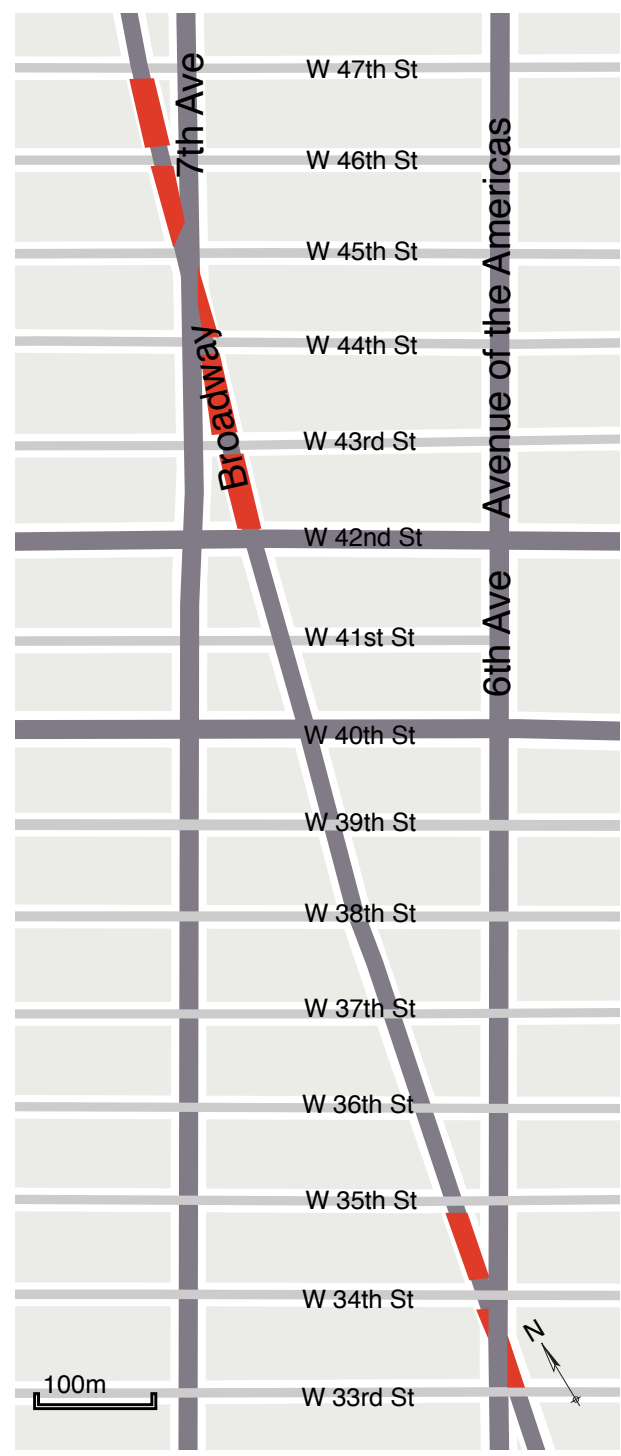

fig.2.2.7 map showing the sections on Broadway that are closed to vehicles 
with locals and tourists enjoying the spaces, bringing lawn chairs and playing catch on the asphalt lanes where taxis were once trapped in gridlock. As the former vehicular lanes of Times Square made way for pedestrians, they finally allowed for a view of the square from the visual centre. The street level experience was transformed from chaos to a framed square similar to an outdoor room. This allowed for greater appreciation of the structures that form the square. The dynamics changed from pedestrians having to view up against the tall structures from one side of the narrow sidewalks to allowing pedestrians to roam freely with their eyes looking up at the massive displays. ${ }^{13}$

\section{Design Strategies}

Times Square, an iconic symbol of New York City, is a place of nonstop energy. As a public space, however, it lacks the pull for visitors to return. Like many tourist attractions, people want to see it for the experience and are satisfied with a single visit; there is no desire to return the next day. Many residents also choose to avoid the area because of the crowds of tourists.

Certain design strategies work in favour of Times Square. It has all the benefits of being connected with 13 different subway stops and being within close walking distance of many other Manhattan attractions. The streets that cut across the pedestrian strips create esplanades between 45th and 47th Streets that form a generously scaled triangle for the crowds of Times Square. But despite all these

13 Ouroussoff, Nicolai. "Architecture Review - Lose the Cars, Keep the Grit." The New York Times, 25 May 2009. http://www.nytimes.com/2009/05/26/arts/design/26clos.html?_r=2 (accessed February 19, 2010). features, other factors work against the success of Times Square as a repeat attraction. The blocks between 42nd and 43rd are awkwardly defined and feel detached because the space is dissected into too many undefined pieces, and, since the implementation of pedestrian strips, these blocks have not been as successful. ${ }^{14}$ The squares need to feel more like squares. The space is available but amenities such as chairs and tables, to support a square are not. The instinct to focus on the spectacular has caused the building bases to be neglected, deterring gatherings from occurring at grade. ${ }^{15}$

The change to a pedestrian-only Times Square is drastic several more changes are necessary to catch up with the pace of tourists. The space provides few places to sit; those seats which are in place are not of the correct scale and style. But these can be finessed over time as the demand is present and the space is such an important place for so many people in New York.

14 Ouroussoff, Nicolai. "Architecture Review - Lose the Cars, Keep the Grit." The New York Times, 25 May 2009. http://www.nytimes.com/2009/05/26/arts/design/26clos.html?_r=2 (accessed February 19, 2010).

15 "Times Square | Project for Public Spaces (PPS)." Placemaking for Communities | Project for Public Spaces (PPS). http://www.pps.org/info/projects/transportation_projects/ timessquare/ (accessed February 19, 2010) 

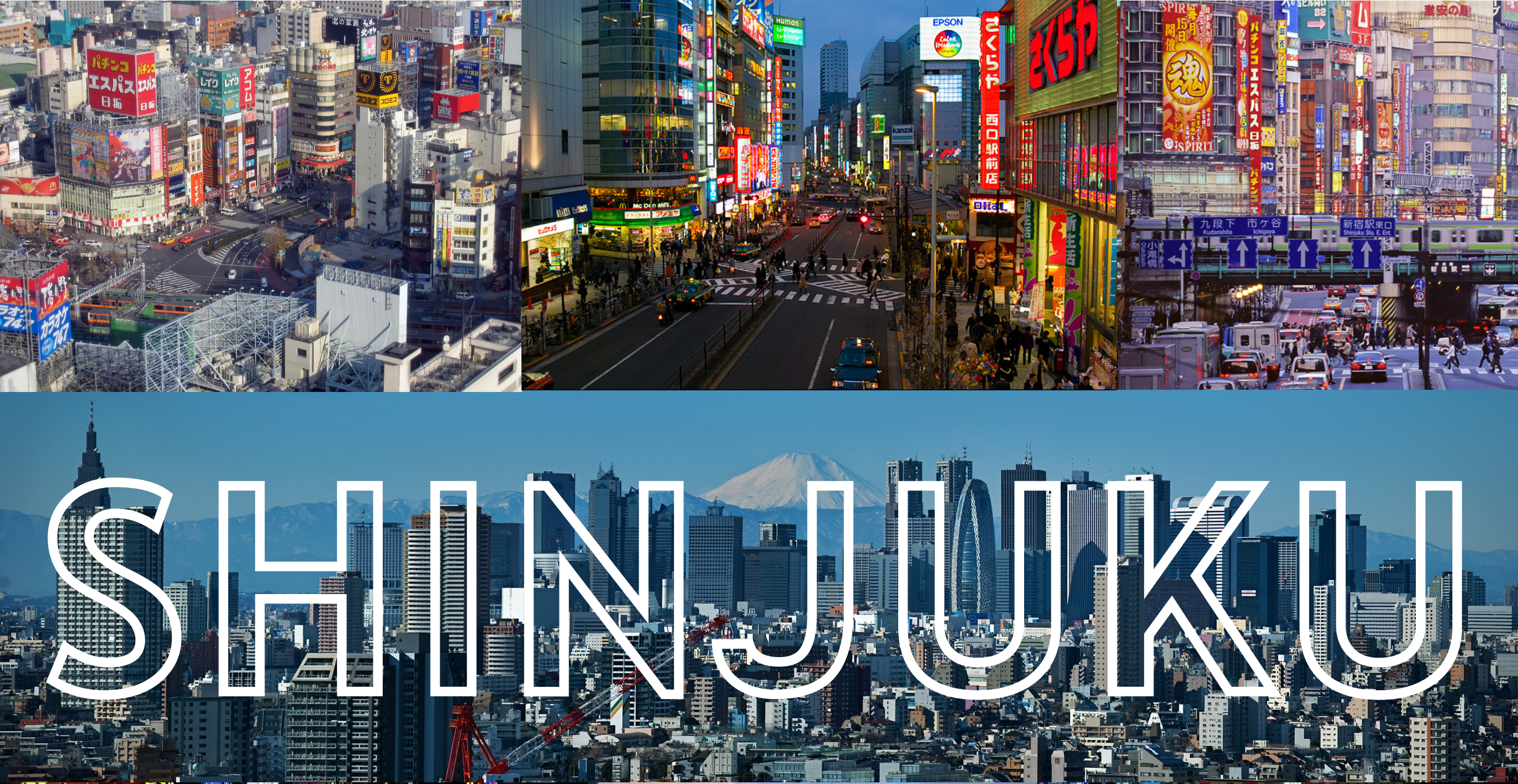

(1)
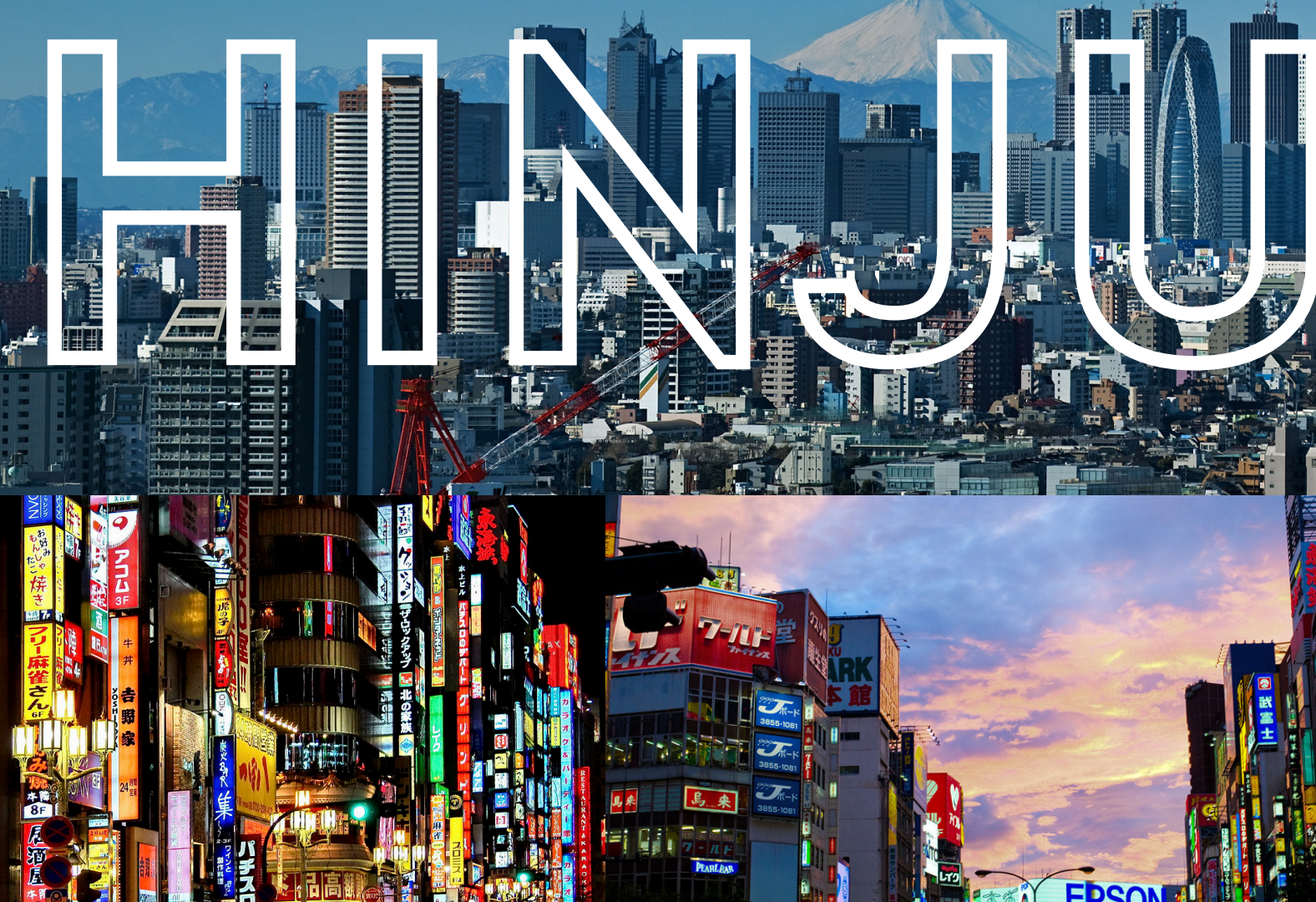

Itis

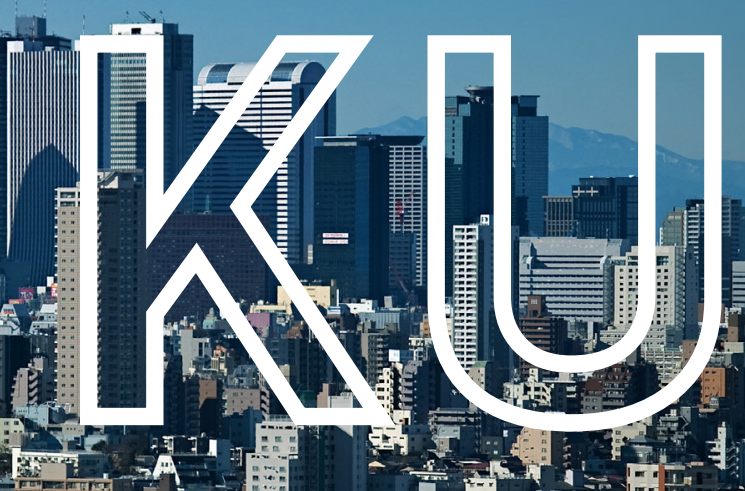

b

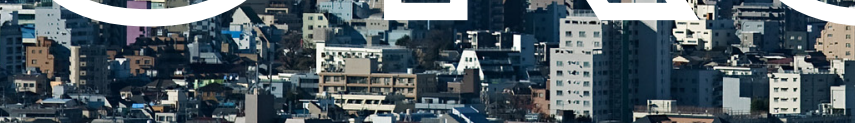

P.t.

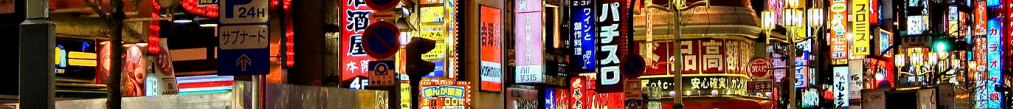

r.
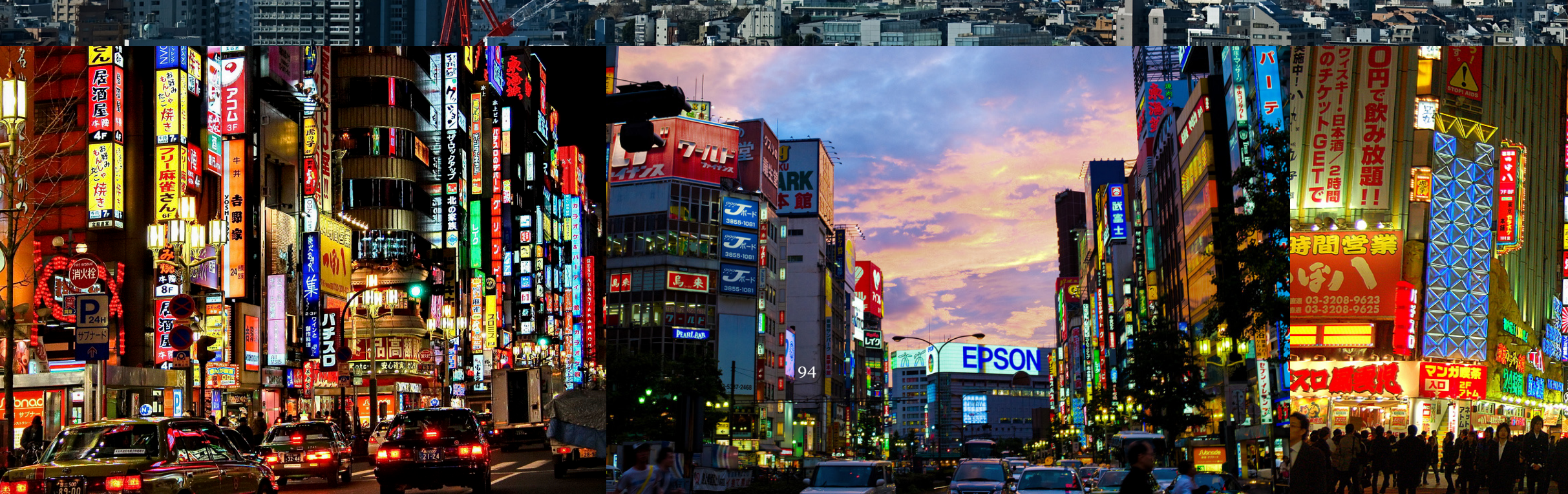

:

.

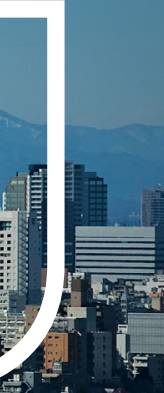

Q1

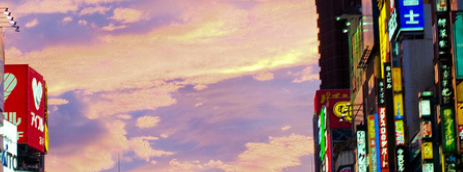

16.6.

2
1
1

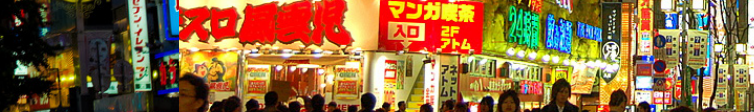
15ive in et 


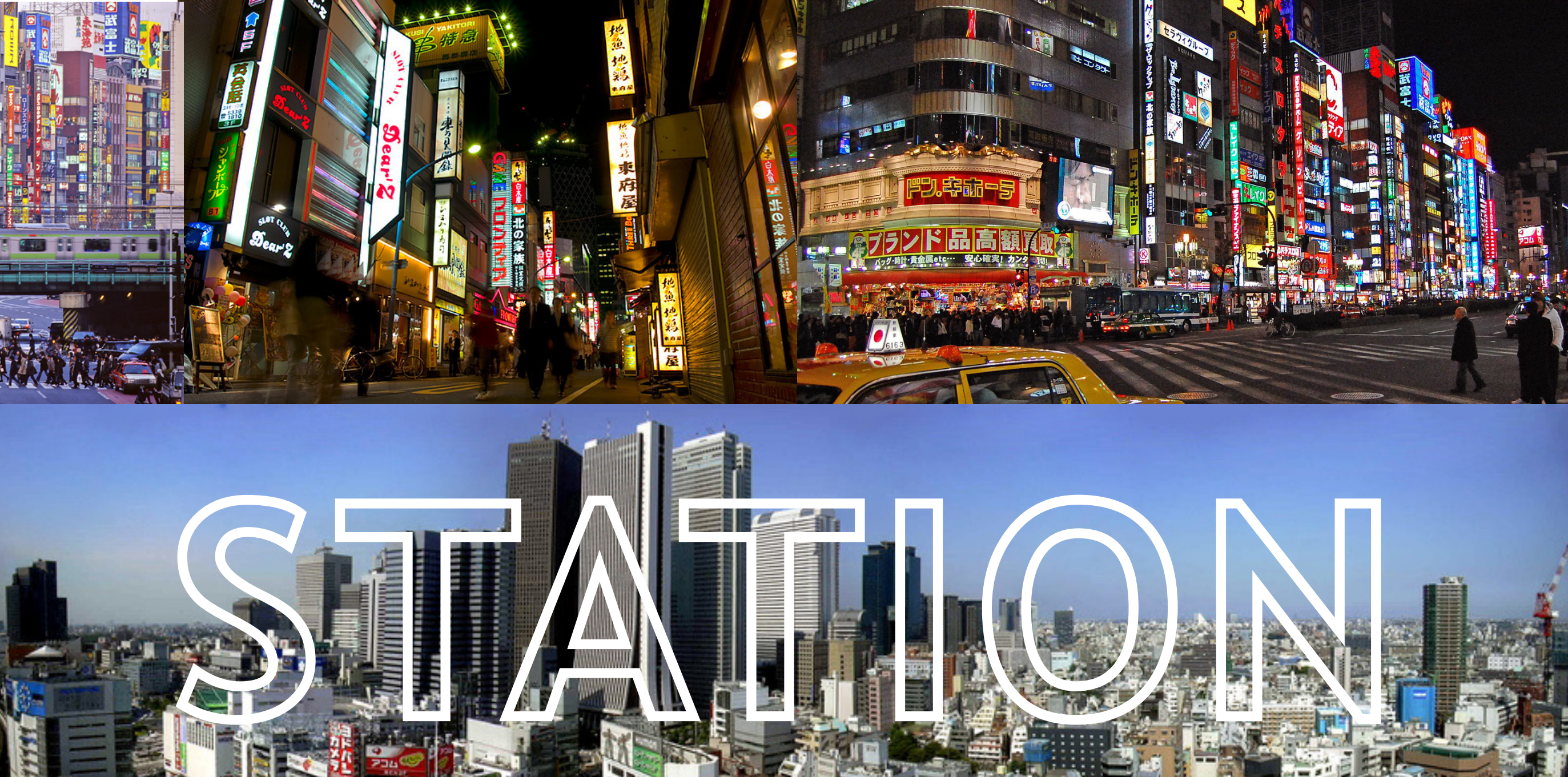




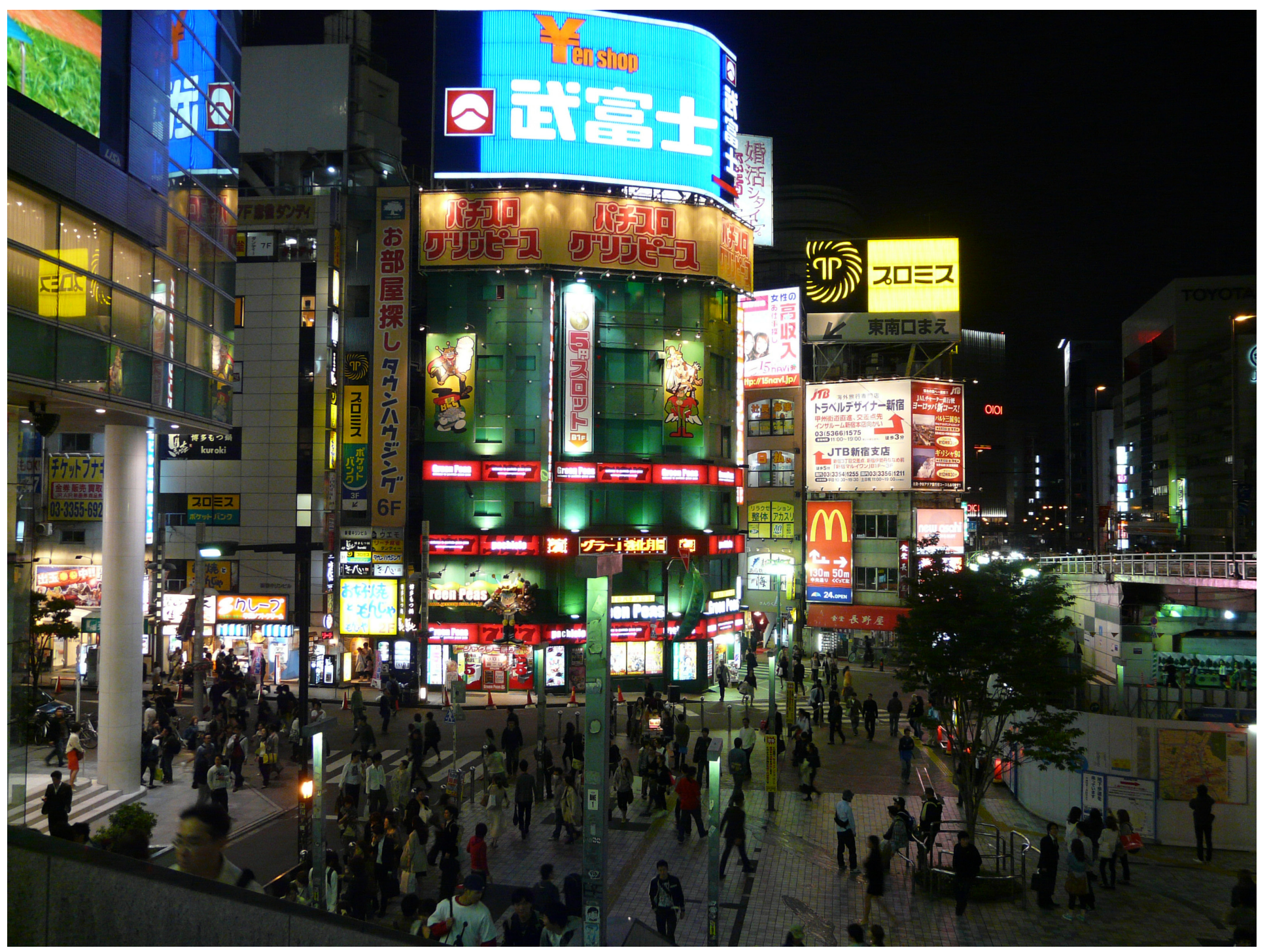

fig.2.3.1 Outside Shinjuku station's south west exit 


\subsection{SHINJUKU, TOKYO}

The busiest train station in the world

Area

$18.23 \mathrm{~km}^{2}$

Population as of $2009^{1}$

314,592

Density $17,460 / \mathrm{km}^{2}$

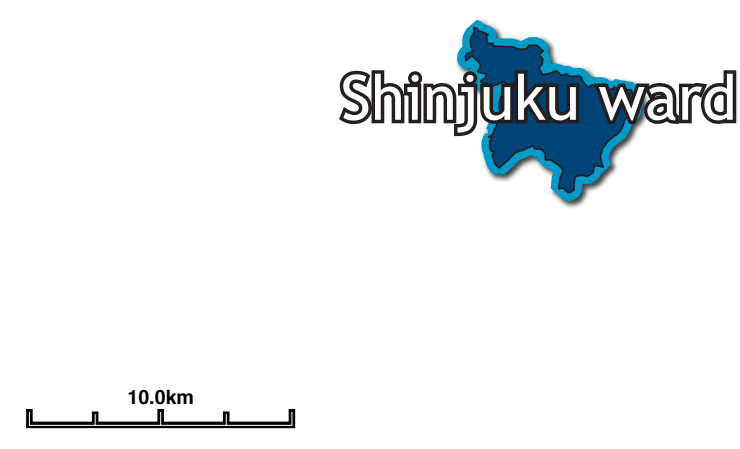

$=10,000$ people

1 "Description of Shinjuku." Shinjuku City Official Website. http://www.city.shinjuku.lg.jp/ foreign/english/aramashi/gaiyou/gaiyou.html (accessed February 20, 2010).

\section{Historical Development}

Urbanization of Shinjuku occurred early, in the Edo period around the 1630 s. When the outer moat of Edo Castle was built, many temples and shrines moved to the Yotsuya area located on the western edge of Shinjuku. The development of the railroad system in the 1860 os provided access from the suburbs to the metropolis through public transportation. Shinjuku station originally opened in 1885 and started as a primary stop for this small town. Having minimal traffic, it was eventually absorbed into a major line, which increased its traffic flow substantially. ${ }^{1}$ The Shinjuku of today is a result of an earthquake that occurred in 1923, which left the surrounding areas severely damaged. This is one of the reasons why the Shinjuku skyline is dominated by skyscrapers. ${ }^{2}$ After World War II, many of the structures around Shinjuku station were destroyed. However, the roads and rail lines - although damaged - were reconstructed, forming the centre of Shinjuku today. Shinjuku ward was established in 1947 when three wards merged together to form what is currently Shinjuku ward. ${ }^{3}$ The city grew rapidly as a downtown district. Despite the competition with neighboring districts it was still able to keep

\footnotetext{
1 "Description of Shinjuku." Shinjuku City Official Website. http://www.city.shinjuku.lg.jp/ foreign/english/aramashi/gaiyou/gaiyou.html (accessed February 20, 2010).

2 "Shinjuku | Japan Travel Guide." Japan Guidebook | Online Travel Guide to Tokyo. http:// www.japanguidebook.com/travel/shinjuku-travel-guide-71.html (accessed February 20, 2010).

3 "History of Shinjuku." Shinjuku City Official Website. http://www.city.shinjuku.lg.jp/ foreign/english/aramashi/rekishi/rekishi.html (accessed February 20, 2010).
} 
pace with department stores, theatres and cafes. In 1991, the Tokyo Metropolitan Government moved to its current building in Shinjuku, where it has now become the centre for both commercialism and government administration. ${ }^{4}$

\section{Public space and city fabric}

Tokyo is divided up into 23 wards one of which is Shinjuku. The combination of department stores, lively retail streets, the Tokyo Metropolitan Government Building, and even a quiet historical stonepaved residential area makes Shinjuku a unique centre for Tokyo. The many feature of Shinjuku require major transit to accommodate traffic to the area. Shinjuku Station is the busiest station in the world with an estimated 3.64 million passengers passing through daily. The heaviest traffic occurs between 7 a.m. to 10:30 p.m. each day. It is a multi-use transfer point for all the main lines of mass transit in Tokyo. The station covers approximately 15 acres and consists of three subway lines and four light rail train companies, all of which conveniently connect to department stores and hotels that the train companies own, which could help to explain the successful relationship between commercial entities and transportation. People are able to transition between bus terminals through conveniently located shops. After-work activities in underground passages connect all the nearby office towers and two high-rise department stores. There is even space made for cultural events and performances. Although at first glance the station might appear to be box-like and overwhelming, navigation of the web is made easy with clear signs in both Japanese and English. There are three main exits: the east exits

\footnotetext{
4 “Area Guides: Shinjuku | TCVB - Tokyo Convention \& Visitors Bureau." Tokyo Convention \& Visitors Bureau. http://www.tcvb.or.jp/en/guide/area05.html (accessed February 20, 2010).
}

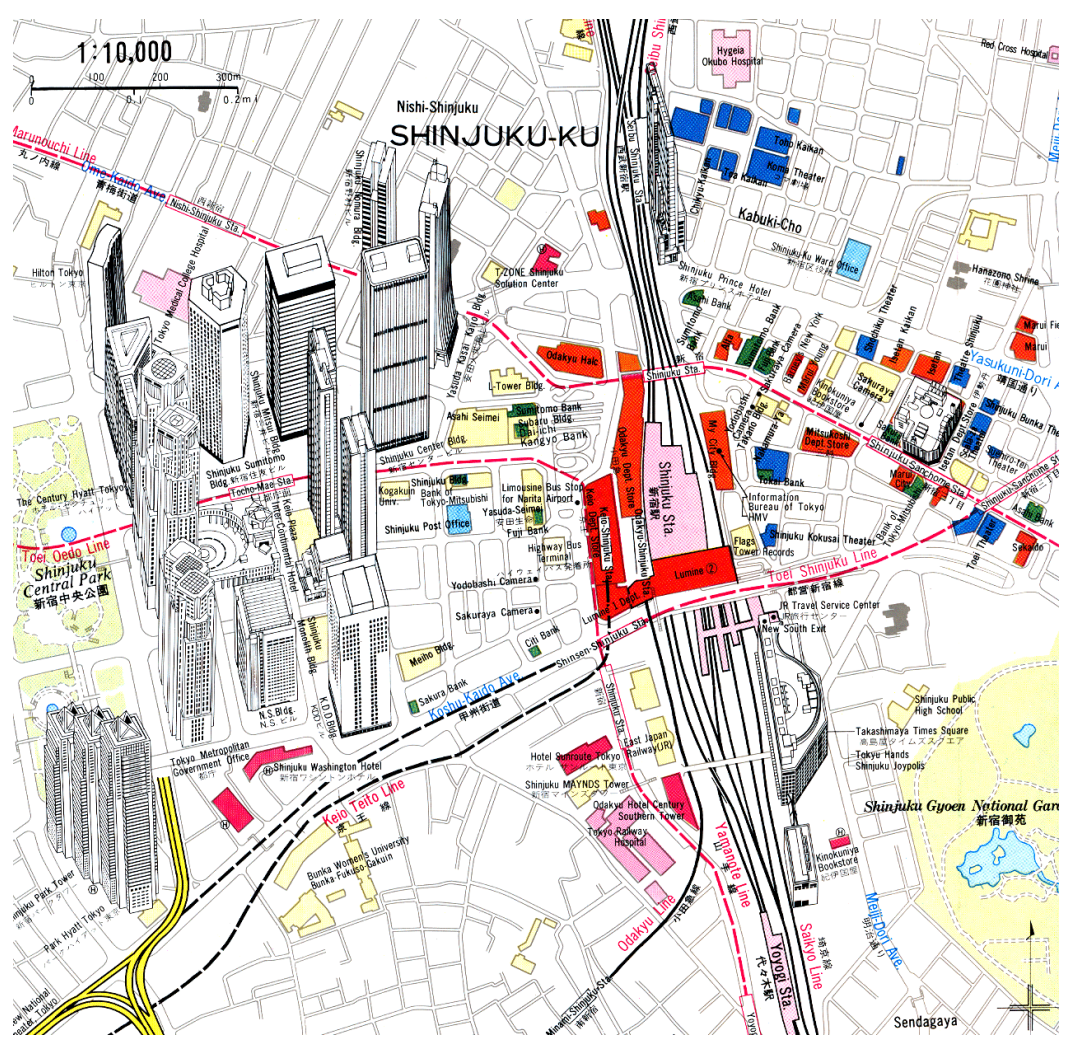

fig.2.3.2 map of Shinjuku area highlighting Shinjuku Station and the many departments stores and government towers connected to it 


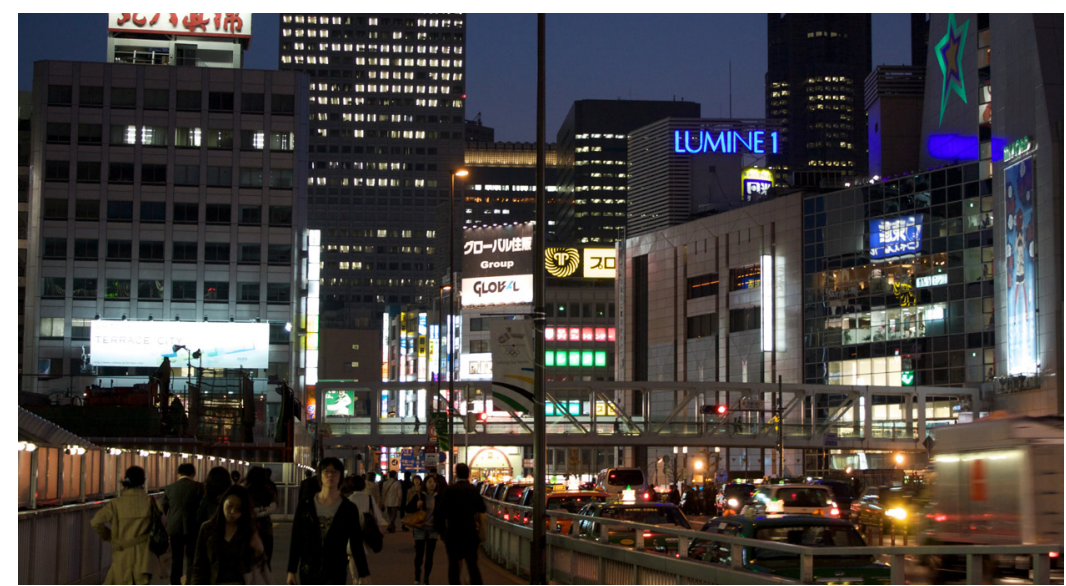

fig.2.3.3 Shinjuku Station south exit

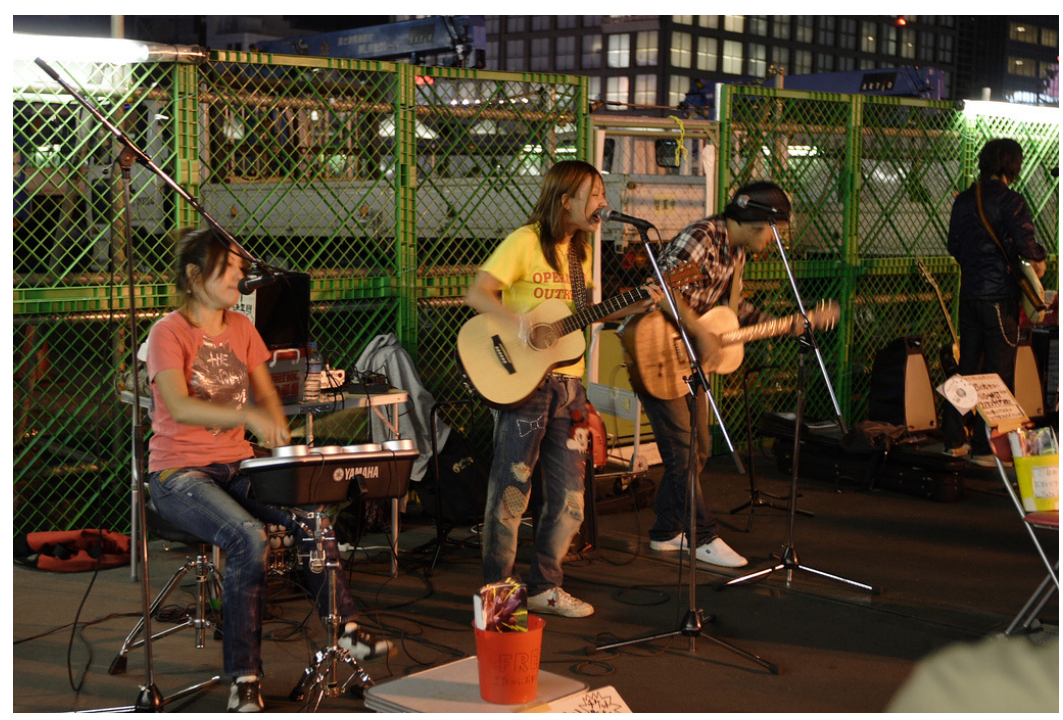

fig.2.3.4 street musicians at the south exit of Shinjuku station onto the street level retail shopping area, the south exits onto the Times Square Shopping Centre, and the West exists which open up to skyscrapers, a business zone and government towers surrounding an open square. Pedestrian walkways connect many of the sidewalks that bypass the busy intersections outside the station. This station is thought of as a meeting place for many individuals because it is the centre where all major train lines in Tokyo converge, and all exits of the station flow into the city. ${ }^{5}$

\section{Authenticity}

Street music is popular at train stations, particularly at Shinjuku Station given the large amount of commuter traffic. Live music from traditional Japanese drums to Jazz is audible from the streets and sidewalks outside the station, People gather to watch performances, creating a lively and creative atmosphere for the streets. With its popularity in Japan, Shinjuku offers great experiences for both the musician and the audience. Quality performances draw large crowds regardless of weather conditions. ${ }^{6}$ The area is both a transition zone as well as a destination constantly drawing crowds. The variety of retail stores, restaurants and street entertainment make it a commercial, practical, and leisurely area. The relationships between all the various amenities and Shinjuku Station make this a successful node within Tokyo: "In Shinjuku district there are more such streets to savor than in most U.S. cities put together, and for sheer sensory impact there is nothing to match its back alleys with their charcoal grills and smells and clouds of smoke."

5 Tarce, Amy. "Shinjuku Eki (Train Station) - Great Public Spaces | Project for Public Spaces (PPS)." Placemaking for Communities | Project for Public Spaces (PPS). http://www.pps.org great public spaces/one?public place id=761\&type id=0\# (accessed February 20, 2010).

6 "Street music «Tokyo Green Space." Tokyo Green Space. http://tokyogreenspace. com/2009/12/20/street-music/ (accessed February 20, 2010).

7 Whyte, William H. City: Rediscovering the Center. New York: Doubleday, 1988. 88 


\section{Image}

Despite the amount of traffic Shinjuku Station witnesses in a day, the space is remarkably clean. ${ }^{8}$ These conditions combined with a well-lit space provide an overall feeling of safety and comfort. The presence of a police station located inside Shinjuku Station further contributes to feelings of public safety.

\section{Pedestrian Friendly}

In response to environmental concerns and the clutter of pedestrian traffic, Japan introduced 'hokousha tengoku' - pedestrian heaven in Japanese - for Shinjuku and other dense commercial districts. Much like Times Square, 'Pedestrian heaven' reduces pedestrian congestion by closing off vehicular roads. Unlike Times Square, however, it happens only on weekends and holidays. The concept has been successful because small stretches of major roads are made pedestrian only and locals are found walking their pets and drifting casually across the laneways. ${ }^{9}$

8 Tarce, Amy. "Shinjuku Eki (Train Station) - Great Public Spaces | Project for Public Spaces (PPS).” Placemaking for Communities | Project for Public Spaces (PPS). http://www.pps.org/ great_public_spaces/one?public_place_id=761\&type_id $=0 \#$ (accessed February 20, 2010).

9 "Reclaiming streets beyond pedestrian heaven " Tokyo Green Space." Tokyo Green Space. http://tokyogreenspace.com/2009/09/28/reclaiming-streets-beyond-pedestrian-heaven/ (accessed February 20, 2010).

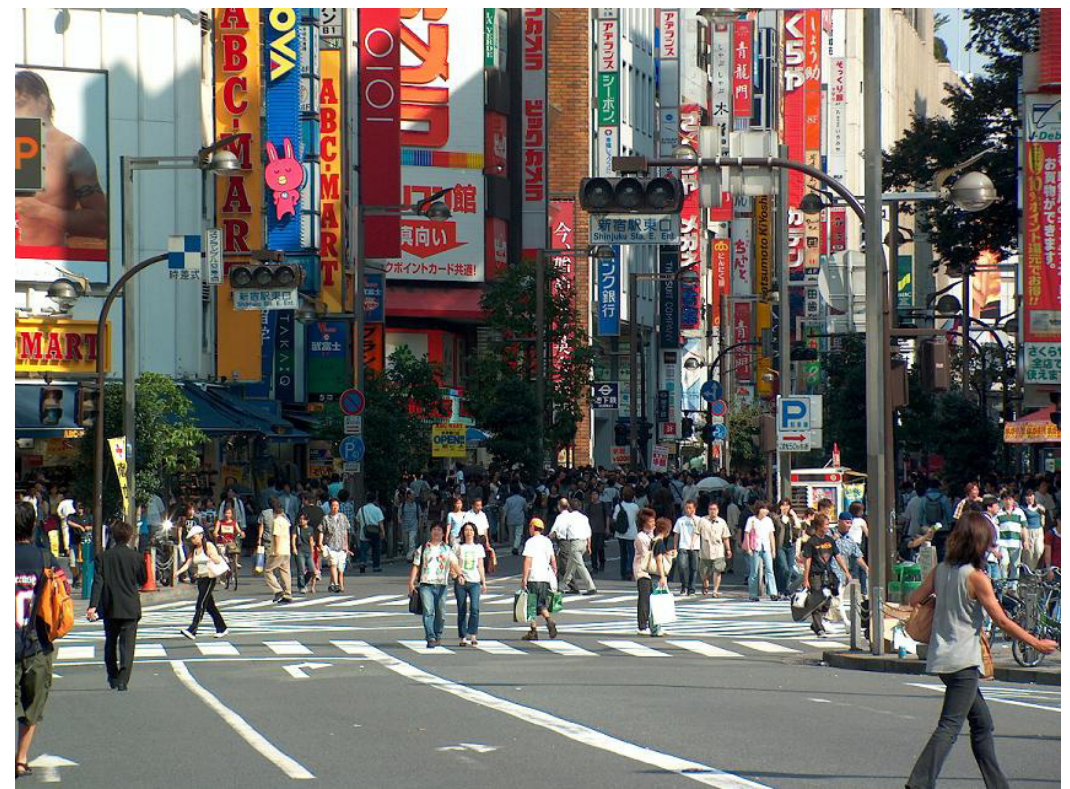

fig.2.3.5 Shinjuku street has practiced 'hokousha tengoku' or 'pedestrian heaven' every Sunday since 1970 


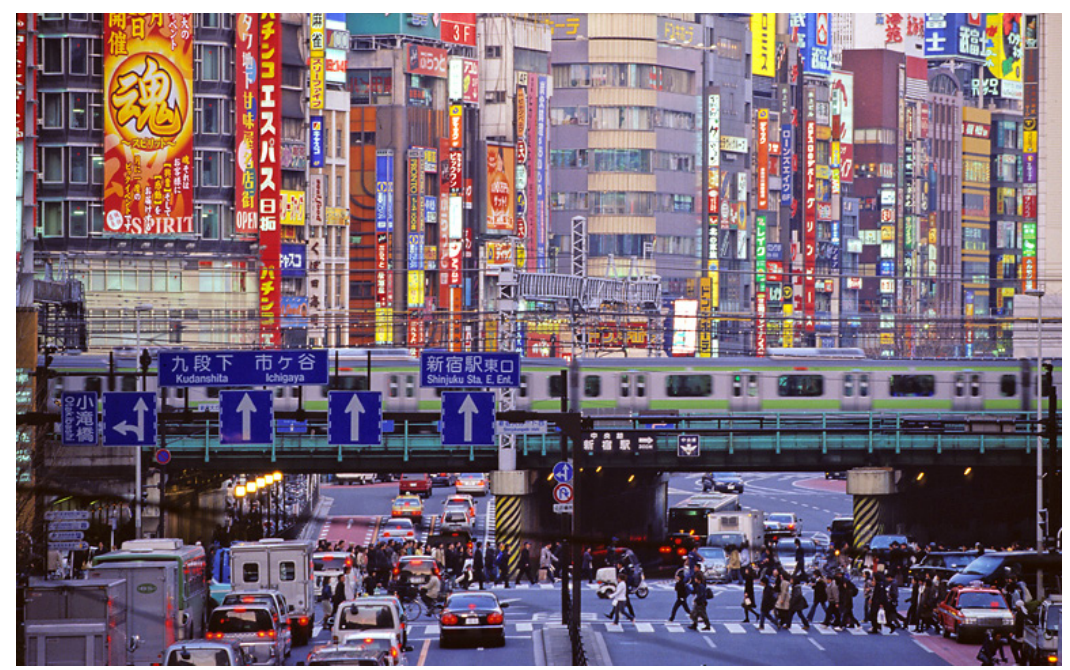

fig.2.3.6 busy streets of Shinjuku with the Yamanote train in foreground

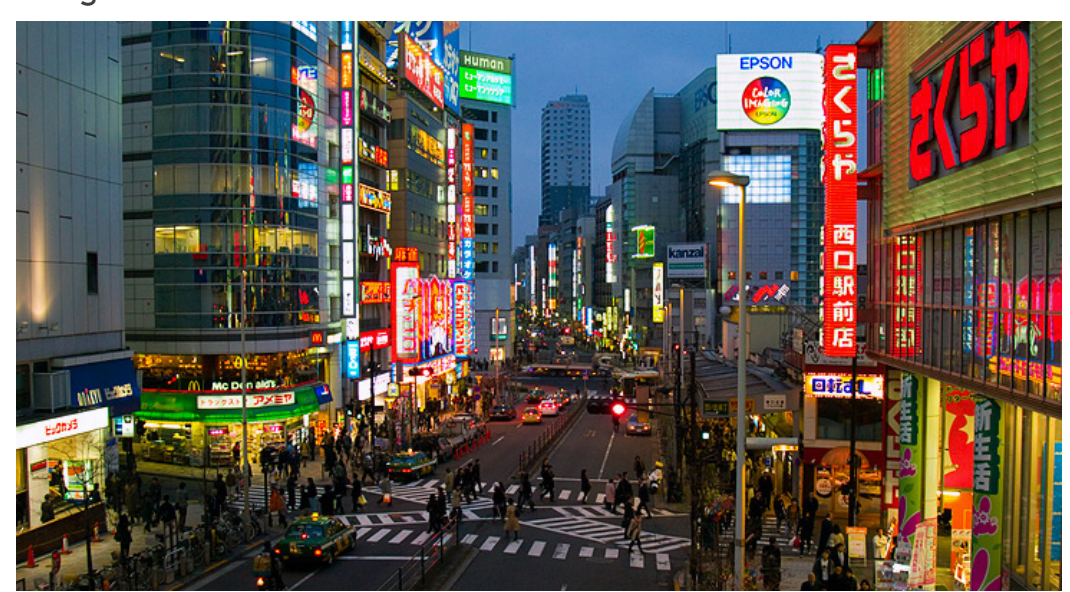

fig.2.3.7 Shinjuku's active street life and array of neon signs in the evening

\section{Visual Assessment}

Shinjuku station may draw crowds as an inevitability, as the transportation centre of Tokyo. Yet, it still manages to attract the public outside of a need for transportation. The variety of amenities offered at Shinjuku provides "something for everyone" whether they are looking for theatre entertainment, shopping, or other tourists. Right outside the station, there are a variety of public realms, offering spacious squares, public performance spaces, busy intersections, crowded sidewalks, and intimate atmospheric alleyways. Everything and everyone is conveniently connected:

Mile after mile, Tokyo's streets are consistently more interesting than ours. Mixture is one reason. The Japanese do not use zoning to enforce a rigid separation of uses, but instead encourage different uses, side by side and upward - shops, showrooms, pachinko parlors, restaurants piled on top of restaurants, four or five stories or more. ${ }^{10}$ 



\subsection{EIGHT DESIGN PRINCIPLES for the use of digital media in Public Space}

As our society becomes increasingly more isolated, it is more challenging to entice members of the community to enjoy the outdoors and come together in public spaces. Artists, architects, and designers can all help with the challenges of creating successful community spaces. First and foremost, the use of digital media facades can initiate new modes of interaction within public spaces. This strategy involves artistic originality and calls for the effectiveness of commercial branding. As much of the visual landscape is taken over by aggressive consumerism, it is crucial to engage the public and return control of the visual landscape to the public. The following principles - as presented below - are based on elements observed in various successful public spaces enhanced by digital media projects as well as historical examples of successful public spaces. These principles also helped shape the design application presented at the end of this thesis.

\section{Artist Installation / Creativity}

Most architectural environments are visually unrestricted; they are ultimately forms of public art. Thus, it is in our best interest to capitalize on architecture in public space to create environments that draw the public. Digital facades have the ability to maintain the physical elements of a structure while changing the visuals. Buildings are valuable canvases for artists to reach out to the public. Ideas expressed in art can enrich the cultural experience of a city and needs 
to be accessible by all. Scott Mcquire explains in 'The Media City': "A crucial role for new media art in public space is the potential to avoid the filter of sites such as the art gallery, and thereby engage audiences who might never cross that threshold." While focusing on the installation, the viewer is also exposed to the details of the architecture creating conversation and debate on the presence and current state of a community's neighborhood. Individual awareness is increased while promoting expression within the community. Through public discourse, viewers are encouraged to understand and respect various community spaces, members, and groups. ${ }^{2}$ By providing a communication form specifically for art, digital media as public installation becomes a platform for constructing social relationships between local artists, the city and the community. The digital facade provides a high-profile venue for emerging artists as well as the city itself for a positive cycle of creative flow between a community its artists.

Artistscanalsoofferinsightsintolocalissuesthroughtheirinstallations. The placement of artist's projects brings new programming into public space, injecting spaces with inspiration and creativity. A space can suddenly attract a volume of movement and activity that such spaces would not ordinarily encounter. This injection of density on certain event dates becomes an integral part of a city's social fabric. Digital facades enriche the urban landscape with a theatre featuring diverse forms of creativity through performances, art, and events.

1 Mcquire, Scott. "Performing Public Space." In The Media City: Media, Architecture an Urban Space (Published in association with Theory, Culture \& Society). Thousand Oaks, CA Sage Publications Ltd, 2008. 149.

2 "Public art and design checklist: What is public art?" Welcome to Arts SA. http://www.arts. sa.gov.au/site/page.cfm?u=291 (accessed June 22, 2009)

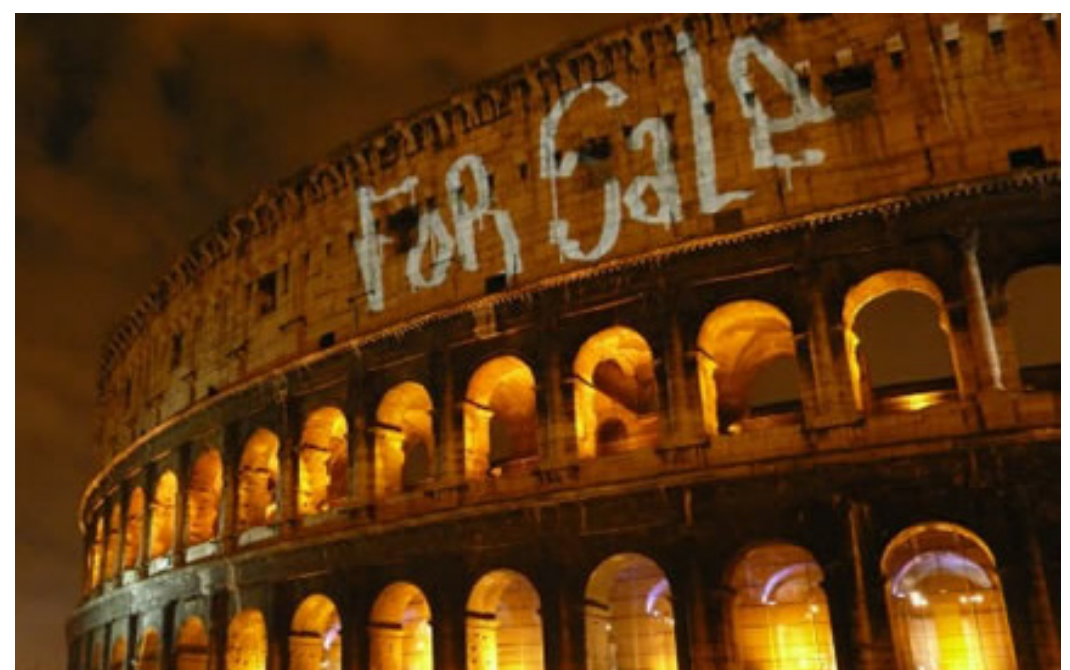

fig.2.4.1 G.R.L presented their project L.A.S.E.R. TAG on Rome's Colosseum in 2007

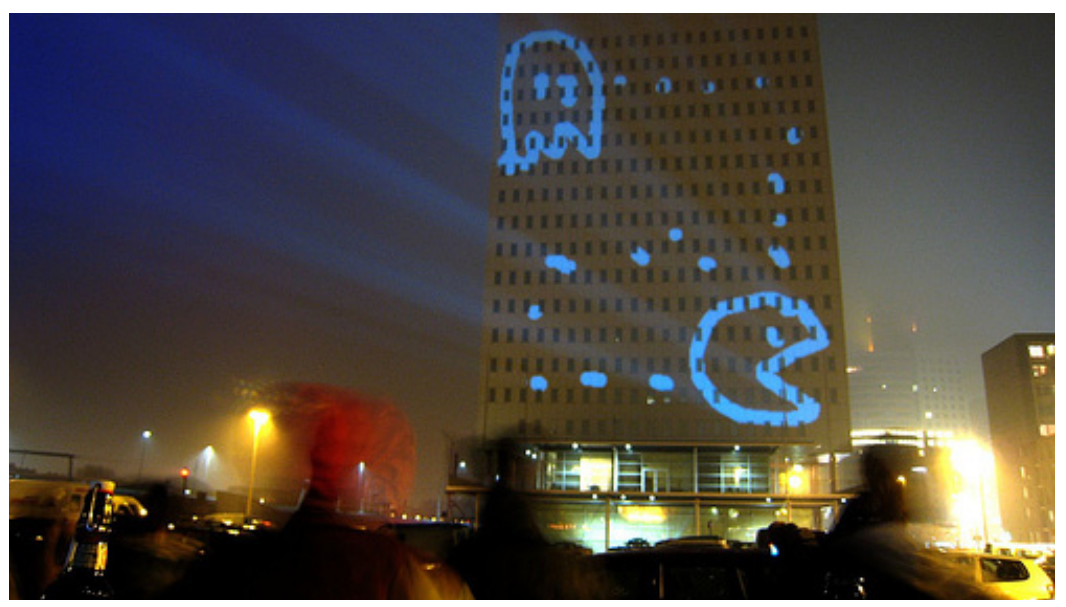

fig.2.4.2 display of 'L.A.S.E.R TAG' on G.R.L.'s Rotterdam tour 


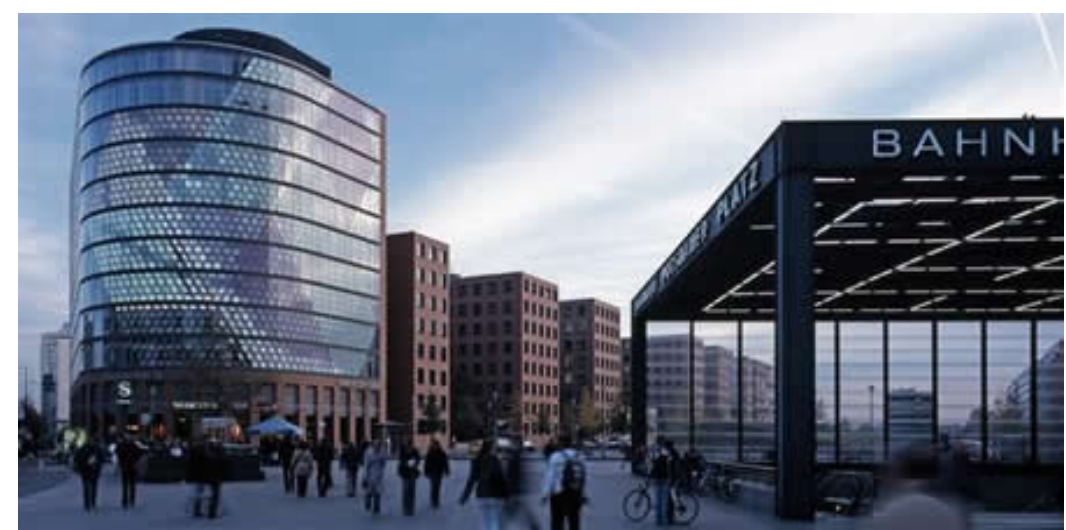

fig.2.4.3 Spots Installation in Potsdamer Platz. Berlin, Germany 2006

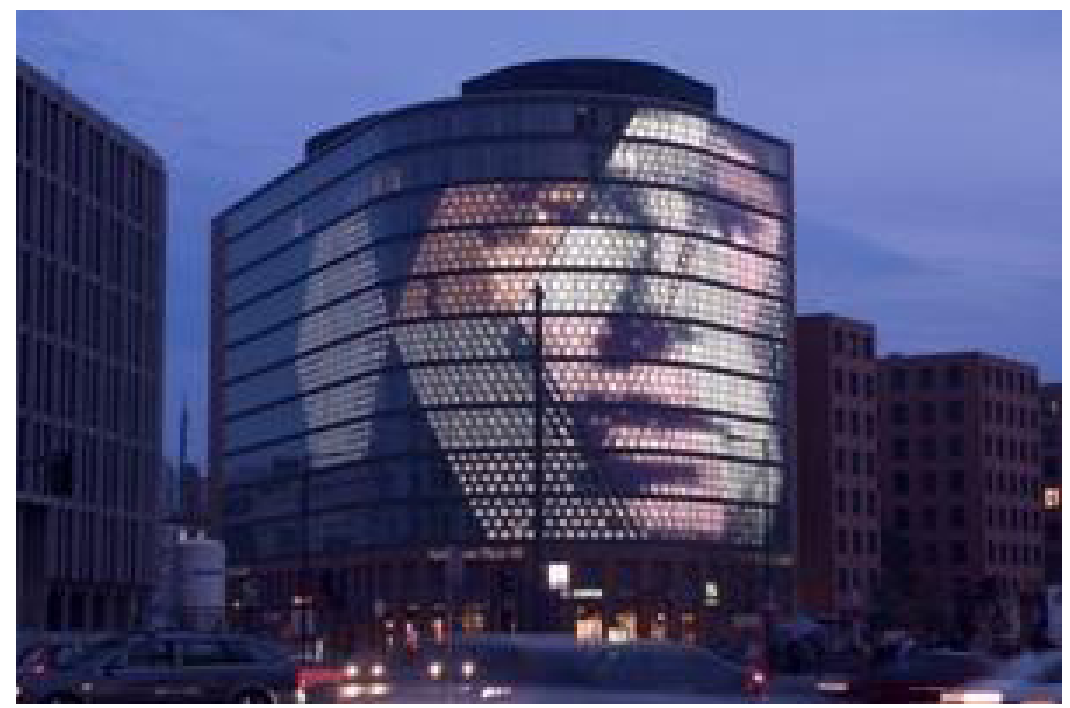

fig.2.4.4 shimmering animation sequences that complement the large scale of the facade
One particular group of artists, called the Graffiti Research Lab, creates innovative tools for artists through open source technology. ${ }^{3}$ This non-profit organization experiments with ways to enrich the public domain by reestablishing the community's relationship with public space while challenging corporate culture. ${ }^{4}$ Projects are made available online and everyone is encouraged to experiment within their own communities. One project in particular called 'Laser Tag' replicates the look and detailing of graffiti through open source coding, a laser pointer and projector. The installation was setup in various locations such as Toronto, Rome, and Tokyo where artists and participants were encouraged to write and draw on building facades digitally without physically defacing the city.

When representatives of the HVB Immobilien AG office wanted something attractive on their facade other than standardized commercial media, they opted for an envelope that showcased artists' installations through light, on its eleven-storey office building. The media facade called SPOTS by realities: united architects provides a canvas to communicate creative concepts to the public through a grid pattern of 1800 fluorescent lamps integrated into the ventilated glazed facade. The intensity of each bulb is individually controlled by a central computer system. This medium set the tone of the installations, resembling low-resolution graphics, with concepts and approaches unique to each artist. Projects are featured from sundown until sunrise when the lamps are most effective. Because it is displayed during less crowded times of the day, it encourages

3 Aldersey-Williams, Hugh, Peter Hall, and Ted Sargent. Design and the Elastic Mind. New York: The Museum Of Modern Art, New York, 2008.

4 “Graffiti Research Lab » L.A.S.E.R. Tag.” Graffiti Research Lab. http://graffitiresearchlab. com/projects/laser-tag/ (accessed June 22, 2009) 
constant activity in the plaza during slow times. Many viewers come for the purpose of the art installation, creating the appearance of a crowd for the pedestrians who gather there by chance. These artistic works provide the office building with a distinctive character within the city and positively influence the surrounding public spaces. ${ }^{5}$

\section{Sustainability / Ecological potentials}

The amount of energy that is required for a digital media facade should be self generated, at least enough for the display itself, and for the internal building usage as well. As the world is facing an energy crisis, to use depleting resources for frivolous effects such as light displays for consumerism becomes a moral issue. It is therefore our responsibility to balance our indulgences in response to our ecological concerns by combining digital media technology with sustainable practices. Currently, there are many options for displays with self-reliant energy, many which harness solar energy. Following are examples of media facades that provide eco-friendly solutions for both media use and building occupancy such as the GreenPix - Zero Energy Media Wall by Simone Giostra \& Partners Architects.

The Zero Energy Media Wall uses a polycrystalline photovoltaic system laminated within the glass of curtain walls. The PV cells on the entire building skin vary in density, reducing heat gain. Daylight is transmitted through the facade in areas required by those who work inside the building while excess solar radiation is transformed into energy for use by the media wall. The media wall emits a colorful glow around the building with 2,922 color LED light points. The

\footnotetext{
5 "Light and Media Facade Installation." realities:united. http://www.realities-united.
} de/\#PROJECT,81,1 (accessed June 22, 2009)

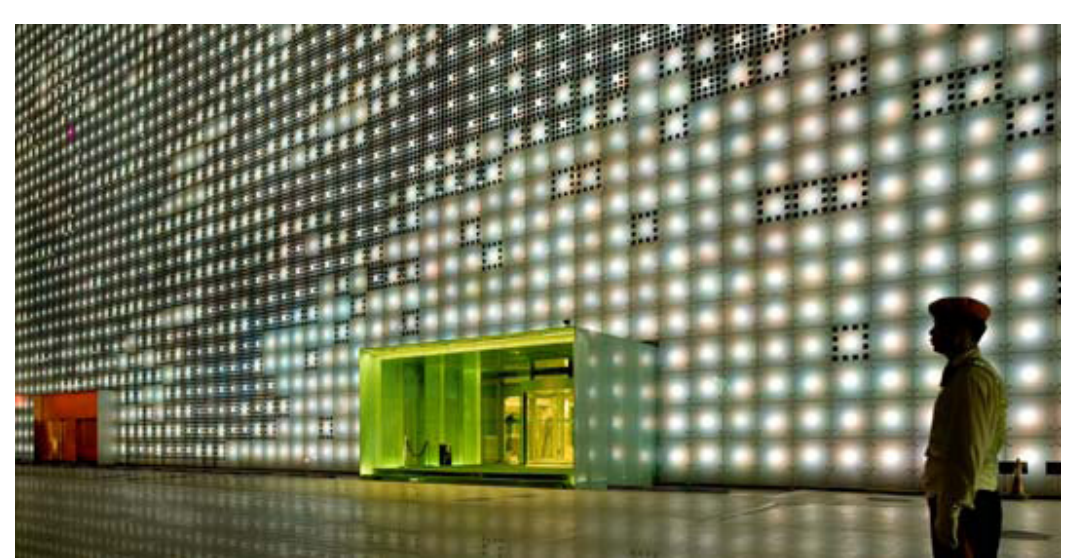

fig.2.4.5 GreenPix - Zero Energy Media Wall by Simone Giostra \& Partners Architects. Beijing, China 2008 


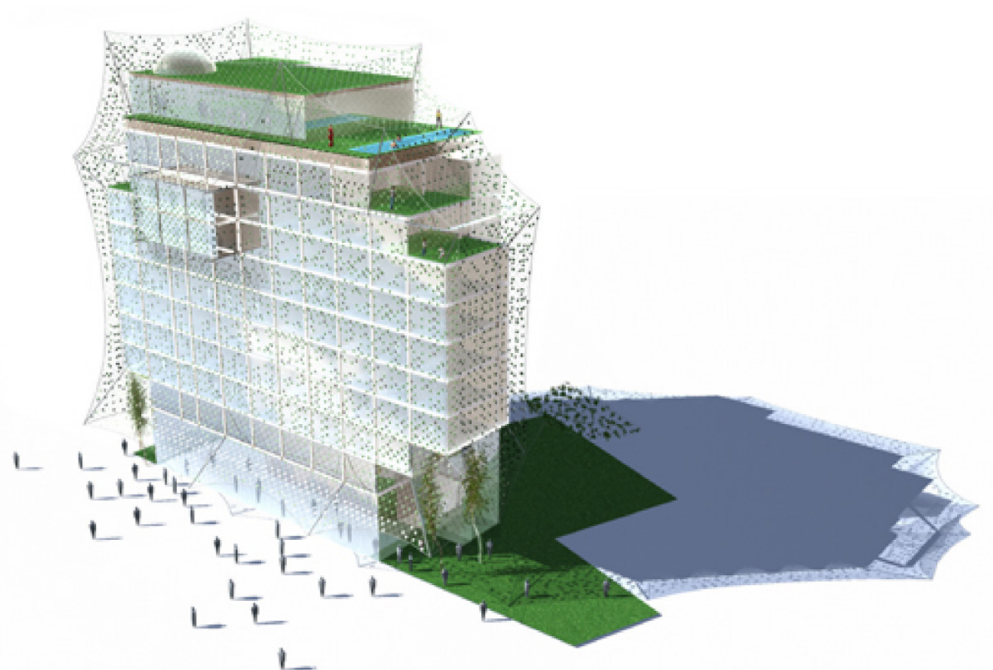

fig.2.4.6 Habitat Hotel concept by James Clar \& Associates

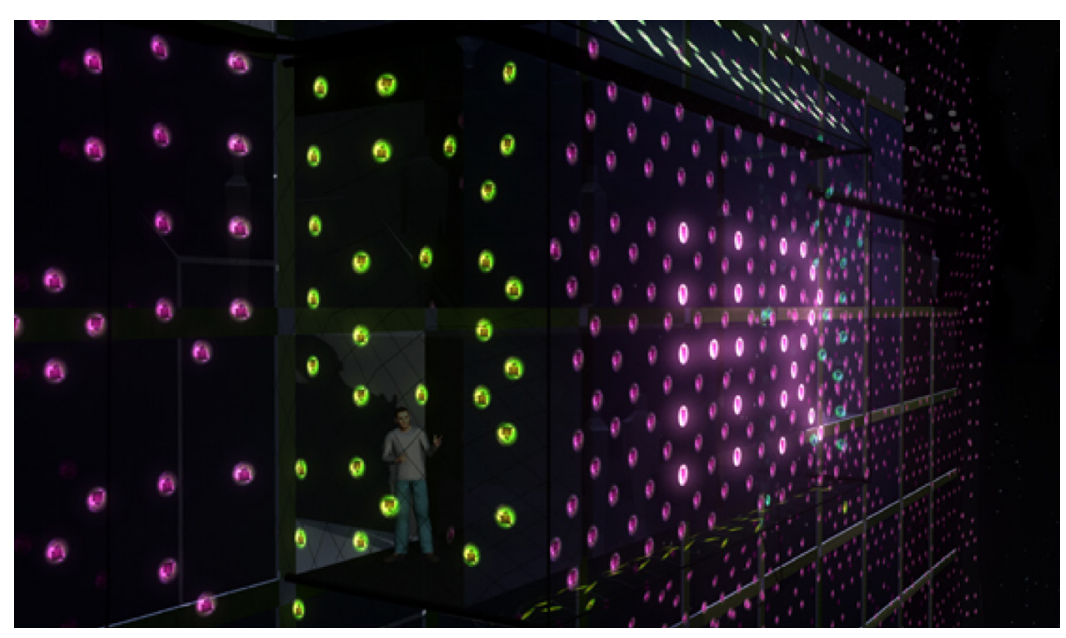

fig.2.4.7 close-up of the individual nodes on the 'energy mesh' entertainment complex passively absorbs energy by day and by night, emits the energy through the media display. The design team was inspired by the flickering light on an ocean's surface and the abstract qualities of low-resolution digital screens used in contemporary art. The low-resolution uses less energy in contrast with the highresolution commercial media facades dominant in China. ${ }^{6}$

Another example of a sustainable solution is the 'energy mesh' used in the conceptual Habitat Hotel. The Habitat Hotel is a working scale model by architect Enric Ruiz of Cloud 9 Architecture. The hotel consists of a building with an 'energy mesh' wrapped around the entire structure. The 'energy mesh' has individual nodes, each of which contain a sensor that collects the sun's energy during the day, giving off a specific color at night, according to the amount of energy collected. The mesh reflects changes in temperature and the colour schemes vary based on the amount of energy collected throughout the day, exaggerating the day's ambiance at night with consistent colour schemes for different weather patterns. ${ }^{7}$

An alternate method for the sustainability of digital media is the re-locatable and reusable structure of the AT\&T Global Pavilion designed by FTL for the 1996 Summer Olympic Games in Atlanta. This structure provided accommodation and broadcast studios; it also entertained and highlighted AT\&T as the official Olympic sponsor.

6 Gissen, David. "Simone Giostra - Greenpix, a Zero-Energy Media Wall." Welcome to the Archinnovation. http://www.archinnovations.com/featured-projects/civic/simone-giostragreenpix-zero-energy-media-wallsimone-giostra-greenpix-zero-energy-media-wall/ (accessed June 23, 2009).

7 “James Clar \& Associates - Space Design [Habitat Hotel]." James Clar. http://www. jamesclar.com/space/2006/habitathotel/index.html (accessed June 23, 2009). 
The structure was composed of tensioned fabric between arches, creating a large room sheltering crowds and acting as a projection screen on the outside for large gatherings at night. Structures at that scale, however, pose problems for future occupancy. The solution was that the entire structure was transferable to each subsequent Olympic site every two years for the next three Olympics. ${ }^{8}$ The use of moveable media facades via architectural structures is one option for large functions that use material and design solutions transferable to the subsequent venues when required, while preserving natural open space for future usage.

\section{Commercial Use / Media Exposure / Economic}

Many innovative devices and projects have resulted from immense competition amongst private industries for our public spaces. As more public spaces are becoming privatized for financial reasons ${ }^{9}$ designers must ensure success for both public domain and private interests. As we have seen, an established brand can revitalize a crumbling district like Times Square, or Potsdamer Platz in Berlin. Berlin enhanced the area by selling large sectors of land to major commercial parties..$^{10}$ Now, many individuals associate Potsdamer Platz with Sony just like Times Square is associated with Disney. This association is beneficial for both parties as the aspirations of the

\footnotetext{
8 Kronenburg, Robert. "FTL Design Engineering Studio." In Portable Architecture. 3 ed. London: Architectural Press, 2003. 195-202.

9 Francis, M., "Changing Values for Public Space." Landscape Architecture. 78, 1: 54-59. January-February, 1988.

10 Klingmann, Anna. Brandscapes: Architecture in the Experience Economy. London: The Mit Press, 2007. 83
}

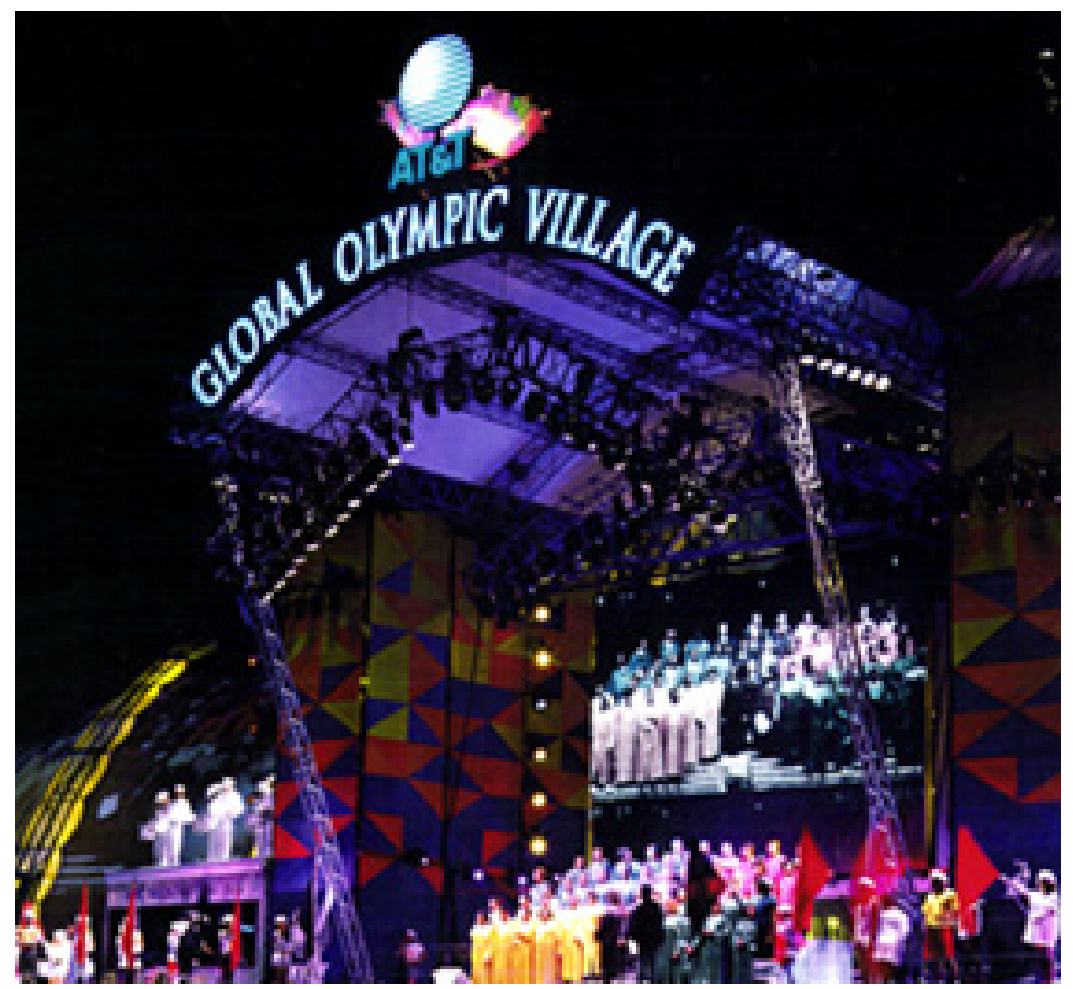

fig.2.4.8 the Astrovision screen above the Olympic stage showed highlights and medal ceremonies 


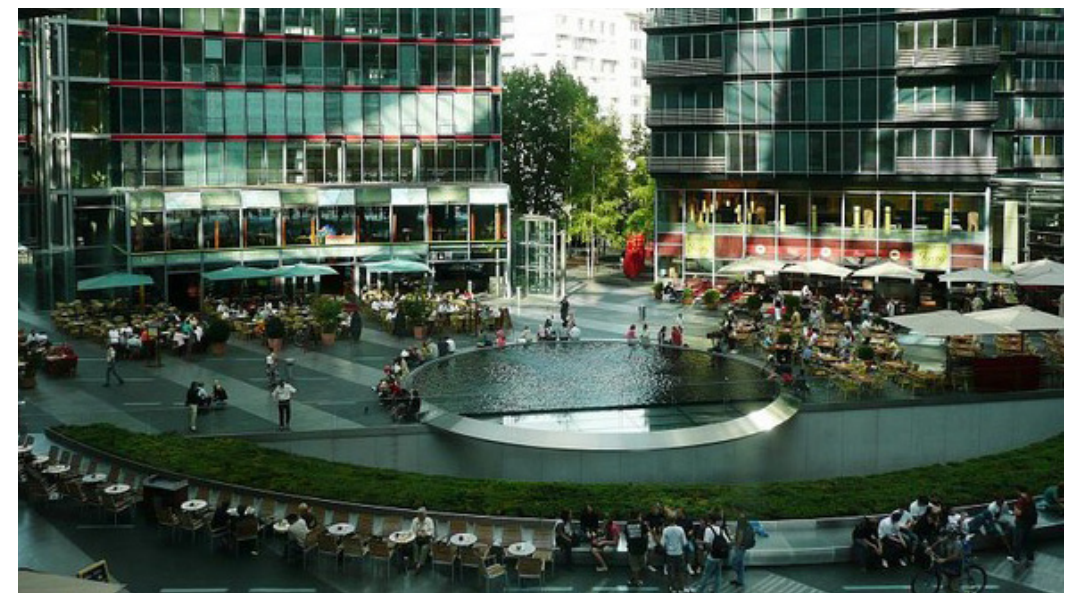

fig.2.4.9 the Sony Center in Potsdamer Platz by Helmut Jahn. Potsdamer Platz, Berlin created in 2000

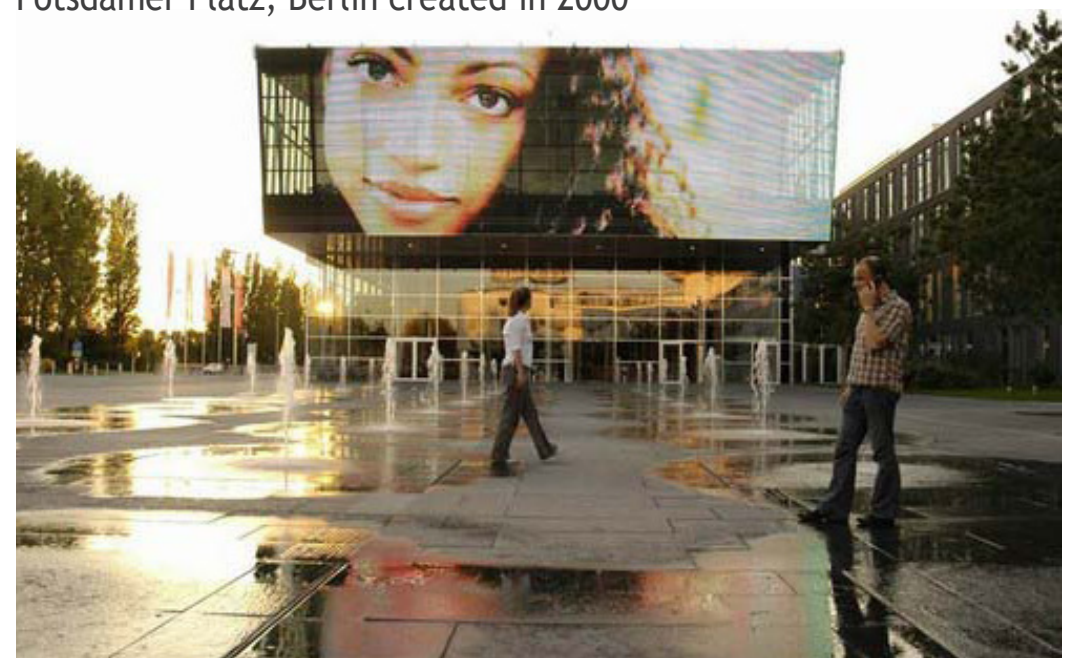

fig.2.4.10 T-Mobile Bonn Headquarters by ag4 mediatecture. Bonn, Germany 2003 brand can influence the site and architecture, while the heritage and culture of the city can be transmitted through the brand. Having a seamless merger of an iconic brand with architecture becomes more tangible to the public, accentuating architecture, and promoting a brand/product while having the financial support of the corporation. Digital media facades have the flexibility and diversity that still images such as billboards do not, using the architecture as a canvas rather than mere scaffolding. Digital screens can extend their content to balance commercial, communal and cultural usage. Designers can explore the integration of screen formats with architecture for the optimal use of both in increasing public reception for architecture as well as the displayed content.

As media facades have become a symbol for metropolitan areas and one of the greatest tools for commercialism, companies constantly upgrade to the latest technology such as LED displays with brighter colours and stronger projections. Companies are using the latest technological advancements for marketing in the city to symbolize their brand as progressive and cutting-edge. Companies looking to invigorate their brand identities do not hesitate to invest in leadingedge technology for a unique look to solidify their corporate image amongst the visual clutter. T-Mobile wanted to celebrate their brand on its headquarters in Bonn, Germany without taking away from the existing transparent architecture of the entrance. Thus the world's first transparent media facade was designed by 'ag4 mediatecture' in a combination of media and architecture. Over 250,000 light emitting diodes cover the $30 \mathrm{~m}$ by $10 \mathrm{~m}$ facade, all attached to horizontal aluminum slats. The transparency of the skin results from large pixel distances. The identity of the building is an ever-changing canvas. With animations and videos supporting the company logo 
and events both inside and outside of the company headquarters. ${ }^{11}$

The facade of Chanel in Ginza Tokyo is another exhibit involving communication media which serves public space. Peter Marino + Associates Architects envisioned the building wrapped in a media facade resembling Chanel's iconic tweed fabric, while keeping daylight and views between interior and exterior, all without solar heat gain. The 10-story-high media wall utilizes a sophisticated system of solar-controlled glazing and optical materials integrated with white LEDs. The opacity of the wall changes depending on the current applied through the electrochromic glass. ${ }^{12}$ The glass is transparent during the day, and opaque at night for displays on one of the largest black-and-white video walls in the world.

The fashion house commissions several artists to create imagery for the facade. The first program by Michal Rovner called "Tweed, Tokyo," used the textures of the facade to evoke dreamy images of crowds that reflected the motion of pedestrians along the boutiques. Passerby could enjoy the interior of the space during retail hours and the artistic project after hours, creating a continuous attraction along the public streets. ${ }^{13}$ This project is exemplary of a seamless integration of a building's exterior and communication media. It maximizes the potential of digital media, highlighting architecture at night when it is

11 “Communicative Interface.” DBZ Deutsche Bauzeitung, edition 12, 2004. http://www.ag4. de/fileadmin/media/pdf/200412_ag4_DBZ_en.pdf (accessed June 23, 2009).

12 Sullivan, C. "Chanel Ginza, Tokyo." Architectural Lighting Magazine, June 1, 2007. http:// www.archlighting.com/industry-news.asp?sectionID=0\&articleID=526791 (accessed June 22, 2009)

13 "Chanel Ginza Tokyo Flagship Store." Architectural SSL Magazine. http://www. architecturalssl.com/content.php?section=resources/02_08_issue\&id=1 proj (accessed February 22, 2010).
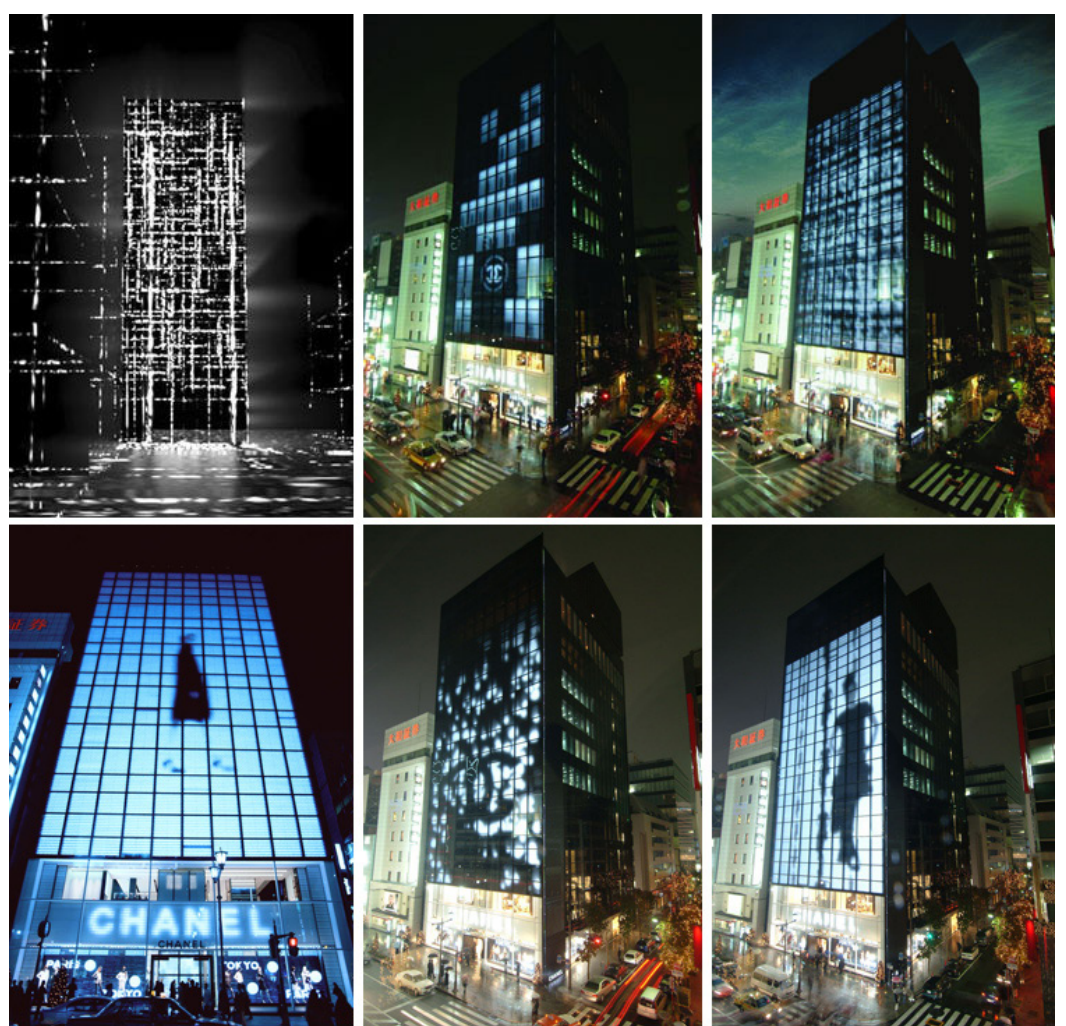

fig.2.4.11 Chanel Ginza Façade by Peter Marino + Associates Architects Retail and Office building. Tokyo, Japan 2004 


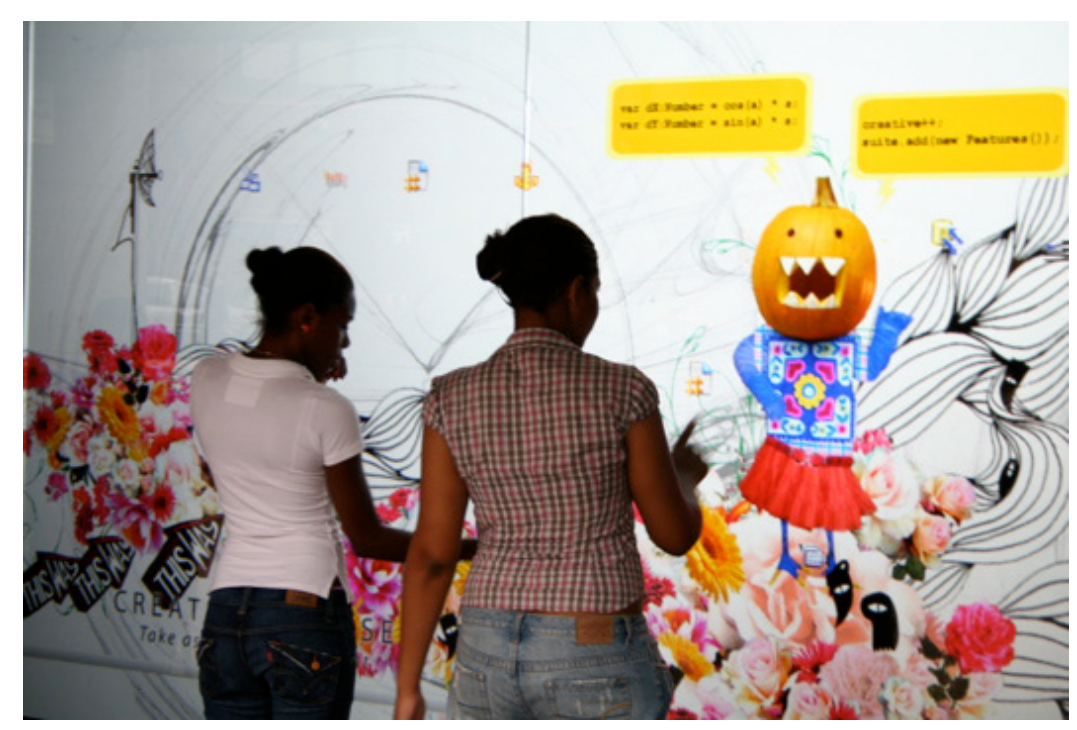

fig.2.4.12 Adobe's CS3 Launch at Union Square. New York City 2007 most needed and effective. The active curtain wall informs the public of the fashion icon while showcasing the architecture at night but allows for the building's own expression during the day. The canvas' ability to reveal itself when required creates a constant engagement with architecture and the public.

Goodby, Silverstein \& Partners capitalized on the traffic along the street in Union Square, New York, for public awareness during the Adobe's CS3 Launch. The marketing team set up a $2 \mathrm{~m}$ by $4.5 \mathrm{~m}$ reactive wall along the Virgin Megastore facing $14^{\text {th }}$ street. The setup included an animation created with Flash and infrared sensors to track pedestrian movements across the reactive mural. The movements of passersby triggered graphic animations that would move at the same speed as pedestrians. ${ }^{14}$ The animation started with simple graphic elements and music. As the viewer walked further the animation progressed, increasing layers of graphics until the participant walked to the end of the media wall, restarting the animation for the next participant. The installation featured a public showcase of the Adobe software but also added to the urban fabric and introduced positive energy generated through curiosity and fascination. The marketing campaign created enthusiasm for both the potentials of the product as well as the public realm, altering people's perception of the street and even their impression of Union Square. As pedestrians take a moment from their fast paced commute to engage with the media mural, awareness is brought to both brand and public realm.

\footnotetext{
14 Ozler, Levent. "Brand New School Creates Interactive Mural for Adobe | Design News." Dexigner Design Portal | Design News. July 15, 2007. http://www.dexigner.com/design_news
} brand-new-school-creates-interactive-mural-for-adobe.html (accessed June 22, 2009). 


\section{Reactive / Social}

Engagement in public art projects are part of the viewing experience, but when an installation is reactive, new social encounters are possible, enriching the experience. Installations that are reactive generate a response to an external trigger by the viewer and can be perceived by the viewer. Reactive art projects can deliver a range of outcomes from increased community participation to unexpected encounters between members of the public. Design of installations that form new ways of interaction are a critical element of an urban atmosphere. Reactive elements let passersby become part of the installation, turning passive spectators into active components of the art. Public control over the medium creates personal attachments to the space and installations, while the designs are ever changing. Reactive installations rely on the element of surprise to capture the attention of an otherwise desensitized general public. The public interacts with each other and the built environment, creating enjoyment and positive energy, bringing pride to the community and increasing the popularity of the area:

There exists however also an interest in communicative phenomena which is not purely technical, but semantic and pragmatic; an interest which is not oriented towards the problems of physical optimalization of messages, but towards the problems of individual and collective use (and misuse) of these messages. In this case it is the human communicative behavior, both individual and collective, which lies in the centre of interest. ${ }^{15}$

15 Maldonado, Tomas. "Notes on Communication" from Communications and Semiotics Seminar. 1962.
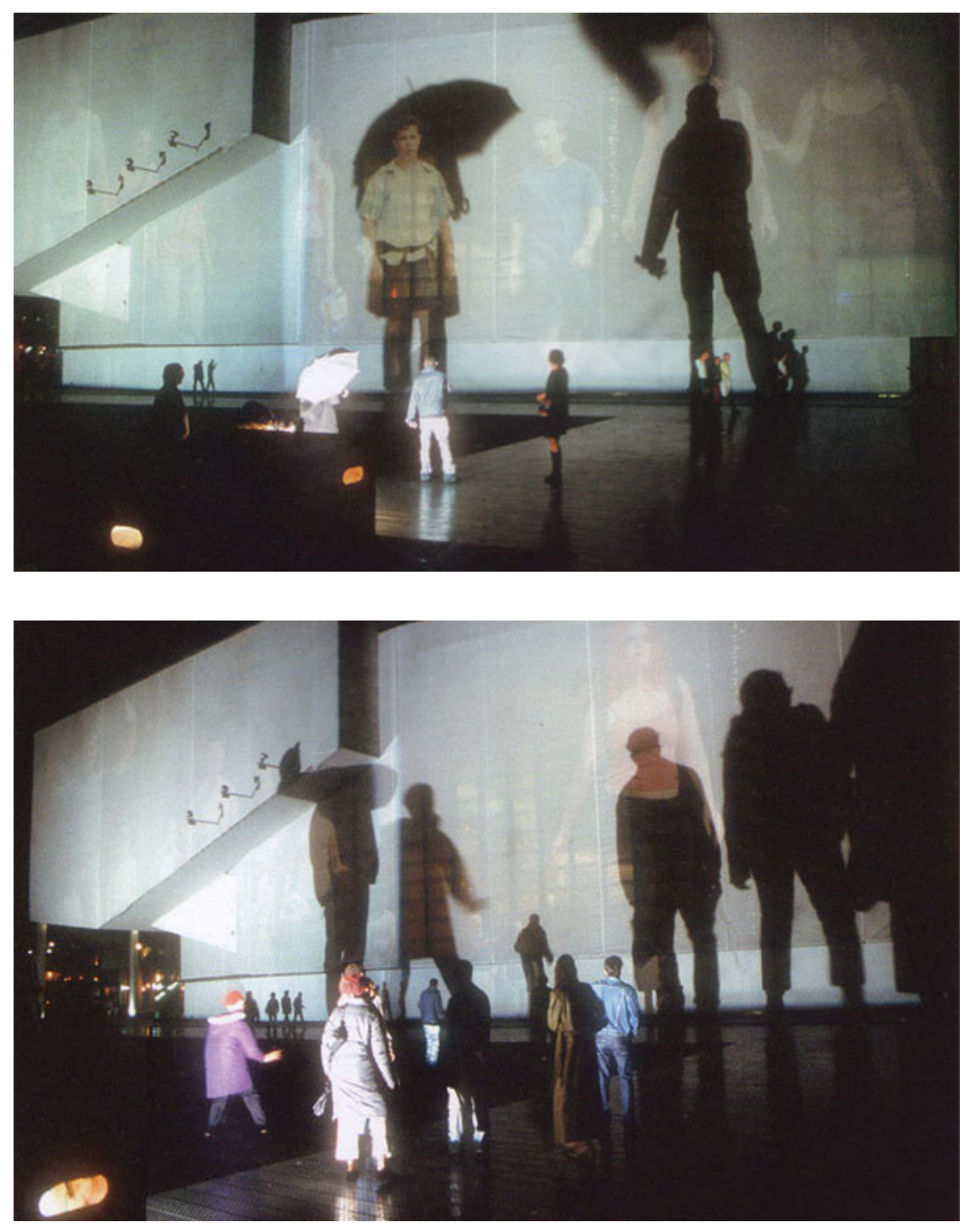

fig.2.4.13 Body Movies by Rafael Lozano-Hemmer. Schouwburg Square, Rotterdam 2001 

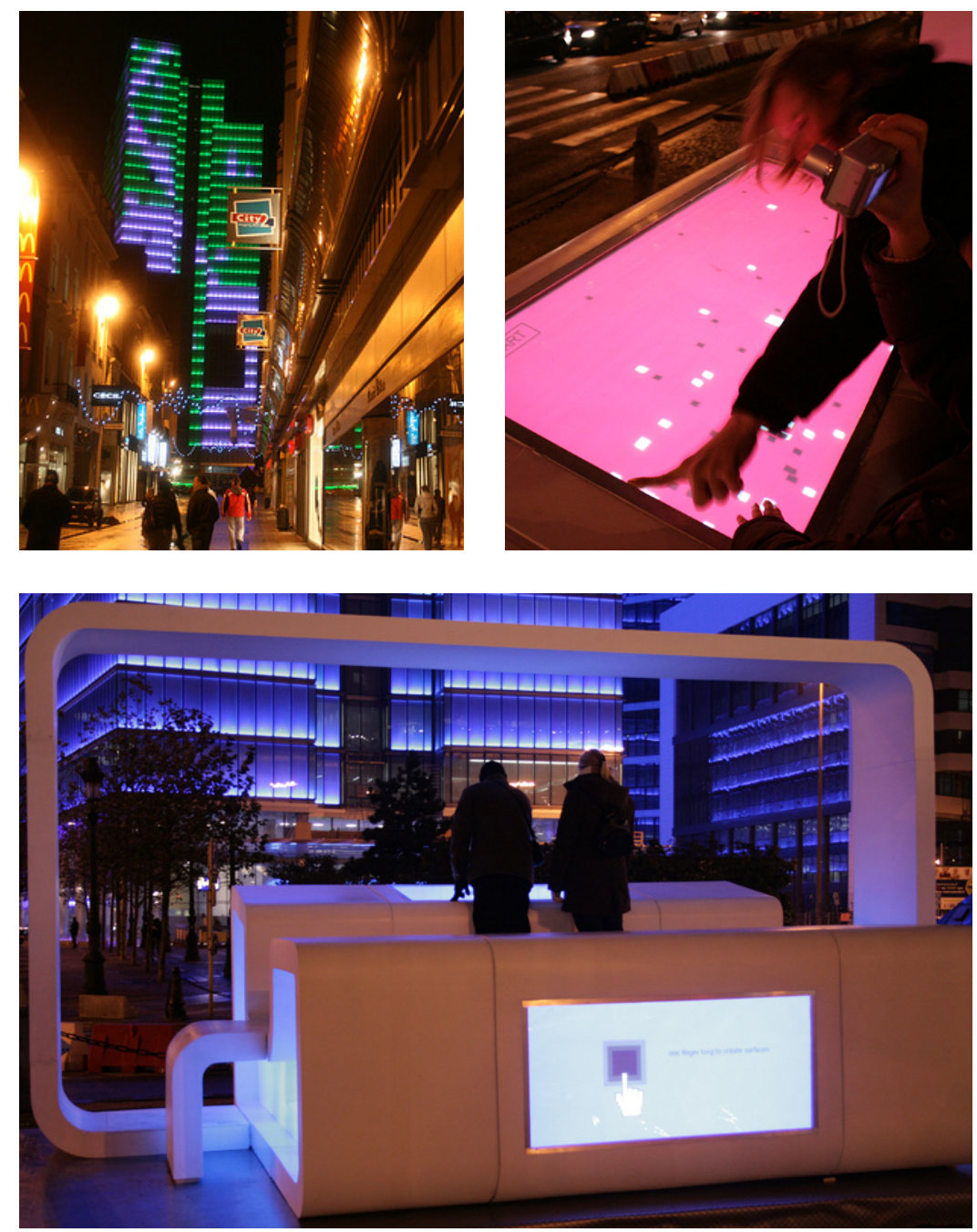

fig.2.4.14 Touch by LAb[au] on the Dexia Tower in Brussels, Belgium 2006
The passive nature of reactive digital facades allow messages to be presented voluntarily, as opposed to the visual attack of idle signs. These responsive systems serve as catalysts for public interaction, allowing for uninhibited public expression and urban communication through engagement with strangers, giving creative license to the public.

An example of an reactive installation is the project Body Movies by Rafael Lozano-Hemmer. One thousand portraits were projected at random onto the facade of the Pathe Cinema in Rotterdam. The portraits were initially hidden by powerful xenon lights at ground level which washed the images over in a white glow. As pedestrians walked by and blocked the spotlights, the portraits were revealed by casting different size shadows onto the walls, matching the silhouettes of pedestrians to the portraits. The image would change when all portraits in the scene were revealed, restarting the whole reactive process..$^{16}$ The installation engaged the public's curiosity and sense of experimentation. The pedestrian unexpectedly becomes an integral part of the performance art. In addition, the initial unpredictable nature of Body Movies allows participants to figure out the action without the use of instructions because of its simple nature.

In the project Touch by $\mathbf{L A b}[\mathbf{a u}]$ participants can directly interact with the lights on the 145 metre Dexia Tower in Brussels. Behind 6000 windows are red green and blue LEDs that can be controlled from the station at the bottom of the tower. The reactive multi-touch-screen allows for more than one person to produce visual displays at the same time. The luminous compositions created on the screen are generated

16 "Body Movies." Rafael Lozano-Hemmer . http://www.lozano-hemmer.com/english/ projects/bodymovies.htm (accessed June 22, 2009) 
directly onto the tower; participants can also choose to send an email. with a postcard attached, of the view of the tower receiving their creation on the project website. The creative process is both tangible and viewable for the immediate public while the transformation of the Dexia Tower can be seen across the city. The project represents collective interaction and public art on an urban scale. ${ }^{17}$

\section{Aesthetics / Facade treatment}

By integrating architecture and digital media a design can manipulate the surface and surrounding space without new construction or demolition of existing structures. Projections can be used to celebrate an already popular community landmark or to enhance an area that is otherwise neglected. Digital facade treatments have the ability to transform neighbourhoods that otherwise feel unsafe or unwelcoming while highlighting architectural details in the evenings. The aesthetics of a digital facade can be viewed from such great distances that when people gather further from the subject it creates a frame and edge of object different from the physical designations, changing the dynamics and organization of the space. The surface is reinvented, transformed into a dynamic visual-spatial performance, making the area interesting because of its unpredictable nature. This way a digital screen can satisfy the commercial and corporate purposes as well as take a role in the city's overall life and culture.

The project Twists and Turns by Mader, Stublic, Wiermann transforms the exterior of the Uniqa Tower in Vienna into modulating

17 “Dexia Tower Touch." LAb[au] laboratory for Architecture and Urbanism. http://lab-au. com/\#/http://lab-au.com/projects/touch/ (accessed June 22, 2009).

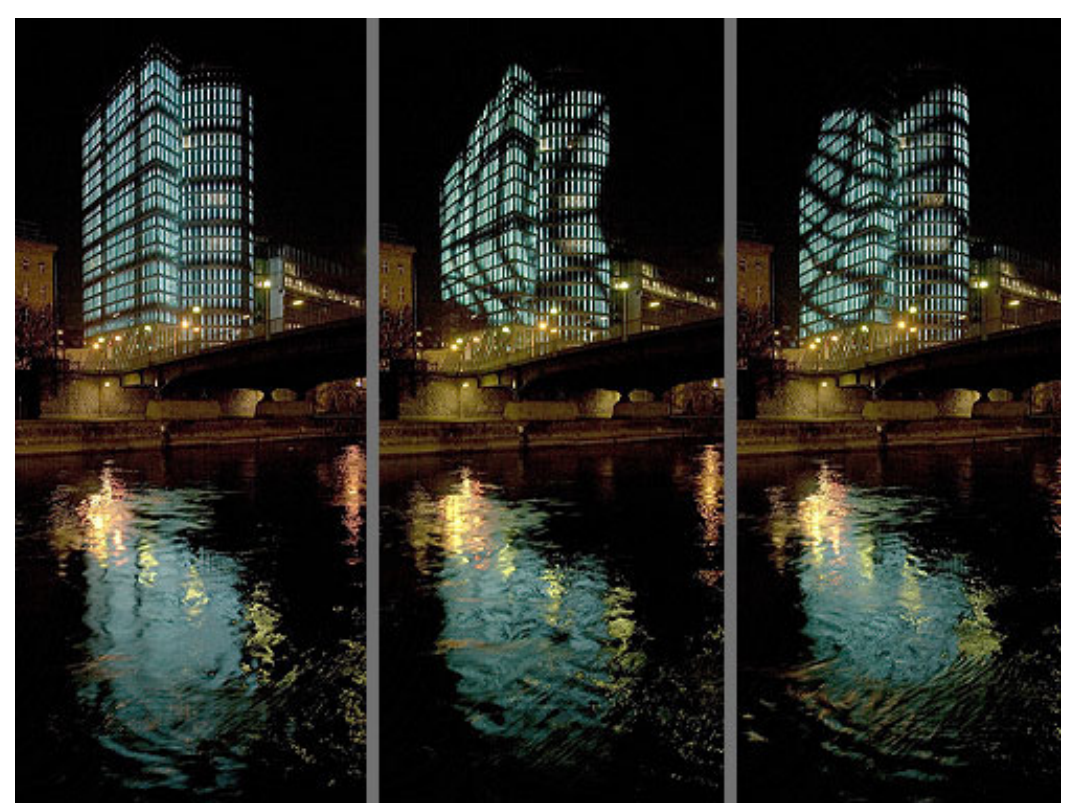

fig.2.4.15 an interplay between architecture and electronic data feed changing over time. Twists and turns by Mader, Stblic, Wiermann on the Uniqa Tower, Vienna 

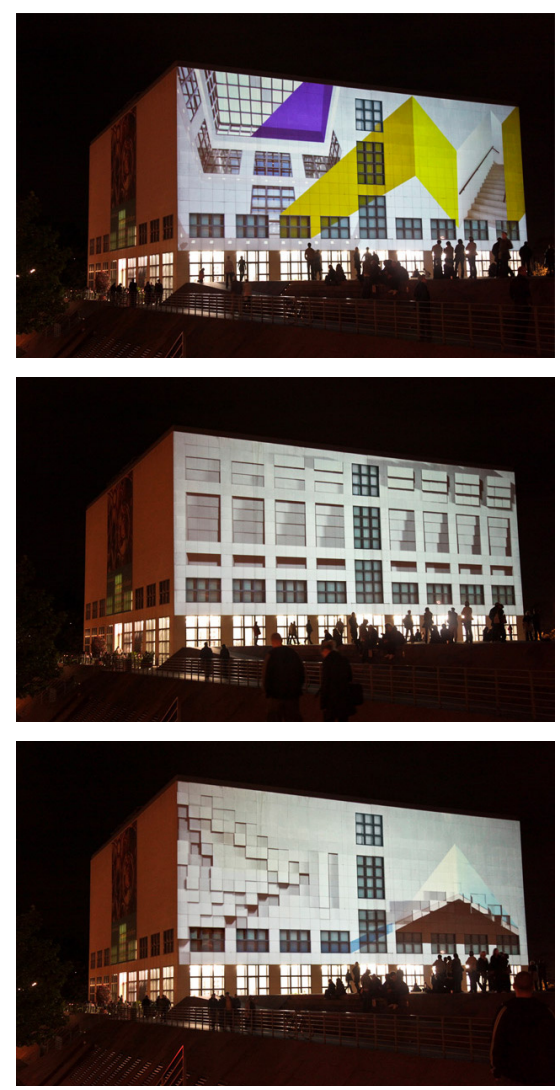

fig.2.4.16 555KUBIK facade video projection on the Kunsthalle in Hamburg, Germany. The concept was "How it would be, if a house was dreaming" abstract forms. The gaps of the building facade are fitted with an LEDgrid capable of receiving video data. The graphics start by highlighting the structure of the tower and gradually shift into alternate forms providing the illusion that the building is contorting into a multitude of distorted forms. The choreography of light configurations on the Uniqa Tower becomes a dynamic addition to the urban landscape. ${ }^{18}$

The video projection 555 Kubik by Urbanscreen turned the facade of the Kunsthalle building in Hamburg, Germany into a living organism. The concept was visually present "How it would be, if a house was dreaming”. The 3D Studio Max animation featured visualizations of the building interior with the simplistic grid of the exterior. The video projection made the building come to life, as geometric shapes danced across the facade, maneuvered and shifted without any effort. The contrast between shadows and illuminations created different volumes on the architecture as illusions of the building envelope were pushed in or pulled outward. The movements matched the patterns of the building exterior precisely, using MXWendler media server for mapping multiple projections. ${ }^{19}$ The added sound effects give the movements weight and friction.

\section{Adaptability / Scale}

The digital facade is an ever-evolving canvas open to the creativity of an artist or the design of a marketing campaign. The ephemeral quality of the video and light permits experimentation and changes

18 "Holger Mader | Alexander Stublic | Heike Wiermann." Holger Mader | Alexander Stublic Heike Wiermann. http://www.webblick.de/ (accessed June 22, 2009).

19 "555 KUBIK Facade Projection - today and tomorrow." today and tomorrow. http://www. todayandtomorrow.net/2009/07/23/555-kubik-facade-projection/ (accessed August 27, 2009) 
in design to customize an installation to its maximum potential in a space. The design of an installation should start with the consideration of context, neighbouring scales, and traffic. The potential size of the crowd, visibility from all angles and the amount of traffic should be kept within an applicable ratio to the surrounding environment:

Architecture is a constant rediscovering of constant human proportions translated into space. Man is always and everywhere essentially the same. He has the same mental equipment though he uses it differently according to his cultural or social background, according to the particular life pattern of which he happens to be a part. Modern architecture has been harping continually on what is different in our time to such an extent even that it has lost touch with what is not different, with what is always essentially the same..$^{20}$

A digital display can help inform and reintroduce human scaled environments in areas that need assistance. While many events and installations have become transferable from place to place, it is important that with each move, they accommodate to the surrounding public area, and the visuals of different patterns day and night, and at different seasons.

The project Blinkenlights by Chaos Computer Club on the famous Haus des Lehrers building at Berlin Alexanderplatz first

20 van Eyck, Aldo . "Is Architecture going to reconcile basic Values?" in Oscar Newman (ed.) CIAM '59 in Otterlo, Stuttgart, 1959.

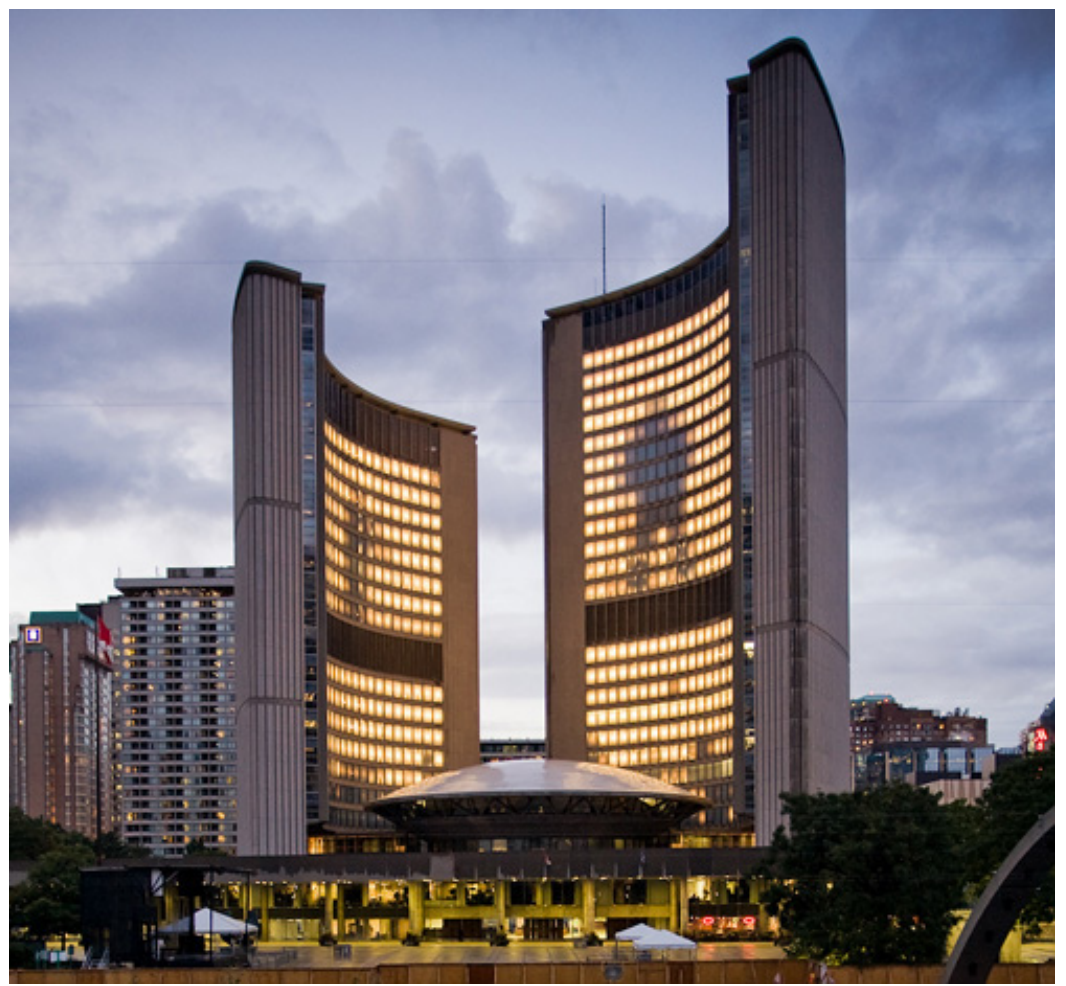

fig.2.4.17 Stereoscope allowed people to play with and contribute to the installation. City Hall, Toronto during Nuit Blanche, 2008 


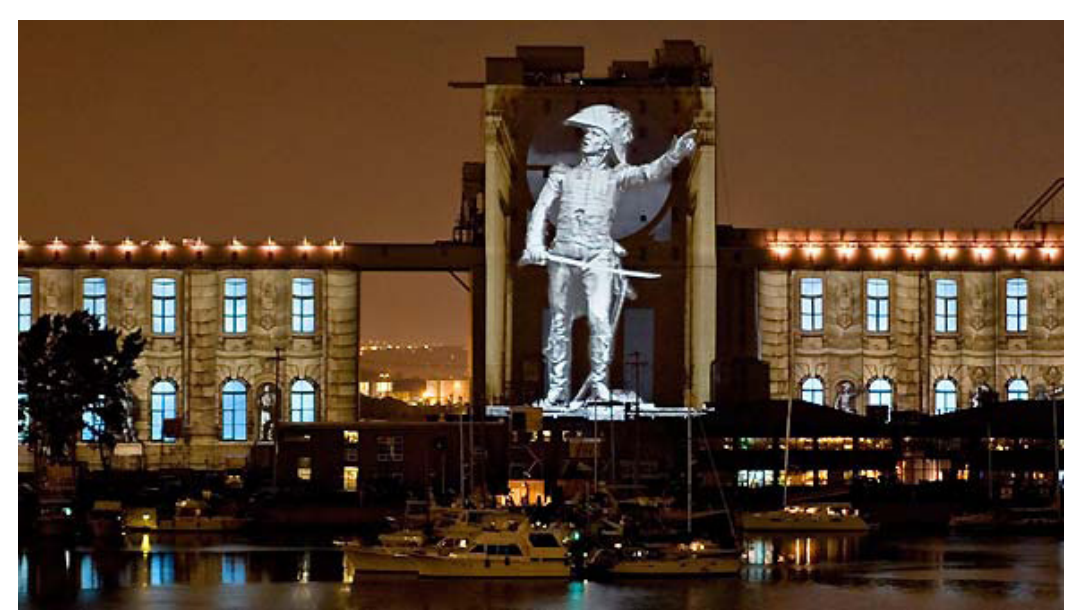

fig.2.4.18 projections transformed grain silos into various other structures introduced the ability to control large-scale reactive media walls using a cellphone. The project has since been applied throughout Europe and on the Toronto City Hall, using the same software adapted to various monumental buildings. Blinkenlights Arcade allowed the public to play Tetris on the Bibliothèque Nationale de France in Paris, transforming the facade into the world's largest reactive computer display. In Toronto, Blinkenlights Stereoscope took advantage of the two opposing structure splitting the facades into areas for gaming, and simple and complex animations. Participants could control animations via the web or cellphones. Crowds gathered around Nathan Philips Square in front of City Hall, viewing the bright lamps behind 960 windows of the two towers, with each window serving as a pixel to the animation. ${ }^{21}$ The novelty of the activity is experienced each time though its simplistic concept and fundamental elements but the details are revamped catering to each site.

\section{Authenticity / Cultural / Identity}

A city can build on its own character with the help of artist installations and messages from digital facades. An area should draw focus from the larger urban fabric, by emphasizing local imagery, and celebrating local traditions, to create connections that are unique to the area and a distinct identity. Art created by local artists who create platform-specific content for a digital media facades create unique experiences. They also retain the heritage of a site or re-evoke the history of a site. When the community can reflect on a piece, they tend to respect the installation more and care about it more: "Places that are 'real' to people invite and reward involvement -

21 "Stereoscope | Project Blinkenlights." Welcome to Project Blinkenlights | Project Blinkenlights. http://www.blinkenlights.net/stereoscope (accessed June 23, 2009). 
intellectual and/or emotional - and provide a sense of psychological connectedness." ${ }^{22}$ It is important for a digital projection to be inspired by history. Highlighting buildings as these "urban artifacts' ${ }^{23}$ that define the city can rehabilitate a historical building and satisfy contemporary interests.

In celebration of Quebec City's 40oth anniversary, Robert Lepage designed an installation to be projected onto 81 grain silos located at the harbourfront. ${ }^{24}$ The project called The Image Mill showcased images that reflected the identity of the city. Sights from pinnacle events throughout the history of Quebec from Samuel de Champlains's settlement to images of the former premier Maurice Duplessis were compiled for the video with the help of the city's historians and archivists. The artist narrates the story of Quebec through engravings, illustrations, photos and video with 27 projectors spanning across 600 metres by 30 metres. ${ }^{25}$ For two months the site-specific motion picture gathered viewers by the thousands to the harbourfront and various elevations of the city, transforming the entire city at night into a viewing platform. The patriotic 40-minute display was accompanied by a soundtrack that heightened the drama and depending on where one was standing,

22 Carmona, Matthew, Tim Heath, Taner Oc, and Steven Tiesdell. Public Places - Urban Spaces. London: Architectural Press, 2003. 105.

23 Rossi, Aldo. The Architecture of the City. London: The Mit Press, 1984

24 "Robert Lepage plans tribute to Quebec City." National Post | Canadian News, Financia News and Opinion. http://www.nationalpost.com/most_popular/story.html?id=442333 (accessed April 27, 2010)

25 “CBC News - Montreal - Massive Robert Lepage show reflects Quebec City’s story." CBC ca - Canadian News Sports Entertainment Kids Docs Radio TV. http://www.cbc.ca/canada/ montreal/story/2008/07/10/qc-lepage-cp-0710.html (accessed April 27, 2010).

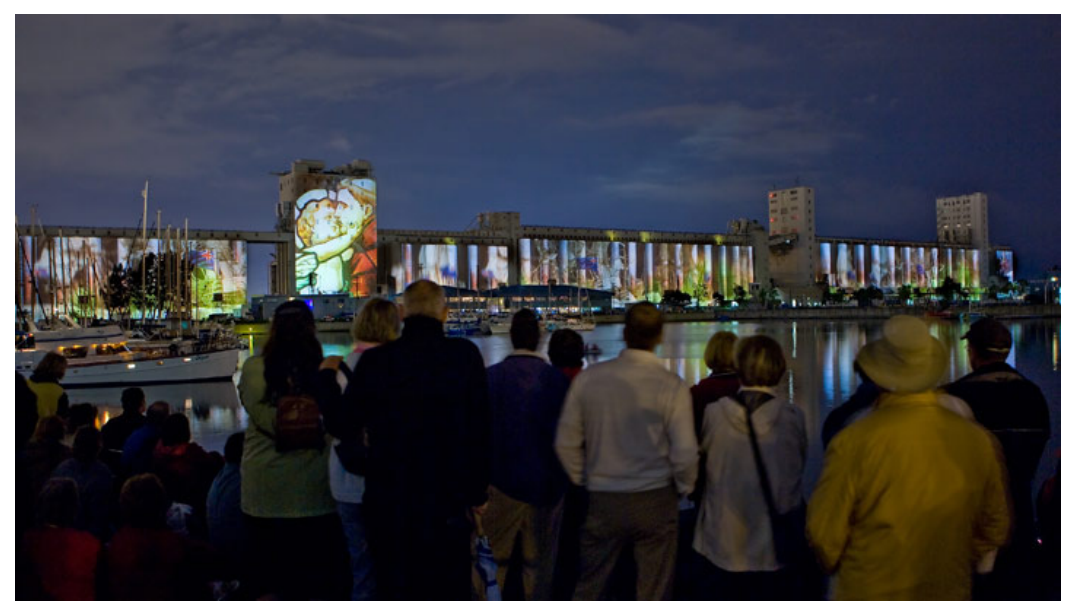

fig.2.4.19 The Image Mill by Robert Lepage. Quebec City, 2008 


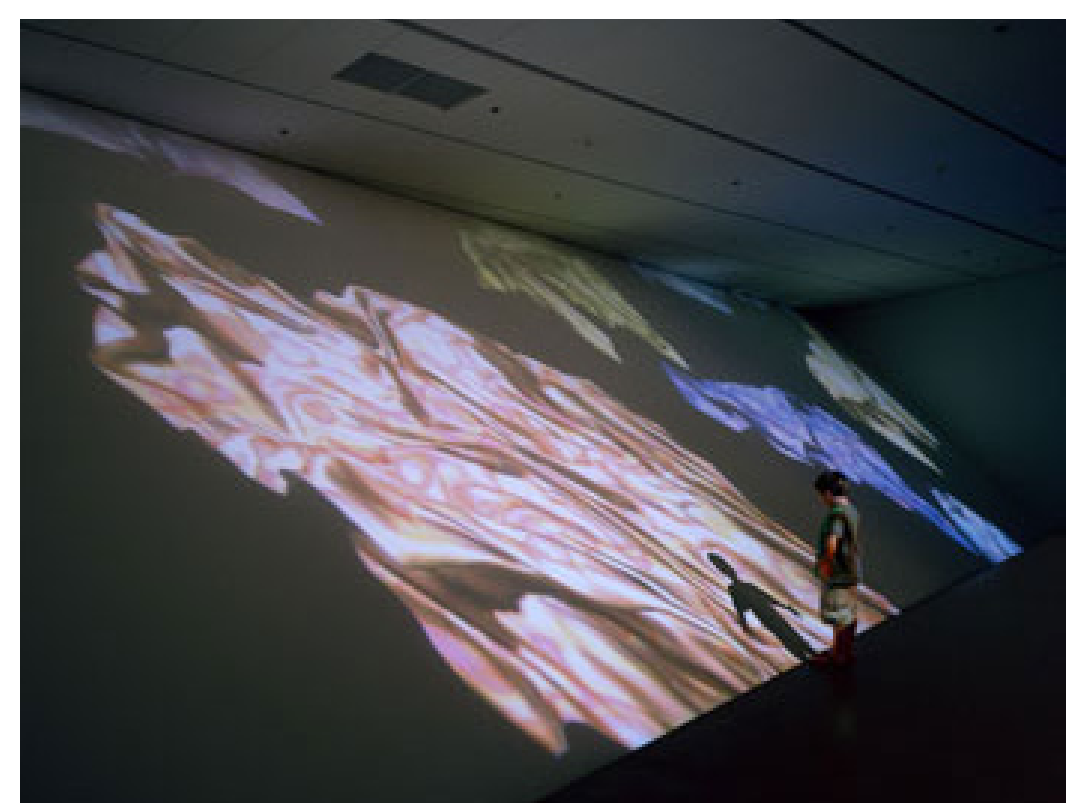

fig.2.4.20 Rock Formations by Jennifer Steinkamp utilized tilted walls in the new addition to the Denver Art Museum designed by Daniel Libeskind would be in surround sound. ${ }^{26}$ The video reached the audience at an emotional level with images of religion, battle and controversy. The thought-provoking sequences heightened the collective spirit of the city, connecting individuals through dramatic renditions of past events. The projection played with the contours of the silos, turning them into bullets, candles, cigarettes and even transforming them entirely into a factory, cruise ship and airport. Lepage's animated impressions of the city brought light to the industrial port and the public to the space.

\section{Multi-sensory/responsive environments}

Installations that are designed to engage multiple senses can produce experiences outside the physical realm of the space. Reactive projects should be designed with an awareness and anticipation of a user's sensations, to conceive of designs that expand a user's consciousness. The same installation depending on the season and times of day can evoke different feelings. In the winter, the sound of snow crunching beneath a pedestrian's feet becomes in the summer, the smell of fresh cut grass in a park. The combination of sensory experiences can evoke feelings beyond the projected screen. One sense can affect another to bring forth a heightened state of perception. A visual exhibition with the additional dimension of sound can resonate in the public urban space, between the buildings and the architecture so that the user can experience an ambient dynamic city. In such a case,

26 "CBC News - Montreal - Massive Robert Lepage show reflects Quebec City’s story.” CBC ca - Canadian News Sports Entertainment Kids Docs Radio TV. http://www.cbc.ca/canada/ montreal/story/2008/07/10/qc-lepage-cp-0710.html (accessed April 27, 2010). 
the union of the auditory and visual senses unites the public, since 'Sight is the sense of the solitary observer, whereas hearing creates a sense of connection and solidarity. ${ }^{27}$ Visual imagery combined with music can absorb audiences into installations. As participants move throughout pieces sound engages participants in the moment to carefully consider what is in view with what is being heard, allowing the person to understand where he/she is in relation to it. ${ }^{28} \mathrm{Just}$ as 'The echo of steps on a paved street has an emotional charge because the sound reverberating from surrounding walls puts us in direct interaction with space; the sound measures spaces and makes its scale comprehensible. ${ }^{29}$ The atmospheric effects of sounds in an exterior space can create an experience of interiority..$^{30}$ People feel at ease and protected when the vibration of sounds helps them navigate within a space..$^{31}$

Installations can transform beyond the physical limitations of the space. The flexibility of projections can use all surfaces available to create texture, depth and dimension. An inanimate surface can be transformed by light and further accentuated with sound. Visual imagery with the addition of sound can cause a space to expand and contract. The audience's perception of the a space is altered and viewers are more aware of their own presence and positions within the space..$^{32}$ When designs are responsive to their environments, projection pieces that are site-specific fit the architecture, resulting

27 Pallasmaa, Juhani. The Eyes of the Skin (Polemics). London: Academy Editions, 1996. 35 28 Miles, Christopher. "Brightness Falls." Art in America, March 2007.

29 Pallasmaa, Juhani. The Eyes of the Skin (Polemics). London: Academy Editions, 1996. 35

30 ibid. 34

31 ibid. 34

32 ibid. 34

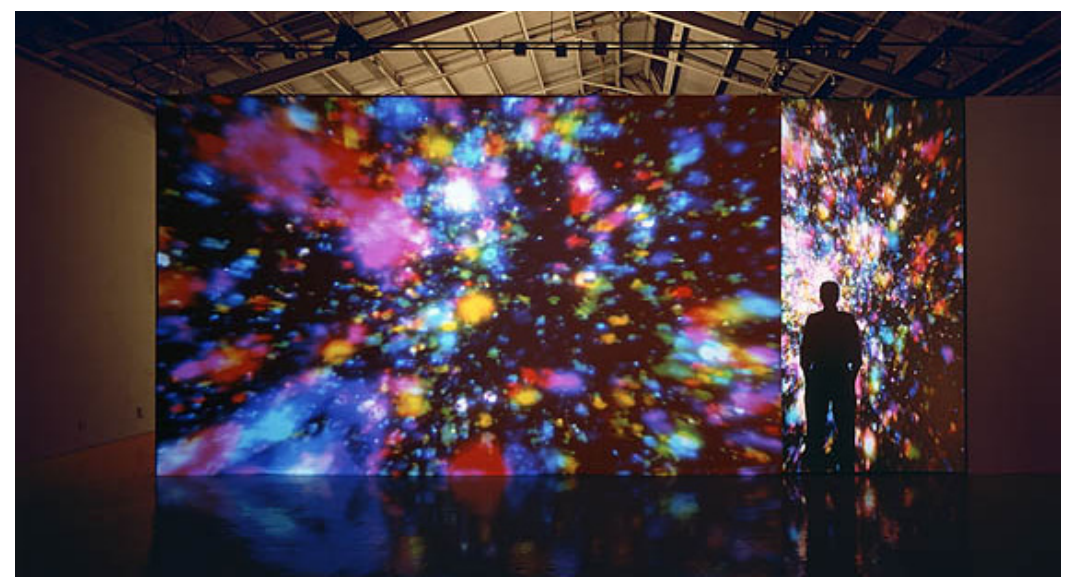

fig.2.4.21 Swell by Jennifer Steinkamp in the The Museum of Contemporary Art, Los Angeles, California 3.7m x 8m

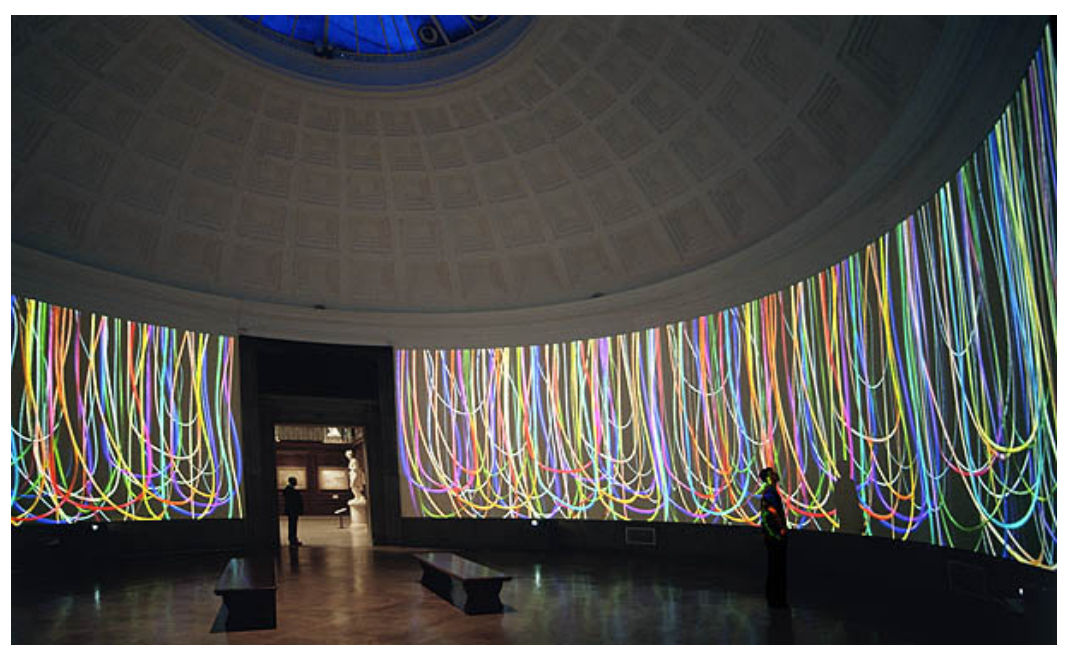

fig.2.4.22 Loop by Jennifer Steinkamp in the Corcoran Gallery of Art, Washington, DC. $13.1 \mathrm{~m}$ in diameter and $4.1 \mathrm{~m}$ tall 
in a sense of engagement. Large-scale projections can completely fill a space, allowing viewers to be immersed in the installation's layers of sensory experiences.

Combining sight and sound, Swell uses two video projectors and sound effects to construct a space where viewers are immersed in sensations. The artist, Jennifer Steinkamp, uses the same animation twice, projected horizontally from the front and vertically from behind a constructed wall that separates the room. As viewers pass through the dividing walls, their shadows intersect with the projections, becoming part of the piece itself. The shadows allow participants to feel their presence in the space and their bodies in relation to the projection as well as the presence of others. The video consists of abstracted imagery of lights and bright colors zooming in and out while sounds characteristic of flowing fluids fill the room. The ambience of the room wavers between storm-like to sunny with colourful flowers as the animation loops. The soundtrack by Bryan Brown is synchronized to the movements of the video. The audio experience heightens the visual form of the glowing colours, creating illusions of an infinite space where light spirals out toward the viewer and spins back into the void. As participants enter the dark room their eyes adjust to the sudden change in light while their bodies and senses take hold of where they are and what they are experiencing. When viewers make sense of the project they start to engage with the installation. ${ }^{33}$

Another multi-sensory installation by the artist Jennifer Steinkamp is Loop with music by electronic composer Jimmy Johnson. The site-specific design uses video projected onto the

33 Greene, David A. "Jennifer Steinkamp." Frieze Magazine, Issue 27 March-April 1996. http://www.frieze.com/issue/review/jennifer_steinkamp1/ (accessed May 2, 2010).
Corcoran's neo-classical Rotunda room to dematerialize the walls and accentuate its details. The six projectors cover the walls of the cylindrical room in an animation of mulitcoloured rope that hang from the base of the dome ceiling. Lifting and undulating, the layers of ropes sway about as if there is a draft in the room. Users are filled with the ambient quality of the digital music that intensifies the experience of the surreal movement of the ropes. The patterns of light are disrupted as visitor's shadows move across the rays of the projectors and their movements are exposed on the walls, adding to the sensory experience. The audience become participants as they experiment with their shadows, uniting the audience and changing the spatial confines of a gallery experience. The combination of visual, auditory and bodily experience immerse people into the space and allow them to explore their own perceptions of their environment. 



\section{Applying the Design Principles}

The primary goal in applying design principles is to inspire the use of visual enhancing digital screens in crafting and refining public spaces with content that can address a range of various audience groups. The flexibility of the design principles allows for choice; not every principle must be applied to each project. Projects should consider successful applications of the digital media and choose the appropriate principles. The design principles not only create a framework for creating public space projects but also provide designers with the knowledge that the greatest achievement of a public installation is the connections people have with the project.

The guidelines address context and scale by deriving ideas from existing contexts and built forms, as well as prevailing historic qualities and characteristics. The application of digital media with these techniques and principles should ideally reflect the traditions and patterns of an urban area. Therefore, digital media can be used to enhance an established identity and create cohesion within communities in their capacity to initiate and encourage participation by the community. The design principles will ensure that installations practice the benefits of connecting with the user in order to be spatially constructive: “...the 'media building' does not simply create a new form of urban spectacle but a new mode of urban performance which alters the dynamics of public space." 34

34 Mcquire, Scott. "Electropolis." The Media City: Media, Architecture and Urban Space
(Published in association with Theory, Culture \& Society). Thousand Oaks, CA: Sage (Published in association
Publications Ltd, 2008. 128. 


\begin{tabular}{|c|c|c|c|c|}
\hline $\begin{array}{l}\text { Elements / } \\
\text { Factors }\end{array}$ & $\begin{array}{l}\text { Artist Installation / } \\
\text { Creativity }\end{array}$ & $\begin{array}{c}\text { Sustainability / Ecological } \\
\text { potentials }\end{array}$ & $\begin{array}{l}\text { Commercial Use / Media } \\
\text { Exposure / Economic }\end{array}$ & Reactive / Social \\
\hline The Challenge & $\begin{array}{l}\text { To create new spaces with } \\
\text { instances of creativity }\end{array}$ & $\begin{array}{l}\text { To employ sustainable and or } \\
\text { renewable energy to digital } \\
\text { media }\end{array}$ & $\begin{array}{l}\text { To have the financial support of a } \\
\text { corporation }\end{array}$ & $\begin{array}{l}\text { To encourage community } \\
\text { involvement and group } \\
\text { interaction }\end{array}$ \\
\hline $\begin{array}{r}\text { The } \\
\text { Approach/ } \\
\text { Methods }\end{array}$ & $\begin{array}{l}\text { Visually enhance public space and } \\
\text { attract the community by making } \\
\text { art accessible to the public }\end{array}$ & $\begin{array}{l}\text { Use sustainable or renewable } \\
\text { technologies }\end{array}$ & $\begin{array}{l}\text { Apply brand aspirations to the } \\
\text { site/architecture and vice versa }\end{array}$ & $\begin{array}{l}\text { Present messages voluntarily } \\
\text { as opposed to involuntarily } \\
\text { (idle signs) }\end{array}$ \\
\hline Application & $\begin{array}{l}\text { Showcase both architecture and } \\
\text { art to the public through visuals }\end{array}$ & $\begin{array}{l}\text { Collect the sun's energy, or other } \\
\text { renewable energy sources in } \\
\text { facade systems }\end{array}$ & $\begin{array}{l}\text { Join architecture and media to } \\
\text { accentuate architecture whilst } \\
\text { promoting brand/product }\end{array}$ & $\begin{array}{l}\text { Give creative license to the } \\
\text { public to create authentic } \\
\text { designs }\end{array}$ \\
\hline $\begin{array}{r}\text { Addressing } \\
\text { Streetscape/ } \\
\text { Public Space }\end{array}$ & $\begin{array}{l}\text { Construct space and visuals that } \\
\text { brings the movement of people } \\
\text { through the space }\end{array}$ & $\begin{array}{l}\text { Combine digital media } \\
\text { technology and sustainability }\end{array}$ & $\begin{array}{l}\text { Create platform for } \\
\text { communication of brand through } \\
\text { architecture }\end{array}$ & $\begin{array}{l}\text { Trigger curiosity through } \\
\text { novelty for a desensitized } \\
\text { public, encouraging discovery, } \\
\text { experimentation, and the } \\
\text { element of surprise }\end{array}$ \\
\hline $\begin{array}{l}\text { Impact on the } \\
\text { city fabric }\end{array}$ & $\begin{array}{l}\text { Become an integral part of } \\
\text { the urban landscape, as an } \\
\text { abstract, constantly modulating } \\
\text { architectural form }\end{array}$ & $\begin{array}{l}\text { Provide ecologically friendly } \\
\text { energy for media uses that are } \\
\text { also aesthetically pleasing during } \\
\text { the day }\end{array}$ & $\begin{array}{l}\text { Use architecture for flexible } \\
\text { versatile media rather than } \\
\text { still images, create energy and } \\
\text { altering the space in use }\end{array}$ & $\begin{array}{l}\text { Create joy and positive energy, } \\
\text { drawing more attention, } \\
\text { so that spectators become } \\
\text { participants. Promote the } \\
\text { elements of collective wonder } \\
\text { and individual thought, } \\
\text { which are ever-changing } \\
\text { because they are generated } \\
\text { by the participants. Lingering } \\
\text { pedestrians create crowds } \\
\text { important for public presence }\end{array}$ \\
\hline Examples & $\begin{array}{l}\text { L.A.S.E.R. TAG by Graffiti } \\
\text { Research Lab } \\
\text { Spots Installation by } \\
\text { realities:united architects }\end{array}$ & $\begin{array}{l}\text { Habitat Hotel by James Clar \& } \\
\text { Associates } \\
\\
\text { GreenPix - Zero Energy Media } \\
\text { Wall by Simone Giostra \& } \\
\text { Partners Architects } \\
\text { AT\&T global pavilion by FTL } \\
\text { Design Studio }\end{array}$ & $\begin{array}{l}\text { T-Mobile Bonn Headquarters by } \\
\text { ag4 mediatecture } \\
\text { Chanel Ginza Façade by Peter } \\
\text { Marino + Associates Architects } \\
\text { Adobe's CS3 Launch by Brand New } \\
\text { School }\end{array}$ & $\begin{array}{l}\text { Body Movies by Rafael Lozano- } \\
\text { Hemmer } \\
\text { Touch by LAB[au] }\end{array}$ \\
\hline
\end{tabular}




\begin{tabular}{|c|c|c|c|}
\hline $\begin{array}{c}\text { Aesthetics / Façade } \\
\text { treatment }\end{array}$ & Adaptability / Scale & $\begin{array}{l}\text { Authenticity / Community } \\
\text { Appreciation }\end{array}$ & $\begin{array}{c}\text { Multi-sensory / Responsive } \\
\text { environments }\end{array}$ \\
\hline $\begin{array}{l}\text { To manipulate surfaces and } \\
\text { spaces without demolition and/ } \\
\text { or construction }\end{array}$ & $\begin{array}{l}\text { To create a comfortable } \\
\text { environment where pedestrians } \\
\text { want to return }\end{array}$ & $\begin{array}{l}\text { To be unique to its context and } \\
\text { to create unique experiences }\end{array}$ & $\begin{array}{l}\text { To engage multiple senses for a } \\
\text { heightened experience }\end{array}$ \\
\hline Celebrate an existing landmark & $\begin{array}{l}\text { Apply ratio to surrounding } \\
\text { environment }\end{array}$ & $\begin{array}{l}\text { Design for the specific city } \\
\text { and site using characteristics } \\
\text { inherent to the place so that the } \\
\text { community can relate to it }\end{array}$ & $\begin{array}{l}\text { Use a combination of sensory } \\
\text { experiences beyond the } \\
\text { projected screen }\end{array}$ \\
\hline $\begin{array}{l}\text { Use areas that are inherently } \\
\text { unpleasing as canvases for visual } \\
\text { performances }\end{array}$ & Employ everything in moderation & $\begin{array}{l}\text { Create an urban identity by } \\
\text { taking the larger urban fabric } \\
\text { into consideration }\end{array}$ & $\begin{array}{l}\text { Design with awareness and } \\
\text { anticipation of a user's } \\
\text { sensations to expand users } \\
\text { consciousness }\end{array}$ \\
\hline $\begin{array}{l}\text { Create presence and brings } \\
\text { attention to facades otherwise } \\
\text { hidden in the dark }\end{array}$ & $\begin{array}{l}\text { Transform a building into a viable } \\
\text { visual addition }\end{array}$ & $\begin{array}{l}\text { Capture the community's spirit } \\
\text { and desires, understanding the } \\
\text { potential needs, conditions and } \\
\text { expectations of the community }\end{array}$ & $\begin{array}{l}\text { Engage in the context of the } \\
\text { site using the advantages of } \\
\text { the installation experienced by } \\
\text { night, day and during various } \\
\text { seasons }\end{array}$ \\
\hline $\begin{array}{l}\text { The surface is not just a barrier } \\
\text { between exterior and interior } \\
\text { conditions but becomes the } \\
\text { canvas for dynamic visual spatial } \\
\text { performances }\end{array}$ & $\begin{array}{l}\text { By using digital media the } \\
\text { architecture becomes the canvas } \\
\text { for changing displays and will not } \\
\text { become outdated }\end{array}$ & $\begin{array}{l}\text { Brings pride and inspiration to } \\
\text { the community }\end{array}$ & $\begin{array}{l}\text { Transforms beyond the physical } \\
\text { limitations of the space }\end{array}$ \\
\hline $\begin{array}{l}\text { Twists and Turns by Mader, } \\
\text { Stublic, Wiermann } \\
\text { 555Kubik by Urbanscreen }\end{array}$ & $\begin{array}{l}\text { Blinkenlights by Chaos Computer } \\
\text { Club }\end{array}$ & The Image Mill by Robert Lepage & $\begin{array}{l}\text { Swell and Loop by Jennifer } \\
\text { Steinkamp }\end{array}$ \\
\hline
\end{tabular}





\subsection{CASE STUDY SYNOPSES}

The main challenge with each of the three case studies is the commercial sector's control of public space. The rise of commercial success brought about the popularity of the space in the first place. However, the fluctuation of capital causes the rise and fall of many public realms, requiring an awareness that a more sustainable approach needs to be taken. Successful public spaces are those which people want to use. People choose to be in a space because there are elements that draw them to it: they are comfortable there and want to return. Although Times Square and the Las Vegas Strip have the ability to attract tourists, they lack the stainability for return visits and appreciation of the space, as observed through the lack of popularity with local residents. Times Square is not a very comfortable place to be with its towering billboards and vertically rising neon lights. There is no continuity between the branching streets, leaving them dull, uninviting, and empty. Las Vegas sidewalks are privatized and the paths seem to lead pedestrians back to the casino floor. These private sectors have the qualities of largeness or grandeur - 'bigger is better'. But for a successful public realm, there must be a pedestrian scale. This scale is crucial to making a subject comfortable in the space. Space that is framed and defined promotes a continuous urban fabric; disorienting breaks disrupt the energy built up from a successful street or square, creating isolation. ${ }^{1}$ Naturally humans feel comfortable when there is a good ratio of pedestrian scaled objects. ${ }^{2}$ In these scenarios, the crowds are already present, as is the space. Private and public sectors benefit from the energy of performances and media facade art installations immersed in the consumer culture. These media facades help reintroduce brands into our visual culture in a way that promotes public space, allowing facades to reveal themselves in the visual landscape.

1 Lynch, Kevin. The Image of the City. London: The Mit Press, 1960. 52

2 Halprin, Lawrence. Cities: Revised Edition. Revised ed. London: The Mit Press, 1972. 98 


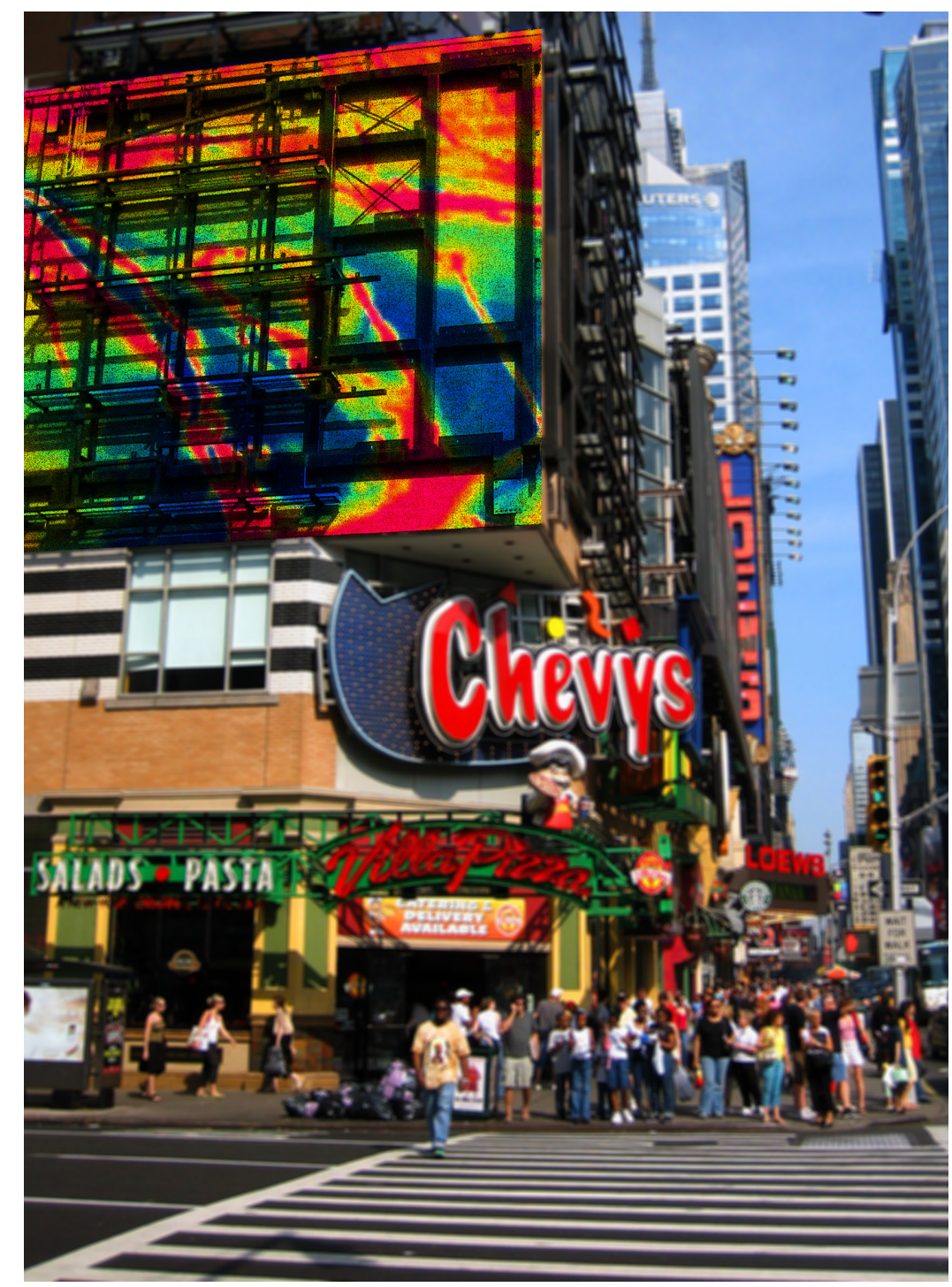

fig.2.5.1

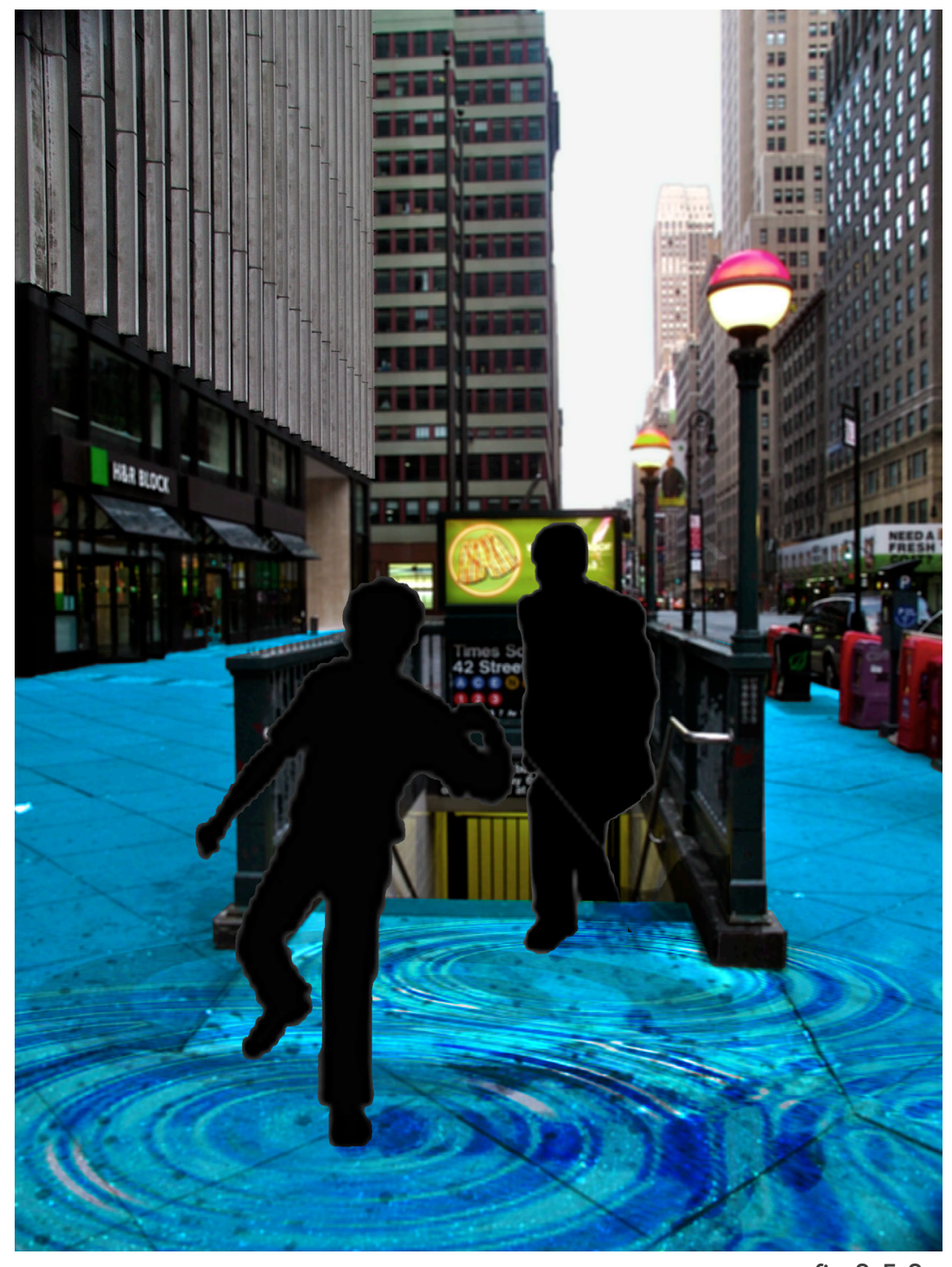

fig.2.5.2 


\section{Principles Applied in Times Square}

+ Aesthetics / Facade treatment

+ Artist Installation / Creativity

+ Commercial Use / Media

Exposure / Economic

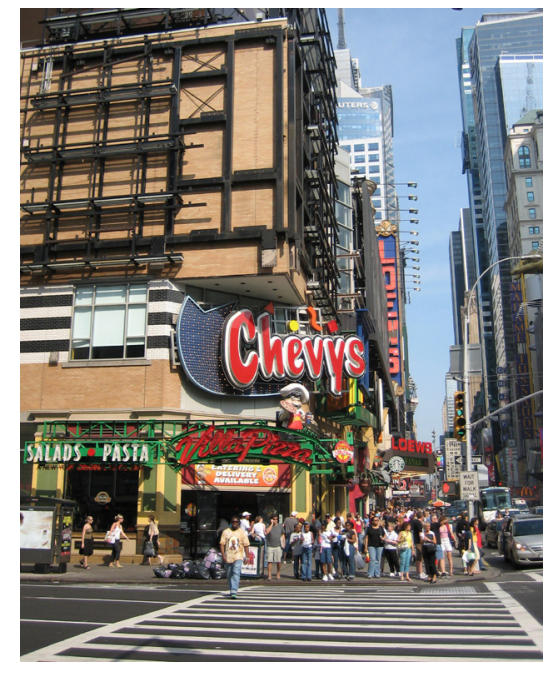

fig.2.5.3

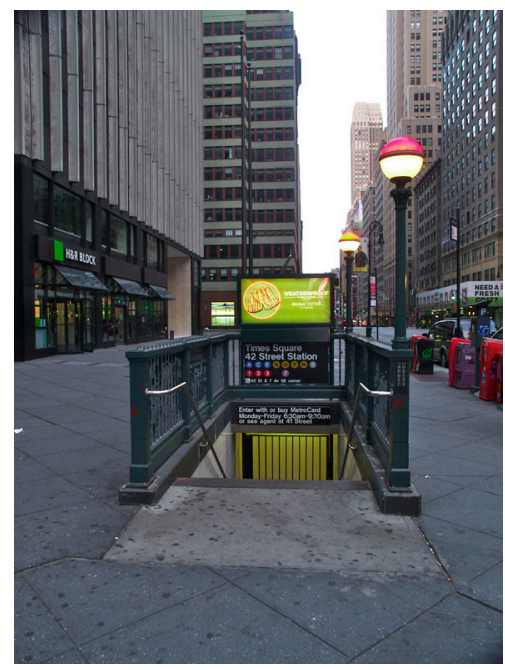

fig.2.5.4
Media facades are capable of transforming any surface into a canvas, yet are versatile enough to become an advertisement. In this scenario, the structure for a still billboard is revealed yet recaptured to be more appealing. Installations placed at key locations help inject the streets with public art projects to enrich the pedestrian experience and promote high quality spaces.

In Times Square, for example, different projections help to promote the side streets that extend off of the main intersection. These additions help to transition between Times Square and the rest of the city. Stark contrasts are made more noticeable when side streets lack the dynamics of the main square where lighting for signage is required by code. Thus, transitional spaces also benefit through digital media. 1 "How Art Economically Benefits Cities | Project for Public Spaces (PPS) ." Placemaking for
Communities | Project for Public Spaces (PPS) . N.p., n.d. Web. 19 Mar. 2010. < http://www.
pps.org/info/pub_art/art_impact>. 


\section{+ Social Interaction \\ + Commercial Use / Media Exposure}

Although visually energetic, billboards do not interact with pedestrians. These suggested additions help engage viewers with novelty and playfulness without losing space for commercial advertising: "A sign of a great place is triangulation. This is the process by which some external stimulus provides a linkage between people and prompts strangers to talk to each other as if they were not". ${ }^{\text {. The }}$ placement of this screen in the pedestrian plaza, and the public seating area can spark the process of triangulation by engaging and entertaining the passersby. The surface area can alternate between interactive displays and advertising. Adding a dimension of social interaction in the space can drastically alter the dynamics between visitors and the square.

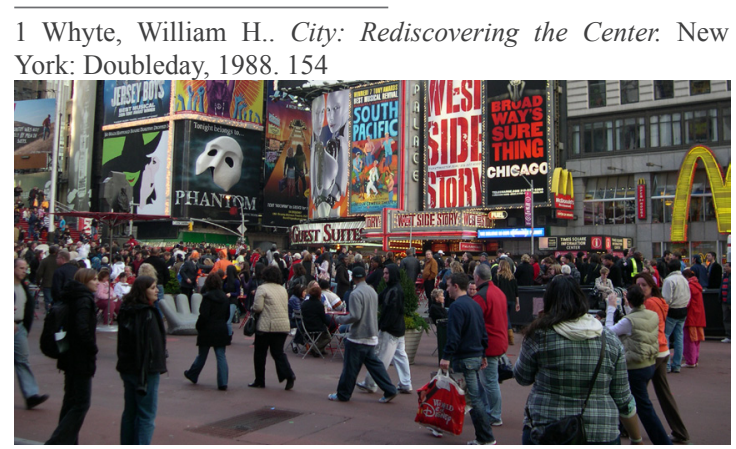

fig.2.5.7

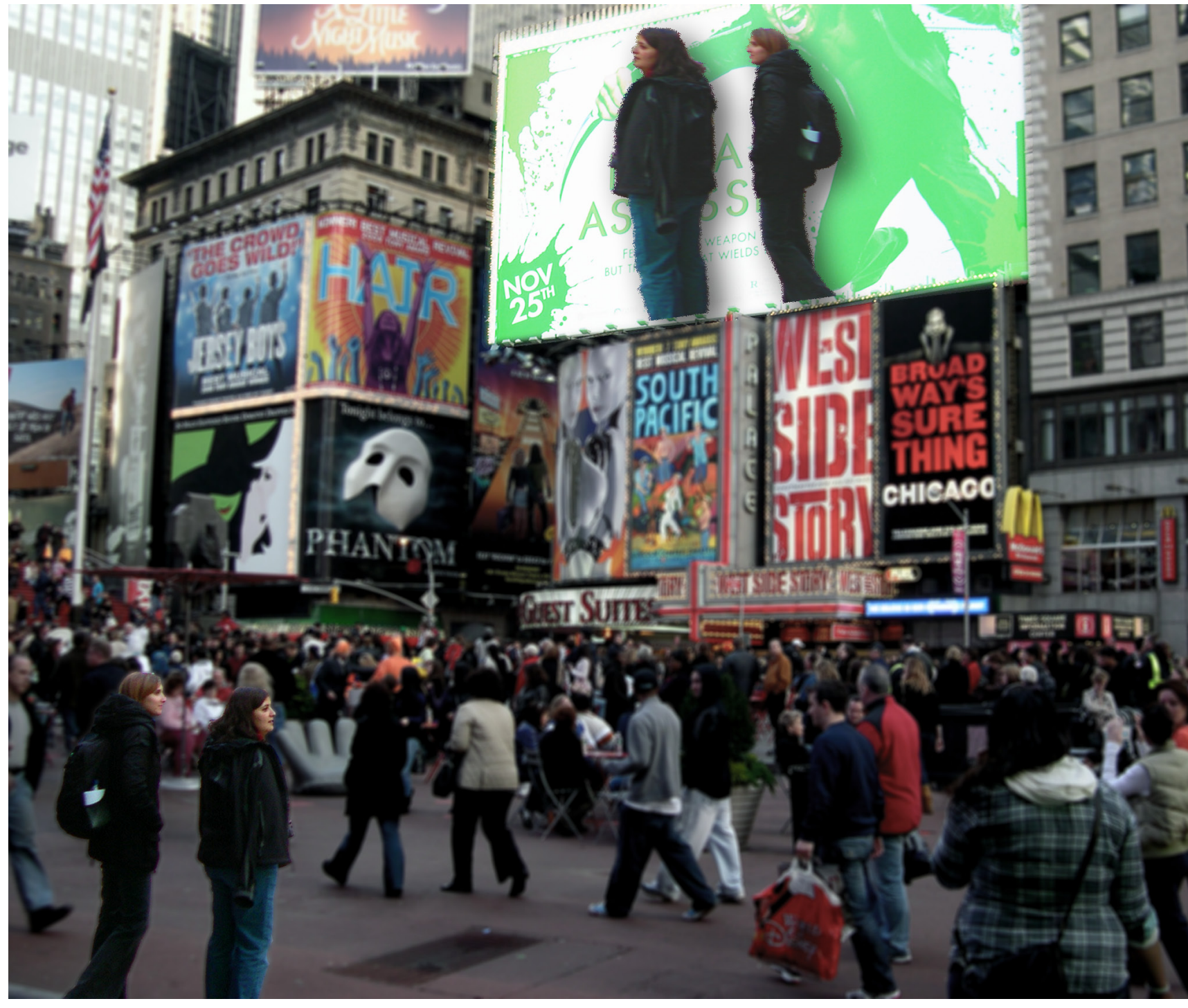

fig.2.5.8 


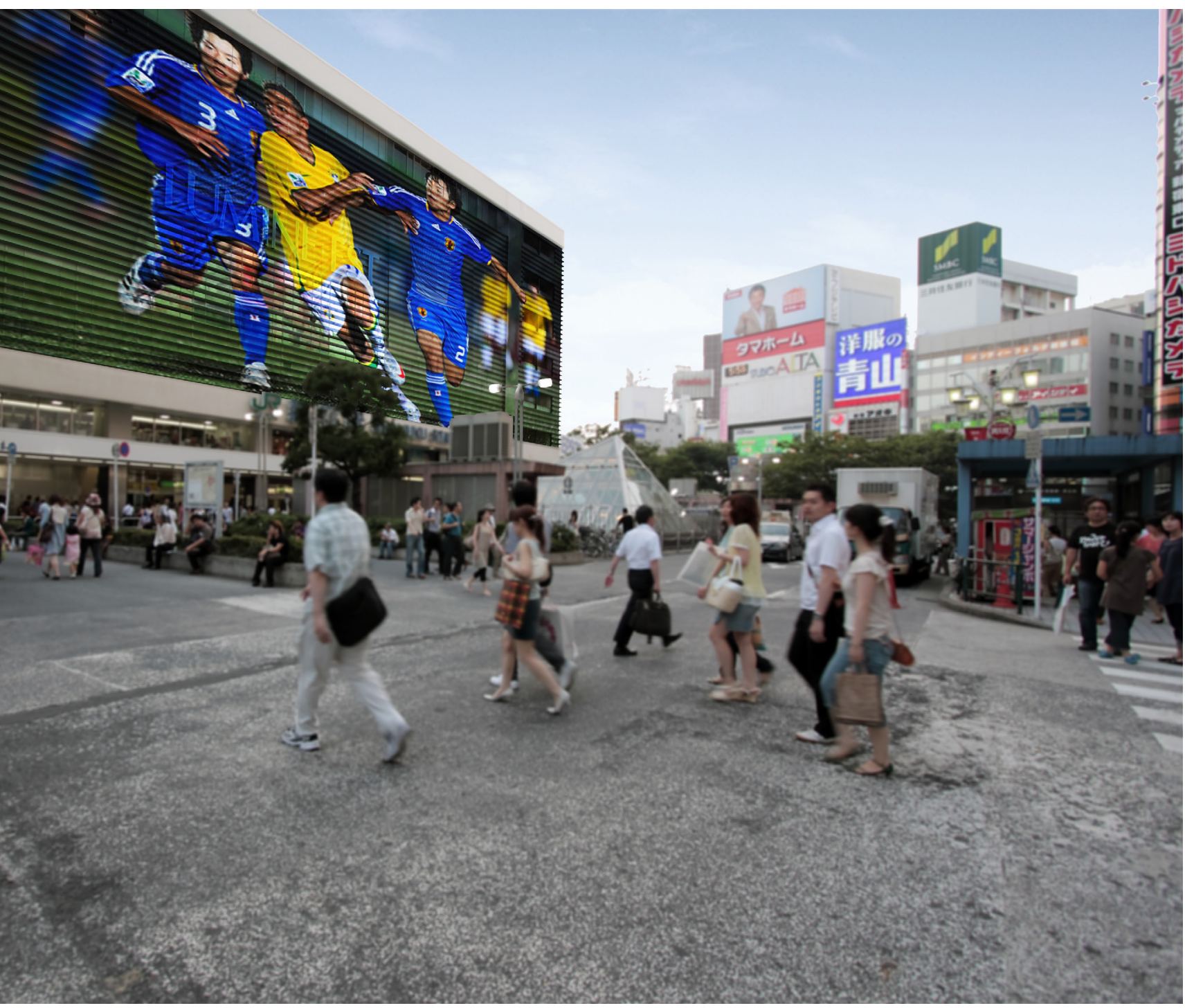

fig.2.5.9

\section{Principles Applied in} Shinjuku Station
+ multi-sensory
+ Social Interaction
+ Authenticity /
Community Appreciation

This scheme shows how the facade of a building could promote events in the area, while also improving its daily operating function. Without any obstructive flat commercial billboards the surface is rendered free from haphazard posters consolidating advertising into a seamless commercial. Jan Gehl notes that public spaces benefit when necessary/ functional activities, optional/recreational activities and social activities are combined in

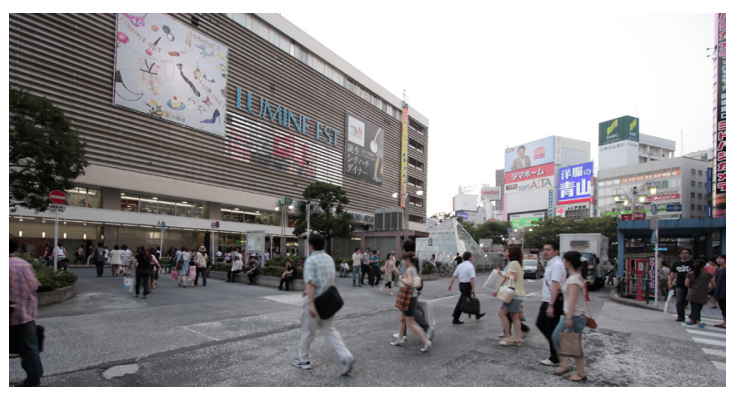

fig.2.5.10 
one space. ${ }^{1}$ A daily commute to a retail centre can better integrate the citizen into the events of a city and encourage communication. For Shinjuku Station, an installation can stream information about the station or events with little or no setup since the canvas is already present for use. The visual element and the corresponding sound echoing through the plaza can transform the place into a performance. It becomes a social gathering space for the city:

In a Society becoming steadily more privatized with private homes, cars, computers, offices and shopping centers, the public component of our lives is disappearing. It is more and more important to make the cities inviting, so we can meet our fellow citizens face to face and experience directly through our senses. Public life in good quality public spaces is an important part of a democratic life and a full life. ${ }^{2}$

1 Gehl, Jan. Life between Buildings: Using Public Space. 4 ed. Skive: Danish Architectural Press, 2001. 14

2 "Jan Gehl" Project for Public Spaces. http://www.pps.org/ jgehl/(accessed May 10, 2010).

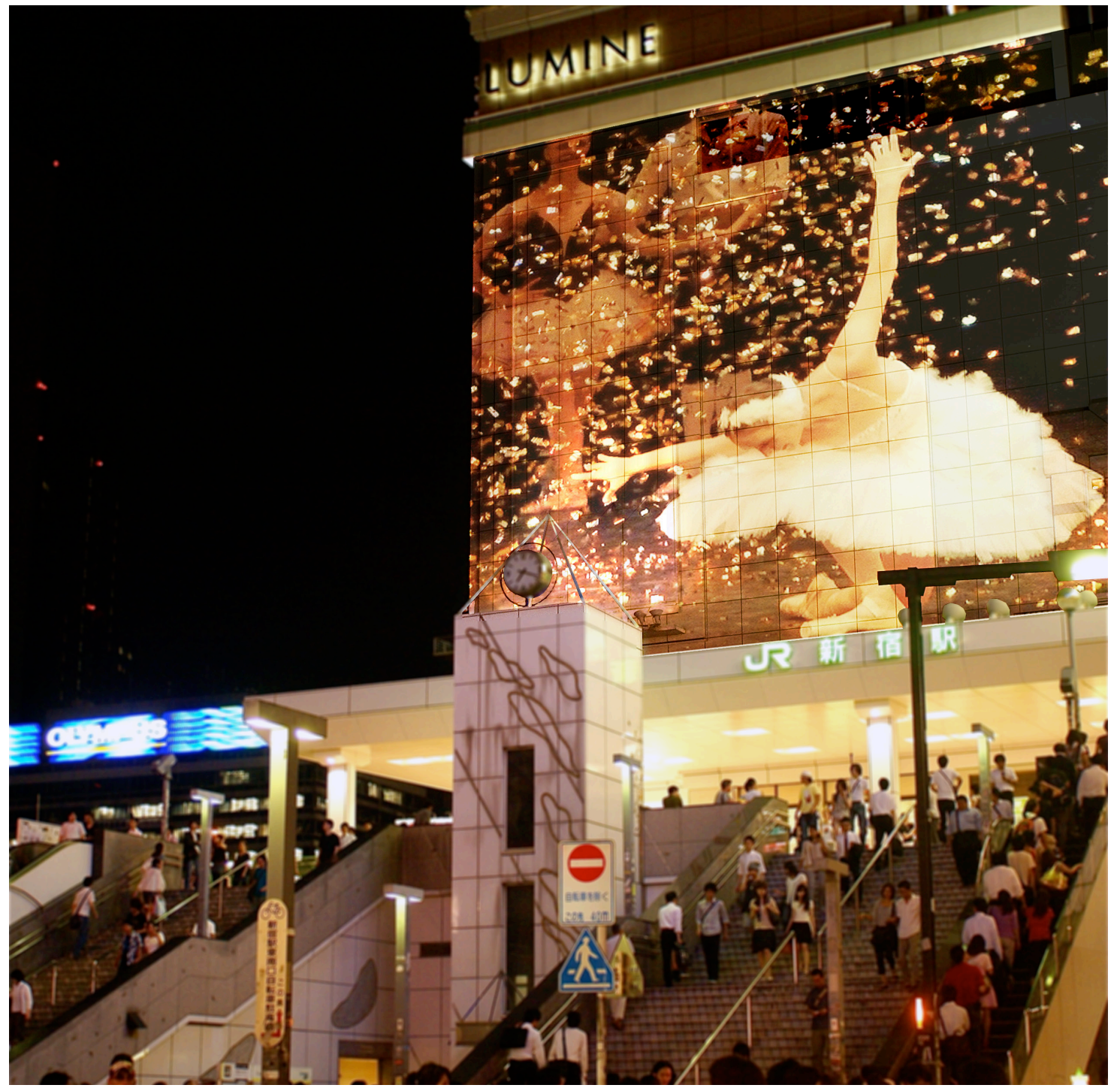

fig.2.5.11 


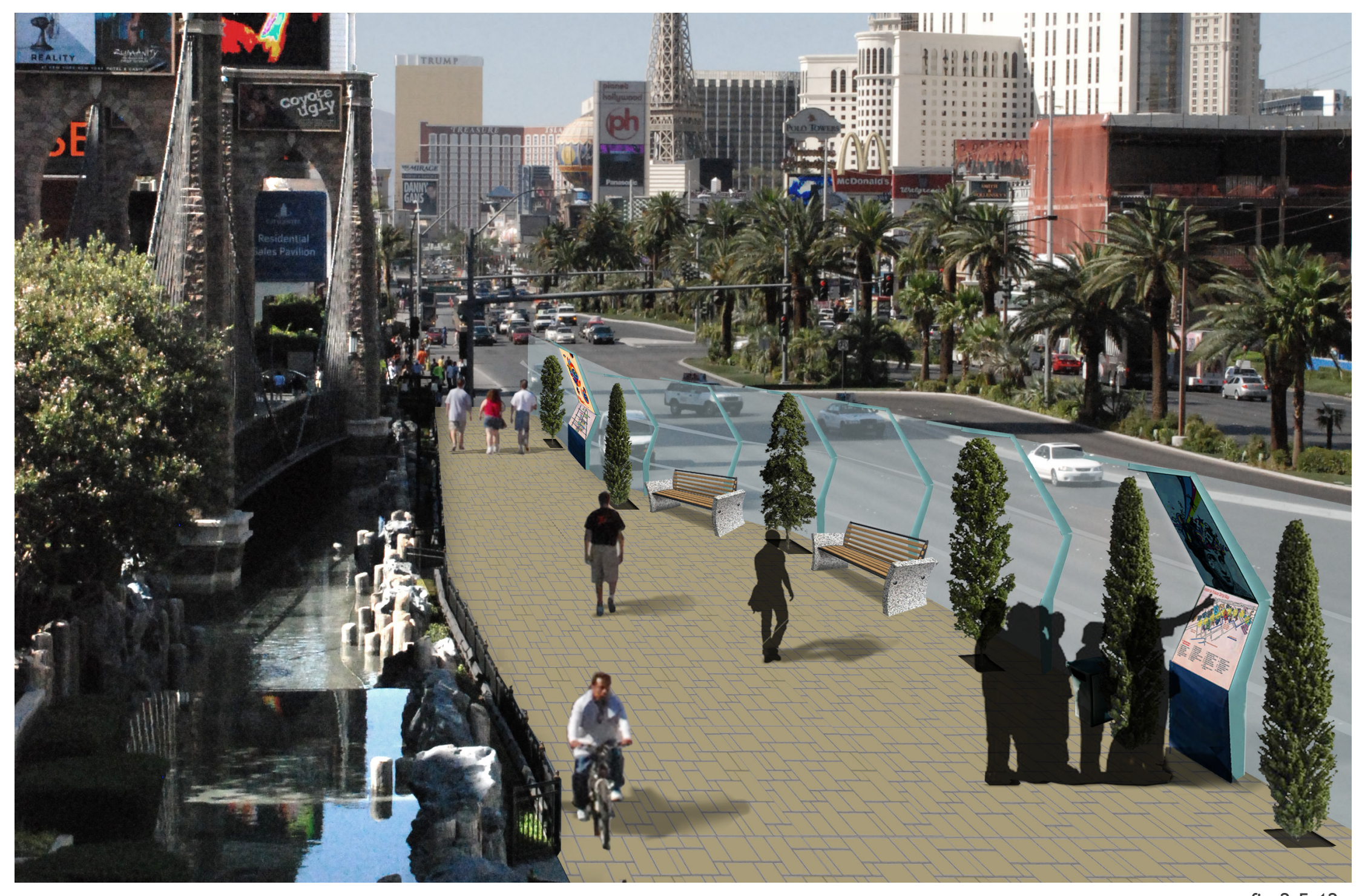

fig.2.5.12 


\section{Principles Applied in Las Vegas}

+ Sustainable Technology /

Ecological potentials

+ Adaptability / Scale

+ Commercial Use / Media

Exposure / Economic

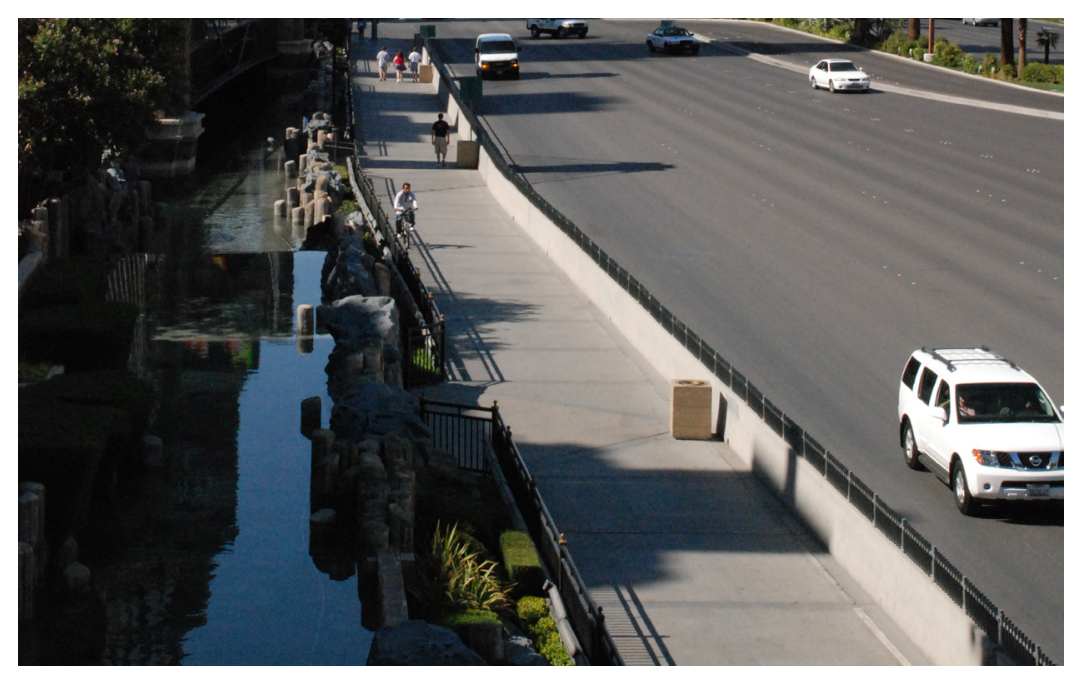

fig.2.5.13
Powered by solar panels, these dynamic electronic displays show navigational information on the lower level, motion sensored interactive installations, and, on occasion, advertisements on the upper window. The structure itself can be colour coded to represent a zone, making it easily identifiable on navigational maps.

The displays, translucent paneling, and poplar trees provide safety from the close proximity of the speeding vehicles and act as an acoustic buffer. A greater sense of space is created with the provided rest areas and extended sidewalk. 

3.0 Application 


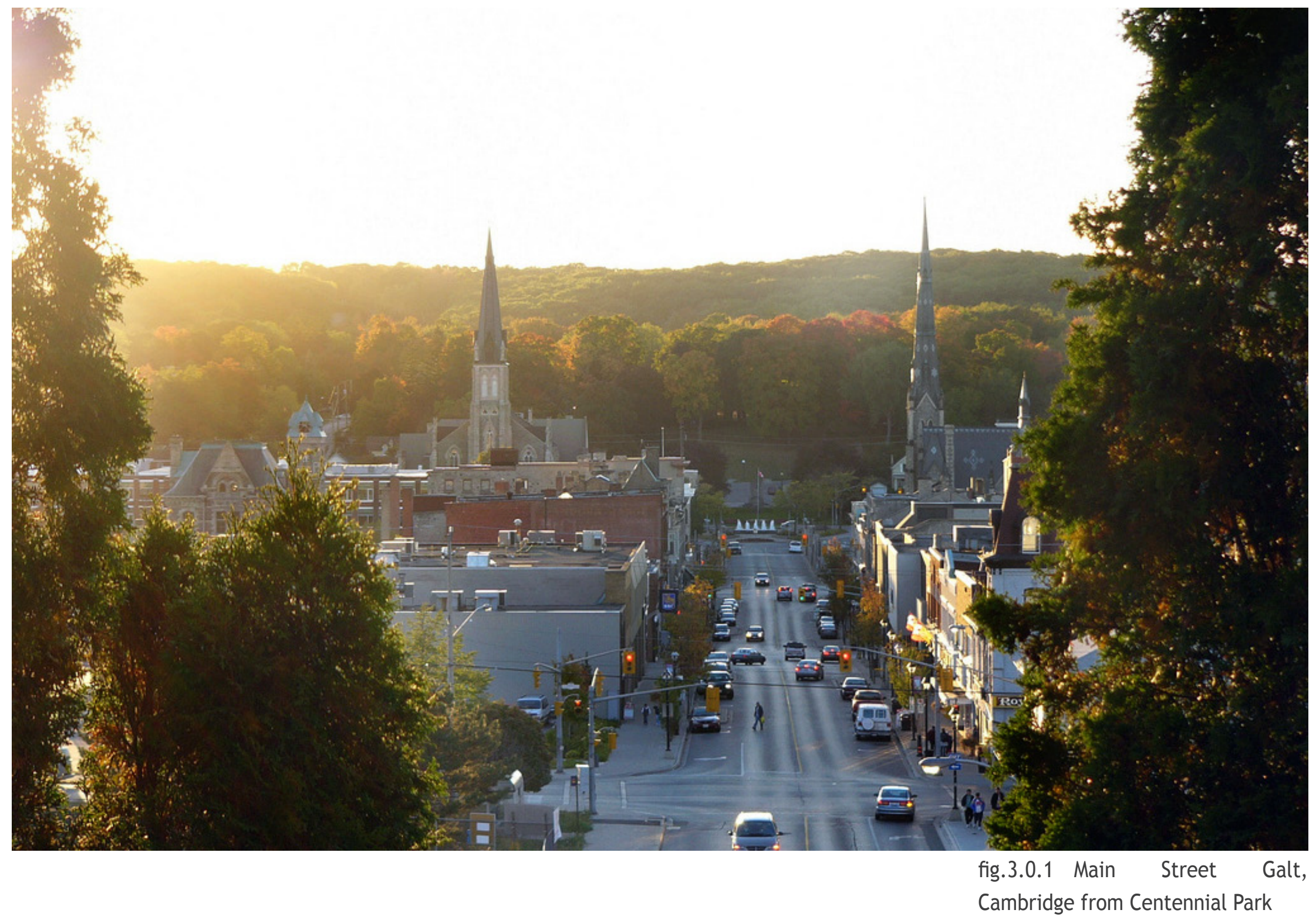




\subsection{GALT CITY CENTRE, CAMBRIDGE, ONTARIO}

\section{AKA “ The Manchester of Canada “}

Area

$112.82 \mathrm{~km}^{2}$

Population as of $2009^{1}$

126,000

Density $1,116.8 / \mathrm{km}^{2}$

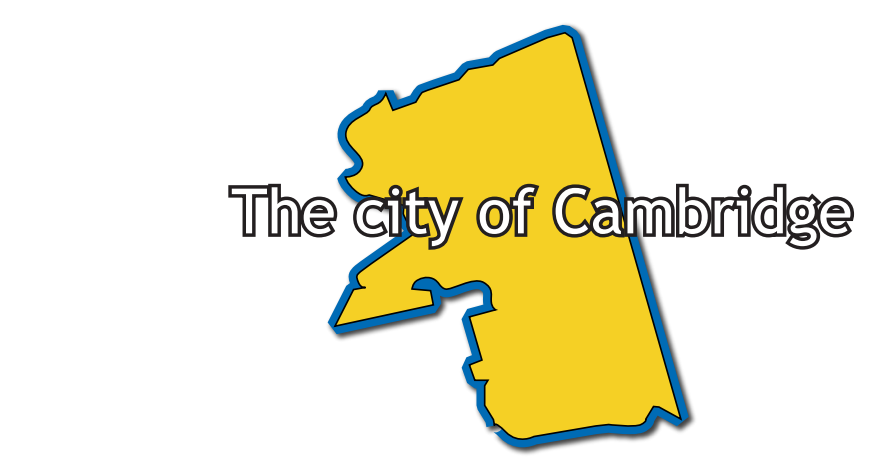

$10.0 \mathrm{~km}$

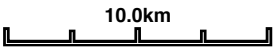

1 "Stats, Facts and Profiles | City of Cambridge, Ontario, Canada." City of Cambridge, Ontario, Canada. http://www.cambridge.ca/economic_development/stats_facts_and_profiles (accessed February 21, 2010).

\section{Historical Development}

In 1784, the British Crown granted a sizable lot of land to the Six Nations Indians. This lot is situated along the Grand River, almost ten kilometers deep on each side from Lake Erie to its source. With the help of Joseph Brant, the Six Nations Indians divided the land into Indian reserves which would then be sold to developers. Honorable William Dickson bought 90, ooo acres of this land in 1816. Dickson chose a site - where Mill Creek flows into the Grand River - as the focal point of the town named Shade's Mills to help populate the countryside. The rest of the land was divided into smaller lots and sold primarily to Scottish settlers. As the new settlement progressed it became in 1825 the largest settlement in the area. When the post office was built in 1827, a name was needed for it. Dickson selected Galt after John Galt, who was a Scottish novelist and Commissioner of the Canada Company. Shade's Mills was then, subsequently, renamed as Galt and by the 1830 s went from an agricultural community to a powerful industrial centre. Galt built a reputation around the world for its quality products such as knitwear, wooden furniture and metal building supplies and became known as "The Manchester of Canada". It was the largest principle town in the area until the twentieth century when Kitchener surpassed it. ${ }^{1}$

\footnotetext{
1 "Historical Information - Evolution of Galt | City of Cambridge, Ontario, Canada." City of Cambridge, Ontario, Canada. http://www.cambridge.ca/city_clerk/city_archives/historical information_evolution_of_galt (accessed February 21, 2010).
} 
To help municipal governments work more effectively, the provincial government decided that the three municipalities Galt, Preston and Hespeler should be amalgamated into the City of Cambridge in 1973. At that time Galt covered the southern half of the city, taking up the largest area in Cambridge. The amalgamation of the three cities helped in the development of a commercial core connecting the previous three downtowns and creating commercial competition for the existing three historic downtowns. In 1977, the merchants and the community formed the Downtown Cambridge Business Improvement Association to promote and maintain a healthy downtown core, branding the commercial area of Galt to Downtown Cambridge. $^{2}$

\section{Public space and the city fabric}

In 1974, the Grand River flooded the streets with water over one meter high and left residents and businesses devastated. ${ }^{3} \mathrm{~A}$ floodwall, called the living levee was constructed to protect the built forms from floods. As a consequence, the wall also became a barrier disconnecting the river from the public realm. This levee changed the look and feel of Galt and negatively impacted the atmosphere along the Grand River. Today, the focal point of the community still revolves around the Grand River and local residents still take pride in the charming look of the river. However, it can still be improved upon greatly to maximize its potential as a public space. Many of the buildings downtown still reflect the historical work of the settlers

\footnotetext{
2 "Brief History of the Community of Galt." About Cambridge History. cambridgeweb.net/ historical/galt.html (accessed February 21, 2010).

3 Swayze, Kevin. "Building boom comes to old Galt downtown in Cambridge." Cambridge Reporter. March 8, 2010. http://www.cambridgereporter.com/news/article/204536 (accessed March 10, 2010).
}

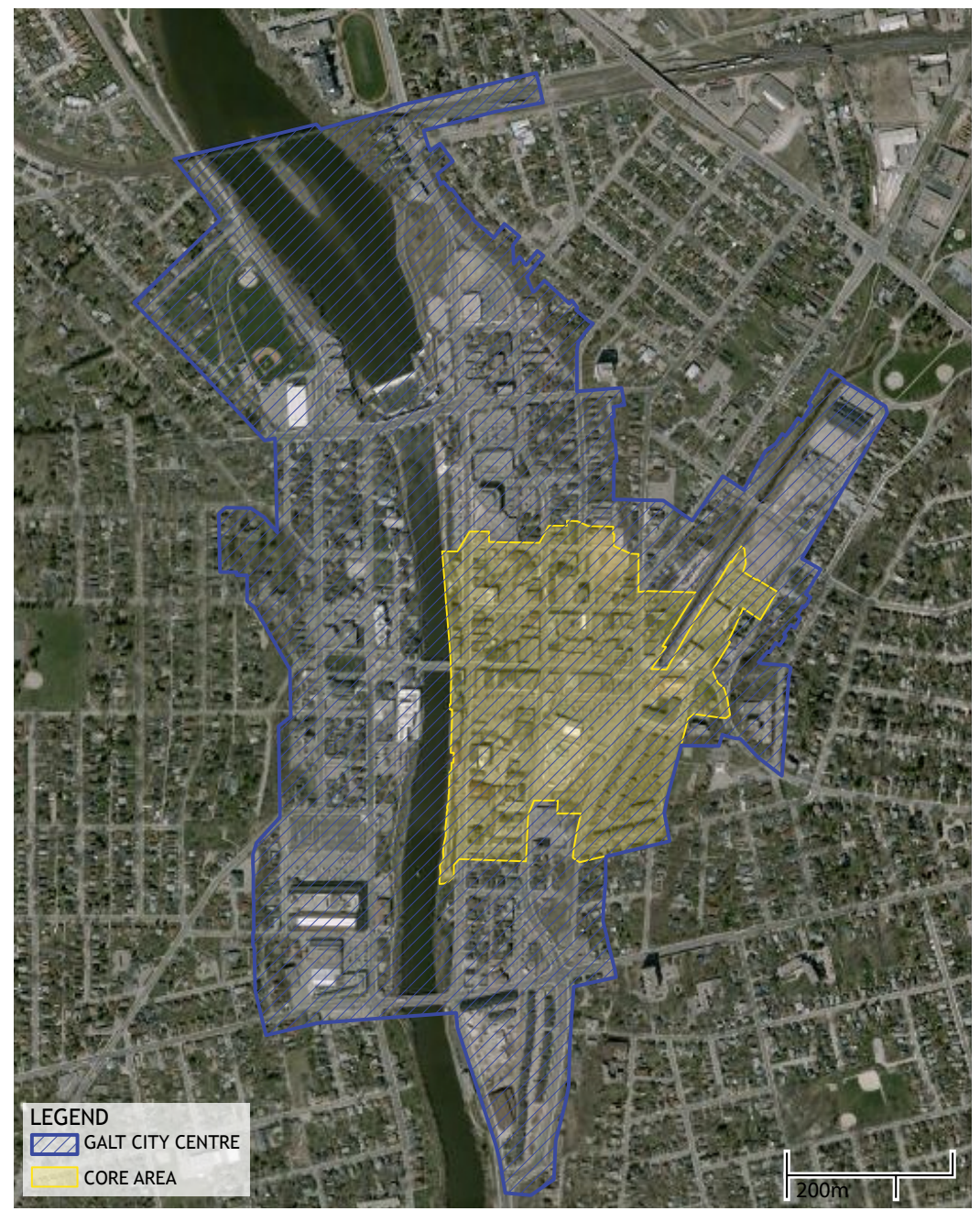

fig.3.0.2 Galt City Centre boundary and the Downtown Cambridge BIA boundary 

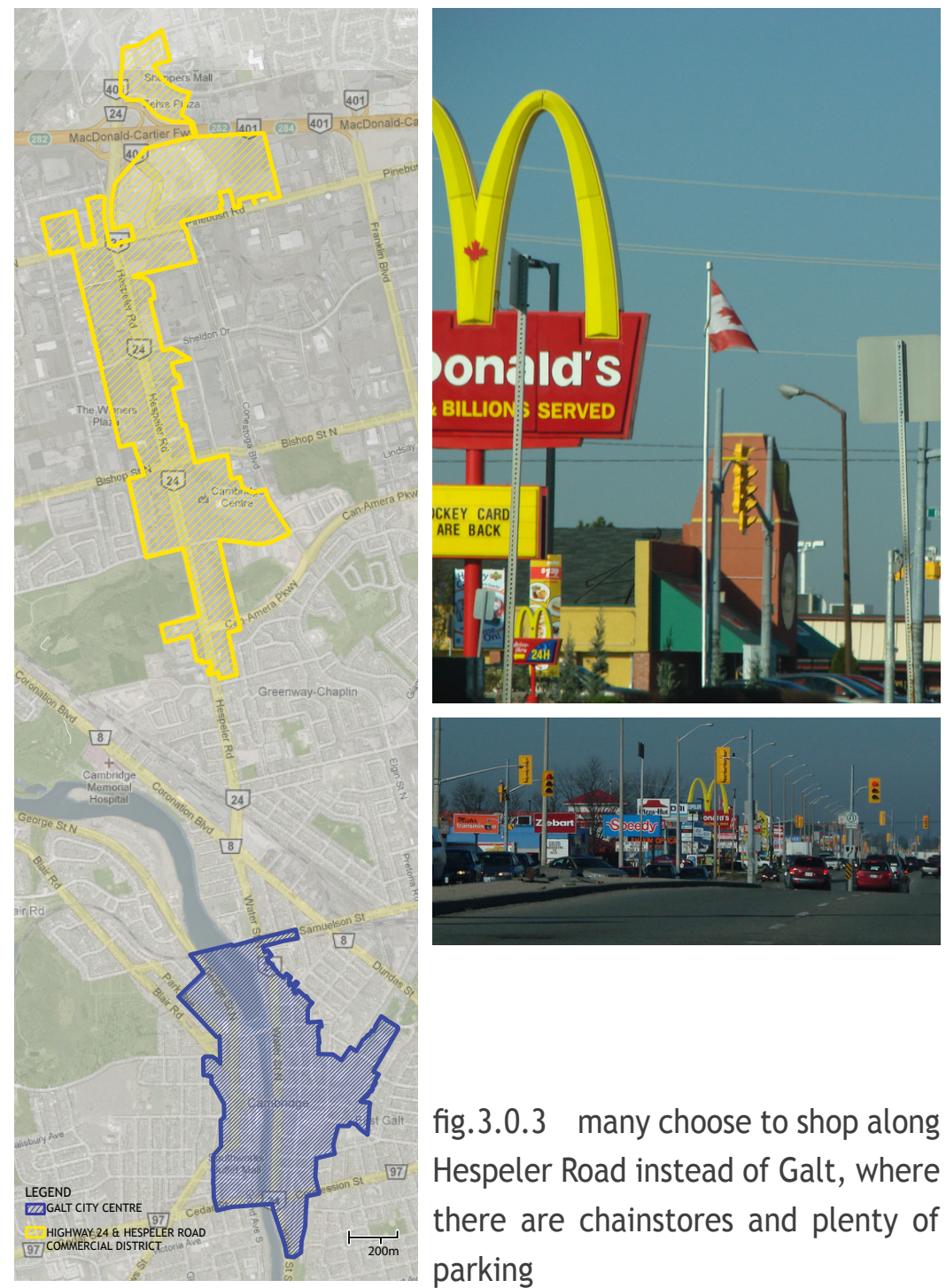

fig.3.0.3 many choose to shop along Hespeler Road instead of Galt, where there are chainstores and plenty of parking when Galt was an industrial centre. West of the Grand River, in Galt City Centre, are many picturesque residences with ample fields and public park space. East of the river, there are small specialty shops and restaurants along Main Street in 'turn of the century' stone structures. Despite how picturesque the old stone buildings are lining the calm river, not many people are seen enjoying it.

\section{Authenticity and Image}

The image of the town is quite distinct, having many historical features preserved, such as the old post office, farmer's market, and the old city hall. The Grand River is also framed with icons of downtown Galt such as the church steeples and quaint pedestrian and traffic bridges.

\section{Displaced}

Galt City Centre has the convenience of a transportation depot near a farmer's market and small retail shops. Unfortunately, these shops do not thrive because residents choose to shop along Hespeler Road, characterized by big box stores and giant outlets.

\section{Visual review and design strategies}

The streets in Galt City Centre are not thriving as a public space; the area surrounding the core relies heavily on the use of automobiles. Galt City Centre becomes an island of pedestrian oriented streets but many pedestrians pass through the area, driving from Brantford straight through Galt City Centre and onto Hespeler Road to access the 401 Highway. Galt City Centre needs to connect the paths leading out of the core area. Currently, they are disconnected and energy 
is quickly dissipated because these places do not flow from one to another. The walks from one retail shop to the next are disrupted by parking lots, abandoned buildings, and/or blank walls. Galt City Centre needs to take advantage of its conveniently located bus terminal. Unfortunately, the amenities are not provided and people will choose to go elsewhere. Once commuters arrive to the core area, they are faced with the backs of buildings and alleyways.

A more pedestrian friendly route needs to be in place, leading visitors out to the Main Street. Once on the Main Street, some attention must be paid to paths connecting to the Grand River, potentially one of its greatest public attractions. Bicycle paths are present but significantly disconnected with no attempts to transition from the streets to the river path. Along the river, there need to be places for people to gather and enjoy the space. Currently, there are benches and areas scattered on both sides of the river but most are hidden. They are unsafe and greatly underused because passersby are unaware of them. These areas should be accessible so that people become aware of them and want to use them.

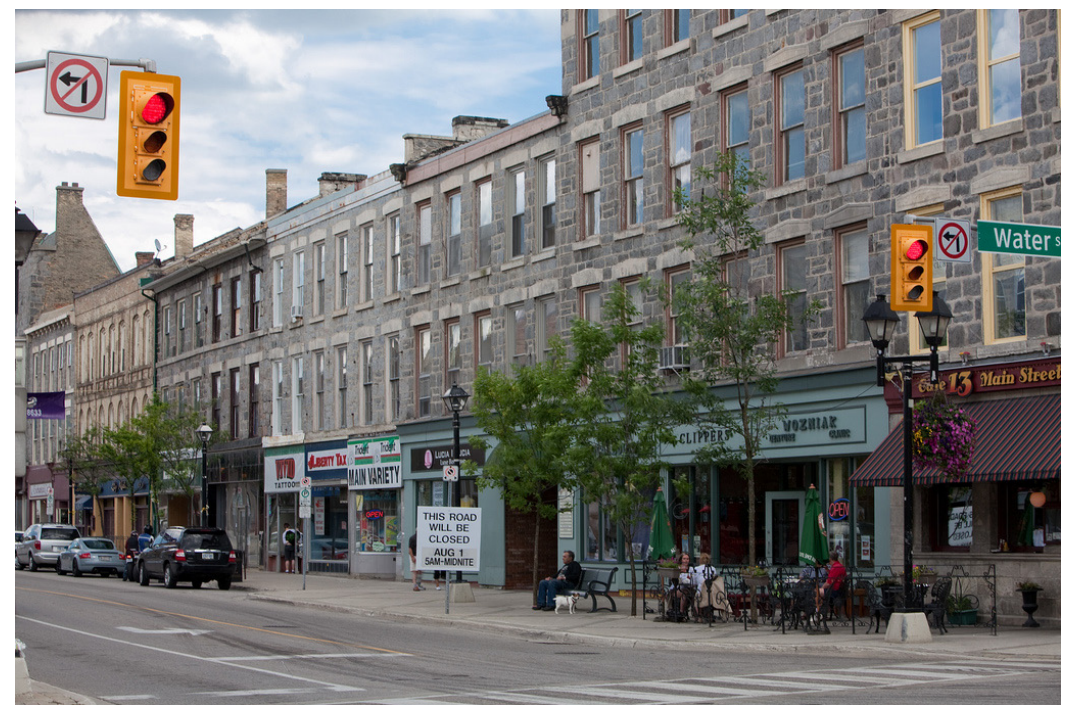

fig.3.0.4 the historical facade of Main Street. Connections made to this retail street could help increase its popularity

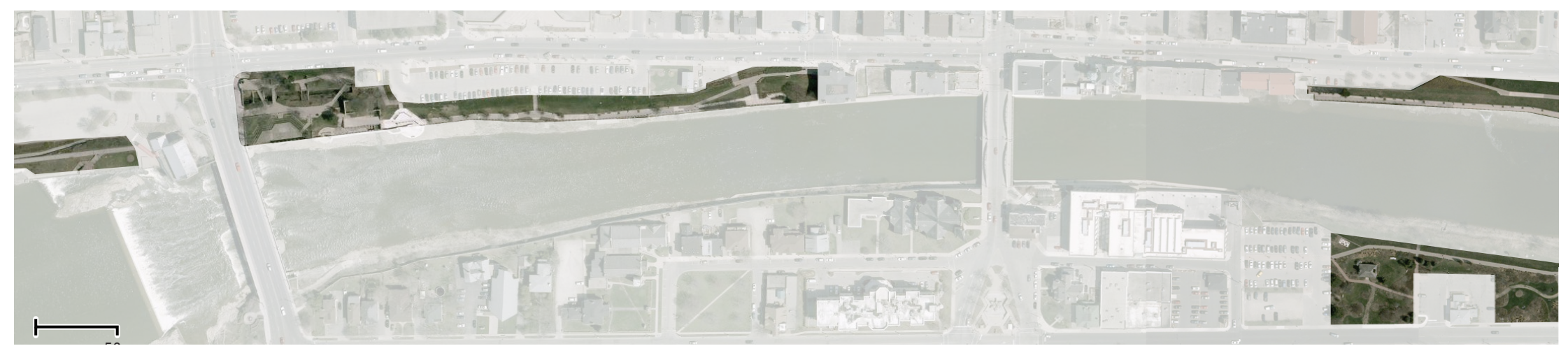

fig.3.0.5 map highlighting disconnected bicycle and pedestrian paths with the occasional seating area 


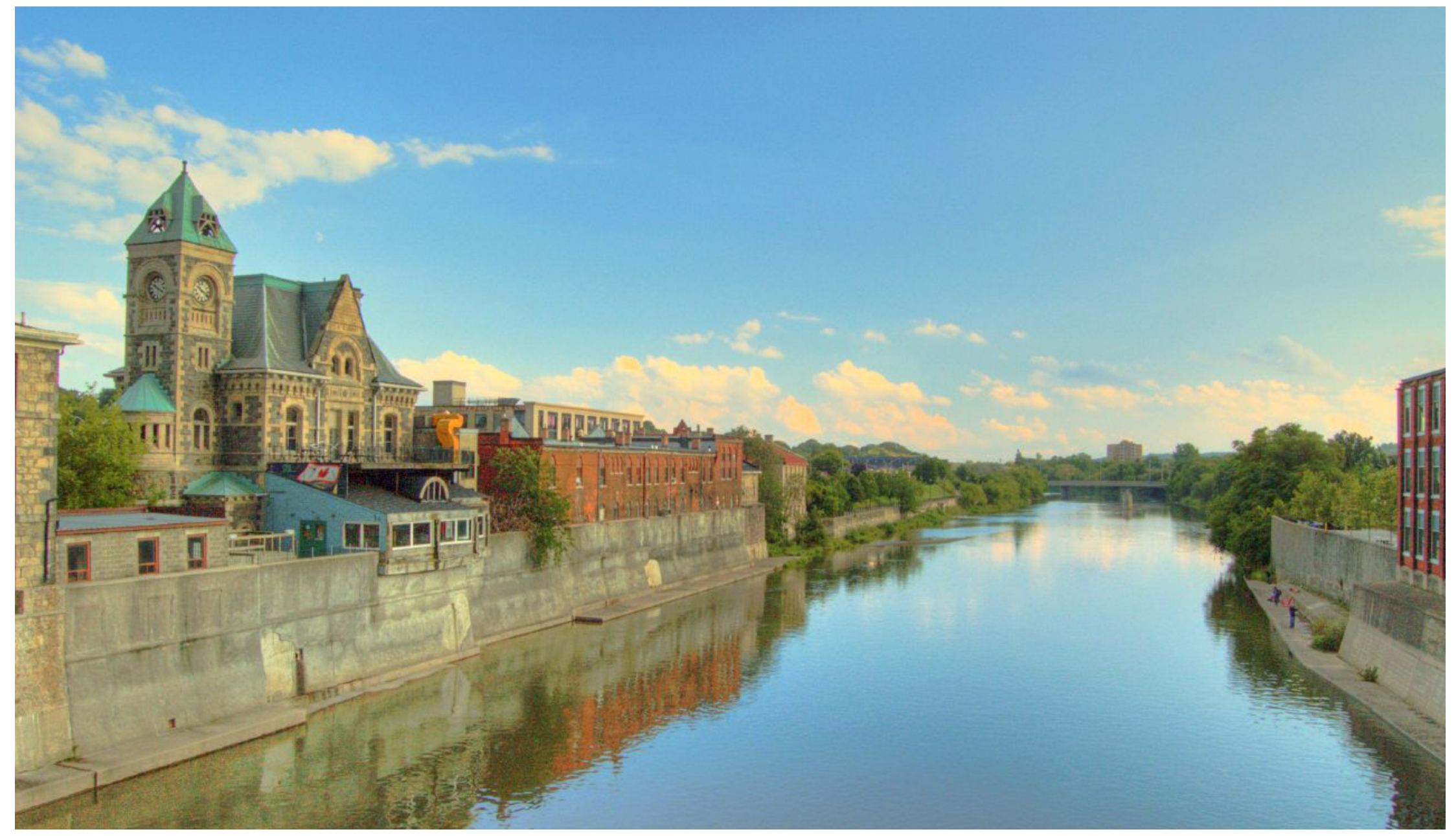

fig.3.0.6 the Grand River holds so much potential yet it is disconnected from pedestrian usage 



\subsection{THE APPLICATION}

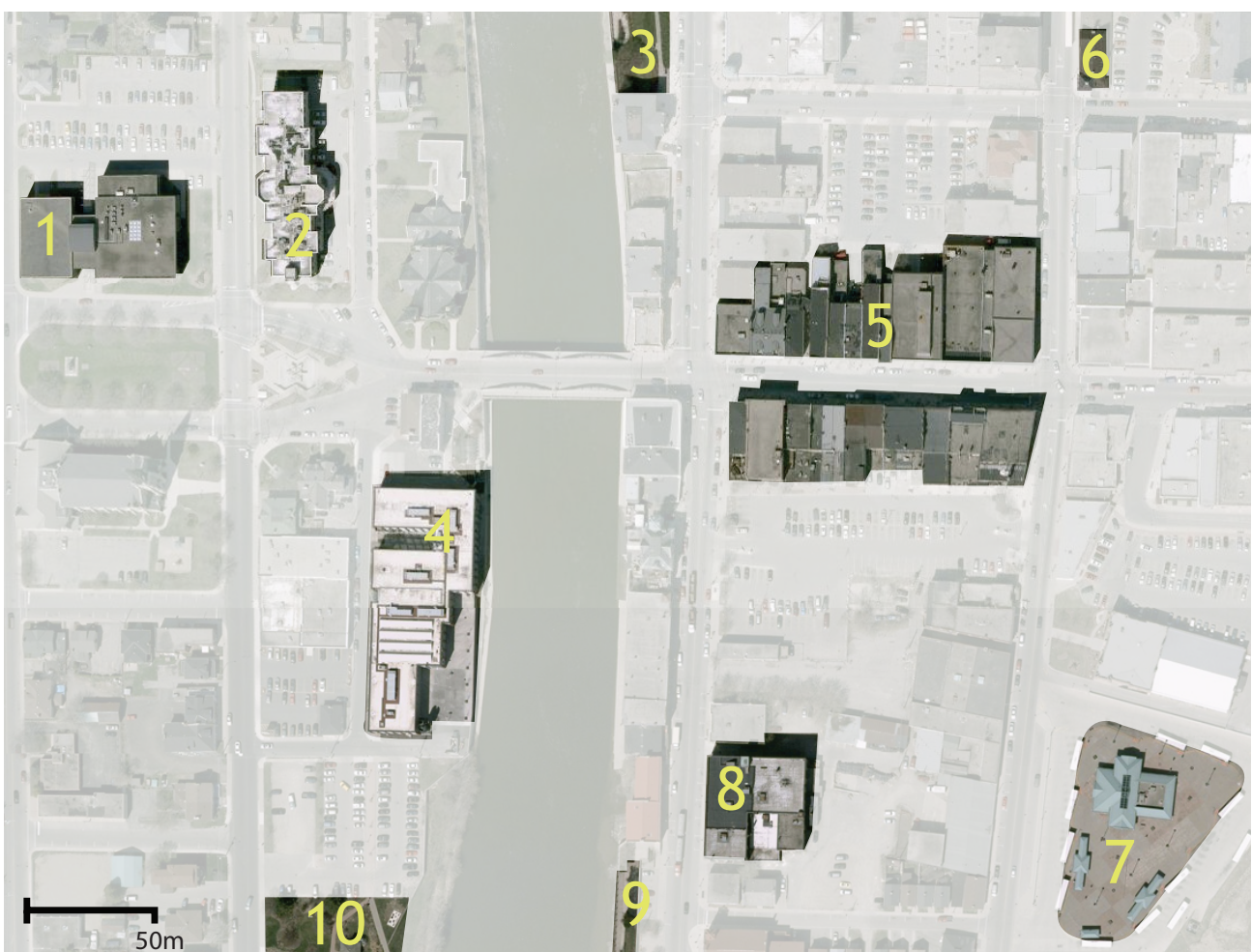

fig.3.1.1 map highlighting many of Galt's features: 1-Cambridge Library; 2-Senior Citizen Centre; 3-Mill Race Park; 4-Design at Riverside; 5-Fashion Boutiques; 6-Farmer's Market; 7-Bus Depot; 8-Tiger Brand Lofts; 9-Bike Trail; 10-Sculpture Garden

\section{Urban condition Galt City Centre}

The Galt City Centre is recognized as Cambridge's largest and its primary downtown core of the three amalgamated cities, Galt, Preston, and Hespeler. Presently, the cnetre is being recommended by the Downtown Cambridge Business Improvement Association (DCBIA) to be the centre of Cambridge, to support the neighboring communities and developments in the area with institutional, residential, and commercial uses. This core area carries a distinct industrial style, especially around the River's edge where many of the buildings have been adapted for new uses. These developments help create a new image of Galt as a mixed-use live/work area, adapting older historic buildings, and encouraging higher density rates ${ }^{1}$. One new development is the conversion of the Tiger Brand Lofts. This building, once a factory for knit products, has been redesigned as open space apartments catering to students and artists. Main Street, in particular, is lined with a number of heritage buildings that are historically significant to the development of Galt City Centre. The core of the downtown is also found in this area. The River attracts various recreational activities such as hiking, fishing, and kayaking. Aesthetically, the Grand River is a natural magnet for the public, as witnessed by the large gathering of people on any sunny day. The

1 "Official Plan | City of Cambridge, Ontario, Canada." City of Cambridge, Ontario, Canada http://www.cambridge.ca/planning_services/policy_planning/official_plan (accessed March 8, 2010). 
active and passive activities initiated along the river are maintained, such as the vegetation and bicycle paths, but many areas still require improvements. The pedestrian paths are not continuous and in many areas vehicular traffic remains predominant. Three bridges in the area, the Main Street Bridge, Concession Street Bridge and Park Hill Road, all link to the river's bank. The bridges are appropriate for vehicular traffic but additional restorations and renovations could be made to improve pedestrian movement across the river. The sidewalks could use a consistent design pattern connecting bridge sidewalks to street sidewalks. The paving would help keep it visually and aesthetically connected and therefore improve the feeling of disconnect currently plaguing the pedestrian walks and the bridge.

Galt City Centre possesses public space capabilities appropriate for supporting a vibrant public realm. The trail systems along the River can be connected to Mill Race Park and the sculpture garden. For the consumer, there are also commercial attractions, like the Cambridge Farmer's Market and fashion boutiques along Main Street. The main branch of the Cambridge Library, Gallery, and many senior citizens facilities are also found here. The core area has supporting transportation for neighboring areas through the centrally located bus terminal. All these factors help support a number of cultural activities, such as the Unsilent Night event, which is part of the 'Christmas in Cambridge' celebrations.

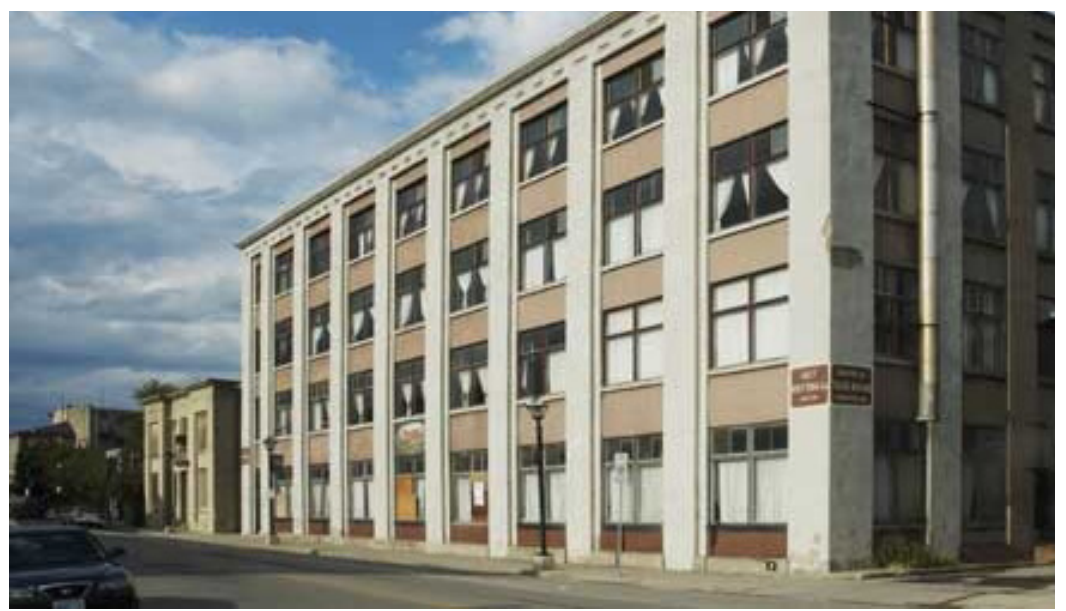

fig.3.1.2 Tiger Lofts is a redevelopment of Cambridge's historic Tiger Brand factory into a loft building

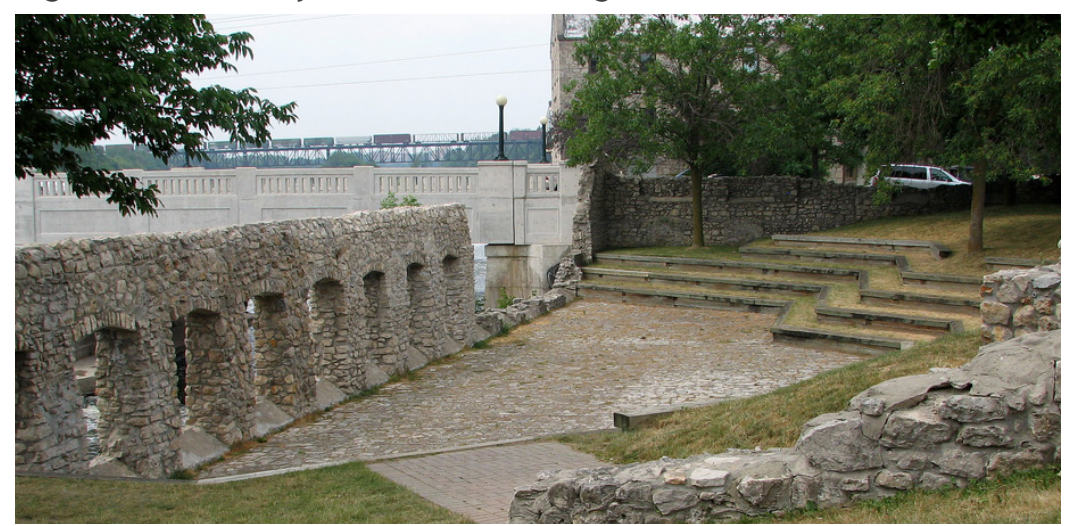

fig.3.1.3 Mill Race Park, part of the Cambridge Heritage River Trail which intends to be "a continuous, integrated trail system along the Grand River, to link commercial and residential districts and eventually to join trails from the adjacent cities of Kitchener and Guelph." 


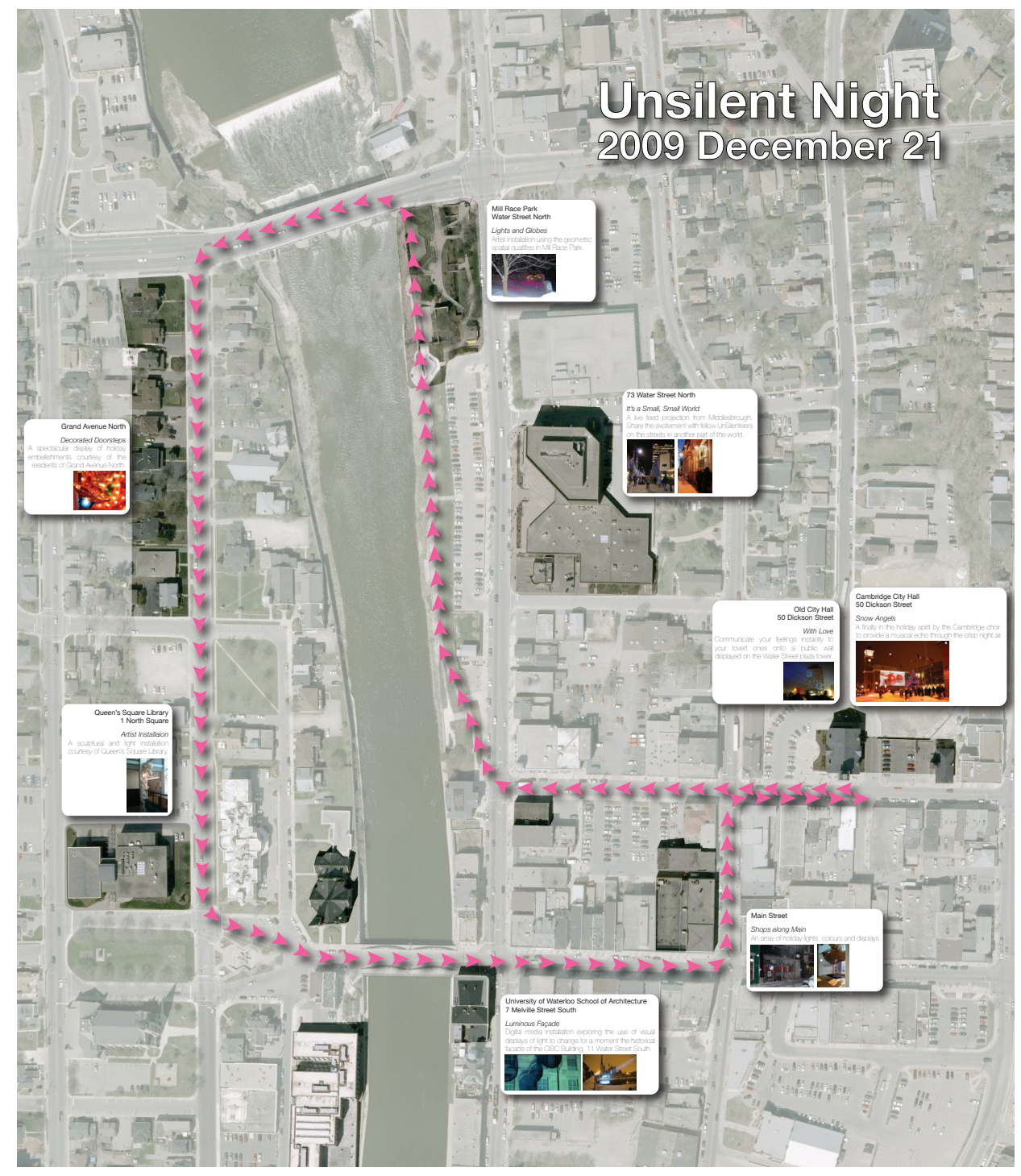

fig.3.1.4 Unsilent Night route and potential attractions

\section{Application Phil Klein's Unsilent Night}

Since 2008, Christmas in Cambridge has included Phil Klein's Unsilent Night event, a collaborative event of music, art and festivities held in over 35 cities across the world. ${ }^{2}$ The event showcases student's and artists' work highlighted by a musical soundtrack composed by Phil Klein. Participants gather with their own portable sound systems (mp3 players, disc players) and together they fill the streets of Galt with a musical echo that can be heard throughout the crisp night air. Community members, the City of Cambridge, Downtown Cambridge Business Improvement Association, and the students of the School of Architecture all contribute to creating an ambient environment filled with artistic imagery, holiday sounds, and enthusiastic crowds. The event focuses on transforming Galt City Centre into a vibrant atmosphere that draws a large public crowd who create energy and generate popularity for both future events and the core area. A route was selected for the event showcasing the river, the bicycle path, Main Street Bridge, and the historic buildings in the downtown. The route ends with the showpiece of Galt City Centre - the new City Hall designed by architect Jack Diamond.

Window installations by the School of Architecture were placed in various abandoned storefronts along the route. Having attractions on both sides of the streets helped connect the walk with visuals and framed the route for participants. Traffic was also diverted to help make for a comfortable pedestrian experience. The bicycle path along the river was highlighted with a series of art and light installations.

2 "Unsilent Night." Unsilent Night. http://www.unsilentnight.com (accessed January 22, 2010). 
The route took participants from City Hall across to the river and back again, all the while combining architecture and the public realm by highlighting the beauty of building facades through the use of video projections.

The Unsilent Night event promoted pedestrian activity crucial to a downtown area where few opportunities for interaction exist. Its success relies on pedestrian culture over a vehicular one. The aim is to promote participation through the appreciation of new media art and creative art installations. The event's videos and sculptures provide an opportunity for community media artists and enthusiasts not only to share experiences, but also to make memories and create a sense of place.

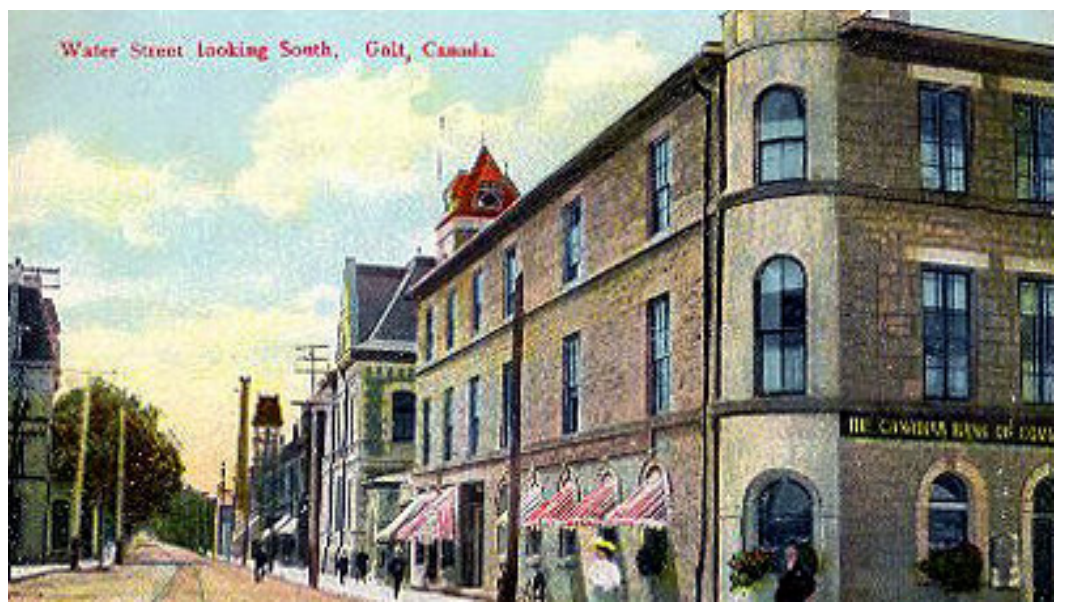

fig.3.1.5 old postcard showing the corner of Main Street and Water Street South 


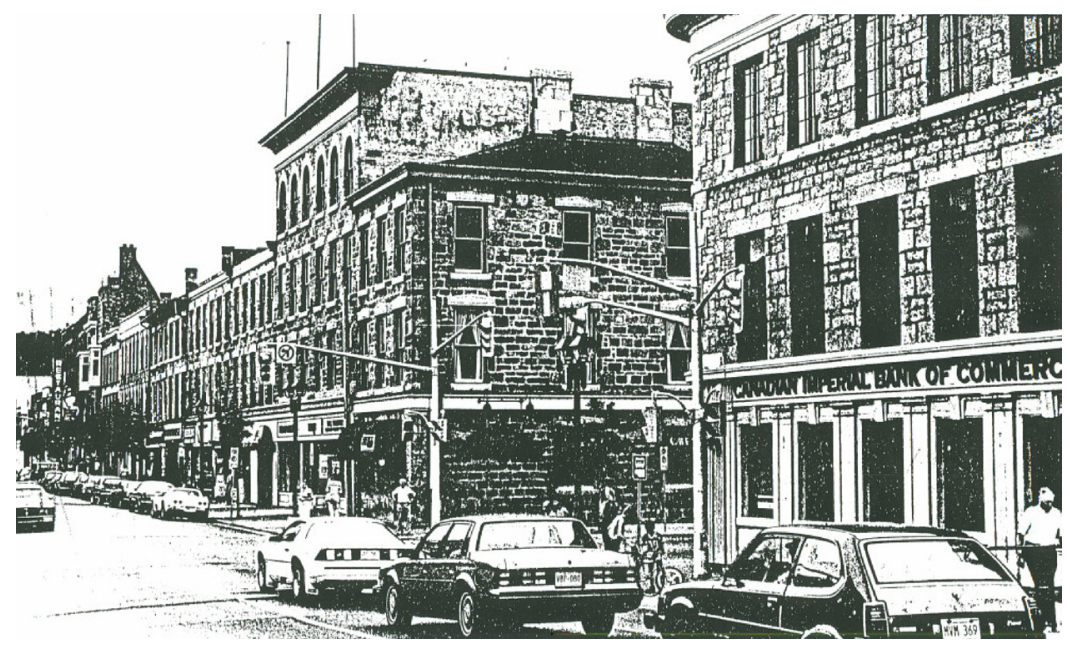

fig.3.1.6 corner of Main Street and Water Street South showing the CIBC building in 1984

\section{CIBC Building and Main Street Bridge}

The site that the CIBC building now sits upon is the location of Galt's first general store called the Red Store in 1824. Owned by Absalom Shade, who is one of the founders of Galt (Shade's Mills), this building also served as his primary home. To facilitate his business, Shade built the first bridge where Main Street Bridge now stands ${ }^{3}$. The Grand River frequently swept away the bridge, causing it to be rebuilt many times. The current bridge dates back to 1931 and was recently restored in 2008. In 1950, Shade replaced the building with a commercial block containing Galt's first bank. Gore Bank opened in 1857 but business struggled and it was eventually taken over by Canadian Imperial Bank of Commerce in 1869, which continues to operate there today. ${ }^{4}$

3 "City Departments | City of Cambridge, Ontario, Canada." City of Cambridge, Ontario, Canada. http://www.cambridge.ca/cs pubaccess/hall of fame.php?aid=44\&cpid=0\&scpid=0 $\&$ did $=0 \&$ sid $=0 \&$ ssid $=0 \&$ tp $=0 \&$ grid $=0($ accessed March 8,2010$)$

4 "About Cambridge History: The Banks." Cambridge History. cambridgeweb.net/historical/ banks.html (accessed March 8, 2010). 
fig.3.2.3 filming Darcy infront of the 'green screen' in

order for colour-separation overlay
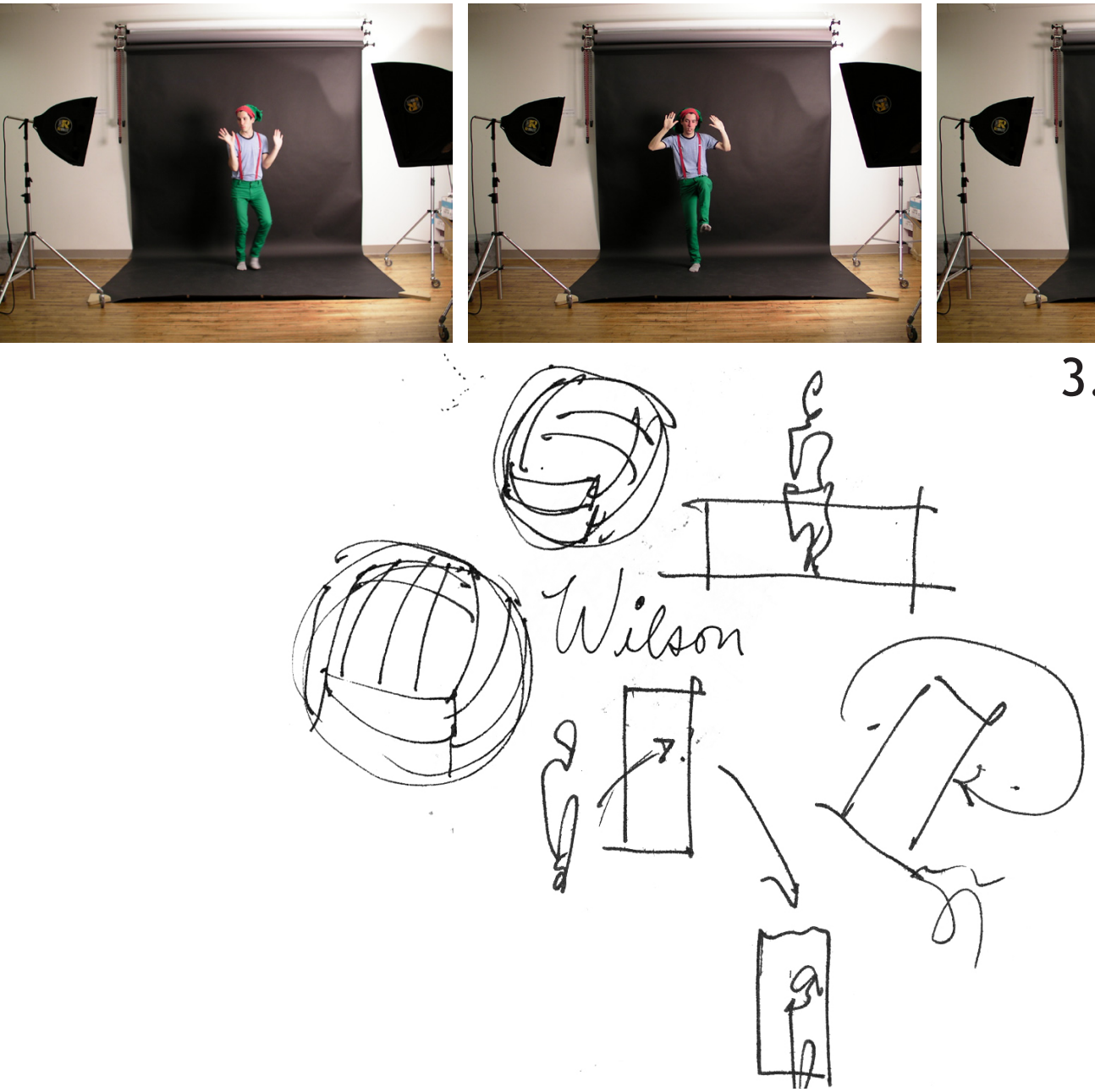

fig.3.2.4 concept sketches of a personal relationship with an object inspired by the struggles between Chuck and Wilson (the volleyball in the film Cast Away)

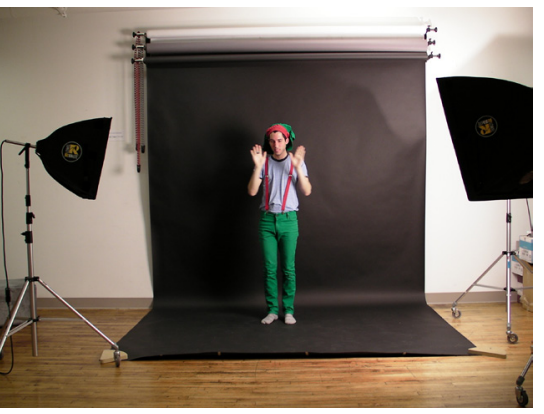

\subsection{VIDEO CONCEPT}

\section{DARCY'S BOX, UNSILENT NIGHT, 2009}

This video follows a playful narrative depicting a personal journey of friendship and sorrow, through the discovery of spectacular events from a simple object. The animation combines geometric shapes with the brick facade of 11 Water Street South (the CIBC Building). The site was chosen because it served as the ideal platform for viewing and displaying the animation along the Unsilent Night pedestrian path. The CIBC facade, with its asymmetric window layout and stone facade, exhibited great potential as a canvas and inspiration for the animation. The location along the river created a unique opportunity to enhance the display with the reflective quality of the Grand River. The dimensions of the facade were taken as an image and acted as the base for the animation and video editing. A storyboard of the concept organized the animation with live action footage. With the animation finalized an actor could act in front of the black backdrop in order create a 'green-screen' effect. The video used animation from Adobe Flash $\mathrm{CS}_{4}$ and video footage compiled using Final Cut Pro. It was then projected from Musagetes library and shot across the Grand River onto the riverbank walls of the CIBC building. To 


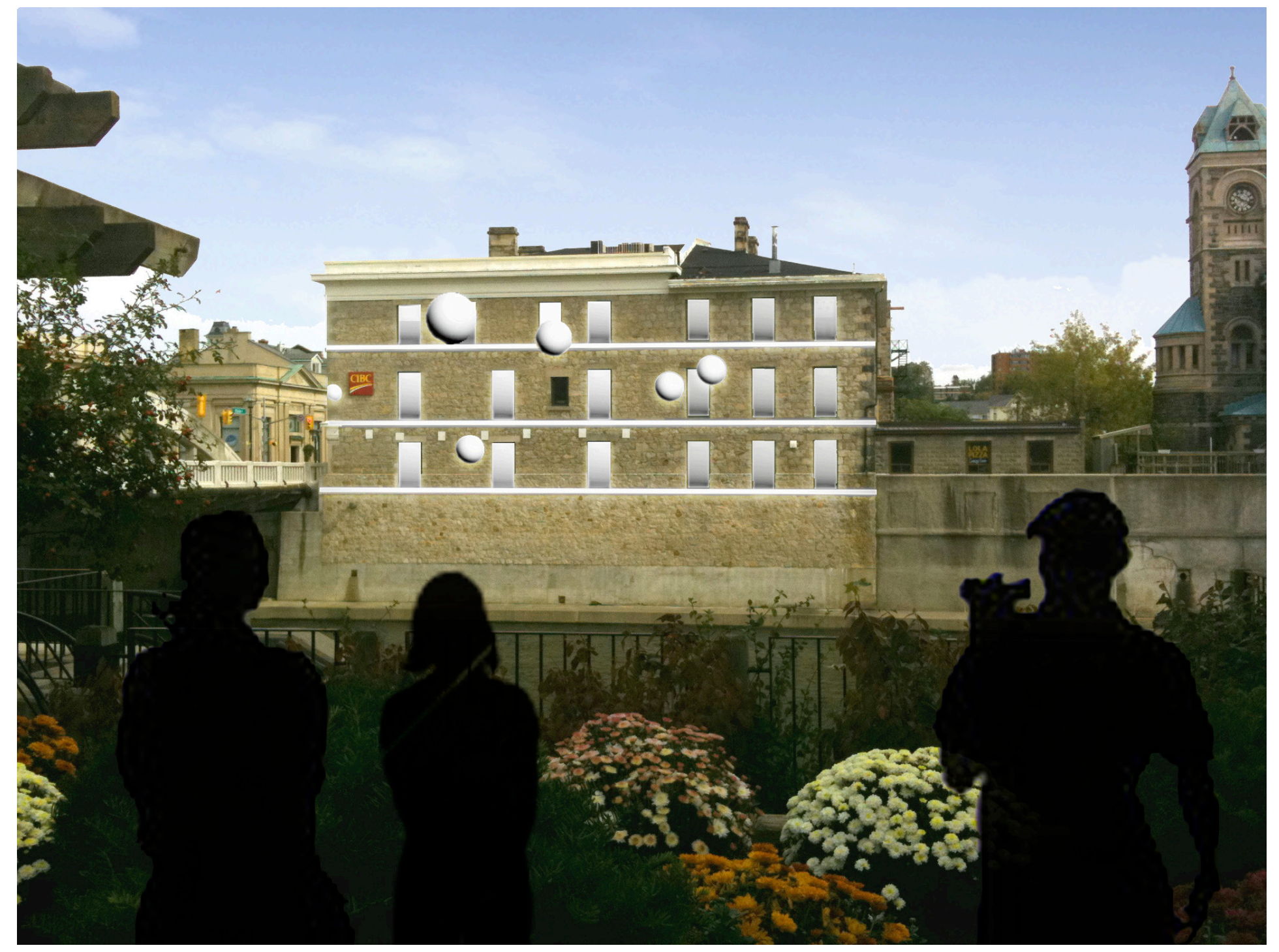

fig.3.2.5 rendering of view from the Mellville Cafe patio 


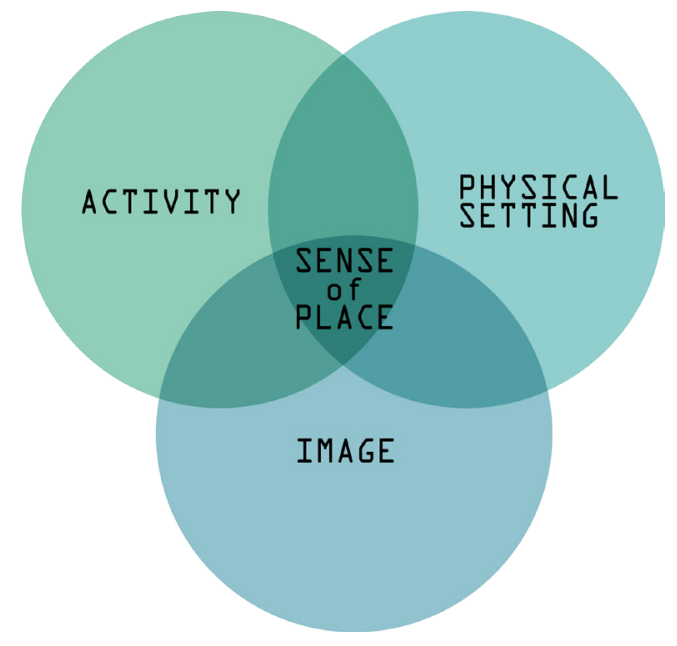

fig.3.2.6 variation of diagrams by John Punter (1991) and John Montogomery (1998) illustrate how urban design actions can contribute to and enhance the potential sense of place

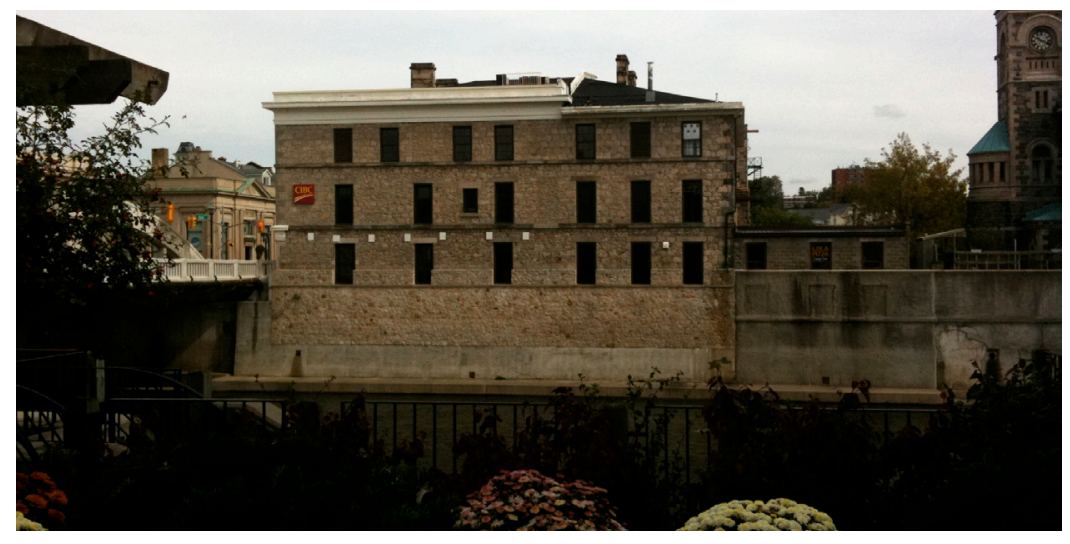

fig.3.2.7 view from Mellville Cafe patio

\section{Principles Applied in Galt}

+ Aesthetics / Facade treatment

+ Artist Installation / Creativity

+ Social Interaction

+ Authenticity / Community

Appreciation 
help fill the entire face of the building from across the river, the projectors needed to be of considerable strength. Using two stacked Christie Roadster HD18K projectors, the desired effect was produced on the stone facade.

Although pedestrians crossing the Main Street Bridge see the riverside facade on a daily basis, it is not often appreciated. The projections liven the facade spotlighting architectural elements and bringing three-dimensionality, transcending the visual nature of the stone. Moreover, the projection allows participants to visualize a virtual space while unconsciously bringing awareness to the fusion of art and architecture. Viewers are inspired by how multimedia can momentarily alter perceptions of our daily lives, all the while creating a public realm from simple alterations of spatial surroundings without physical manipulation. The installation operated from December 21, 2009 until January 2, 2010 for the duration of the Christmas holiday season.

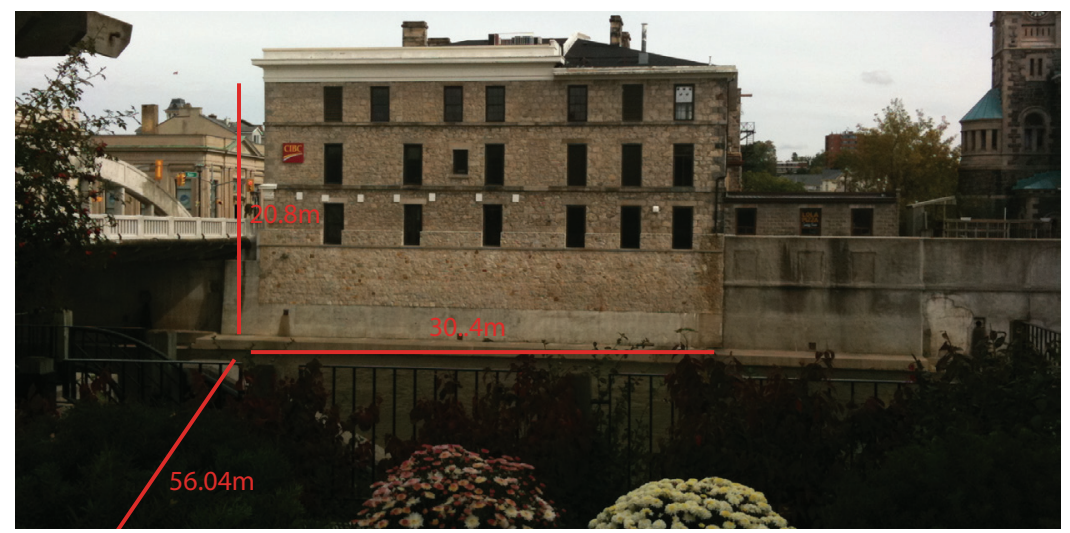

fig.3.2.8 dimensions of the facade and distance from the location of the projectors help determine the power of the projector needed for the ideal results

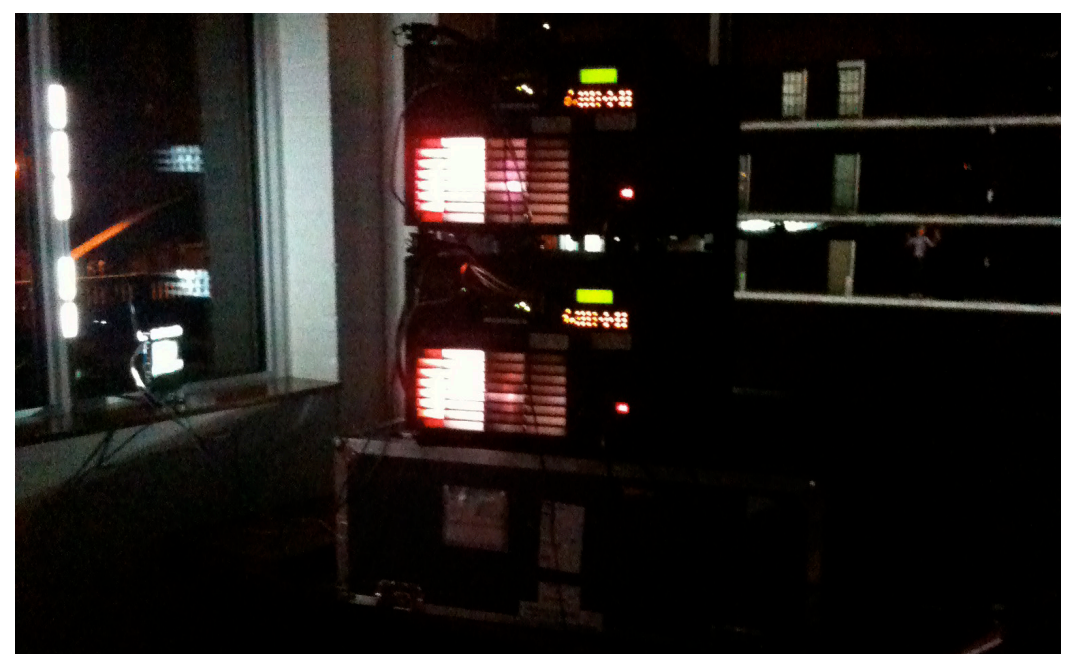

fig.3.2.9 two stacked Christie Roadster HD18K located in the north west corner of the Musagetes Library 


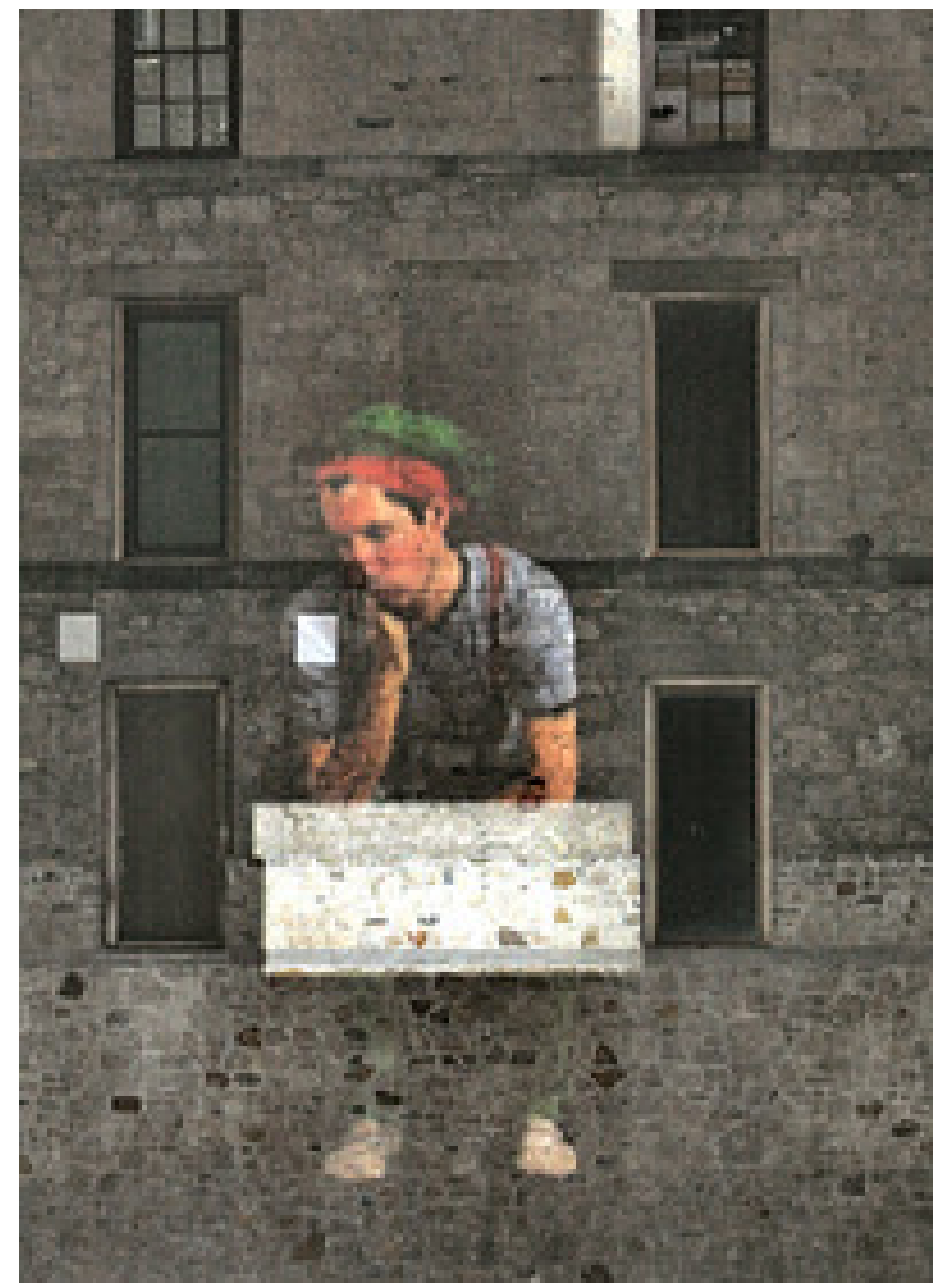

fig.3.2.10 video still from the Cambirdge Times, a local newspaper

\section{Applied design principles Artist Installation / Creativity}

The modern urban citizen rushes through his/her day by filtering out sound and visual noise in which a city is submerged. In contrast, Unsilent Night is a day to contemplate, notice, and enjoy the details of audiovisual stimulation. The integration of technology communication was key in helping to promote the public realm, art, and architecture. The many visual elements creating this public spectacle were neither promoting consumption nor products of corporations, providing an experience for audiences free of corporatization.

The event brought together media artists, installation artists, and architecture students in a creative collaboration, drawing the community together for the sake of art. Different techniques were used to transform structures (otherwise hidden in the dark) into holiday-inspired objects. The unique digital performances explored both media and structural surfaces and challenged viewers' spatial perceptions of architecture. During a snowy night from Main Street Bridge and the patio of Melville Café, participants viewed, the animation illuminated facade, which created a seamless integration with the reflection off the river. Furthermore, the installation showcased the architectural form and uniqueness of this street corner. In the animation, the construction of imagery in different dimensions created illusions of spatial qualities. The animation interacted with the qualities of the stone and the rhythms of the ornamentation. For a moment, the historical facade was transformed into performance art, available for community residents to view. 


\section{Interaction / Social}

Unsilent Night encourages the community to bring friends and family out to meet other members of the community and get involved with the music and celebrations. The projections turn Main Street Bridge, into a social node. Art becomes accessible to the public; people stop to take notice of pieces, taking moments to enjoy the performances and appreciate the space. For those who do not know of the event, the gathering crowds incite curiosity. The curiosity garners debate and discussion and creates social interaction that would not have otherwise occurred. The crowds create a public presence, enlivening the space and creating a friendly atmosphere for informal gatherings. Joe from The Cambridge Advocate describes the event:

It wasn't just the music and lights that got to me. There were families out walking together; laughing. There were couples holding hands. Next year I hope to be hand in hand with someone. There were seniors in wheelchairs enjoying the night. We had hot chocolate at the end of it and random people gave each other hugs ... It may be called Unsilent Night but tonight it said a lot about the people in our city, we owe much gratitude to the planning of such event to all those involved. My hat goes off once again to the University of Waterloo School of Architecture Students.”

5 "Unsilent Night - The Cambridge Advocate." The Cambridge Advocate - A true voice for you the public. http://thecambridgeadvocate.com/archives/unsilent-night/ (accessed March 9, 2010)

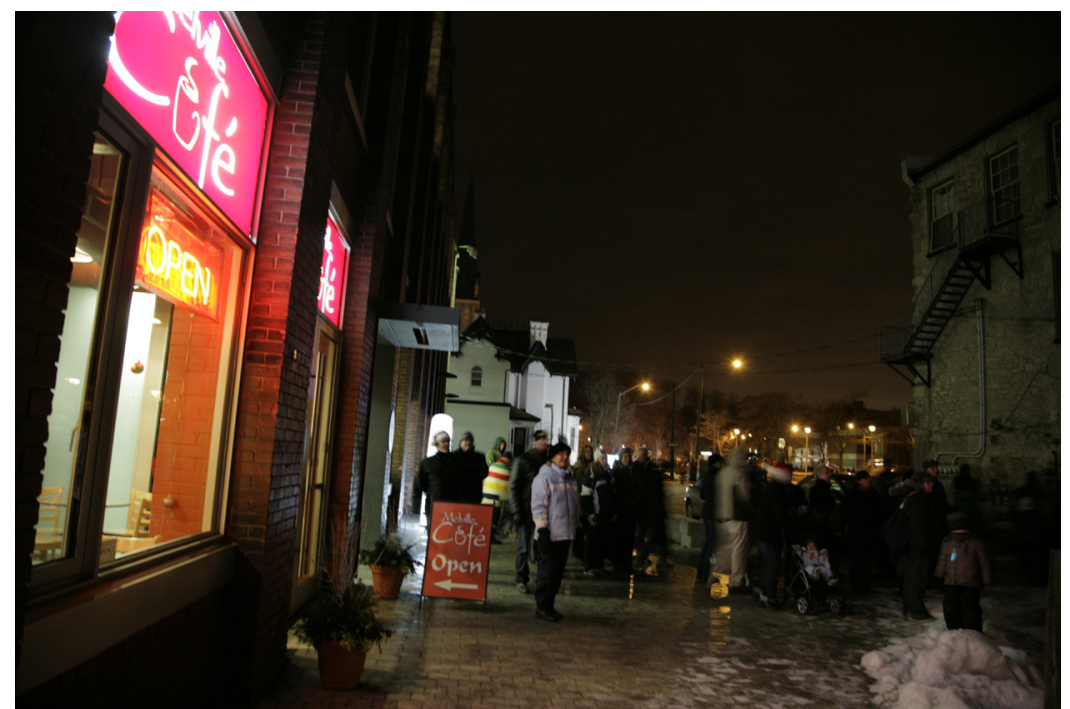

fig.3.2.11 participants follow the route to the next installation

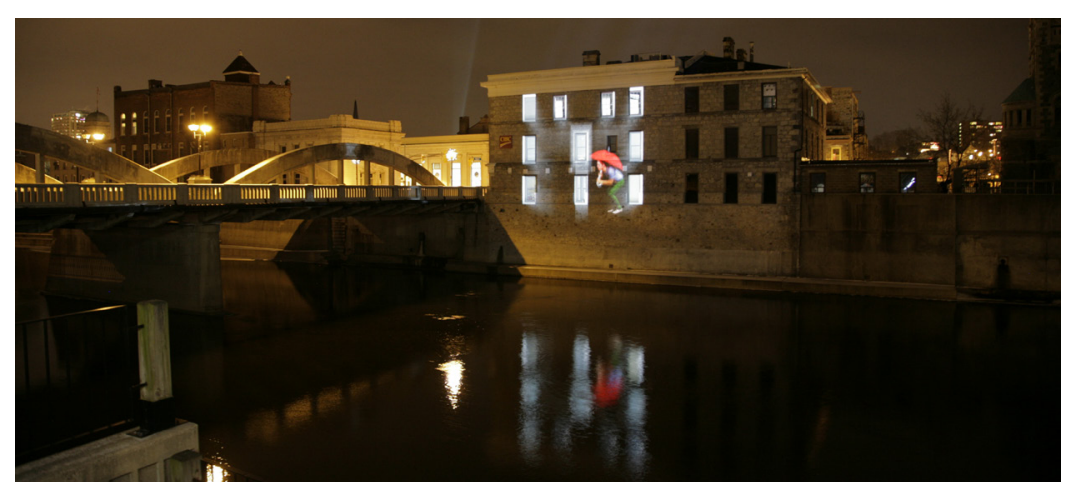

fig.3.2.12 view from Mellville patio of the animation sequence hightling the windows of the CIBC facade 


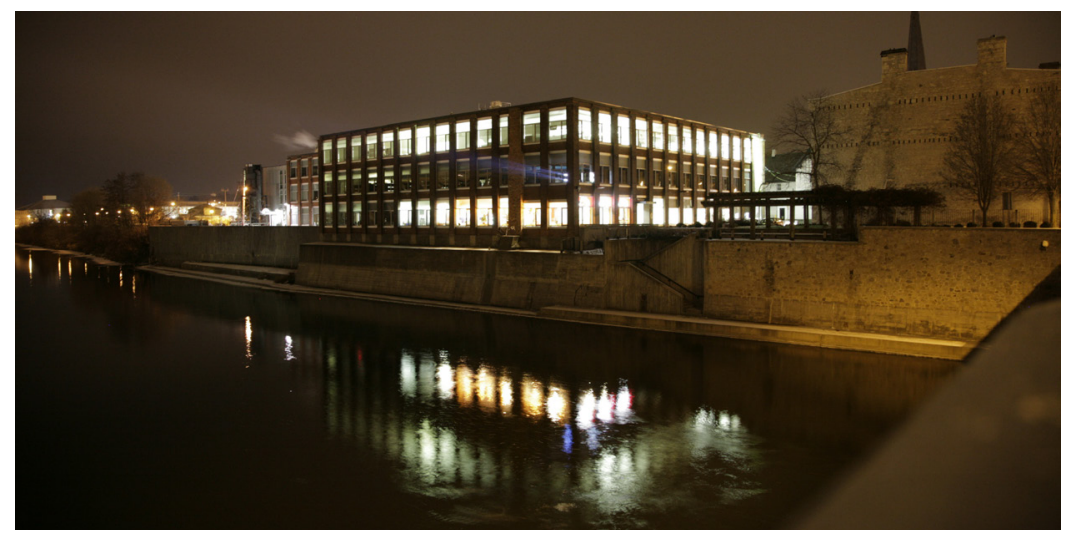

fig.3.2.13 looking from Main Street Bridge towards the location of the projector in the School of Architecture

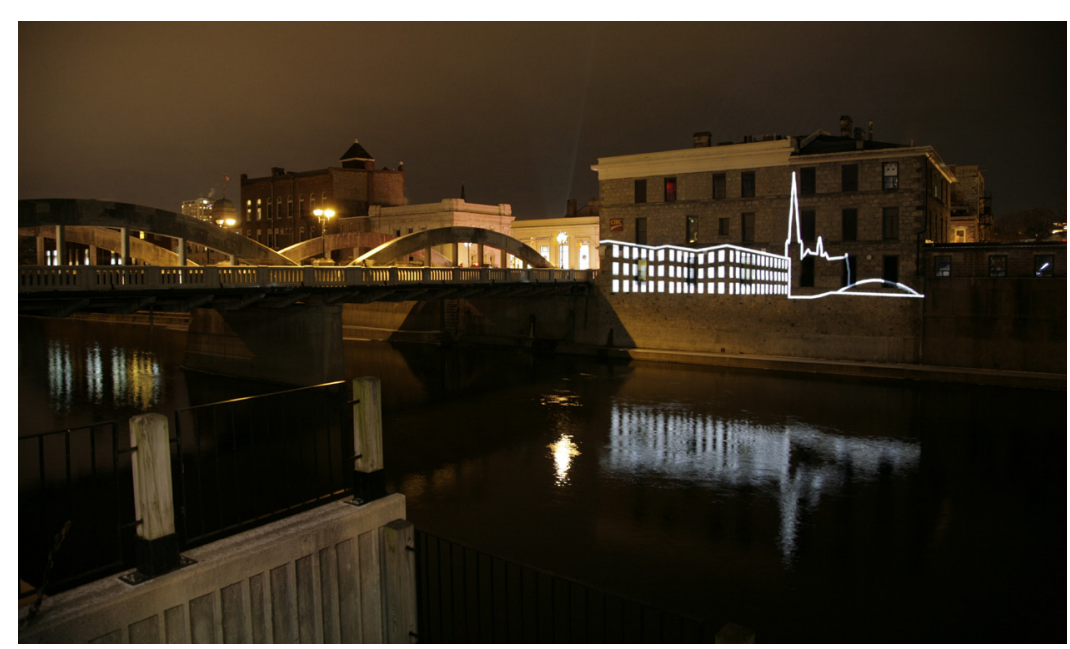

fig.3.2.14 tracing the outlines of the church steeple, the many lit windows of the School of Architecture and Main Street Bridge

\section{Aesthetics / Facade treatment}

The projection uses the facade as a canvas by visually manipulating the surface to celebrate its historical landmark. The projection is expressed three dimensionally by combining structure and media to help support a new visual addition in the night landscape. By using digital media, the architecture is free of unsightly modifications without becoming occluded.

Moreover, the video highlights dimensions of the window openings in the thick stonewall of the facade. An elf character, designed to act as a playful guide, begins in a window and gradually dances his way to the building ledges. His playful movements take advantage of the level separations, highlighting the ledges underneath the window. Having three different levels, as well as a canvas on the floodwall, the elf takes shelter from falling three-dimensional objects by maneuvering about different levels, changing scales and jumping from one area to the next. The windows become the surface of a floating cube that manipulates its surface by highlighting and casting shadows for a multidimensional visual performance. Joe writes, "We crossed over Main Street and on the East wall of the river was a holographic image played of an Elf intermixed with a light show. The lights made up the skyline of the city..." ${ }^{\prime}$ The features of the facade and surrounding structures are highlighted, giving public attention and detail to areas often ignored. Showcasing the texture of the facade, the stone-walls are temporarily transformed into a story.

6 " Unsilent Night - The Cambridge Advocate." The Cambridge Advocate - A true voice fo you the public. http://thecambridgeadvocate.com/archives/unsilent-night/ (accessed March 9 , 2010). 


\section{Authenticity / Community Appreciation}

The eccentricity of the installation creates memories that forever connect with the site. The vast contrast between the projections and the surroundings leaves the audience with a powerful experience. The installations can generate spectacle, encourage debate, and hopefully inspire members of the community to create future public artworks. The event not only addresses the need for community interaction but encourages the collaborative efforts of city officials, community sponsors, and members of the School of Architecture.

The community's contribution to the art itself encourages participation. The video integrates a transition to various films made by students, giving creative license to the public by allowing their input for the designs of the community.

The animation reflects the character of the area which the audience members can recognize. The iconic skyline of the School of Architecture, Main Street Bridge, and the church spires of Queen's Square are identifiable by many students, faculty and local residents. Enhancing regional pride for the city. The video projection illuminates the old historical facade. It blends the old with the new, a theme in which Galt takes pride.
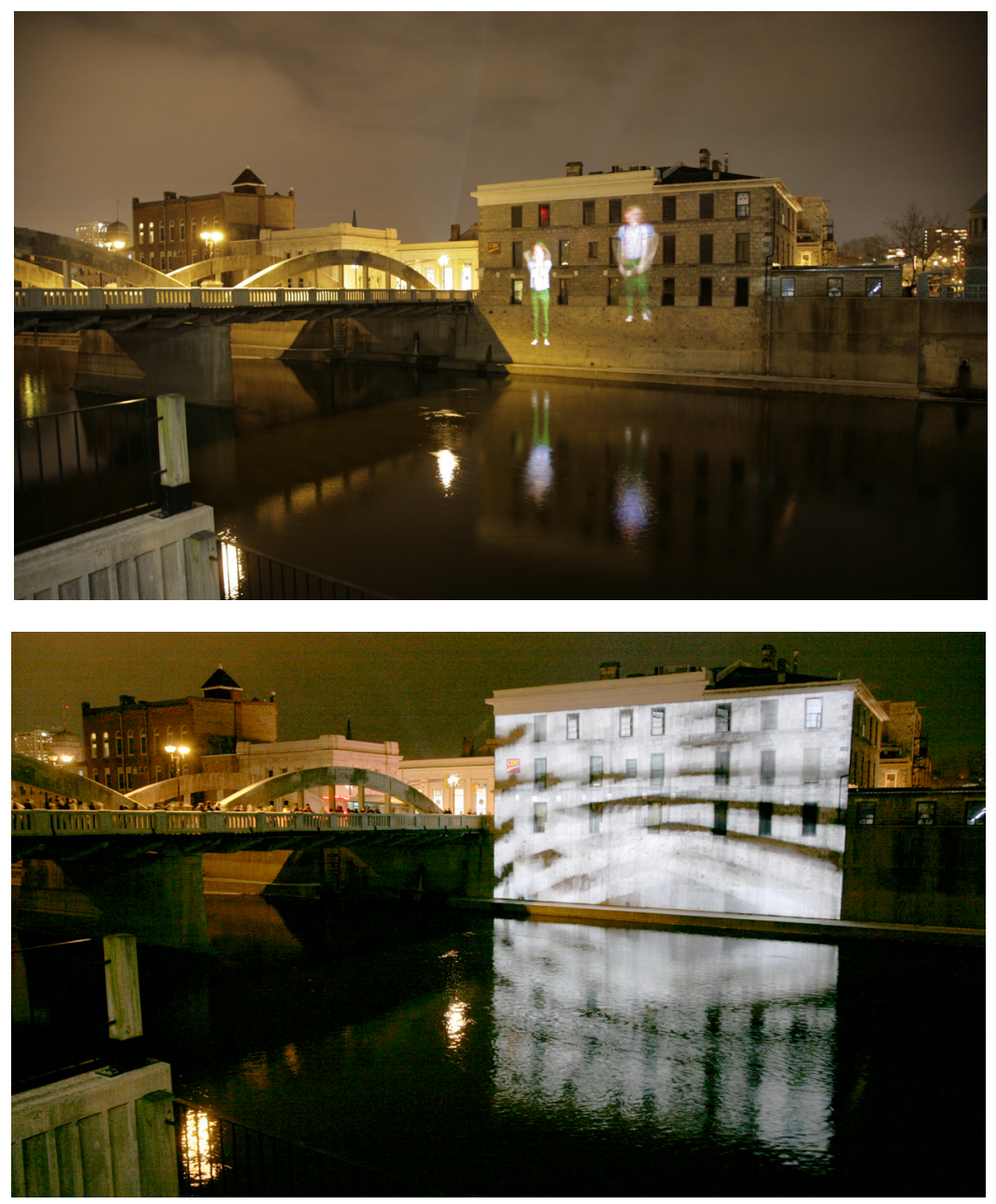

fig.3.2.15 one object transforms into the next while threedimensional objects visually obscure the two dimensionality of the facade 


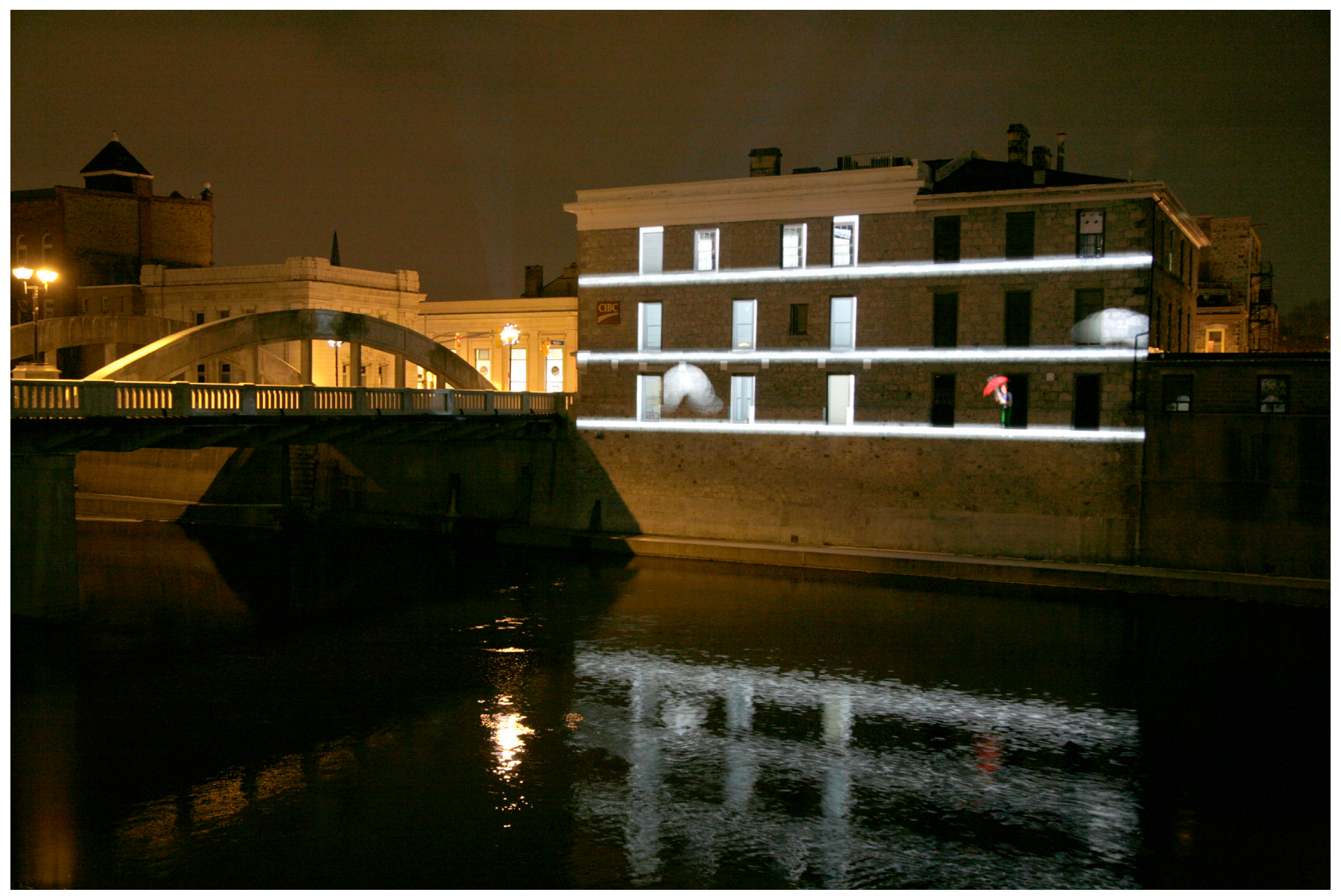

fig.3.2.16 Darcy and his red umbrella take shelter in one of the windows of the $\mathrm{CIBC}$ facade while spheres rain down on the 



\subsection{BUILDING FROM UNSILENT NIGHT}

As an on going process of urban renewal for Galt, concepts from the Unsilent Night event must serve as a launching point from which to continuously reinvigorate the downtown area by creating an everchanging and noninvasive application that highlights the buildings and landmarks. A reinvigoration of public interest and a revival of historic pride is necessary. The following map highlights surfaces that can be explored for the application of projections. Seasons, context, and historical identity have all been taken into account in the assessment of facades. Similar to Las Vegas's revival of Fremont Street after the addition of The Fremont Experience, these projections can provide Downtown Cambridge with the opportunity to showcase its historical past, using light and sound to attract visitors once again to the site. However, in contrast to Fremont, instead of building new surfaces for the performance, these pieces use the existing historical buildings as canvases capitalizing on the contrasts between day and night. The installations generate enthusiasm within the community for the built form and encourage usage all year round. The continuously changing content and strategic locations encourage the community to return in anticipation for each new project. In this way culture can grow and can foster a sense of community. The possibilities for themes and content generate a network of creative and cultural parties within the community. Indeed, this ever-changing digital layer could very well redefine the urban fabric of Galt in a positive light to create everlasting local pride and identity throughout the community. 


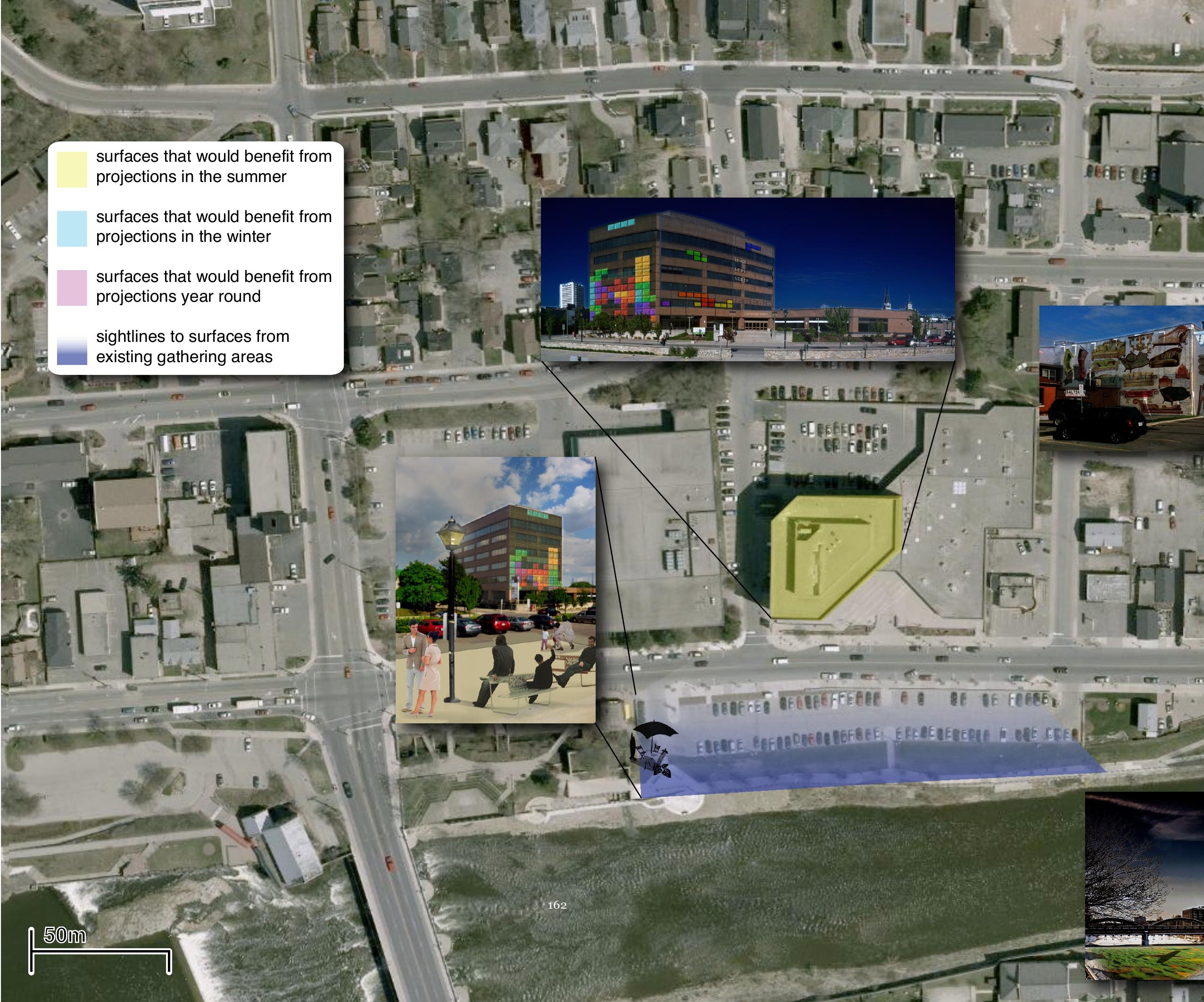




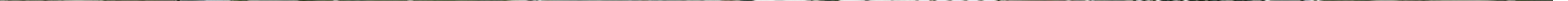




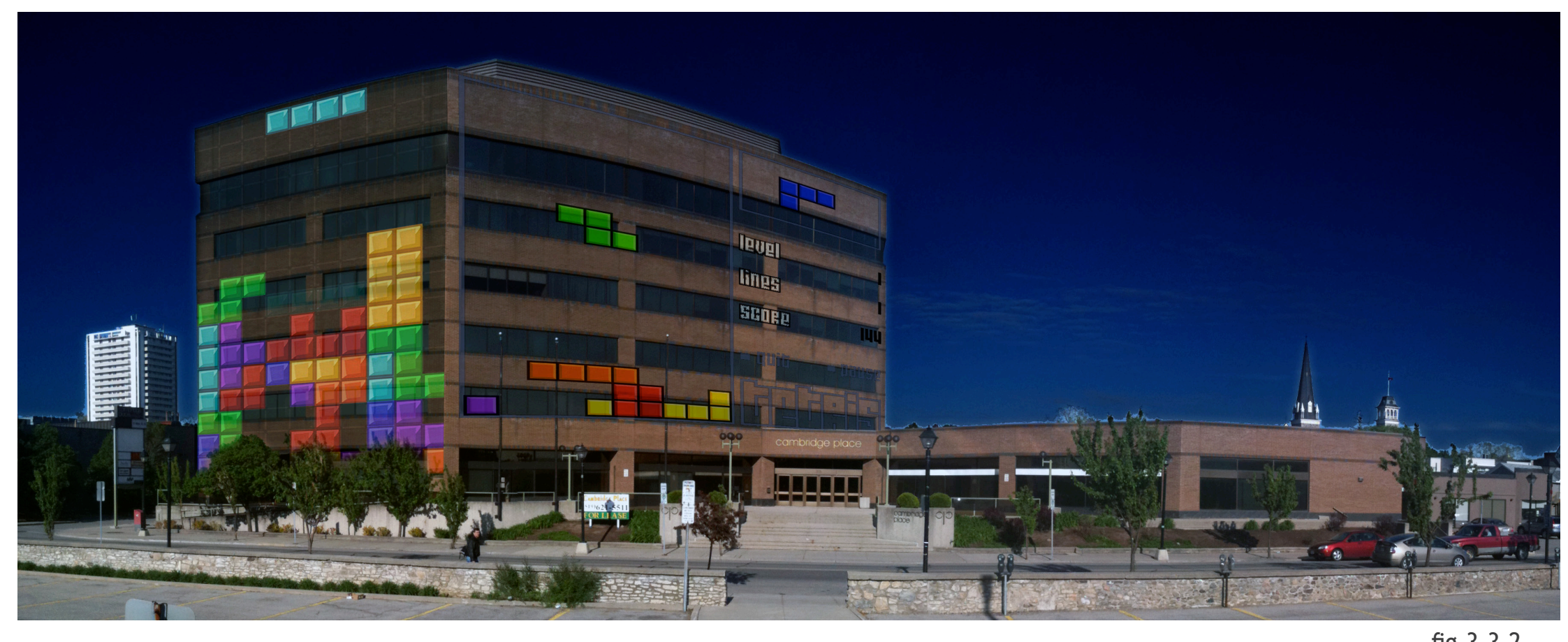

fig.3.3.2 


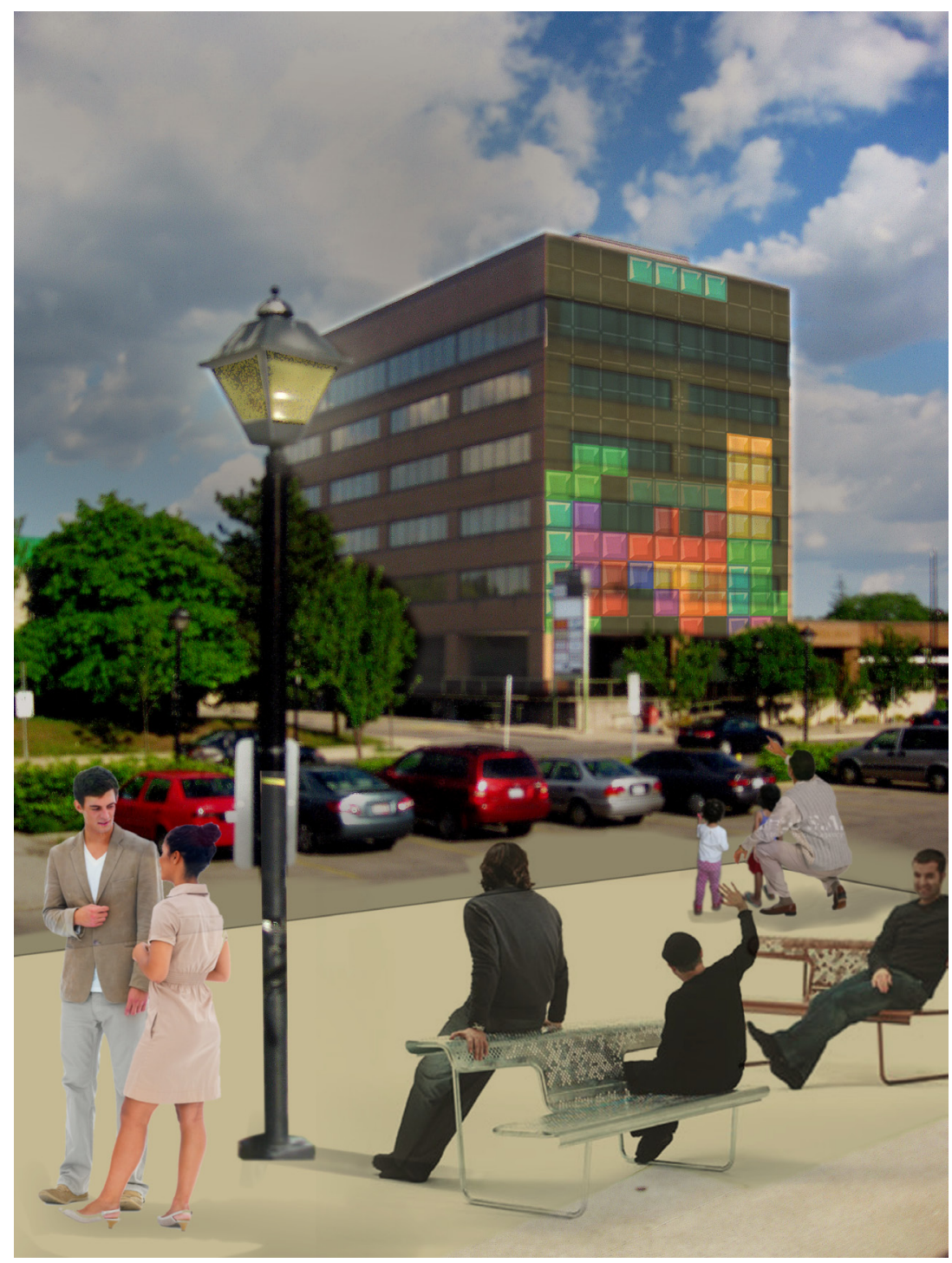

fig.3.3.3

\section{Cambridge Place 73 Water Street North}

The Cambridge Place facing the popular summer kiosk LA Franks, stands out from its surrounding structures. Many people gather at the kiosk in the summer for drinks and food and to enjoy the weather. Although the business generates a high volume of traffic, sufficient seating is not provided in and around the area. The area would benefit from an extended patio area from the flood berm as it disconnects the sidewalk from the Grand River. Pedestrians from the sidewalk cannot view the River path and, therefore, the path along the river is less frequented. This extension to the LA Franks patio provides seating and a visible connection to the river. The installation of reactive projections could be beneficial here in the summer as locals gather for longer amounts of time. The street presence from pedestrians helps to create a lively character for the area, for those entering from the Hespler Road into the downtown core.

\section{Principles Applied}

$$
\begin{aligned}
& \text { + artist Installation / creativity } \\
& \text { + reactive / social interaction } \\
& \text { + aesthetics / facade treatment }
\end{aligned}
$$




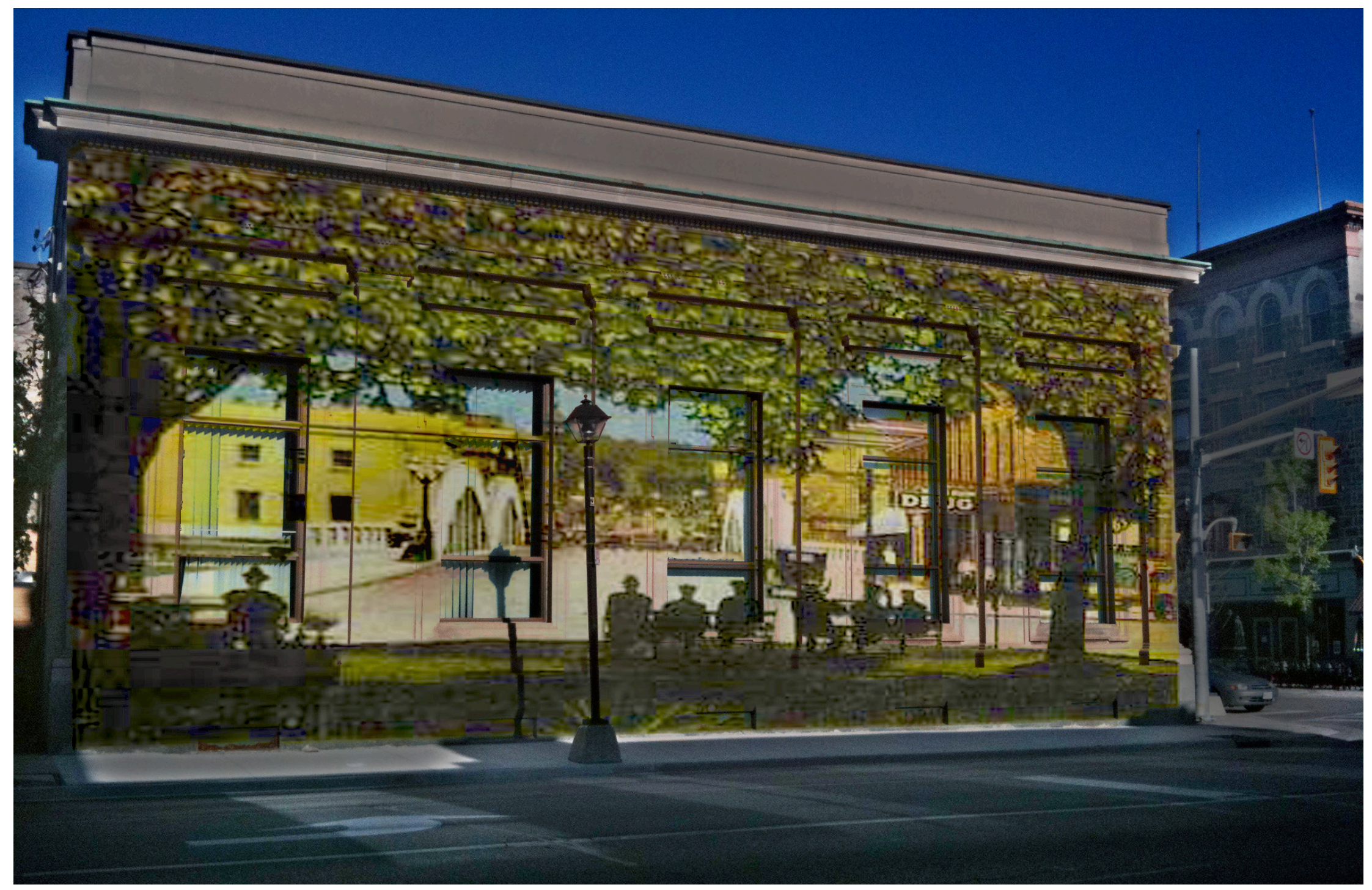




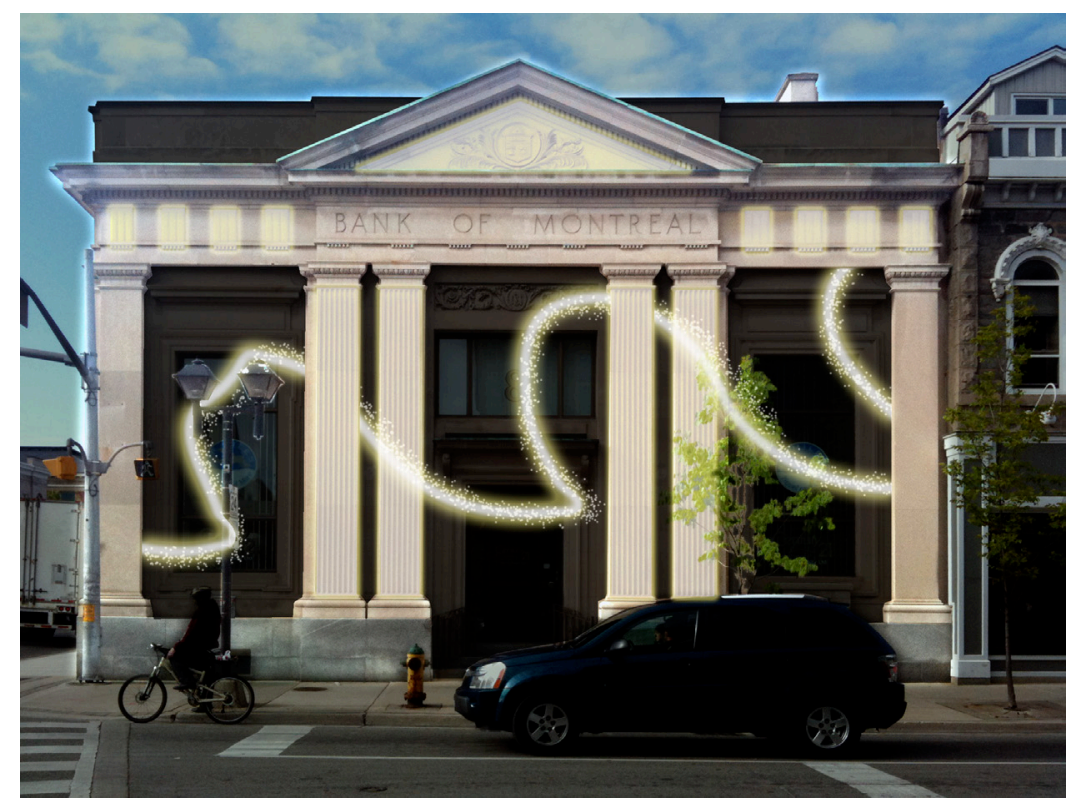

fig.3.3.5

\section{Principles Applied}

\section{+ authenticity / community appreciation}

+ commercial use / media exposure / economic

+ artist installation / creativity

\section{Century 21 Watson Realty Limited 8 Main Street}

The old Bank of Montreal building across from the patio of Cafe 13, at the corner of Water Street and Main Street, has great architectural details for the use of projections. The same view of the building, from across the Main Street bridge, looking east, can be found in old historical postcards and is seen here projected onto the corresponding facade. This showcases the structure and the intersection's significance and long standing permanence in the history of the city. In the summer months the facade facing the patio to Cafe 13 provides an excellent canvas for creative exploration of depth and animation. 


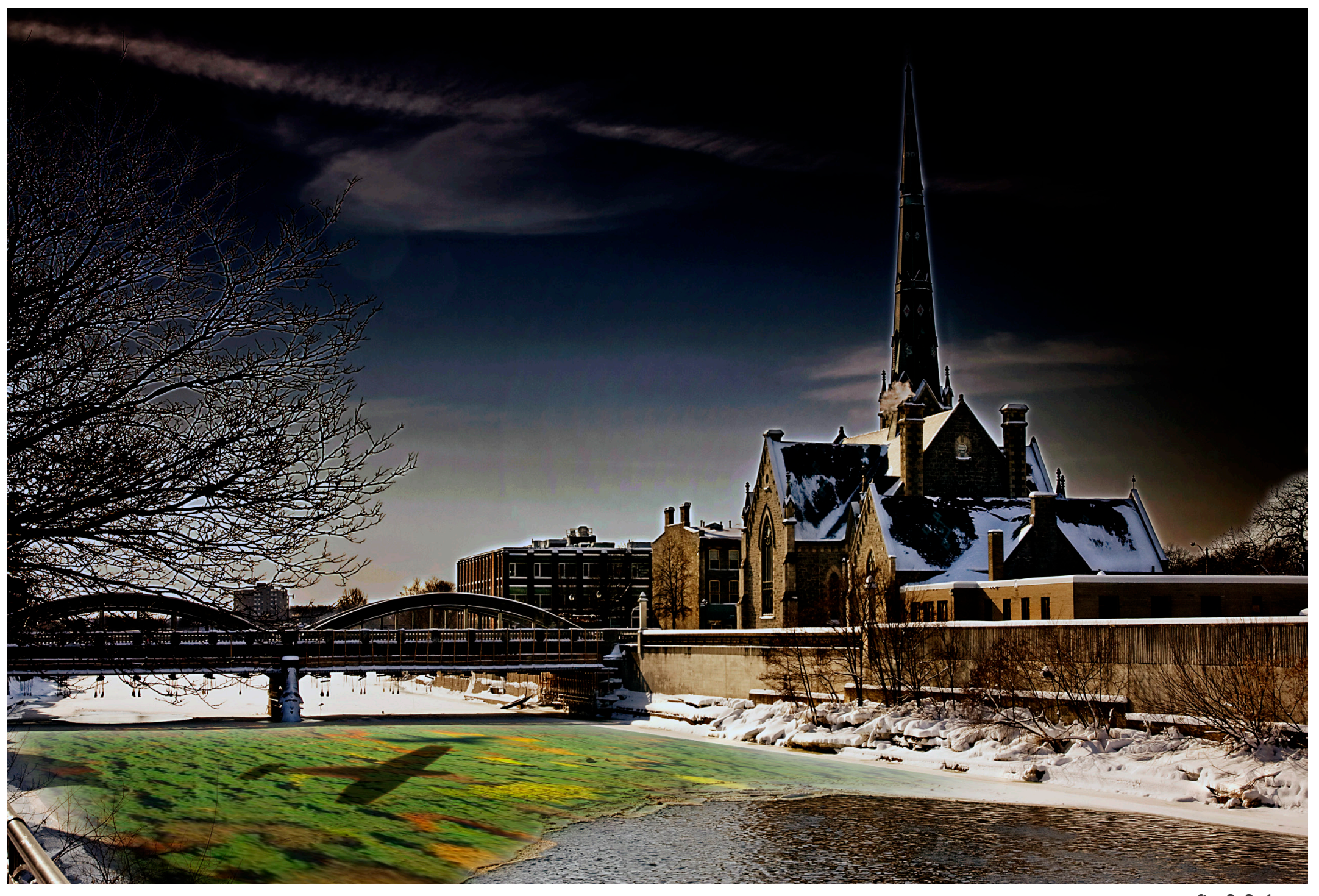

fig.3.3.6 


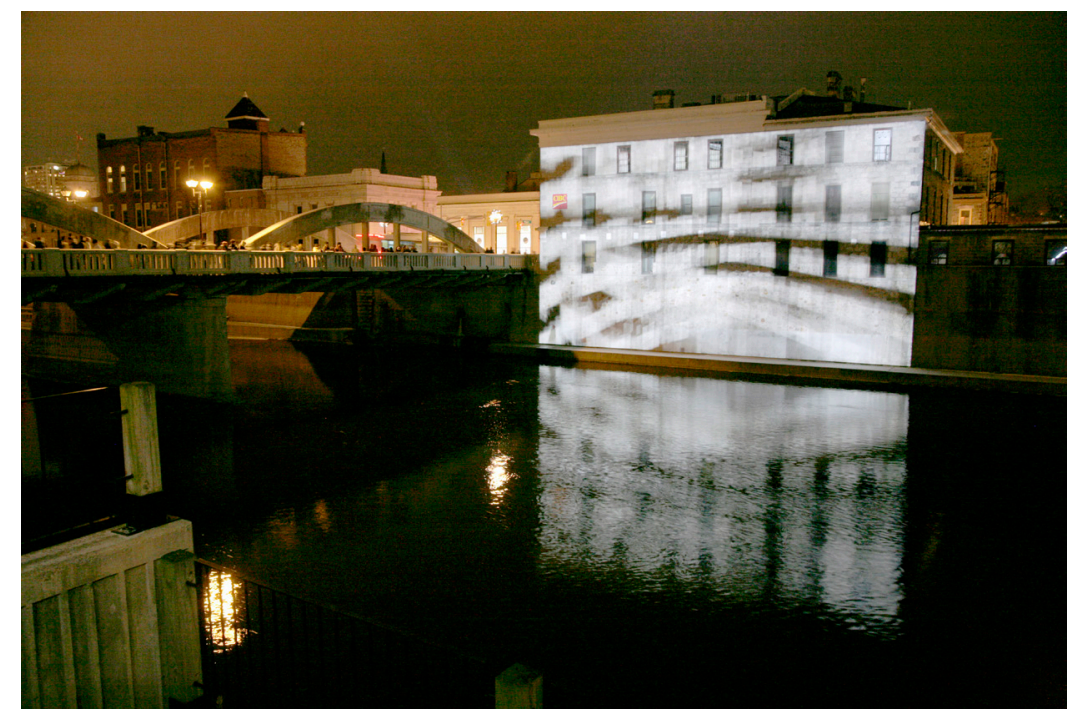

fig.3.3.7

\section{Principles Applied}

+ multi-sensory / responsive environments

+ adaptability / scale

+ authenticity / community appreciation

\section{The Grand River}

Projections can make the best use of surfaces by taking into account the changing seasons. Furthermore, creating projections yearround, and using seasonal changes to the advantage of installations, creates lasting memories of the city and the spaces, engaging the body's senses. In the winter months, when the river is frozen solid, projections can be made right onto the river, drawing pedestrians along Main Street bridge with projections of endless creative potential, from images depicting warmer seasons to underwater animations. In the summer months, the focus could be on the areas visible from the outdoor patio of Melville Cafe where the projections can take advantage of the reflections off of the Grand River. 


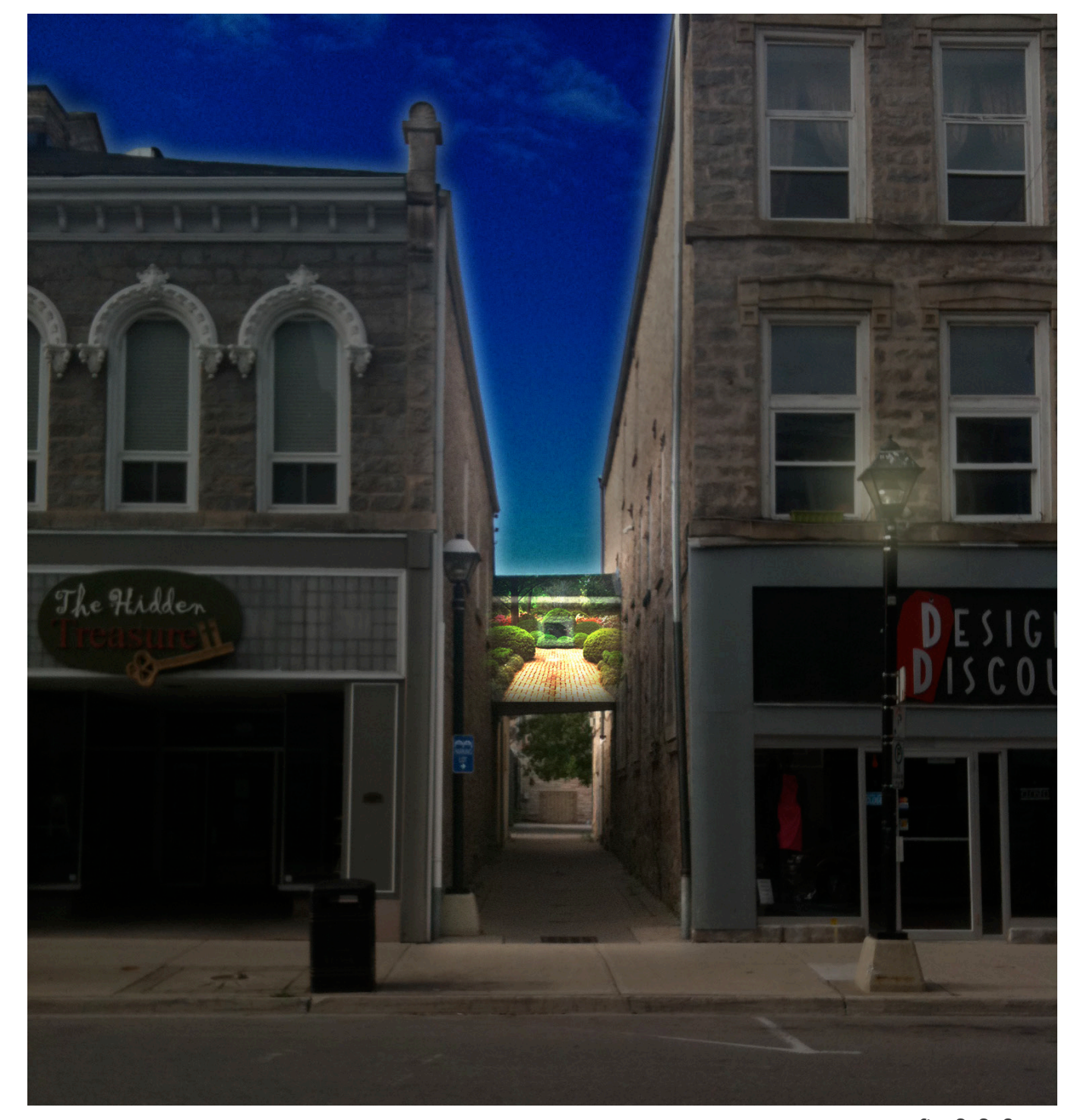

fig.3.3.8 


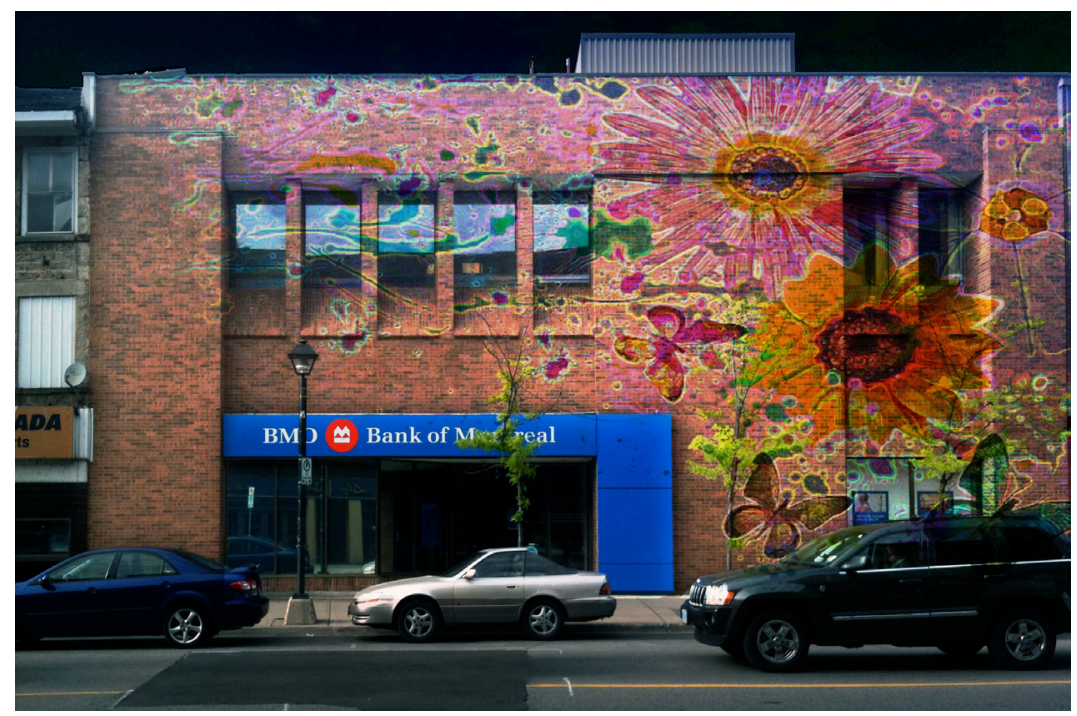

fig.3.3.9

\section{Principles Applied}

+ authenticity / community appreciation

+ adaptability / scale

+ Commercial Use / Media Exposure / Economic

\section{Main Street alleyway and Bank of Montreal 44 Main Street}

Alleyways are not often considered to be viable public spaces, owing to their physical narrowness, and to the sense of caution of danger created by their lack of light. However, public access through dark alleyways can be spotlighted for added safety and comfort. The alleyway located off Main Street, featuring a one storey connection, can be an intimate location for an installation. The projections of light can help to spotlight the dark alleyways for night time frequenters and help to showcase it for pedestrians unaware of its existence.

Projections made downtown could add to the overall experience and the streetscape of downtown Galt. The large surface area of the Bank of Montreal sits across from the outdoor patio of 'Lily Ruth's'. An added layer of digital entertainment could take attention away from the dense traffic along Main Street a nuisance, because of the patio's close proximity toe the road. In this scenario digital content could reflect the logo of the Cafe. Patrons would frequently visit the area anticipating the next installation. In the summer, focus would be on the areas adjacent to the outdoor patios and not on noisy traffic. 


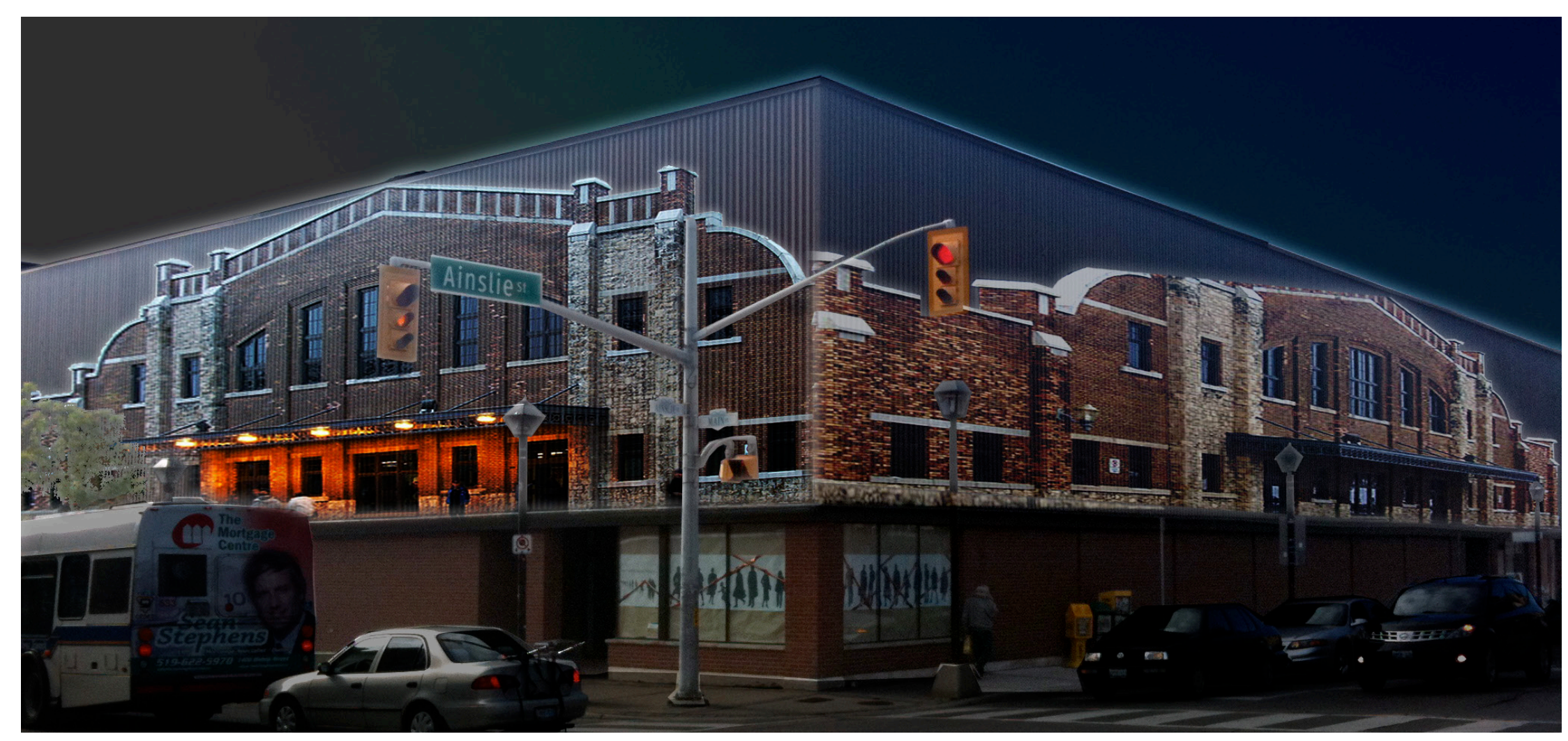

fig. 3.3.10

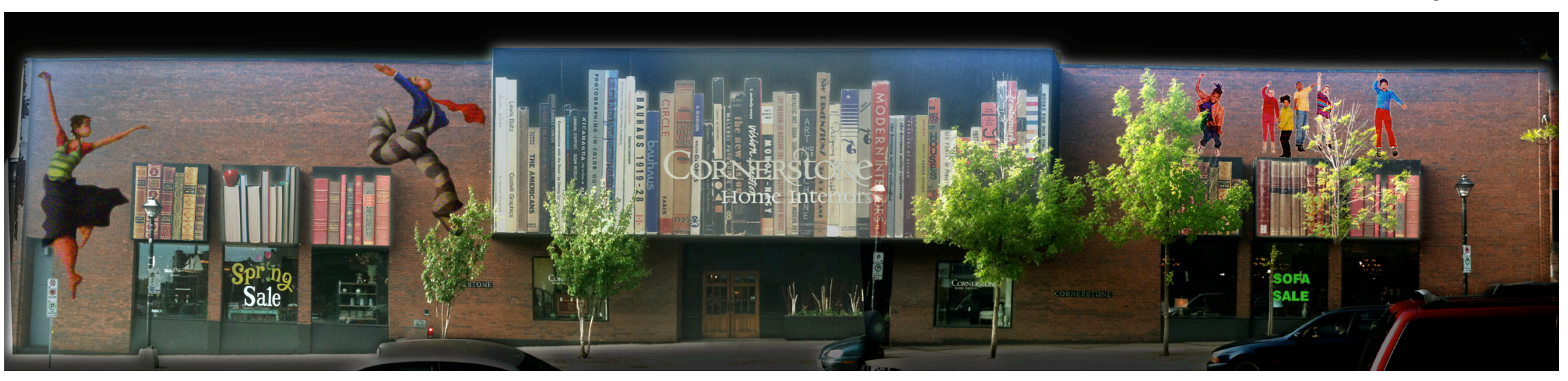




\section{Main Street and Ainslie Street North Cornerstone Home Interior 90 Main Street}

The metal siding covering the structure along the corner of Main Street and Ainslie breaks the rhythm of Main Street which is otherwise consistent in its presentation of storefronts. As pedestrians stroll along the line of small retail stores, the urban fabric is broken with the trailing metal siding which covers the existing structure. Here it is shown highlighted with the facade of 'Galt Arena', North America's oldest functioning arena, which expresses the mysterious potential underneath the metal siding, and brings a sense of pride to locals for their historical hockey arena. A similar situation occurs along Cornerstone Home Interior, where the length of the facade breaks the pattern set by the rest of Main Street. Pedestrians are left strolling along without engagement with the storefront. Added animations could bring life to the blank facade and could bring interest back to Main Street.

\section{Principles Applied}

+ aesthetics/ facade treatment

+ authenticity / community appreciation

+ artist installation / creativity 


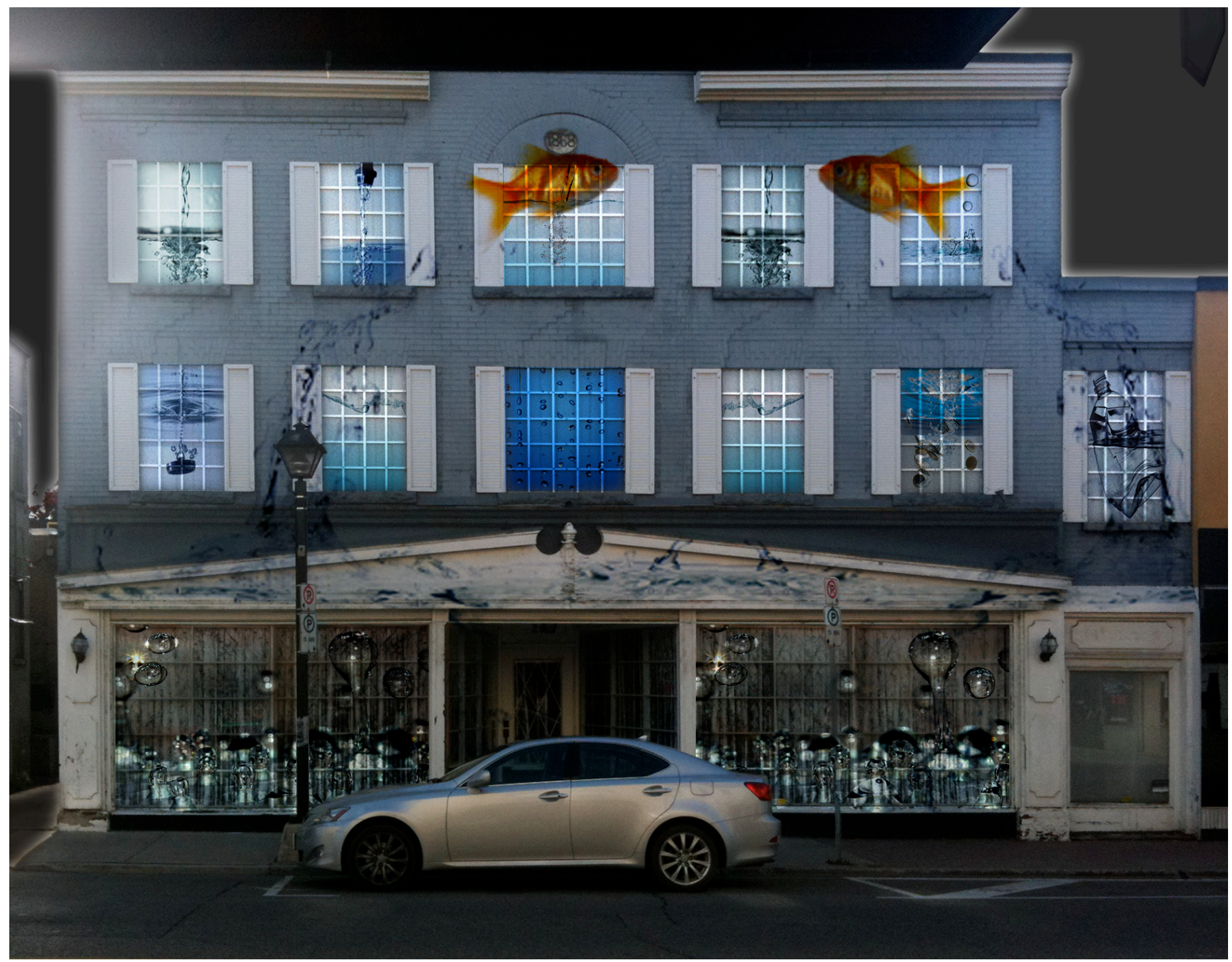

fig.3.3.12 


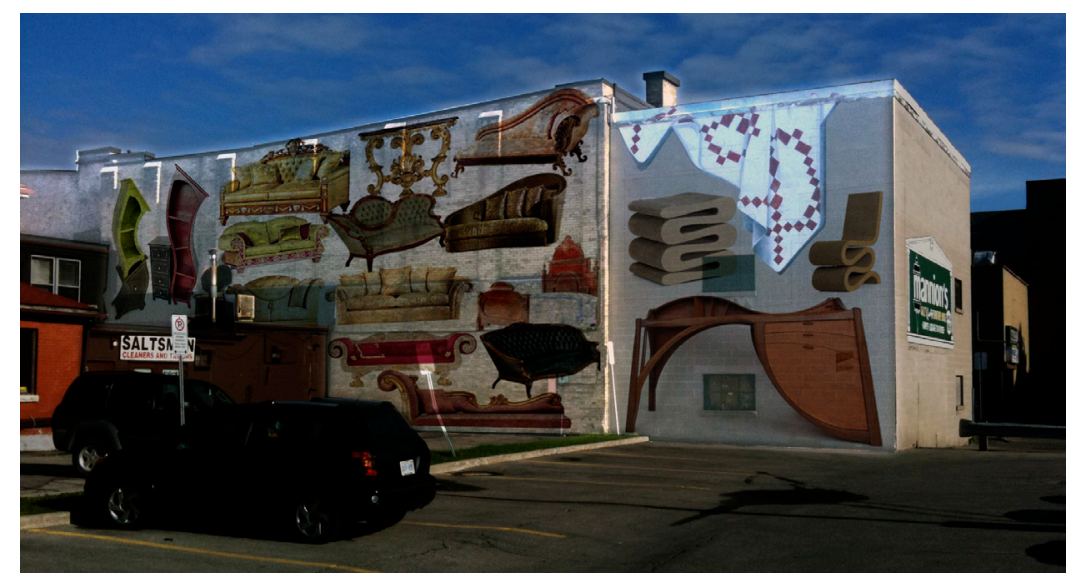

fig.3.3.13

\section{Principles Applied}

+ aesthetics/ facade treatment

+ Commercial Use / Media Exposure / Economic

+ artist installation / creativity

\section{Ainslie Street North Front facade and North Facade}

Ainslie Street benefits from its many small cafes along the east side; however the street also has a lot of empty storefronts characteristic of much of Galt. Projections could be used for facades facing patios or large areas that break the urban fabric. In the case of the old Mannions Furniture Store, recognizable to many locals from the existing signage at the rear, the empty unit sits across El Rinconsito Mexicano's patio. Animated projections would light up Ainslie for pedestrians and patrons of the cafes. The North facade, framing a parking lot, faces Euphoria Smoothy and Bistro. The parking lot breaks up much of the South side walk of Dickson Street and the installations could help highlight the existing infrastructure framing the edges and taking attention away from the parking area. 




\subsection{CONCLUSION}

"Along the Unsilent Night route, a variety of light installations were set up in Mill Race Park, Trinity Square and the Queen's Square library. The most impressive display was at the Main Street bridge where travellers stopped to watch the antics of a giant elf projected from the school of architecture onto the riverside of the CIBC building."1 - Cambridge Times

1 "CambridgeTimes Article: Unsilent night blows up ." Cambridgetimes.ca | Your Cambridge online newspaper | Today's stories from the Cambridge Times . http://www.cambridgetimes.ca/ news/local/article/247041--unsilent-night-blows-up (accessed March 9, 2010).
There is a powerful transformation which occurs when the aesthetic quality of digital media is applied to facades and public realms. A dialogue ensues between the public and visual artists that can be seen in the many examples described throughout the study. This thesis advocates for the use of digital screens as tools to enhance civilians' personal interactions with public spaces. I look to technology and building exteriors for possibilities of animating the space.

To understand the importance of our public spaces in North America, we must first look at how they evolved from the initial stages of vibrant and democratic centres to abandoned and dysfunctional spaces resulting from limited design and suburban sprawl. The case studies presented investigated three destinations, recognized for their prominence in media, and their iconic billboards. However, of the three case studies, only one presents a sustainable model. In New York's Times Square, the first case study, its area is enriched with a strong association to theatre. It experienced "ebbs and flows" of development as a red-light district in the 1980s, and became associated with the Disney Corporation in the late 1990s, while maintaining its reputation as an entertainment district. Its symbolic bright lights attract visitors from all over the world, yet the same attraction has led to serious challenges, such as overcrowding which becomes a real safety issue. One solution, the "pedestrianization" of its streets, allowed for its use by local residents to safely negotiate 
traffic dangers. The square also incorporates digital screens; the lit billboards act as an aesthetic backdrop that serve as markers of a collective history to the events.

Unlike New York Square, the Las Vegas Strip, the second case study, incorporates a boulevard of large spaces and even larger signs that overwhelm the buildings - as first observed in the seminal work of "Learning from Las Vegas". This area is not scaled for pedestrians because the privatization of its streets left gaps between properties and disorienting paths designed for the sole purpose of directing people to casinos. The popularity of themed resorts lead to the understanding that the identity of Las Vegas lies in the remaking of historical landmarks - an artificial quality that the city revels in. Shinjuku Station, the third case, offers a complex organization where everything connect and operates smoothly with the high-density traffic. Its space is utilized to maximum efficiency. Digital screens work well because of the station's fast pace. The ever-changing projection acts as a new exhibition format for cultural content adding social dialogue into spaces of necessity.

From these case studies, we understand that practical elements are necessary to make a public space successful. The design principles that I have presented, outline the basic steps necessary to creating successful public spaces. More importantly, the principles helped inform me on how to make digital screens that support more meaningful community interaction and celebrate the architecture which houses these devices. These principles can help architects, designers, and other urban planners in determining how to better use digital screens to celebrate our public spaces and engage the public.

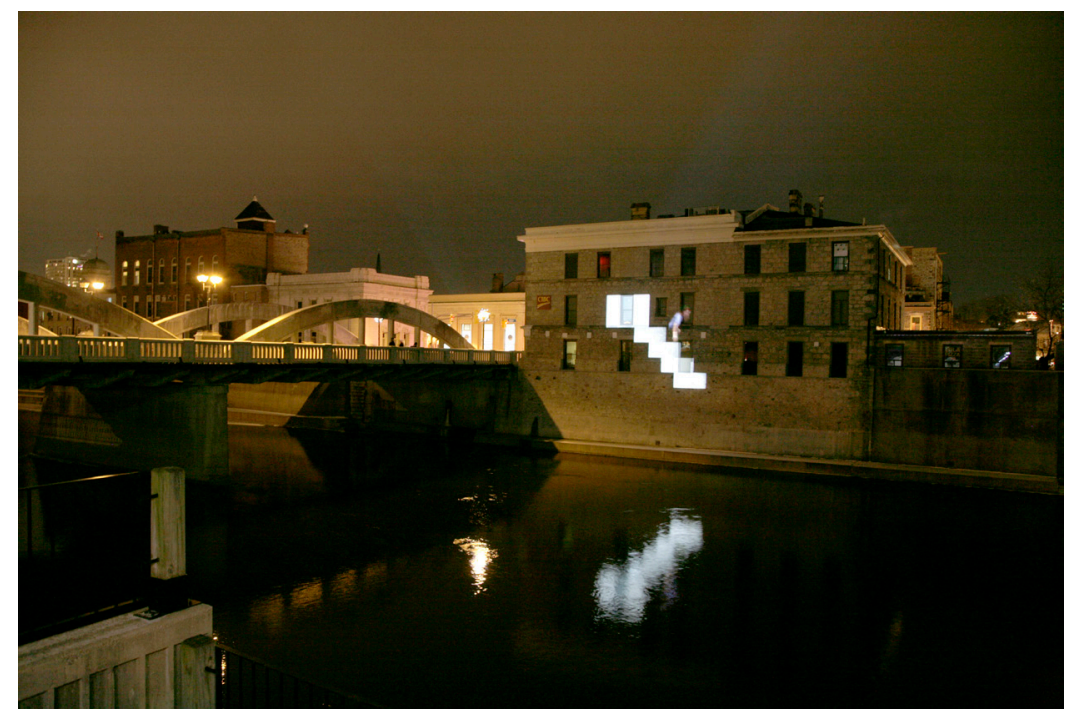

fig.4.0.1 


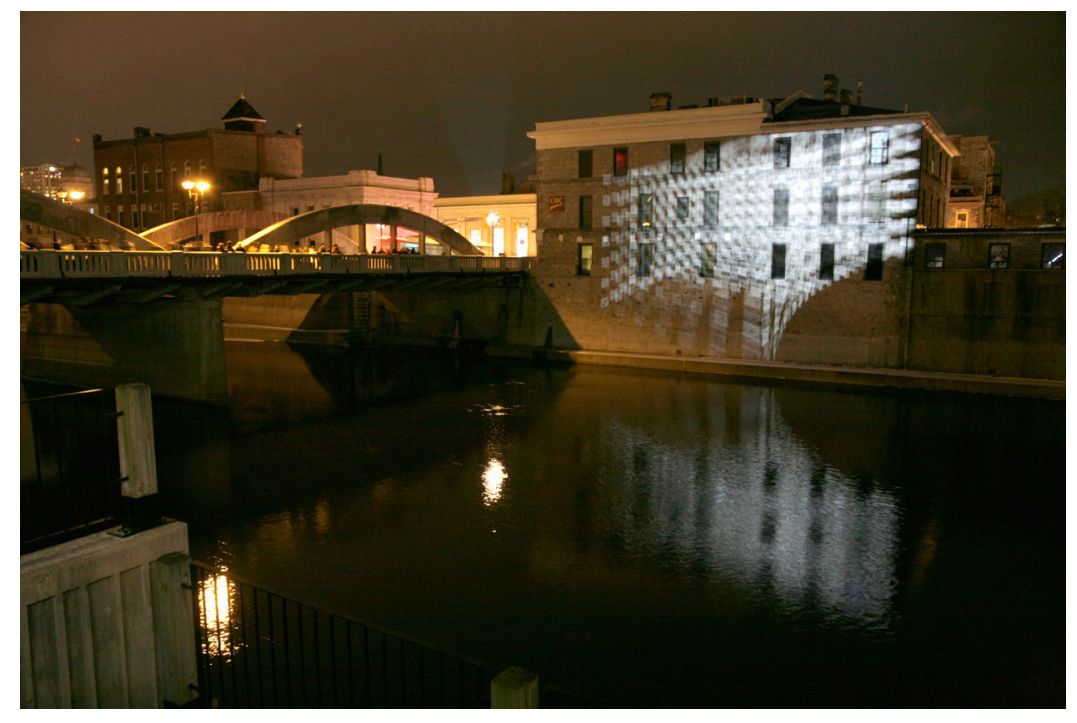

fig.4.0.2
Each of the following design principles recall successful examples of installations, and demonstrate how to use digital design installations as catalysts in creating a sense of place for communities:

Interactive - Interactive installations inspire creative public spaces in which participants help to shape the space they enjoy.

Creative - Artist installations make art accessible to the public; installations can inspire the community and become a platform to communicate ideas.

Economic - Marketing efforts are integrated in an attempt to present a more cohesive and unified message to consumers with compelling content that people enjoy, making for successful public spaces.

Aesthetic - Facade treatments allow graphics and content to be changed frequently, which can open up a larger realm of creative opportunity.

Sustainable - Self-reliant energy sources are used for digital visual content.

Adaptable - Installations reflect the scale of the space and context. The use of digital medium allows content to be generated in response to the public realm in real time.

Authentic - Visuals must genuinely represent a community and express the heritage and characteristics of the place in order for the city to maintain the connections the site has made to its people.

Mulit-sensory - Awareness of the users' surroundings are acknowledged by enhancing the visuals with means that involve the other senses.

The proposed design tactics do not place emphasis on a reliance of technology to engage the public with the built form. But rather the 
principles highlight present technological systems and celebrate the enormous creative potentials that exist:

Historians have shown how architects in the midnineteenth century tended to ignore or reject developments in technology ... as unconnected with architecture and unworthy of it ... the architect should accept the methods and the elements he already has.

These principles also work for facade installations without the use of technology, stressing the social importance of public interaction with the built form.

To test their efficiency, these design principles were applied in the core area of Galt City Centre located in Cambridge, Ontario. This application proposed to augment the existing historical architectural context, drawing attention its detail and uniqueness through the use of digital media. Capitalizing on the annual Christmas Event of Unsilent Night, a video animation was applied digitally on a building facade to celebrate the core area's public realm. All the city really needed was encouragement to come out and celebrate itself, which we provided. The digital media enhanced an already existing urban realm by celebrating Galt City Centre's historical buildings and the creativity of community members. The event drew the populace (around 1500) into the heart of the city, creating an entertaining social sphere and creating a collective memory for the community. The citizens' participation at the site specific projection allowed them

1 Venturi, Robert. Complexity and Contradiction in Architecture. New York: Museum Of Modern Art, 1968

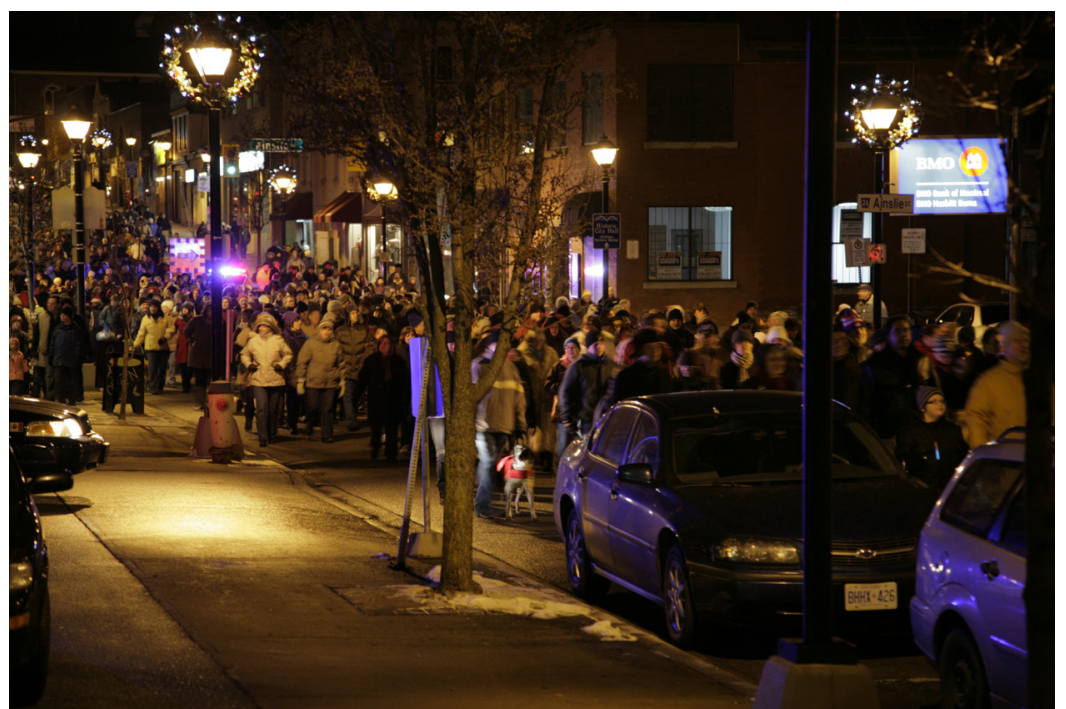

fig.4.0.3 crowds make their way down Dickson Street from City Hall, the start of the Unsilent Night route 
to rediscover many of the spaces previously forgotten, while the gathering of participants created many new public spaces. Spectators gathered on the Main Street Bridge and transformed it into a public viewing platform full of social engagement and active participation. David Bebee from the Waterloo Region Record writes:

Hundreds of people gathered with portable music systems to tour the historic downtown which hugs the Grand River as it flows south. Participants are serenaded by music as they view creative installations including projected displays...The project was beamed on to the wall of the historic building which houses the Main Street CIBC bank. I really like the effort put in by Cambridge City Hall to showcase the river whenever possible. Geography probably gives them some advantage but it still takes a lot of planning for the number of successful events in pulled off in Galt involving the Grand. ${ }^{2}$

\section{Challenges}

Arguments against digital signage and media relate primarily to visual clutter. Overuse or careless use of the dynamic medium could add to the visual pollution caused by commercial competition. Installations should thus seek to address locations where digital media can be integrated to enhance the urban landscape and its architecture. Designers should be conscious of the value of digital visual enhancements to architecture and the spatial qualities necessary to engage the public.

2 Bebee, David. "A Year On The Grand : Unsilent night on the Grand." TheRecord.com Blogs: Blogs. http://therecord.blogs.com/a_year_on_the_grand/2009/12/unsilent-night-on-the-grand. html (accessed March 2, 2010).
Engaging the public with novel interactions can be challenging, especially as technology continues to evolve at an increasingly rapid pace with respect to new forms of facade treatments and complex response systems. However, I argue that the proposed design principles are flexible guidelines that are responsive and sensitive to context while establishing a dialogue with users. Therefore, they provide guidelines for long-term use.

\section{Recommendations for Future Research}

The depth and complexity involved with technology is connected to the speed of its updates. This thesis looks at aspects of digital media in public space and how that technology can be used symbiotically with sophisticated architectural responses to enhance details in texture and quality of facades. It is impossible to predict which forms and technologies will be next. Future research could include the study of implementing integrated design processes between digital media facades and architecture. The number of possibilities in this field are endless. The complexity and sophisticated details of this kind of work require close cooperation of design teams, architects, engineers, and clients at all stages of projects. Studies can also look to new energy sources and sustainable means of production.

Another potential project would look at the implementation of digital media screens through public planning policies. Policy makers could provide valuable input and resources for planning future installations. Furthermore, policy makers could provide insight on zoning requirements in the use of digital media in cities. These policy assessments could help digital media better address community goals and priorities, and establish guidelines for relevant evaluation criteria in order to enhance future policies. 


\section{BIBLIOGRAPHY}

Aldersey-Williams, Hugh, Peter Hall, and Ted Sargent. Design and the Elastic Mind. New York: The Museum Of Modern Art, New York, 2008.

Augé, Marc. Non-places: Introduction to anthropology of supermodernity. London; New York 1995.

Bebee, David. "A Year On The Grand : Unsilent night on the Grand." TheRecord.com Blogs: Blogs. http://therecord.blogs.com/a year_on_the_grand/2009/12/unsilent-night-on-the-grand.html (accessed March 2, 2010).

Carmona, Matthew, Tim Heath, Taner Oc, and Steven Tiesdell. Public Places - Urban Spaces. London: Architectural Press, 2003.

Carr, Stephen, Mark Francis, Leanne G. Rivlin, and Andrew M. Stone. Public Space (Environment and Behavior). New York: Cambridge University Press, 1993.

Collins, Glenn. "An Eco-Friendly Billboard for Times Square" The New York Times, November 14, 2008. http://www.nytimes. com/2008/11/15/nyregion/15billboard.html (accessed May 10, 2010).
Eliot, Marc. Down 42nd Street: Sex, Money, Culture, and Politics at the Crossroads of the World. New York: Warner Books, 2001. http:// www.newyorkhistory.info/42nd-Street/timessquare.html (accessed February 19, 2010).

Francis, M., "Changing Values for Public Space." Landscape Architecture. 78, 1: 54-59. January-February, 1988.

Gehl, Jan. "seeing-a matter of distance." Life between Buildings: Using Public Space. 6 ed. Copenhagen: Danish Architectural Press, 2008.

Gehl, Jan. Life between Buildings: Using Public Space. 4 ed. Skive: Danish Architectural Press, 2001.

Gilfoyle, Timothy J. Millennium Park: Creating a Chicago Landmark (Historical Studies of Urban America). Chicago: University Of Chicago Press, 2006.

Gissen, David. "Simone Giostra - Greenpix, a Zero-Energy Media Wall." Welcome to the Archinnovation. http://www.archinnovations. com/featured-projects/civic/simone-giostra-greenpix-zero-energymedia-wallsimone-giostra-greenpix-zero-energy-media-wall/ (accessed June 23, 2009).

Grede, Rob. "Rising above the advertising clutter." BizTimes: Milwaukee and Southeastern Wisconsin Business News, March 29, 2002. http://www.biztimes.com/ (accessed March 20, 2010).

Greene, David A. “Jennifer Steinkamp.” Frieze Magazine, Issue 27 
March-April 1996. http://www.frieze.com/issue/review/jennifer_ steinkamp1/ (accessed May 2, 2010).

Halprin, Lawrence. Cities: Revised Edition. Revised ed. London: The Mit Press, 1972.

Howard, Ebenezer. Garden Cities of To-morrow. Albany New York: Bibliolife, 2009.

Jacobs, Jane. The Death and Life of Great American Cities. Reissue ed. New York: Random House, 2002.

Kent, Fred. "Project for Public Spaces (PPS) - Placemaking for Communities - The Power of Ten." Placemaking for Communities | Project for Public Spaces (PPS). http://www.pps.org/info/ newsletter/november2004/november2004_ten (accessed March 13, 2010).

Klingmann, Anna. Brandscapes: Architecture in the Experience Economy. London: The Mit Press, 2007.

Kronenburg, Robert. "FTL Design Engineering Studio.” In Portable Architecture. 3 ed. London: Architectural Press, 2003. 195-202.

Lynch, Kevin. The Image of the City. London: The Mit Press, 1960.

Mcquire, Scott. The Media City: Media, Architecture and Urban Space (Published in association with Theory, Culture \& Society). Thousand Oaks, CA: Sage Publications Ltd, 2008.

Miles, Christopher. “Brightness Falls.” Art in America, March 2007.
Ouroussoff, Nicolai. "Architecture Review - Lose the Cars, Keep the Grit." The New York Times, 25 May 2009. http://www.nytimes. com/2009/05/26/arts/design/26clos.html?_r=2 (accessed February 19, 2010).

Ozler, Levent. "Brand New School Creates Interactive Mural for Adobe | Design News." Dexigner Design Portal | Design News. July 15, 2007. http://www.dexigner.com/design_news/brand-newschool-creates-interactive-mural-for-adobe.html (accessed June 22, 2009).

Pallasmaa, Juhani. The Eyes of the Skin (Polemics). London: Academy Editions, 1996.

Rattenbu, Kester. Robert Venturi and Denise Scott Brown: Learning from Las Vegas: SuperCrit 2. 1 ed. New York: Routledge, 2007.

Sagalyn, Synne B. Times Square Roulette: Remaking the city icon. London: The MIT Press, 2001.

Slessor, Catherine. "Public Engagement - evolution of public space | Architectural Review, The" Find Articles at BNET. http://findarticles.com/p/articles/mi_m3575/is_1250_209/ ai_74929075/?tag=content; col1 (accessed February 13, 2010).

Solomon, Linda. "What We Saw at the Opening Ceremonies of the Vancouver 2010 Olympic Games." The Vancouver Observer, February 13, 2010. http://www.vancouverobserver.com/ blogs/overheardolympics/2010/02/13/what-we-saw-openingceremonies-vancouver-2010-olympic-games(accessedMay10,2010). 
Sullivan, C. "Chanel Ginza, Tokyo.” Architectural Lighting Magazine, June 1, 2007. http://www.archlighting.com/industry-news.asp?sect ionID $=0$ \&articleID=526791 (accessed June 22, 2009).

Swayze, Kevin. "Building boom comes to old Galt downtown in Cambridge." Cambridge Reporter. March 8, 2010. http://www. cambridgereporter.com/news/article/204536 (accessed March 10, 2010).

Tarce, Amy. "Shinjuku Eki (Train Station) - Great Public Spaces | Project for Public Spaces (PPS).” Placemaking for Communities | Project for Public Spaces (PPS). http://www.pps.org/great_public_ spaces/one?public_place_id=761\&type_id=0\# (accessed February 20, 2010).

Taylor, William R. Inventing Times Square: Commerce and Culture at the Crossroads of the World. New York: Russell Sage Foundation Publications, 1991.

Tschichold, Jan. The New Typography: A Handbook for Modern Designers (1st English translation). Berkeley: University of California Press, 1995.

Whyte, William H. City: Rediscovering the Center. New York: Doubleday, 1988.

Whyte, William H. The Social Life of Small Urban Spaces. New York: Project For Public Spaces Inc, 2001.

“555 KUBIK Facade Projection - today and tomorrow.” today and tomorrow. http://www.todayandtomorrow.net/2009/07/23/555kubik-facade-projection/ (accessed August 27, 2009).

"About Cambridge History: The Banks." Cambridge History. cambridgeweb.net/historical/banks.html (accessed March 8, 2010).

"Area Guides: Shinjuku | TCVB - Tokyo Convention \& Visitors Bureau." Tokyo Convention \& Visitors Bureau. http://www.tcvb. or.jp/en/guide/areao5.html (accessed February 20, 2010).

Rafael Lozano-Hemmer. "Body Movies." http://www.lozanohemmer.com/english/projects/bodymovies.htm (accessed June 22, 2009).

"Brief History of the Community of Galt." About Cambridge History. cambridgeweb.net/historical/galt.html (accessed February 21, 2010).

"CambridgeTimes Article: Unsilent night blows up." Cambridgetimes. ca | Your Cambridge online newspaper | Today's stories from the Cambridge Times . http://www.cambridgetimes.ca/news/local/ article/247041--unsilent-night-blows-up (accessed March 9, 2010).

"CBC News - Montreal - Massive Robert Lepage show reflects Quebec City's story.” CBC.ca-Canadian News Sports Entertainment Kids Docs Radio TV. http://www.cbc.ca/canada/montreal/story/2008/07/10/ qc-lepage-cp-0710.html (accessed April 27, 2010).

"Chanel Ginza Tokyo Flagship Store." Architectural S S L M a gazine.htt p: / / w w w a r chitecturals sl. 
com / content.ph p s e ction = resources / o 2 _o 8 _ issue\&id=1proj (accessed February 22, 2010).

"City Departments | City of Cambridge, Ontario, Canada." City of Cambridge, Ontario, Canada. http://www.cambridge.ca/cs pubaccess $/$ hall_of_fame.php?aid=44\&cpid $=$ o\&scpid $=$ o\&did=o\&si $\mathrm{d}=\mathrm{o \& ssid}=0 \& \mathrm{tp}=\mathrm{o \& grid}=\mathrm{o}($ accessed March 8, 2010).

"Communicative Interface." DBZ Deutsche Bauzeitung, edition 12, 2004. http://www.ag4.de/fileadmin/media/pdf/200412_ag4_ DBZ_en.pdf (accessed June 23, 2009).

"Description of Shinjuku." Shinjuku City Official Website. http:// www.city.shinjuku.lg.jp/foreign/english/aramashi/gaiyou/gaiyou. html (accessed February 20, 2010).

"Dexia Tower Touch." LAb[au] laboratory for Architecture and Urbanism. http://lab-au.com/\#/http://lab-au.com/projects/touch/ (accessed June 22, 2009).

“Graffiti Research Lab » L.A.S.E.R. Tag.” Graffiti Research Lab. http://graffitiresearchlab.com/projects/laser-tag/ (accessed June 22, 2009).

"Granville Island" Placemaking for Communities | Project for Public Spaces (PPS) .http://www.pps.org/info/newsletter/november2004/ november2004_granville (accessed February 20, 2010).

"Historical Information - Evolution of Galt | City of Cambridge, Ontario, Canada." City of Cambridge, Ontario, Canada. http://www. cambridge.ca/city_clerk/city_archives/historical_information_ evolution_of_galt (accessed February 21, 2010).

"History of Shinjuku." Shinjuku City Official Website. http://www. city.shinjuku.lg.jp/foreign/english/aramashi/rekishi/rekishi.html (accessed February 20, 2010).

"Holger Mader | Alexander Stublic | Heike Wiermann.” Holger Mader | Alexander Stublic | Heike Wiermann. http://www.webblick. de/ (accessed June 22, 2009).

"How Art Economically Benefits Cities | Project for Public Spaces (PPS) ." Placemaking for Communities | Project for Public Spaces (PPS) . N.p., n.d. Web. 19 Mar. 2010. <http://www.pps.org/info/ pub_art/art_impact>.

"James Clar \& Associates - Space Design [Habitat Hotel]." James Clar. http://www.jamesclar.com/space/2006/habitathotel/index. html (accessed June 23, 2009).

"Jan Gehl” Project for Public Spaces. http://www.pps.org/jgehl/ (accessed May 10, 2010).

"Light and Media Facade Installation.” realities:united. http://www. realities-united.de/\#PROJECT,81,1 (accessed June 22, 2009).

"Official Plan | City of Cambridge, Ontario, Canada." City of Cambridge, Ontario, Canada. http://www.cambridge.ca/planning services/policy_planning/official_plan (accessed March 8, 2010). 
"Public art and design checklist: What is public art?" Welcome to Arts SA. http://www.arts.sa.gov.au/site/page.cfm?u=291 (accessed June 22, 2009).

"Reclaiming streets beyond pedestrian heaven « Tokyo Green Space." Tokyo Green Space. http://tokyogreenspace.com/2009/o9/28/ reclaiming-streets-beyond-pedestrian-heaven/ (accessed February 20, 2010).

"Robert Lepage plans tribute to Quebec City." National Post | Canadian News, Financial News and Opinion. http://www. nationalpost.com/most_popular/story.html?id=442333 (accessed April 27, 2010).

"Shinjuku | Japan Travel Guide.” Japan Guidebook | Online Travel Guide to Tokyo. http://www.japanguidebook.com/travel/shinjukutravel-guide-71.html (accessed February 20, 2010).

"Sin, Salvation and Shopping in Times Square | Times Square New York City." Home | Times Square New York City. http://www. timessquare.com/New_York_City/Times_Square_NYC/Sin,_ Salvation_and_Shopping_in_Times_Square/ (accessed February 21,2010 ).

"Stereoscope | Project Blinkenlights." Welcome to Project Blinkenlights | Project Blinkenlights. http://www.blinkenlights.net/ stereoscope (accessed June 23, 2009).

"Street music « Tokyo Green Space." Tokyo Green Space. http:// tokyogreenspace.com/2009/12/20/street-music/ (accessed
February 20, 2010).

“Times Square | Project for Public Spaces (PPS)." Placemaking for Communities | Project for Public Spaces (PPS). http://www.pps. org/info/projects/transportation_projects/timessquare/ (accessed February 19, 2010).

“Toronto Life Square." PCL. http://www.pcl.com/projects/ Active/o900342/index.aspx (accessed May 11, 2010).

"Unsilent Night - The Cambridge Advocate." The Cambridge Advocate - A true voice for you the public. http://thecambridgeadvocate.com/ archives/unsilent-night/ (accessed March 9, 2010).

“Unsilent Night.” Unsilent Night. http://www.unsilentnight.com (accessed January 22, 2010). 




\section{Appendix}




\begin{tabular}{|c|c|c|c|c|}
\hline $\begin{array}{l}\text { digital media } \\
\text { outlets }\end{array}$ & LED lights & $\begin{array}{l}\text { LED display integrated } \\
\text { with photovoltaic system }\end{array}$ & Mediamesh & three layer wall system \\
\hline Description & $\begin{array}{l}\text { light-emitting diodes arranged in } \\
\text { various grid like formations can } \\
\text { be controlled to play animations } \\
\text { and patterns } \\
\text { installed anywhere from the } \\
\text { exterior to the interior panels in } \\
\text { a wall system }\end{array}$ & $\begin{array}{l}\text { the facade harvests solar energy } \\
\text { by day and uses it to illuminate } \\
\text { the screen at night }\end{array}$ & $\begin{array}{l}\text { stainless steel mesh fabric with } \\
\text { interwoven LED profiles that } \\
\text { display graphics, animated text } \\
\text { and video of high resolution by } \\
\text { connections to media controls }\end{array}$ & $\begin{array}{l}\text { a combination of optical } \\
\text { materials - white LEDs, solar- } \\
\text { control glazings - Electrochromic } \\
\text { glass, and double layer of gray- } \\
\text { tinted Low-E laminated glass } \\
\text { with stainless-steel mesh }\end{array}$ \\
\hline pros & $\begin{array}{l}\text { highly efficient LEDs produce } \\
\text { more light per watt than other } \\
\text { available lighting mediums } \\
\text { long service life } \\
\text { radiates little heat }\end{array}$ & $\begin{array}{l}\text { flexibility in available sizes } \\
\text { display is self-sufficient in energy }\end{array}$ & $\begin{array}{l}\text { 70\% transparent for building } \\
\text { occupants for significant } \\
\text { aesthetic advantages } \\
\\
\text { installations use just one-sixth } \\
\text { the electricity of conventional } \\
\text { LED boards and provide passive } \\
\text { solar gain from the sun } \\
\text { unobtrusive when not in use }\end{array}$ & $\begin{array}{l}\text { the skin of the building is able } \\
\text { to perform multiple functions, } \\
\text { such as providing privacy being } \\
\text { translucent, performing as } \\
\text { storefront displays, and providing } \\
\text { natural daylight to evening light } \\
\text { effects }\end{array}$ \\
\hline cons & $\begin{array}{l}\text { relatively greater initial cost } \\
\text { temperature dependant should } \\
\text { be integrated with ventilated } \\
\text { systems }\end{array}$ & $\begin{array}{l}\text { back up energy required from } \\
\text { alternate power source }\end{array}$ & $\begin{array}{l}\text { greater initial cost } \\
\text { selective viewing distance }\end{array}$ & $\begin{array}{l}\text { highly integrated wall assembly; } \\
\text { committed design team required } \\
\text { to test various materials until } \\
\text { desired effect is achieved }\end{array}$ \\
\hline Examples & $\begin{array}{l}\text { Touch by LAB[au] } \\
\text { Twists and Turns by Mader, } \\
\text { Stublic, Wiermann }\end{array}$ & $\begin{array}{l}\text { GreenPix - Zero Energy Media } \\
\text { Wall by Simone Giostra \& } \\
\text { Partners Architects } \\
\text { Habitat Hotel by James Clar \& } \\
\text { Associates }\end{array}$ & $\begin{array}{l}\text { T-Mobile Bonn Headquarters by } \\
\text { ag4 mediatecture }\end{array}$ & $\begin{array}{l}\text { Chanel Ginza Façade by Peter } \\
\text { Marino + Associates Architects }\end{array}$ \\
\hline
\end{tabular}




\begin{tabular}{|c|c|c|c|}
\hline $\begin{array}{l}\text { simple lamp setup } \\
\text { behind existing glazing }\end{array}$ & $\begin{array}{c}\text { fluorescent lamps } \\
\text { integrated with glass } \\
\text { facade }\end{array}$ & projections & $\begin{array}{l}\text { projections coupled with } \\
\text { responsive technology }\end{array}$ \\
\hline $\begin{array}{l}\text { computer controlled lamps } \\
\text { arranged behind a building's } \\
\text { front windows to produce a } \\
\text { monochrome matrix reflecting } \\
\text { the existing building window } \\
\text { layout }\end{array}$ & $\begin{array}{l}\text { light matrix of fluorescent lamps, } \\
\text { integrated into the ventilated } \\
\text { glass facade of the building } \\
\text { individual brightnesses and } \\
\text { power switches are controlled by } \\
\text { a central computer }\end{array}$ & $\begin{array}{l}\text { projects video image on a } \\
\text { surface using a very bright } \\
\text { light }\end{array}$ & $\begin{array}{l}\text { projections with the addition of } \\
\text { simple responsive systems such as } \\
\text { spot lighting, laser pointers, and } \\
\text { motion sensors }\end{array}$ \\
\hline $\begin{array}{l}\text { simple setup, user controlled } \\
\text { and can be integrated into } \\
\text { responsive systems via control } \\
\text { over cellphone or internet }\end{array}$ & $\begin{array}{l}\text { can be integrated with the } \\
\text { existing glass facades } \\
\text { relatively fast setup and low cost }\end{array}$ & $\begin{array}{l}\text { projectors can correct any } \\
\text { curves, blurriness, and other } \\
\text { inconsistencies of the surface } \\
\text { through manual settings and } \\
\text { can therefore be used on any } \\
\text { surface } \\
\text { completely unobtrusive to } \\
\text { built form }\end{array}$ & $\begin{array}{l}\text { projections completely engage } \\
\text { the users as their actions trigger } \\
\text { the projections } \\
\text { completely unobtrusive to built } \\
\text { form }\end{array}$ \\
\hline $\begin{array}{l}\text { not as bright as LEDs and are } \\
\text { therefore efficient only in the } \\
\text { evenings } \\
\text { restricted to simple large pixel } \\
\text { animations and window layout }\end{array}$ & $\begin{array}{l}\text { not as bright as LEDs and are } \\
\text { therefore efficient only in the } \\
\text { evenings } \\
\text { more permanent then simple } \\
\text { lamp setup } \\
\text { restricted to simple large pixel } \\
\text { animations and window layout }\end{array}$ & $\begin{array}{l}\text { efficient at night although } \\
\text { technologies exist for } \\
\text { projections that are visible } \\
\text { during the day at higher costs }\end{array}$ & $\begin{array}{l}\text { simple responsive systems only } \\
\text { respond to few if not only one } \\
\text { user at a time }\end{array}$ \\
\hline $\begin{array}{l}\text { Blinkenlights by Chaos Computer } \\
\text { Club }\end{array}$ & $\begin{array}{l}\text { Spots Installation by } \\
\text { realities:united architects }\end{array}$ & $\begin{array}{l}\text { AT\&T global pavilion by FTL } \\
\text { Design Studio } \\
\text { 555KUBIK by Urbanscreen } \\
\text { Swell and Loop by Jennifer } \\
\text { Steinkamp } \\
\text { The Image Mill by Robert } \\
\text { Lepage }\end{array}$ & $\begin{array}{l}\text { Body Movies by Rafael Lozano- } \\
\text { Hemmer } \\
\text { L.A.S.E.R. TAG by Graffiti } \\
\text { Research Lab } \\
\text { Adobe's CS3 Launch by Brand New } \\
\text { School }\end{array}$ \\
\hline
\end{tabular}





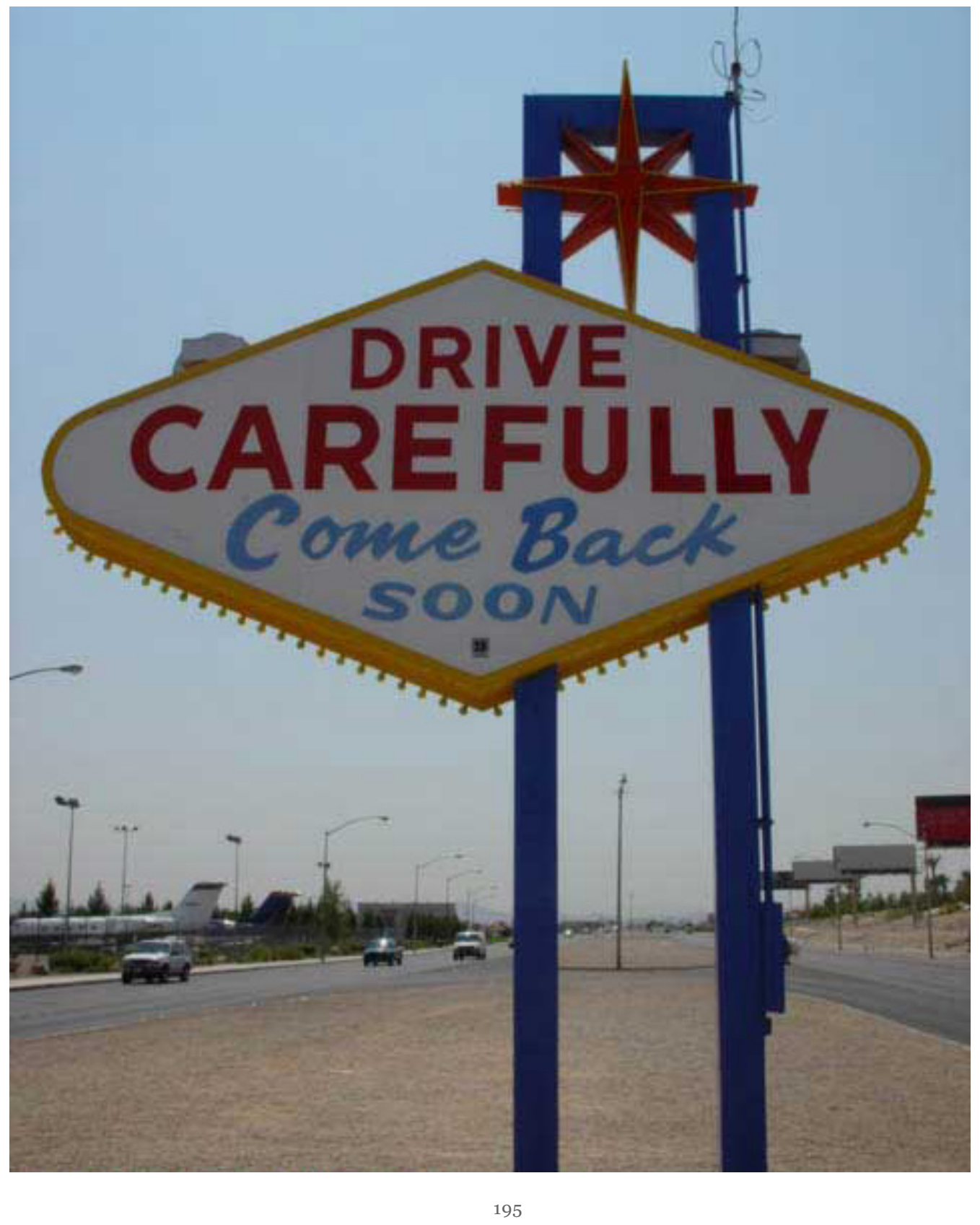

